Edited by

XINSHEN DIAO, PETER HAZELL,

SHASHIDHARA KOLAVALLI, AND DANIELLE RESNICK

\title{
Ghana's Economic
}

and Agricultural

Transformation

Past Performance and Future Prospects

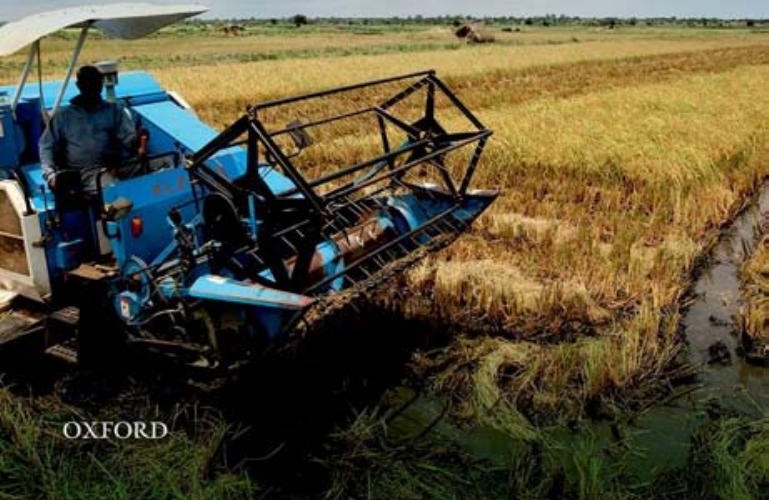


Ghana's Economic and Agricultural Transformation 



\title{
Ghana's Economic and Agricultural Transformation
}

Past Performance and Future Prospects

\author{
Edited by \\ XINSHEN DIAO, PETER HAZELL, \\ SHASHIDHARA KOLAVALLI, \\ AND DANIELLE RESNICK
}




\section{OXFORD \\ UNIVERSITY PRESS}

\section{Great Clarendon Street, Oxford, OX2 6DP, United Kingdom}

Oxford University Press is a department of the University of Oxford.

It furthers the University's objective of excellence in research, scholarship, and education by publishing worldwide. Oxford is a registered trade mark of Oxford University Press in the UK and in certain other countries

(C) International Food Policy Research Institute (IFPRI) 2019

The moral rights of the authors have been asserted

First Edition published in 2019

Impression: 1

Some rights reserved. No part of this publication may be reproduced, stored in a retrieval system, or transmitted, in any form or by any means, for commercial purposes, without the prior permission in writing of Oxford University Press, or as expressly

permitted by law, by licence or under terms agreed with the appropriate reprographics rights organization.

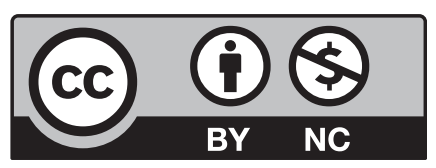

This is an open access publication, available online and distributed under the terms of a

Creative Commons Attribution - Non Commercial 4.0

International licence (CC BY-NC 4.0), a copy of which is available at http://creativecommons.org/licenses/by-nc/4.0/.

Enquiries concerning reproduction outside the scope of this licence should be sent to the Rights Department, Oxford University Press, at the address above

Published in the United States of America by Oxford University Press 198 Madison Avenue, New York, NY 10016, United States of America

British Library Cataloguing in Publication Data

Data available

Library of Congress Control Number: 2019938558

ISBN 978-0-19-884534-8

Printed and bound in Great Britain by Clays Ltd, Elcograf S.p.A.

Links to third party websites are provided by Oxford in good faith and for information only. Oxford disclaims any responsibility for the materials contained in any third party website referenced in this work.

Any opinions stated in the book are those of the author(s) and are not necessarily representative of or endorsed by IFPRI. 


\section{Preface}

Economic growth accelerated across much of sub-Saharan African (hereinafter called Africa) in recent years, and although outpaced by Asia, the rates of growth achieved were nevertheless unprecedented for many countries. This led to a period of euphoria among many experts who believed African economies seemed finally to be taking off. Some African countries were even characterized as African "lions", counterparts to the so-called Asian "tigers". However, unlike the economic transformations of the Asian tigers, rapid urbanization and the movement of workers out of agriculture has not been accompanied by any significant growth in industry or export manufacturing, nor has there been an agricultural green revolution. Rather, workers have moved primarily into a burgeoning but low-productivity service sector, and agriculture has remained largely traditional with only modest growth in land productivity. There are growing concerns that this pattern of transformation may be unsustainable, and at best can lead to only moderate rates of economic growth.

This book explores these issues using Ghana as a case study. Ghana is unusual by African standards in that it is blessed with minerals, favorable agricultural conditions, and easy access to international shipping. The country has also been successful in terms of growth in per capita income (PCI) and agricultural output, reductions in poverty, and the achievement of middleincome status and a broadly democratic and peaceful society. Per capita incomes have grown consistently since the mid-1980s, but at 2.8 percent per year on average its growth has been less than half of what China and some other East Asian tigers experienced at similar stages of their economic transformation and offers only a slow path to greater prosperity. And despite all of Ghana's latent advantages, the structural changes in the national economy have been typical of much of Africa, with rapid urbanization without a growing industrial sector, and a rapidly growing services sector.

This book aims to explain why Ghana has not transformed its economy more substantially, why its agriculture sector-beyond cocoa-has not played a greater role and explores options for the country's future transformation. Answering these puzzles and looking prospectively requires both political and economic analysis to ensure that potential technical options are also politically feasible. 
The Ghana experience shows that while enabling policies appear necessary for achieving and sustaining rapid economic growth, they are not sufficient. As late developers, African countries face limited opportunities for export manufacturing so must depend more on their domestic and regional markets to absorb increases in output. Since demand in these markets is generally less elastic than in world markets, sector growth rates are constrained by growth in demand, which in turn depend on growth in national income and its distribution. This calls for a more balanced growth strategy than was the case in the tiger economies, with broad support for productivity growth within all sectors, freeing up regional trade within Africa, and overcoming many market and institutional failures that constrain private sector development and the effectiveness of market solutions. Governments need to play more proactive roles in promoting and guiding their economic transformations, much as happened in the Asian tigers. However, the ability of governments to play more proactive roles is constrained by their political and institutional contexts.

With very few exceptions, African government policies towards agriculture over recent decades have ranged from half-hearted to detrimental, despite enormous opportunities to grow the sector through productivity-enhancing technologies. Ghana, for example, spends very little on agricultural development beyond its cocoa sector, and changing this political dynamic is not easy, complicated by the varying agendas and off budget projects of both successive executives and different donors that undermine a more coherent strategy. Even where political factors are more enabling, public sector capabilities to take more proactive approaches are limiting, the result of years of institutional neglect by governments and donors. For example, Ghana's few attempts to partner with the private sector to fix market failures along important value chains for some promising manufacturing and agriculture commodities have not been particularly successful.

In the end, whether countries like Ghana can sustain or even increase their past rates of economic growth will come down to government effectiveness in finding solutions to the bottlenecks in key segments of the industrial and agricultural sectors. It will also require government willingness to engage more widely with the private sector, and the development of innovative institutional arrangements for moving the agenda forward despite remaining weak public sector capacities and market failures. 


\section{Acknowledgments}

This book draws on the extensive work undertaken by IFPRI's Ghana Strategy Support Program (GSSP) since 2005. The idea of a book emerged from a conference on Transforming Agriculture held in Accra, November 8-9, 2012. It soon became evident, however, that additional research was needed beyond the conference papers to fully address Ghana's transformation issues, and this led to a concerted research effort over the subsequent five years. The authors are very grateful to all the contributors to this book for fitting this work into their already busy schedules. They are also grateful to Alejandro Nin-Pratt for providing an update of his earlier work on the relationship between population density and the purchase of modern inputs and the value of output/ha in different ecological zones in Ghana, which is included in Chapter 4. Special mention must also be made to Peixun Fang and Jane Lole for the excellent research support they provided for various chapters. The authors thank Springer for allowing the re-printing of a map in chapter 4 that originally appeared in Agriculture and Human Values ("Changes in Ghanaian farming systems: stagnation or a quiet transformation?") and Elsevier for agreeing to re-print some material in chapter 5 that previously appeared in World Development ("Cities and rural transformation: A spatial analysis of rural livelihoods in Ghana").

This book would not have been possible without the sustained funding support for the GSSP provided by USAID (from both the Ghana country mission and the Bureau for Food Security (BFS) in Washington, DC), and from IFPRI and the CGIAR's Research Program of Policies, Institutions and Markets (PIM).

Finally, we would like to dedicate this book to the memory of Eduardo Magalhaes who sadly and prematurely passed away in August 2017. In addition to contributing as an author of Chapter 4, Eduardo provided outstanding statistical support for much of the research underlying this book. He will be greatly missed. 



\section{Contents}

List of Figures and Map xi

List of Tables xiii

List of Contributors xvii

1. Introduction 1

Xinshen Diao, Peter Hazell, Shashidhara Kolavalli, and

Danielle Resnick

\section{GHANA'S ECONOMIC TRANSFORMATION}

2. Ghana's Economy-wide Transformation: Past Patterns and Future Prospects

Xinshen Diao and Peter Hazell

3. Strong Democracy, Weak State: The Political Economy of

Ghana's Stalled Structural Transformation

Danielle Resnick

\section{AGRICULTURE'S ROLE IN GHANA'S TRANSFORMATION}

4. Ghana's Agricultural Transformation: Past Patterns and Sources of Change

Peter Hazell, Xinshen Diao, and Eduardo Magalhaes

5. Urbanization and its Impact on Ghana's Rural Transformation Xinshen Diao, Eduardo Magalhaes, and Jed Silver

6. Agricultural Transformation in the Savannah: Perspectives from the Village

Michael Johnson, Nazaire Houssou, Shashidhara Kolavalli, and Peter Hazell

7. Public Expenditure on Agriculture and its Impact Samuel Benin

8. Developing Agricultural Value Chains 
9. Unleashing the Power of Mechanization Xinshen Diao, Frances Cossar, Nazaire Houssou, and Shashidhara Kolavalli

10. Future Prospects

Xinshen Diao, Peter Hazell, Shashidhara Kolavalli, and Danielle Resnick

Index 


\section{List of Figures and Map}

\section{Figures}

1.1a. GDP shares of agriculture, manufacturing, and services in the national economy, Africa averages and Ghana (\%)

1.1b. Employment shares of agriculture, industry, and services in total employment, Africa averages and Ghana (\%)

2.1. Sector shares of GDP

2.2. Annual growth rates of value-added per worker and GDP per capita in 1984-2011 (\%)

2.3. Sector allocation of increased employment

3.1. Average nominal rates of assistance for all agriculture in Ghana (\%)

3.2. Shifts in sectoral public expenditures, 1980-2007

3.3. Trends in Ghana's governance profile, 2000-14

3.4. Domestic credit to the private sector (average \% of GDP)

4.1. Distribution of increases in food crop areas and annual growth rates by region

4.2. Trends in land and labor productivity, 1991-2011

4.3a. Patterns of intensification against population density in the forest zone comparing full sample with least and most cost-efficient farmers

4.3b. Patterns of intensification against population density in the savannah zone comparing full sample with least and most cost-efficient farmers

5.1. Annual growth rate in the population between census years, and urban population share in census years, 1960-2010

5.2. Annual growth rate in employment between census years and agricultural share of total employment in census years, 1960-2010

5.3. Ghana map showing the different types of districts

5.4. Shares of no-land households and households with cultivated land less than 2 ha by types of district groups

5.5. Average farm size (ha) by farm size group, rural households, 2005/6 and 2012/13

6.1. Changes in labor and land productivity by farm size, representative village in the transition zone, 1990-2010 
6A.1. Crop rotations between maize and legume (groundnuts or cowpeas) for a one-acre plot example and between two growing seasons in the Ejura area

6A.2. Gross margins and annual price trends in Ejura, 1980-2015 (constant 2015 US\$ $/ \mathrm{kg}$ )

7.1. Agricultural public expenditure in Ghana by subsector, 1961-2012

7.2. Agricultural output per hectare by subsector in Ghana, 1961-2012

7.3. Ratio of agricultural public expenditure to output by subsector in Ghana, 1961-2012

7.4. Government recurrent and developmental expenditures in agriculture (2000 GHS, millions)

9.1. Tractor imports, 2003 to 2012

9.2. R-value measure of farming system evolution in Ghana, 1961-2011

\section{Map}

4.1. Ecological zones of Ghana 


\section{List of Tables}

2.1. Countries with uninterrupted per capita GDP growth for thirty years

2.2. Changes in sector GDPs and sector shares over 1975-2016, selected years

2.3. Growth in per capita GDP, labor productivity, and total factor productivity (\%)

2.4. Annualized growth rate in employment for Ghana and by sector (\%)

2.5a. Employment structure of private non-agriculture by formal/informal, rural/urban, and industry in 2000

2.5b. Employment structure of private non-agriculture by formal/informal, rural/urban, and industry in 2010

2.6. Contribution of the informal and formal sectors to the national increase in total employment over 2000 to 2010; by sector and rural and urban (\%) 30

2.7. A typology of growth strategies, growth patterns, and outcomes

2.8. Key model coefficients: Sector-wise labor productivity, and GDP and employment shares, 1984, 2000, and 2011

2.9. Decomposition of Ghana's economy-wide labor productivity growth in 1984-2011 and 2000-11 (results sum to total growth rate for economy each period)

2.10. Contributions of each sector to Ghana's economy-wide labor productivity growth in 1984-2011 and 2000-11 (\% shares)

2.11. Shares of value-added and employment and labor productivity for three groups of manufacturing firms in Ghana

3.1. Timeline of political regimes and governments since Ghana's Independence

3.2. Comparisons of public management across selected African countries (Ibrahim Index of African Governance, ranging from 0-100)

3.3. Comparisons of domestic credit to the private sector (\% of GDP), $2014 \quad 75$

3.4. Sources of communal conflict in Ghana

4.1. Annualized growth rates of value of output by commodity groups, 1994-2013

4.2. Composition of crop agriculture, 2012

4.3. Growth in crop area, output, and yield, by period (\%/year) 
4.4. Growth in value added/ha and crop area, by commodity, 1995-2013 (\%/year)

4.5. Production of major food crops by agroecological zone, 2010-12 averages

4.6. Fertilizer use (tons of nutrients)

4.7. Share of rural households using modern inputs and hired labor (\%) 104

4.8. Growth in national and agricultural labor forces

4.9. Agricultural wages in Ghana, 1991-2012, by type of work (new cedis, deflated by CPI)

4.10. Changes in the size distribution of farms amongst rural households (\%) 106

4.11. Distribution of farms and operated area by farm size groups, 1992 and 2012

4.12. Composition of farm household by type of livelihood strategy

4.13. Changes in household and per capita expenditure, 2005/6 and 2012/13

4.14. Annualized growth rates in crop prices, 1998-2012 (\%)

4.15. Annualized growth rates in input prices, 1998-2012 (\%)

4.16. Changes in rural population density, 1991-2013

5.1. Population densities by district group, 2000 and 2010 (people $/ \mathrm{km}^{2}$ )

5.2. Distribution of rural households by agricultural, nonagricultural, and mixed occupations across district groups (each type of district's total rural households $=100$ )

5.3. Types of primary employment amongst non-agriculture-only households, by district type, 2000 and 2010

5.4. Rural poverty rate in the north and south across district groups

5.5a. Shares of rural households by farm size and district group, 2005/6

5.5b. Shares of rural households by farm size and district group, 2012/13

5.6. Share of rural farm households using organic and inorganic fertilizer, 2012/13

5.7. Share of rural farm households using herbicides or insecticides, 2012/13

5.8. Share of rural households using mechanization, 2012/13

5.9. Probit model regressions for input use, pooled data of GLSS5 and GLSS6

6.1. Location and names of the selected villages

6.2. Changes in village population, 2000 to 2010

6.3. Changes in cultivated farm size distribution (\%) 
6.4. Trends in the share of farmers renting mechanical equipment, by farm size

6.5. Selected farm input costs (\% of total crop expenditure)

6.6. Trends in maize yields ( $\mathrm{t} / \mathrm{ha})$

6.7. Value of agricultural production, income, and consumption expenditures (real US\$)

6.8. Model results for the average farm in the representative transition zone village, 1990, 2000, and 2010

6.9. Selected model results by farm size group, representative village in the transition zone, 1990, 2000, and 2010

6.10. Decomposition of changes in selected variables by farm size group, representative village in the transition zone, 1990-2010

6A.1. Summary description of model parameters and variables

6A.2. Percent shares in the type of land available by farm type and for each decade (1990-2010)

6A.3. Maize yields by type of seed and responses to fertilizer

7.1. Data sources for public spending and agricultural output, 1961-2012

7.2. Agricultural expenditure and output per hectare by subsector in Ghana, 1961-2012

7.3. Government expenditures on agriculture and rural development (2000 GHS, millions)

7.4. Government expenditures, by sector

7.5. Description and summary statistics of variables, 1961-2012 annual average

7A.1. Data and sources on public expenditures in Ghana, 1961-2012

7A.2. Sources of data for the variables used in the regression analysis, 1961-2012

7B.1. Stationarity test results for level and first difference of dependent variables, 1961-2012

7B.2a. Determinants of agricultural expenditure on cocoa and noncocoa subsectors in Ghana (with total agricultural output), 1961-2012

7B.2b. Effect of agricultural expenditure on total agricultural output in Ghana, 1961-2012

7B.3a. Determinants of agricultural expenditure on cocoa and noncocoa subsectors in Ghana (with subsector agricultural output), 1961-2012

7B.3b. Effect of subsector agricultural expenditure on subsector agricultural output in Ghana, 1961-2012

8.1. Requirements for improving quality in selected value chains

9.1. Share of rural households using mechanization (percent) 
XVi LIST OF TABLES

9.2. Crop area per rural person, by region, 2000 and 2010246

9.3. Changes in the farm size distribution, 2005/6 and 2012/13 247

9.4. Summary of Ghana's current supply models for agricultural mechanization 


\section{List of Contributors}

Samuel Benin is the deputy director for IFPRI's Africa Regional Office.

Frances Cossar is a post-doctoral researcher in land use and food security at the University of Edinburgh and former research analyst at IFPRI.

Xinshen Diao is a senior research fellow and deputy division director of the Development Strategy and Governance division at IFPRI.

Peter Hazell is an independent researcher, and former director of the Development Strategy and Governance division at IFPRI.

Nazaire Houssou is an Economic Growth Specialist at USAID-Benin and was a former research fellow for IFPRI's Ghana Strategy Support Program.

Michael Johnson is the director of agriculture science, technology, and innovation at the Foundation for a Smoke-Free World.

Shashidhara Kolavalli is an independent researcher. He also was the former country leader for IFPRI's Ghana Strategy Support Program.

Eduardo Magalhaes was an independent consultant and former research analyst at IFPRI.

Danielle Resnick is a senior research fellow and governance theme leader in the Development Strategy and Governance division at IFPRI.

Jed Silver is PhD student at the University of California, Berkeley and a former senior research assistant at IFPRI. 



\title{
1 \\ Introduction
}

\author{
Xinshen Diao, Peter Hazell, Shashidhara Kolavalli, \\ and Danielle Resnick
}

\subsection{Introduction}

Economic growth accelerated across much of sub-Saharan African (hereinafter called Africa) during 2005-15 (Badiane and Makombe 2014; Rodrik 2018). Although outpaced by Asia, the rates of growth achieved were nevertheless unprecedented for many African countries and led to a period of euphoria among many experts who believed African economies seemed finally to be taking off. During this period, a number of African countries graduated to "lower-middle-income" status and excitement grew about the rise of Africa's expanding middle class (Ncube and Lufumpa 2015; Shimeles and Ncube 2015). As should be expected, this growth was accompanied by structural changes in the composition of national economies (Rodrik 2018). Agriculture shrank as a share of both national GDP and the total labor force, and urbanization proceeded rapidly. Already, nearly 40 percent of the population in Africa is urbanized, and the UN projects that by 2050 the urban population share will reach 56 percent (UN 2014).

However, unlike most of today's rich countries, and many Asian and Latin American countries, this growth was not driven by workers moving into industry. Rather, in much of Africa, industry at large, including manufacturing, has remained flat while workers have moved into a burgeoning services sector. The services sector is now the largest sector in Africa, and already accounts for over half of Africa's total GDP (Figure 1.1). Yet an economic transformation based predominantly on services is problematic because much of the sector comprises informal, labor-intensive activities, with labor productivity that is little, if any, better than traditional agriculture. These kinds of services do not offer realistic pathways to creating the number and types of productive jobs needed to raise living standards for most Africans (McMillan, Rodrik, and Sepúlveda 2017). For that, it is necessary to grow the industrial sector, ideally export manufacturing, which can absorb large numbers of semi-skilled workers, 


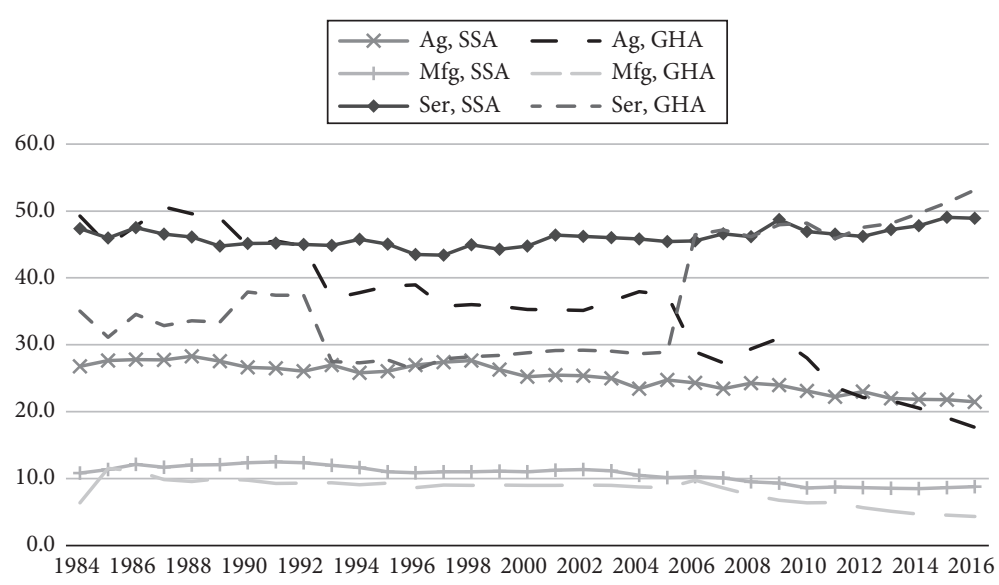

Figure 1.1a. GDP shares of agriculture, manufacturing, and services in the national economy, Africa averages and Ghana (\%)

Note: SSA is a simple average of shares for thirty-three SSA countries with data available in all years for all the three sectors in World Development Indicators, excluding South Africa.

Source: Authors' calculation using data from World Development Indicators.
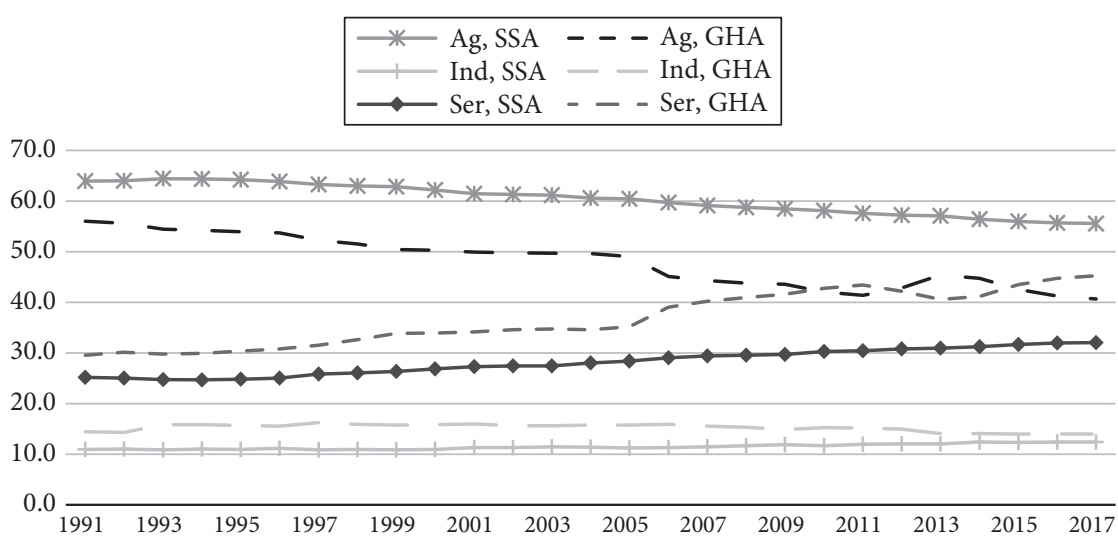

Figure 1.1b. Employment shares of agriculture, industry, and services in total employment, Africa averages and Ghana (\%)

Note: SSA is a simple average of shares for thirty-seven SSA countries with data available in all years for all the three sectors in World Development Indicators, excluding South Africa.

Source: Authors' calculation using data from World Development Indicators.

and/or grow the more productive parts of the agricultural sector, such as nontraditional exports. Moreover, unlike manufacturing or nontraditional agriculture, whose outputs can be exported, services are mainly consumed in the domestic market and their growth is constrained by growth in national demand. 
Thus, service-led transformation can only take African countries so far, and will at best lead to modest rates of national economic growth (Rodrik 2018; McMillan, Rodrik, and Sepúlveda 2017).

Why have African economies developed in this way and why has industrialization been so difficult to achieve? And if industrialization is going to be difficult to achieve for African countries, what viable policy options exist to generate sustainable structural transformations in the region? To tackle these important questions in a tractable manner, this book focuses on the experience of one country-Ghana-and examines the country's overall economic performance since it went through a major Structural Adjustment Program (SAP) in the early 1980s and provides a detailed analysis of the performance of the agricultural sector. In so doing, the book aims to explain why Ghana has not transformed its economy more substantially, why its agriculture sectorbeyond cocoa-has not played a greater role, and what it must do in the future if it is to continue with a successful transformation. Addressing these puzzles requires integrating economic and political analyses. Finally, the book considers what the rest of Africa can learn from Ghana's experience.

\subsection{Why Agriculture?}

If, as much economic opinion suggests, it is going to be a difficult and slow process for Africa to become a major manufacturing hub like Asia (Kormawa and Jerome 2014), then exploiting opportunities for promoting growth of productive jobs outside manufacturing will be essential. One of the more promising options lies in transforming agriculture because it is still the dominant employer in Africa and faces a rapidly growing market at both country and continental levels. Africa's demand for food is growing fast and is projected to more than double by 2050 (Badiane and Ulimwengu 2017), driven by population growth, rising incomes, rapid urbanization, changes in national diets towards greater consumption of higher value fresh and processed foods, and more open intra-regional trade policies. Moreover, agricultural growth helps leverage rapid growth in the larger agri-food system, including agro-processing and trading. The World Bank (2014) estimates that African agribusiness (defined to include all aspects of the agri-food system except on-farm production) could become a $\$ 1$ trillion market by 2030 (in 2010 prices), and that does not include the value of the additional agricultural production that will be needed to support growth in agribusiness.

Exploiting this potential will require a major shift from traditional to more productive and market-driven farming practices, as well as the development of 
agricultural value chains and the broader agri-food system. This is an important growth opportunity for Africa but requires that African governments be willing to invest in agriculture and create the enabling environment for a market and private-sector-led transformation of the agri-food system. This manifestly depends on the economic factors driving different options, domestic political forces, donor influences, and institutional capabilities in Africa. Indeed, with few exceptions, African government policies towards agriculture over recent decades have ranged from half-hearted to detrimental, despite enormous opportunities to grow the sector through productivity-enhancing technologies. As such, examining the future prospects for agricultural transformation needs to also consider political economy dynamics shaping the feasibility of available choices.

\subsection{Why Ghana?}

Since Africa is a diverse continent, richer insights about future transformation trajectories are more likely from country case studies than continent-wide analyses. Therefore, this book focuses in depth on Ghana, which has been viewed as one of Africa's success stories in terms of growth in per capita income (PCI), agricultural output, the achievement of middle-income status, reductions in poverty, and the maintenance of peace and social cohesion (Fosu 2009; McKay et al. 2016; Aryeetey and Baah-Boateng 2016; Aryeetey and Kanbur 2017). This success should not be surprising given that by many standards Ghana has it all: a rich mineral base (particularly bauxite, gold, diamonds, phosphates, and oil); a robust and consolidated democracy; generous amounts of agricultural land per capita; a generally favorable climate for agriculture; and a well-developed coastal city and port with direct access to international shipping lanes. It is a country with multiple options and has had the potential to become an agriculture-led, minerals-led, or manufacturing-led economy. Moreover, in developing its manufacturing base, Ghana could choose between industries that add value to domestic agriculture and minerals outputs, or develop entrepôt industries that add value to imported materials. And in developing an agricultureled strategy, Ghana has sufficient land that it could choose between a small or large farm-led agricultural development strategy.

Despite this exceptionalism, Ghana demonstrates many shared characteristics with other countries on the continent. Like most other African countries, Ghana underwent a painful but much-needed structural adjustment period in the 1980s that required the state to retrench from much of the economy rather 
than take a proactive role. In the 1990s, Ghana was part of the "third wave" of democratization (Huntington 1991) that swept the region, which elevated the role of voter preferences and non-state actors, including civil society organizations, in the policy arena. Around the same time, Ghana also embraced decentralization and, like Kenya, Zambia, and other countries, increasingly has devolved subnational agricultural functions to locally elected governments. Collectively, these processes have resulted in more pressures and actors involved in the broader economy and the agricultural sector.

In addition, just as unemployment is one of the most pressing concerns for Africa, the lack of productive jobs for a large share of workers is problematic in Ghana, especially as there are growing concerns about its future growth prospects (Aryeetey and Kanbur 2017). Per capita incomes have grown consistently since the mid-1980s; but, at 2.8 percent per year on average, its growth is much lower than achieved in many Asian countries that started at similar levels of per capita incomes in the 1960s. Moreover, despite all of Ghana's latent advantages, the structural changes in the national economy have been typical of much of Africa, with "urbanization without industrialization" (Gollin et al. 2016), and a rapidly growing services sector (see Figure 1.1 again). Although Ghana has done well with its minerals and cocoa exports, it has been less effective at producing more manufactured and nontraditional agricultural exports for the world and West African regional markets. In fact, the country seems unable to compete more effectively with imports like rice, poultry, processed foods, or manufactured consumer goods that are taking large shares of its rapidly growing domestic markets. Enhancing exports or import substitutes in these areas promise to create many jobs, boost national per capita income, absorb a growing labor force, and enable more workers to shift out of traditional agriculture.

In other words, the Ghanaian experience is typical of the broader African struggle for sustainable structural change. Agriculture offers options for improving transformation, and this book contextualizes the viability of those options given political economy constraints, past investment decisions, and the broader global environment in which Ghana, and much of Africa, must now compete.

\subsection{Overview}

The book is organized in two parts. Part I focuses on Ghana's overall economic development, describing the economic transformation that has occurred since Independence in 1957, the political forces that have shaped it, and the 
prospects for future growth. Part II is concerned with the role played by the agricultural sector in Ghana's transformation, the reasons why the sector has not been more of a driving force in Ghana's economic transformation, and again the prospects for future growth.

\subsubsection{The National Economic Transformation}

Following Independence, Ghana launched a state-led program of industrialization and large-scale state-owned farming, and a series of heavily subsidized programs of support for smallholder production of prioritized food staples. Most of these initiatives failed or became financially unsustainable, contributing to a turbulent period of economic and political crises, during which time the economy shrank by nearly one third. In 1984, a new revolutionary government led by Jerry Rawlings began to implement a series of major economic reforms as part of a Structural Adjustment Program (SAP) supported by the IMF and World Bank. Together with a return to democratically elected government in 1992, the SAP helped turn the economy around and embed a basic market-led development strategy in which the government focused primarily on creating an enabling economic environment rather than trying to promote specific lines of economic activity. While many other countries also adopted a similar SAP, Ghana implemented its reform program more comprehensively than most. The economy began to grow almost immediately after the SAP was launched, and Ghana has succeeded in achieving uninterrupted growth in annual per capita income (PCI) for more than thirty years, an achievement matched by only five other developing countries in the developing world, including just two in Africa (Botswana and Mauritius).

This growth was accompanied by significant changes in the economic structure of the country. However, as noted above, while agriculture's relative importance in national GDP and employment shrank, it was not replaced in relative importance by a rapidly growing industrial or manufacturing sector. Rather it was the services sector that took off, and today accounts for more than half of national GDP and 45 percent of national employment. At the same time the industrial sector stagnated, and its manufacturing component shrank from 12 percent of national GDP in 1985 to a mere 5 percent in 2014. Ghana has also rapidly urbanized, and today more than half the population lives in urban areas. Gollin et al. (2016) have characterized the rapid growth of Ghana's urban centers with their heavy economic reliance on services as "consumption cities". 
What have been the predominant sources of labor productivity growth in Ghana to explain these patterns? And is this productivity growth sustainable? Since labor productivity is a key determinant of national per capita income (PCI), Chapter 2 addresses these questions in detail. Average PCI has grown by 2.8 percent per annum on average since 1984, a rate fast enough to double the PCI every twenty-five years. This correlates highly with the gains in labor productivity over the same period. Using an analytical framework developed by Rodrik (2014), Chapter 2 shows that the predominant source of labor productivity growth in Ghana has come from productivity increases within sectors, with the agricultural sector showing a particularly strong performance. Rodrik attributes this source of growth to what he calls "fundamental capabilities," or the longer-term benefits from investments in better institutions, healthier and better educated workers, technologies, and more enabling policies. Another source of productivity growth arises from the movement of workers from low to higher productivity sectors, (e.g., from traditional agriculture to manufacturing). Rodrik calls this the gains from "structural change," which result from changes in the relative importance of different sectors in national income and employment.

In Ghana, about 75 percent of total growth in labor productivity between 1984 and 2011 was attributable to within-sector labor productivity growth and only 25 percent to structural change. This not only is very different from the pattern observed in many Asian countries, but also is even unusual by African standards, where the movement of workers to higher productivity sectors is usually an important source of labor productivity growth during the early stages of a country's economic transformation. The reason for the low gain in labor productivity from structural change in Ghana is that so many workers have moved from agriculture to the services sector, and the labor productivity of many services is not much higher than in traditional agriculture. In some cases it is even lower, meaning that the movement of a worker from traditional agriculture to such a low-productivity service sector actually detracts from the nation's average labor productivity.

A key challenge for Ghana's ongoing pattern of economic transformation is that it may be hard to sustain, let alone accelerate, growth in PCI. While within-sector labor productivities will continue to benefit from past and ongoing improvements in fundamentals, these promise at best a modest if steady contribution to PCI growth. Their contribution may also slow as some important past sources of past productivity growth run out of steam. For example, growth in labor productivity within the agricultural sector, which Chapter 2 shows accounted for 40 percent of the increase in national labor 
productivity over 1984-2011, will slow as the land frontier is exploited and future growth will need to come from agricultural intensification.

Ghana will need to do a better job of tapping into the benefits of structural change, and this requires policies that can generate more rapid growth of sectors that can achieve a) high levels of labor productivity relative to traditional agriculture, and b) absorb lots of workers from lower productivity sectors like traditional agriculture. The most promising possibilities for creating productive employment lie in agricultural intensification and the growth of modern industries, such as agro-industries. There is not only a growing national demand that offers market opportunities in these sectors, but also increasing regional economic cooperation, which should allow Ghana to increase its exports into the West Africa regional market. But this will require more effective strategies for overcoming some of the market failure problems along key manufacturing and agricultural value chains, and the eventual uptake of agricultural intensification strategies.

Does the government have the incentives and capacity to pursue such strategies? Addressing this question is the main focus of Chapter 3. In other areas of the world, economic transformation has required pro-active interventions by a capable state. Historically, the Asian tigers were guided by a "developmental state" characterized by a well-trained and meritocratic bureaucracy led by leaders with long-term economic strategies operating in authoritarian regimes. This confluence of circumstances briefly occurred in Ghana under Rawlings between 1983 and 1992 when strong national leadership and a cadre of highly competent economists drove the economic reforms under the SAP. A developmental state approach was less viable when Ghana transitioned to democracy in 1992 when responsiveness to citizen demands became a primary concern of the government. Despite several attempts to strengthen Ghana's civil services and public institutions under the Fourth Republic, public sector capacity is a notable weakness among the country's governance successes.

Consequently, the governance setting has been more conducive to providing an enabling investment and policy environment (i.e., Rodrik's "fundamentals"), including in the agricultural sector, than to proactively identifying and implementing state-guided economic activities. Therefore, some areas of the economy that are fraught with market failure problems have remained underdeveloped, and this has contributed to the limited growth of higher productivity sectors, and hence the low gains in productivity growth from structural change. This limitation is especially true of some manufacturing and agricultural value chains, such as those for nontraditional exports like pineapples, and 
commodities that must compete with imported foods like rice, poultry, tomato paste, processed foods, and many manufactured consumer goods. Several examples are given in Chapter 3, especially of missed opportunities by the state to better support agro-industries. Like many other African countries, a key challenge is how to achieve a more proactive public development role to overcome some of the market failures in key value chains like manufacturing and nontraditional agricultural exports. These issues recur in Part II and in the concluding chapter of the book.

\subsubsection{The Agricultural Transformation}

Part II of the book is concerned with the role played by the agricultural sector in Ghana's transformation. Overall, the sector has performed successfully since the 1980s in several dimensions, but it has not exploited its potential to become a more important source of export earnings beyond cocoa, or to reduce the country's growing dependence on many imported foods. Given the importance of agriculture in the Ghanaian economy, Chapters 4-9 provide a comprehensive review of the agricultural transformation that has occurred, and seek to answer why it has evolved the way it has, what is holding it back, and identify options for future growth.

Chapter 4 describes the main features of the agricultural transformation that have occurred since the policy reforms of the 1980s, and provides regional as well as national insights. In the north, substantial increases in farm production and incomes have come more from increases in the cropped area and crop mix than from increases in yields. Land productivity has increased only modestly, but labor productivity has increased substantially in line with wages. In the south, farm households have taken advantage of growth in urban-rural linkages to diversify into nonagricultural sources of income, and farms have become smaller and more part-time at the expense of larger farms. These livelihood patterns seem likely to sustain into the future as long as the nonagricultural economy, especially in middle- and small-sized towns, continues to flourish, and as long as farmers can successfully adapt to a shrinking land frontier, especially in the northern region.

Chapter 4 then investigates three underlying factors that explain agricultural performance. One is government policy. While the government has done a good job in creating and sustaining an enabling economic environment for farmers and private investment along agricultural value chains, apart from cocoa it has not done enough on public investment or on supportive policies to 
help overcome market failures along many value chains, especially those for export crops, import substitutes, and agroprocessing. Rural population growth is a second driver. In many other contexts, this might be expected to lead to more intensive agricultural practices. However, in Ghana, an elastic land frontier, and the pull of higher wages in the nonfarm economy, have eased the pressure of the land constraint. Instead of induced innovation leading to higher land productivity, the pressure has been on farmers to adopt laborsaving technologies that increase labor productivity in line with wages. Third, urbanization has had a major impact on rural livelihood patterns, especially in districts containing urban centers. Urbanization has led to more part-time farming and considerable income diversification, which is the focus of Chapter 5. Yet, despite having greater access to urban markets, services, infrastructure, and an increasing population pressure on the land base, there is little evidence of agricultural intensification leading to higher land productivity even in the more urbanized areas.

Given the powerful impact urbanization has had on agriculture, Chapter 5 explores the issue in more depth and asks how urbanization in Ghana has affected rural employment, farm size distribution, and the use of modern inputs. Recognizing that urbanization has not affected agriculture equally throughout the country, the chapter develops a spatial typology of rural areas by the 2000 and 2010 National Censuses of Population and Housing. Seven types of districts are identified based on their city population size and location in the north or south of the country. In turn, both the 2000 and 2010 Censuses and the two rounds of Ghana Living Standards Surveys' data are used to calculate the share of households employed in agriculture, nonagriculture, or both across these seven different district types. The findings illustrate that urbanization is increasing the share of rural households in the nonfarm economy. It has also contributed to an increase in the share of small, part-time farms in urbanized areas, and a shift towards more medium-sized farms in the agriculturally important areas of the north. The chapter further tests the induced innovation hypothesis, which predicts that urbanization and associated increases in population density and market access should lead to more intensive farming practices. The findings show though that while there has been substantial uptake of fertilizers, herbicides, and mechanization in recent years, there is only limited support that this has been driven by urbanization other than through its influence on rural wages.

To complement the secondary data used in the previous chapters and obtain a deeper understanding of the changes that have occurred at farm and village levels, Chapter 6 draws on primary data collected by authors in 
four representative villages in the northern part of the country. In doing so, the chapter asks what major changes in farming practices and household livelihood strategies occurred from the 1980s to the present? The chapter also addresses several key questions. What were the key driving factors that drove farmers' adaptation decisions, and why, despite continuing rural population growth, did they generally choose to adopt technologies and farming practices that increase labor productivity relative to land productivity? Also, what happens once options for bringing more land into production become exhausted? As discussed in Chapter 4, how well farmers adjust to increasing land scarcity will be critical for the future sustainability of agricultural growth in Ghana.

The surveyed villages span two agro-ecological zones in the country, namely the transition and savannah zones, which were chosen for study because these zones grow the predominant share of the country's cereal and legume crops, and until recently still had an ample supply of new land available for farming. However, because the land frontier is finally becoming exhausted in some areas, one village was selected in each zone that has reached its land frontier and one that still has virgin land left, in order to obtain insights into how farmers and villages are adjusting to emerging land scarcities. The data collection drew on focus group discussions and individual interviews with selected farmers, village leaders, and local extension and government officials in 2015. The detailed narratives provided in the chapter are complemented by a farm model analysis to better understand the economic factors driving changes on small, medium, and large-sized farms in the villages, and to quantify some of their impacts. The findings show that over the last three decades, farmers have been adept at adjusting to increasing population pressure, changing household needs and expanding market opportunities by increasing the size of their operated farms and growing more market-oriented crops. This adjustment has been complicated by an increasing scarcity of virgin land, which has compelled farmers to reduce fallow periods or acquire land in other more distant communities that still have a virgin land frontier. With shortened fallow periods, there has been a decline in soil fertility, and farmers have had to adjust by using inorganic fertilizer-essentially to maintain rather than increase yields, introduce soil fertility management practices like legume-cereal rotations, and adopt new crops and crop varieties that are more tolerant of less fertile soils and to changing rainfall patterns. Another factor complicating farmers' adaptation has been the increasing cost of labor and difficulties in accessing it at critical times of the agricultural season. Farmers have adjusted to this problem by adopting labor-saving technologies 
like tractors and herbicides, and by growing crops that require less labor. As a result of all their adaptations, farmers have managed to substantially increase their farm incomes and labor productivity, but land productivity has increased only modestly. A key issue is how far these farmers can go in further adjusting to increasing land and labor scarcities without having to switch to more intensive farming practices.

There are many aspects of the agricultural transformation that might warrant detailed analysis in a book of this nature, but we focus on three topics that emerge as especially important from the discussions in Chapters 2 through 4. One is the crucial role of public investment in agriculture. Another is the problem of market and institutional failures along key agricultural value chains, and the need for more proactive public sector solutions. A third is the need for more effective public-private partnerships in agriculture and agribusiness. Public investment is taken up in Chapter 7, while value chains and some aspects of public-private partnership issues are taken up in Chapter 8. Finally, Chapter 9 focuses on agricultural mechanization. Not only is mechanization an important topic in its own right at a time of increasing labor costs, but the government's current interventions in the supply of mechanization services in competition with the private sector is an important example of the problems that arise when the government fails to adequately support and partner with the private sector.

Along with the creation of enabling policies, public investment in agriculture plays a crucial role in promoting agricultural growth and conditioning its distributional outcomes. Chapter 7 asks whether Ghana has invested enough resources in agriculture and how the patterns of investment in the sector have impacted agricultural productivity growth. Specifically, the chapter examines trends in public agricultural spending over the period 1961-2012, and disaggregates that spending into the cocoa and noncocoa sectors. The majority of total spending has gone into the cocoa subsector, while the noncocoa subsector, which includes all the country's food staples, has been neglected. The government's public spending on agriculture has fallen short of 10 percent of its total expenditure in most years since 1961, and in recent times the share has averaged only 2 to 3 percent, which is low even by African standards. The government has also spent relatively little on complementary investments in rural roads and other essential rural infrastructure. More detailed insights are provided by looking at the types of spending within the agricultural sector and their regional allocation. Two econometric analyses then estimate the impact of public spending on agricultural productivity growth, and provide some useful insights into the marginal returns to public investments in the 
cocoa and noncocoa subsectors, and by type of public investment. This is followed by a discussion of some of the government's recent attempts to promote noncocoa agricultural growth through several new subsidy and investment programs.

Strengthening agricultural value chains are critical for enhancing Ghana's domestic market and export potential. But how can agricultural value chains be further developed in Ghana given prevailing market failure problems that constrain the private sector from playing a greater role? Can the government play a greater role in developing value chains for priority commodities, particularly nontraditional export commodities and import substitutes, as has been done for cocoa or in regions such as South East Asia? These are the central questions of Chapter 8 . While Ghana remains relatively selfsufficient in basic staples, the composition of agricultural output has not adequately changed to reflect the growth in domestic demand for higherincome elastic foods like rice, poultry, and tomatoes, nor has agro-processing expanded to meet a growing urban demand for processed and pre-cooked foods. One consequence has been rapid growth in the importation of rice, poultry meat, and processed tomato paste, while nontraditional agricultural exports like pineapples have languished.

As such, the chapter first recognizes the successful, decades-long public interventions in the cocoa subsector through the Ghana Cocoa Board. Using this experience as a benchmark, the chapter evaluates how interventions in three other value chains compare: pineapples, rice, and tomatoes. These latter three crops have under-exploited opportunities because of the inability of farmers to produce sufficient amounts of high-quality farm products that meet urban market, agroprocessor, and export demands. In turn, this is due to a lack of better seed varieties, an absence of quality control through grading and pricing along value chains, inadequate post-harvest handling (especially transport, and cold storage and modern processing facilities), and few largescale agribusinesses willing or able to take the lead in developing new export markets. The findings reveal opportunities and constraints along the value chains of these commodities, identifies the roles that the public sector should ideally play and, in turn, analyzes whether it has the capacity to feasibly do so.

Finally, Chapter 9 turns to agricultural mechanization and asks how the government could more effectively engage with the private sector to enhance the development of agricultural mechanization. Agricultural mechanization, both in the form of animal and tractor power, has expanded markedly since the early 2000s with about one third of Ghana's farmers reporting to use some form of mechanization for land preparation. Yet in 2007, with a belief that 
mechanization services to smallholders cannot be left to the private sector alone through its own importation of tractors, of which most are second-hand, the government started to directly engage in the importation of tractors, which were given to the so-called Agricultural Mechanization Services Centers (AMSECs) at heavily subsidized prices. The AMSEC was one of the four initiatives included in the country's agricultural development strategy in 2007.

After reviewing recent developments in the uptake of agricultural mechanization in Ghana, and the factors that are driving the growth in farmers' demand, the chapter then discusses possible supply-side constraints, and evaluates AMSEC's impact on existing private sector mechanization alternatives. The chapter concludes that such interventions often lead to market distortions in machinery prices, encouraging rent-seeking behavior, and discouraging the development of a private sector supply system. The programs are also unnecessarily costly to the public sector. Instead, the government would be more effective in achieving its goals if it were to withdraw from the AMSEC program and instead play a more complementary and supporting role to the private sector. This might include funding appropriate mechanization research, technical training of young mechanics, and ensuring that financial institutions can provide the longer-term lending needed by private agents and farmers in the mechanization supply chain.

Chapter 10 concludes the book by looking to the future. It reviews key findings from each of the preceding chapters and then considers the implications given future trends and Ghana's policy environment. The chapter highlights the need to develop a broader swath of high-productivity industrial and agricultural activities if Ghana is to succeed in sustaining or even accelerating its rate of growth in per capita income. To this end, the chapter identifies considerable opportunities within the agriculture sector and broader food system, including meeting a rapidly growing domestic demand for higher-value foods like fruits, vegetables, and livestock products, and for processed and pre-cooked foods. There are also substantial import substitution opportunities for commodities such as rice, poultry, and tomatoes, as well as for many imported processed foods, and opportunities for developing nontraditional agricultural exports to the West African regional market and beyond. To meet these demands, the required supply response will need to be market driven with the private sector taking the lead. However, the government has key roles to play in removing some of the constraints holding back both the speed and scope of the transformation, and helping to ensure that it is inclusive of small farms and of the many small and medium-sized enterprises (SMEs) that operate along agricultural value chains and within the food 
system more generally. Creating the necessary enabling policy environment will require the development of more effective state-private sector relationships, including with large businesses, SMEs and small traders. Other key areas for further attention include land policy reforms, infrastructure, agricultural research and extension, seed systems, fertilizer, soil management, irrigation, mechanization, financial services, regulation of farm inputs and outputs, coordination along value chains, and linking small farms to value chains. Importantly, the chapter acknowledges that the feasibility of addressing all of these areas requires a consideration of the political and policy environment, and more effective public-private partnerships than has been evident in the past. The chapter also provides an update on the government's most recent initiative-Planting for Food and Jobs (PFJ) - and contrasts this with the vision of a market-and-private-sector-led transformation of the agri-food system previously discussed. The chapter concludes with some broader implications of Ghana's experience for other African countries.

\section{References}

Aryeetey, Ernest and William Baah-Boateng. 2016. "Ghana: A Successful Growth Story with Job Creation Concerns," in Haroon Bhorat and Fin Tarp (eds), African Lions: Growth Traps and Opportunities for Six African Economies. Washington DC: Brookings Institution Press, 77-108.

Aryeetey, Ernest and Ravi Kanbur. 2017. The Economy of Ghana Sixty Years after Independence. Oxford: Oxford University Press.

Badiane, O., and T. Makombe (eds). 2014. "Beyond a Middle Income Africa: Transforming African Economies for Sustained Growth with Rising Employment and Incomes." ReSAKSS Annual Trends and Outlook Report 2014. Washington, DC: International Food Policy Research Institute.

Badiane, O., and J. Ulimwengu. 2017. "Business Pathways to the Future of Smallholder Farming in the Context of Transforming Value Chains," in African Agriculture Status Report 2017: The Business of Smallholder Agriculture in SubSaharan Africa. Nairobi: AGRA.

Fosu, Augustin Kwasi. 2009. "Country Role Models for Development Success: The Ghana Case.” Research Paper No. 2009/42. Helsinki: UNU-WIDER.

Gollin, D., R. Jedwab, and D. Vollrath. 2016. "Urbanization with and without Industrialization." Journal of Economic Growth 21(1): 35-70.

Huntington, Samuel. 1991. The Third Wave: Democratization in the Late Twentieth Century. Norman, OK: University of Oklahoma Press. 
Kormawa, Patrick, and Afeikhena Jerome. 2014. "Renewing Industrialization Strategies in Africa," in: Beyond a Middle Income Africa: Transforming African Economies for Sustained Growth with Rising Employment and Incomes. ReSAKSS Annual Trends and Outlook Report 2014. Washington, DC: International Food Policy Research Institute.

McKay, Andy, Jukka Pirttilä, and Finn Tarp. 2016. “Ghana: Poverty Reduction over Thirty Years," in C. Arndt, A. McKay, and F. Tarp (eds), Growth and Poverty in Sub-Saharan Africa, UNU-WIDER Studies in Development Economics. Oxford : Oxford University Press, 69-88.

McMillan, Margaret, Dani Rodrik, and Claudia Sepúlveda (eds.). 2017. Structural Change, Fundamentals, and Growth: A Framework and Case Studies. IFPRI, Washington DC.

Ncube, Mthuli, and Charles Lufumpa (eds). 2015. The Emerging Middle Class in Africa. Abidjan and London: African Development Bank and Routledge.

Rodrik, D. 2014. “The Past, Present, and Future of Economic Growth,” in Franklin Allen et al., Towards a Better Global Economy: Policy Implications for Citizens Worldwide in the 21st Century. Oxford: Oxford University Press, 70-137.

Rodrik, D. 2018. “An African Growth Miracle?” Journal of African Economies 27(1): 10-27.

Shimeles, Abebe, and Mthuli Ncube. 2015. "The Making of the Middle-Class in Africa: Evidence from DHS Data," Journal of Development Studies 51(2): 178-93.

United Nations (UN). 2014. World Urbanization Prospects: 2014 Revision. New York: Department of Economic and Social Affairs, UN. 
PART I

GHANA'S ECONOMIC TRANSFORMATION 



\section{2 \\ Ghana's Economy-wide Transformation \\ Past Patterns and Future Prospects}

Xinshen Diao and Peter Hazell

\subsection{Introduction}

Ghana has experienced a successful economic and political transformation since its Structural Adjustment Program (SAP) of the 1980s, and is one of the few African countries to have attained lower-middle-income status, or to have achieved the Millennium Development Goal (MDG) of halving poverty by 2015. This chapter describes the economy-wide transformation that has occurred, and uses a growth decomposition framework to identify the main sources of economic growth. It is found that while Ghana has benefited from significant growth in labor productivity within important sectors, and there have been structural changes in the sense that agriculture has shrunk as a share of national GDP and employment while other sectors have grown faster, still there has been relatively little progress in moving workers out of lowproductivity sectors like traditional agriculture into more productive sectors like manufacturing or modern services. We question whether this pattern of transformation is sustainable in the future, and explore alternative options that may be needed. Chapter 3 provides a complementary analysis of the political transformation that has occurred in Ghana, and thence the political and governance challenges facing the country as it seeks to adopt a more sustainable type of transformation.

The chapter is structured as follows. Section 2.2 describes the patterns of growth that have occurred in Ghana since the country launched its SAP in 1983, including the growth in national and per capita incomes, the changing sector composition of the economy, and the changes in employment. In Section 2.3 we present a conceptual framework developed by Rodrik (2014, 2018) and use it to decompose the sources of growth in labor productivity and identify the relative importance of within-sector productivity growth compared to the structural shifting of workers from low to higher productivity 
sectors. This leads in Section 2.4 to a discussion of the sustainability of the past pattern of growth, and of future growth opportunities and challenges. Finally, Section 2.5 concludes.

\subsection{Ghana's Economic Transformation since the 1980s}

\subsubsection{Growth in National Per Capita Income}

Ghana started its SAP ${ }^{1}$ in 1983 (see Chapter 3 for further details), earlier than most other African countries that eventually went through a similar IMF- and World Bank-guided reform process. GDP per capita has grown modestly but steadily since the mid-1980s. In fact, over the thirty-four years 1984 to 2017, Ghana experienced positive per capita GDP growth every single year, and this despite population growth of 2.5 to 2.8 percent per annum, and rainfallinduced fluctuations in the output of its largest sector-agriculture. Only five other developing countries in the world have managed to achieve uninterrupted growth in per capita GDP over thirty or more years since 1960. These five countries include two in Africa and three in Asia (Table 2.1). If we also consider countries with just one year's interruption over thirty years, then there are three other Asian countries that can be included: two are past Asian growth miracles, Korea and Singapore, plus India (Table 2.1).

Table 2.1. Countries with uninterrupted per capita GDP growth for thirty years

\begin{tabular}{|c|c|c|c|c|}
\hline & Growth period & $\begin{array}{l}\text { Number of } \\
\text { growth years } \\
\text { uninterrupted }\end{array}$ & $\begin{array}{l}\text { With one } \\
\text { year growth } \\
\text { interruption }\end{array}$ & $\begin{array}{l}\text { Average annual per } \\
\text { capita GDP growth } \\
\text { rate within the } \\
\text { growth period }^{\mathrm{b}}\end{array}$ \\
\hline Ghana & 1984-2017 & 37 & & 2.8 \\
\hline Botswana & 1961-92 & 32 & & 7.7 \\
\hline Mauritius & 1984-2016 & 33 & & 4.3 \\
\hline China & 1977-2017 & 41 & & 8.5 \\
\hline Thailand & $1961-96$ & 36 & & 5.4 \\
\hline Vietnam $^{\mathrm{a}}$ & 1985-2017 & 33 & & 4.9 \\
\hline India & 1980-2017 & & 38 & 4.5 \\
\hline Korea & $1961-97$ & & 37 & 7.5 \\
\hline Singapore & $1965-97$ & & 33 & 6.7 \\
\hline
\end{tabular}

\footnotetext{
Note: ${ }^{\text {a }}$ Vietnam's data available since 1985.

${ }^{\mathrm{b}}$ Based on simple average.
}

Source: Authors' calculation using data of World Development Indicators (WDI), World Bank (2017).

\footnotetext{
1 Also known as the Economic Reform Program (ERP).
} 
Another remarkable feature of Ghana's experience is that the economy began to grow almost immediately after it implemented its SAP, whereas many other countries that adopted similar reform programs went through painful adjustment periods, sometimes characterized as "lost decades," before their economies bounced back.

\subsubsection{Structural Change}

Ghana differs in one important respect from the other countries in Table 2.1 that have experienced uninterrupted growth over many years, and that is Ghana's average annual growth in per capita GDP has been slowest. An important reason for this is that the other countries have experienced more rapid industrialization, often leading to periods of very rapid growth (Rodrik 2014). In Ghana, however, despite achieving low-middle-income country by $2008,{ }^{2}$ there has been very little industrialization while services have grown rapidly (Figure 2.1).

Ghana rebased its national accounts in 2007-10, which makes comparisons of the structure of GDP at different periods more difficult. When the national accounts were revised in 2006, significant adjustments were made to both the

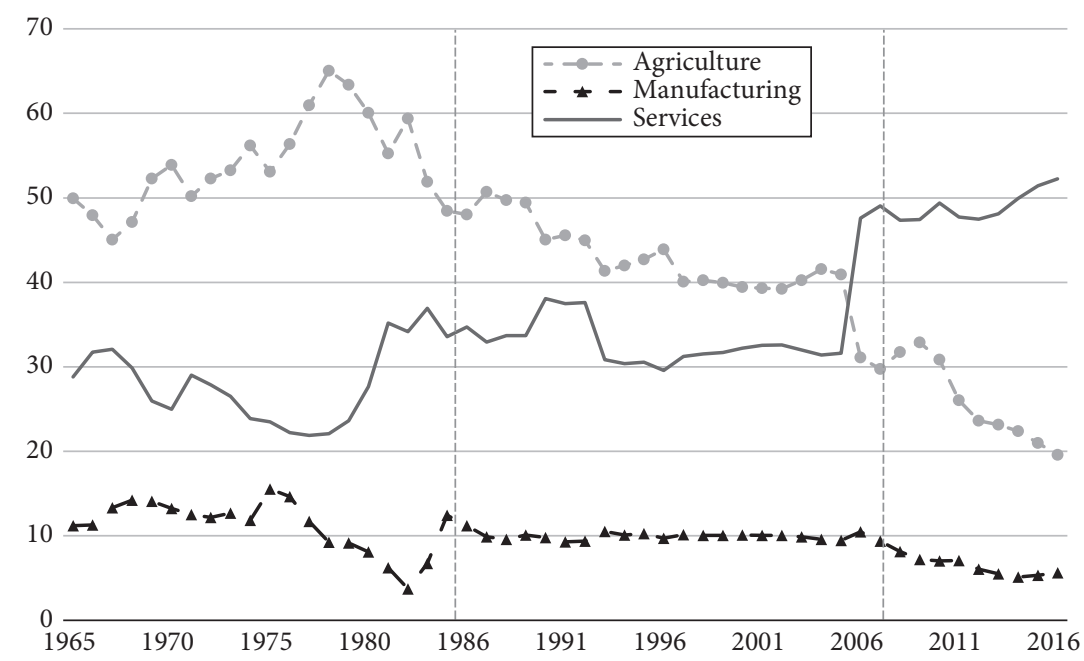

Figure 2.1. Sector shares of GDP

Source: Authors' calculation using World Development Indicators, World Bank (2017).

\footnotetext{
${ }^{2}$ As measured by the gross national income (GNI) per capita at current US\$, using the World Bank Atlas method.
} 
level and structure of GDP compared to prior 2006 estimates based on a 1993 reference year. GDP in the newly rebased national account was 60 percent higher than that in the old estimate, and about 70 percent of this increase was due to the inclusion of service activities that were simply not covered under the old system (GSS 2010). The sudden jump in the service share in 2006 from about 30 percent of GDP to nearly 50 percent reflects this rebasing result (Figure 2.1).

Despite the complications arising from this rebasing, it is clear from Figure 2.1 that the structure of Ghanaian economy changed significantly over 1965-2016. Table 2.2 provides some additional details for the period 1975-2016. The period from 1975 to 1983 shows how badly Ghana’s economy suffered prior to the SAP that began in 1983. Measured in constant US dollars, GDP in 1983 was only 79 percent of the level attained in 1975 (Table 2.2). Moreover, while all sectors were producing less in 1983 than in 1975, some sectors had suffered far more than others. Industry, which includes manufacturing, tumbled the most, and industrial GDP in 1983 was only about half its 1975 value. Agriculture contracted by about 19 percent in this period, while services fell the least, declining by only 6 percent (Table 2.2 ).

During 1983 to 1993 , national economic growth quickly recovered with implementation of the SAP, and by 1988 national GDP in constant terms had returned to its 1974 level. Again, there were important differences by sector. Agricultural GDP only recovered to its 1975 level by 1993, while industry's GDP was still 14 percent below its 1975 level even in 1993. Manufacturing did even worse; its GDP was not much higher in 1993 than in 1983, at about half its 1975 level. The poor performance of manufacturing is explained by the industrialization policies pursued in the 1960s and 1970s, involving state ownership and centralized planning. As in other countries following similar industrialization policies, this created state-owned, overstaffed, inefficient, and

Table 2.2. Changes in sector GDPs and sector shares over 1975-2016, selected years

\begin{tabular}{|c|c|c|c|c|c|c|c|c|c|}
\hline \multirow[t]{2}{*}{ GDP (constant 2000 US\$) } & \multicolumn{5}{|c|}{ GDP relative to $1975(1975=1.00)$} & \multicolumn{4}{|c|}{ Sector share of GDP } \\
\hline & 1983 & 1984 & 1985 & 1988 & 1993 & 1985 & 1993 & 2006 & 2016 \\
\hline National & 0.79 & 0.85 & 0.90 & 1.05 & 1.30 & & & & \\
\hline Agriculture GDP & 0.81 & 0.88 & 0.89 & 0.95 & 1.04 & 48.4 & 41.4 & 31.1 & 19.6 \\
\hline Industry GDP & 0.49 & 0.54 & 0.63 & 0.81 & 0.86 & 18.0 & 27.8 & 21.3 & 28.2 \\
\hline Manufacturing GDP & 0.49 & 0.55 & 0.68 & 0.87 & 0.54 & 12.4 & 10.5 & 10.5 & 5.6 \\
\hline Services GDP & 0.94 & 1.01 & 1.08 & 1.36 & 2.05 & 33.6 & 30.8 & 47.6 & 52.2 \\
\hline
\end{tabular}

Source: Authors' calculation using World Development Indicators, World Bank (2006 and 2017) 
politicized firms. These had become a major burden on government finances by 1983 , and were crowding out the private sector (Leite et al. 2000). Although the government was committed to reforming the state enterprises as part of the SAP, actual progress was slow (Leite et al. 2000). There were still widespread doubts in some policy circles about the benefits of large-scale privatization (Friedrich Ebert Foundation 1994: 9-17). Moreover, an overall policy environment conducive to private-sector-led development had yet to be fully established, and privatizing or otherwise reforming some 350 state enterprises was inevitably a slow process.

Unlike industry, the service sector proved more resilient during 1975-83. Its GDP share was only down 6 percent in 1983, and it recovered quickly with the SAP reforms. By 1984 it had already recovered to its 1975 level of GDP, and by 1993 its GDP had virtually doubled.

During the period 1993-2016, the same pattern of structural change continued, led by the service sector. The GDP share of services changed little between 1993 and 2006 under the old 1993 based accounting system (Figure 2.1), but many new types of service activities were growing that were not being captured in the national accounts. When the national accounts were rebased in 2006, services jumped from 32 percent to 48 percent of national GDP, and had reached more than 50 percent by 2016. During this sub-period, agriculture's share in GDP continued to decline, and industry's share remained flat. Manufacturing, however, plummeted and only accounted for 5.6 percent of national GDP in 2016.

\subsubsection{Aggregate Productivity Growth}

Increases in productivity are essential for sustained growth in per capita incomes. There are several ways of measuring productivity growth, all of which are vulnerable to weak data, so we report and compare several different productivity measures in this section. The most direct measure is labor productivity for the economy as a whole. Figure 2.2 compares annual growth rates of labor productivity measured by value-added per worker and GDP per capita. ${ }^{3}$

Given that the growth rates for employment and the total population were similar (averaging 2.7 percent annually over 1984 to 2010), and that total value-added differs from GDP only by the government's net indirect tax

\footnotetext{
${ }^{3}$ Value-added for the total economy was obtained from Gronigen Growth and Development Centre (GGDC), University of Gronigen (Timmer et al. 2015).
} 


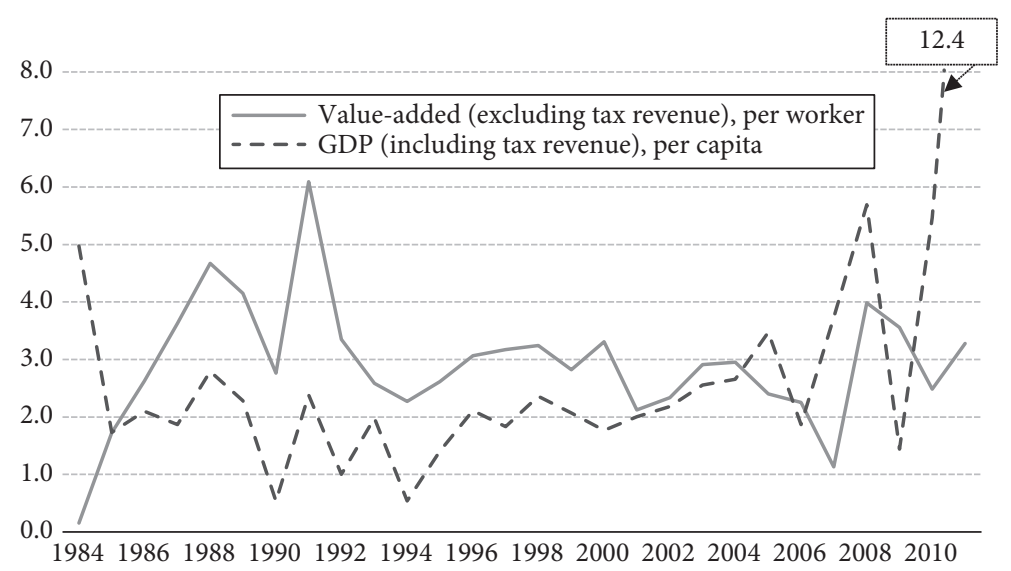

Figure 2.2. Annual growth rates of value-added per worker and GDP per capita in 1984-2011 (\%)

Source: Authors' calculation using data of GGDC (Timmer et al. 2015) for labor productivity and World Development Indicators, World Bank (2017) for per capita GDP.

revenue (which is included in GDP), then we should expect to find similar trends in the growth of GDP per capita and value-added per capita. Figure 2.2 generally confirms this expectation. ${ }^{4}$ Both productivity and PCI measures fluctuated during the SAP period 1984-94 because of the shocks induced by an array of policy changes, and again in the late 2000s after the economy was shocked again by the discovery of oil and the development of oil exports.

A problem with labor productivity is that its growth can result from resource expansion (e.g., land expansion in agriculture), or capital deepening in industry, as well as from increases in the productivity of the resources that are used. In principle, total factor productivity (TFP) is a better productivity indicator because it avoids this problem, but its use depends critically on the calculation of the capital stock and capital services, which are difficult to quantify. Moreover, when a Cobb-Douglas production function for GDP is assumed for growth accounting purposes, the shares of labor and capital in GDP are also difficult to measure and have to be assumed. Keeping these limitations in mind, we have compiled alternative estimates of growth in TFP using two major data sources. One is the Conference Board Total Economy Database (TED) $)^{5}$ which provides growth accounting and total factor productivity measures for many countries, including Ghana, for 1990-2011. Another source is

\footnotetext{
4 The fluctuations in the gap between the two trends are mainly due to fluctuations in net indirect tax revenue as a proportion of the GDP but not in the economy's total value-added.

${ }^{5}$ The Conference Board Total Economy Database, January 2014, http://www.conference-board.org/ data/economydatabase/.
} 
Table 2.3. Growth in per capita GDP, labor productivity, and total factor productivity (\%)

\begin{tabular}{|c|c|c|c|c|c|c|c|c|}
\hline & $\begin{array}{l}\text { GDP } \\
\text { per }\end{array}$ & $\begin{array}{l}\text { Labor } \\
\text { product }\end{array}$ & tivity & Total & factor produ & ctivity (TFP) & & \\
\hline & UNSD & GGDC & TED & TED & & WDP & & \\
\hline & & & & & $\Delta$ TFP_K06 & $\Delta \mathrm{TFP} \_\mathrm{K} 13$ & $\Delta \mathrm{TFP} \_$Keff & $\Delta \mathrm{TFP} \_\mathrm{Ks}$ \\
\hline 1984-2011 & 2.8 & 2.9 & & & & & & \\
\hline $1984-2010$ & 2.4 & 2.9 & & & 2.2 & 1.9 & 2.4 & 2.2 \\
\hline 1990-2011 & 2.8 & 2.9 & 3.1 & 3.4 & & & & \\
\hline $1990-2000$ & 1.6 & 3.2 & 3.0 & 3.7 & 1.4 & 0.7 & 1.4 & 1.4 \\
\hline
\end{tabular}

Notes: ${ }^{1}$ Labor force data is the same between GGDC and TED.

${ }^{2}$ Growth accounting method is used by TED for TFP estimates and share of labor and capital is the same (0.5) in the estimation.

${ }^{3}$ We chose growth accounting-Hick neutral measure in WDP. There are four different TFP estimates $\left(\Delta T F P \_K 06, \Delta T F P \_K 13, \Delta T F P \_K e f f\right.$, and $\left.\Delta T F P \_K s\right)$ in WDP based on alternative estimates or assumptions of initial capital stock and depreciation rate which lead to different capital stocks (i.e., K06, K13, Ks and Keff). Depreciation rate is assumed to be constant over time at 6 percent or 13.3 percent, respectively, for K06 and K13, and ten years of investment is used as an adequate proxy for the initial capital stock estimation in both cases. For the case of Ks the initial capital stock is computed based on the assumption that the country is at its steady state capital-output ratio, and deprecation rate is at 6 percent and constant over time. The time-varying depreciation rate is used for computing capital stock in the case of Keff.

Sources: GDP per capita is from World bank Indicators, World Bank (2017); labor productivity GGDC is from Timmer et al. (2015); labor productivity TED and TFP TED are from The Conference Board Total Economy Database (2014); and four TFP measures of WDP are from UNIDO (2014).

the United Nations Industrial Development Organization (UNIDO), which has developed a World Productivity Database (WPD) containing information on levels and growth of aggregate total factor productivity (TFP) for 112 countries, including Ghana, for 1960-2000. ${ }^{6}$ Both databases provide crude estimates given the limited information available for most African countries including Ghana.

Table 2.3 reports the various estimates of TFP growth in Ghana for 1984-2010 and 1990-2011, and compares them to the labor productivity measures used to calculate Figure 2.2. We also include a separate estimate of labor productivity using TED data. Despite their differences, there is considerable agreement amongst the various productivity estimates, and average TFP growth over 1984-2010 was similar in magnitude to the growth in labor productivity as measured by GDP per worker. This implies that the lion's share of the growth in living standards in Ghana has been due to TFP growth rather than resource expansion (land) or capital deepening.

6 Isaksson (2007). "World Productivity Database: A Technical Description,” Staff Working Paper No. 10/2007, Research and Statistics Branch, UNIDO. 


\subsubsection{Changes in Employment}

Table 2.4 shows the average annual growth rates in employment by sector, and for time periods determined by the years in which population censuses were conducted. Prior to the SAP (1960-84) employment grew at about 3.2 percent per annum in agriculture, manufacturing, and for the economy in total. Employment in services grew a little faster (3.8 percent per year), mostly in finance and government services. However, employment in "other" industry (mining, utilities, and construction) actually shrank by 1.4 percent per year during this period. Growth in employment slowed across the economy during 1985-2000 as the country adjusted to the SAP reforms, except for other industry (including mining and construction) where employment rebounded to grow at 8.2 percent per year. During 2000-2010, growth in total employment recovered to 3.3 percent per year, driven by accelerated growth of employment in services (6.8 percent) and manufacturing (3.5 percent). Within services, employment grew fastest in trade, finance, and other services. Growth in agricultural employment slowed further to 0.7 percent per year during this period, reflecting in part the rapid pace of urbanization in the country and the growth of rural nonfarm activity (see Chapter 5).

Table 2.4. Annualized growth rate in employment for Ghana and by sector (\%)

\begin{tabular}{|c|c|c|c|c|c|}
\hline & Total economy & Agriculture & Manufacturing & Other industry & Services \\
\hline $1960-84$ & 3.2 & 3.2 & 3.1 & -1.4 & 3.8 \\
\hline 1984-2000 & 2.0 & 1.2 & 1.8 & 8.2 & 3.0 \\
\hline $2000-10$ & 3.3 & 0.7 & 3.5 & 2.2 & 6.8 \\
\hline \multirow[t]{3}{*}{ 1960-2010 } & 2.8 & 2.0 & 2.8 & 2.3 & 4.1 \\
\hline & \multicolumn{3}{|c|}{ Within other industry } & & \\
\hline & Mining & Utilities & Construction & & \\
\hline 1960-84 & -2.3 & 0.4 & -1.2 & & \\
\hline 1984-2000 & 10.5 & 3.2 & 7.9 & & \\
\hline $2000-10$ & -1.6 & 4.6 & 3.7 & & \\
\hline \multirow[t]{3}{*}{ 1960-2010 } & 1.7 & 2.1 & 2.6 & & \\
\hline & \multicolumn{5}{|c|}{ Within services } \\
\hline & Trade & Transport & Finance & Government & Others \\
\hline $1960-84$ & 3.3 & 2.6 & 5.8 & 5.3 & 4.9 \\
\hline 1984-2000 & 3.0 & 3.6 & 8.9 & 0.9 & 5.0 \\
\hline $2000-10$ & 7.0 & 5.4 & 8.3 & 5.7 & 7.7 \\
\hline 1960-2010 & 3.9 & 3.4 & 7.3 & 4.0 & 5.5 \\
\hline
\end{tabular}

Source: Authors' calculation using GGDC data (Timmer et al. 2015). 


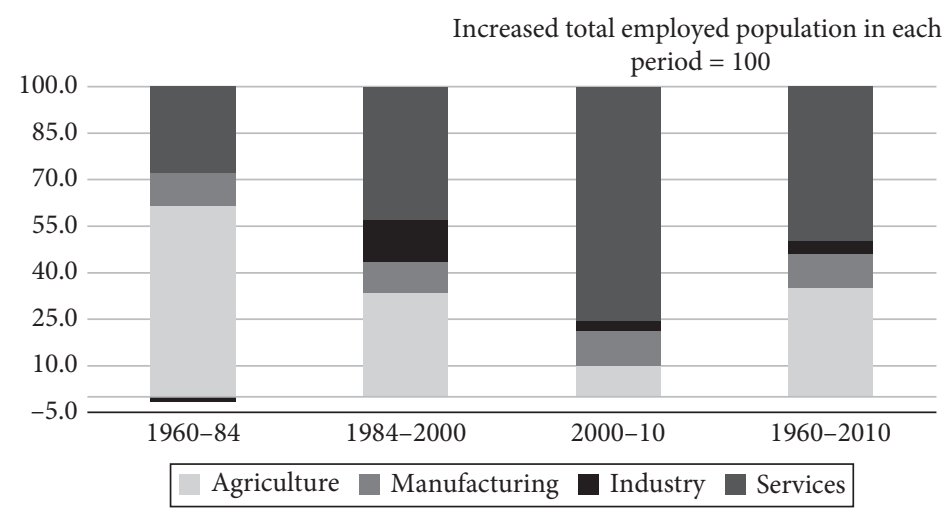

Figure 2.3. Sector allocation of increased employment Source: Authors' calculation using GGDC data (Timmer et al. 2015).

Figure 2.3 shows more starkly the growing importance of service sector employment in Ghana. Of all the jobs created in the national economy during 2000-10, about three quarters were created in the service sector. This was almost double the share of additional jobs created in services during 1984-2000. By contrast, agriculture's contribution to additional employment has shrunk dramatically, adding only 10 percent of all jobs in 2000-10, down from about a third in 1984-2000. Industry, including manufacturing, created slightly more jobs than agriculture during 2000-10, but its share of new jobs was lower than in 1984-2000. A glimmer of good news is that manufacturing created more jobs in 2000-10 than 1984-2000, but the share involved is still small and, given that manufacturing's share of GDP declined between 2006 and 2016, raises questions about the productivity of the manufacturing jobs that were created.

Another distinctive feature of the employment patterns in Ghana is the importance of the informal economy rather than the formal economy in creating nonagricultural employment. The available census data classify employment status into seven groups: (a) self-employed with employees, (b) self-employed without employees, (c) paid wage/salary worker, (d) domestic worker, (e) unpaid family worker, (f) unpaid apprentice, and (g) other; and six choices in institutions: (a) public, (b) formal private, (c) individual/family enterprise, (d) publicprivate mixed or parastatal, (e) foreign and international, (g) others. We define formal sector employment as primary occupations in public, parastatal, and foreign/international entities, or in the private sector when renumerated through regular wages or a salary. The remaining occupation groups are defined as informal employment. We netted out public sector and agricultural employment, disaggregated by rural and urban locations, and tabulated the results by private sector for 2000 and 2010 (Table 2.5a and 2.5b). 
Table 2.5a. Employment structure of private non-agriculture by formal/informal, rural/urban, and industry in 2000

\begin{tabular}{|c|c|c|c|c|c|c|c|c|c|}
\hline & \multicolumn{9}{|c|}{ Total private nonagricultural employment for the country is 100} \\
\hline & \multicolumn{3}{|c|}{2000 Rural } & \multicolumn{3}{|c|}{2000 Urban } & \multicolumn{3}{|c|}{2000 National } \\
\hline & Formal & Informal & Total rural & Formal & Informal & Total urban & Formal & Informal & Total national \\
\hline Mining & 0.5 & 1.0 & 1.4 & 0.9 & 1.0 & 1.9 & 1.4 & 1.9 & 3.3 \\
\hline Manufacturing & 0.8 & 8.4 & 9.2 & 3.5 & 13.3 & 16.8 & 4.3 & 21.7 & 26.0 \\
\hline Utilities & 0.1 & 0.3 & 0.3 & 0.3 & 0.2 & 0.5 & 0.3 & 0.5 & 0.9 \\
\hline Construction & 0.5 & 1.6 & 2.0 & 1.6 & 3.6 & 5.2 & 2.1 & 5.2 & 7.3 \\
\hline Trade services & 0.7 & 9.2 & 9.9 & 4.2 & 28.2 & 32.5 & 4.9 & 37.5 & 42.3 \\
\hline Transport services & 0.6 & 1.1 & 1.7 & 2.9 & 2.9 & 5.8 & 3.5 & 3.9 & 7.5 \\
\hline Business services & 0.3 & 0.5 & 0.8 & 1.9 & 1.0 & 2.9 & 2.1 & 1.5 & 3.7 \\
\hline Personal services & 0.4 & 2.2 & 2.6 & 1.9 & 4.6 & 6.5 & 2.3 & 6.8 & 9.1 \\
\hline \multirow[t]{4}{*}{ Total } & 3.8 & 24.2 & 28.0 & 17.2 & 54.8 & 72.0 & 21.0 & 79.0 & 100 \\
\hline & \multicolumn{9}{|c|}{ Each sector in rural is 100} \\
\hline & \multicolumn{3}{|c|}{2000 Rural } & \multicolumn{3}{|c|}{2000 Urban } & \multicolumn{3}{|c|}{2000 National } \\
\hline & Formal & Informal & Total rural & Formal & Informal & Total urban & Formal & Informal & Total national \\
\hline Mining & 32.1 & 67.9 & 100 & 49.3 & 50.7 & 100 & 42.0 & 58.0 & 100 \\
\hline Manufacturing & 8.9 & 91.1 & 100 & 20.7 & 79.3 & 100 & 16.5 & 83.5 & 100 \\
\hline Utilities & 20.3 & 79.7 & 100 & 55.0 & 45.0 & 100 & 41.1 & 58.9 & 100 \\
\hline Construction & 22.8 & 77.2 & 100 & 31.2 & 68.8 & 100 & 28.8 & 71.2 & 100 \\
\hline Trade services & 6.6 & 93.4 & 100 & 13.1 & 86.9 & 100 & 11.5 & 88.5 & 100 \\
\hline Transport services & 37.2 & 62.8 & 100 & 50.3 & 49.7 & 100 & 47.3 & 52.7 & 100 \\
\hline Business services & 35.4 & 64.6 & 100 & 64.3 & 35.7 & 100 & 58.4 & 41.6 & 100 \\
\hline Personal services & 15.7 & 84.3 & 100 & 29.6 & 70.4 & 100 & 25.6 & 74.4 & 100 \\
\hline Total & 13.5 & 86.5 & 100 & 23.9 & 76.1 & 100 & 21.0 & 79.0 & 100 \\
\hline
\end{tabular}

Source: Authors' calculation using Census data of 2000 (GSS 2003). 
Table 2.5b. Employment structure of private non-agriculture by formal/informal, rural/urban, and industry in 2010

\begin{tabular}{|c|c|c|c|c|c|c|c|c|c|}
\hline & \multicolumn{9}{|c|}{ Total private nonagricultural employment for the country is 100} \\
\hline & \multicolumn{3}{|c|}{2010 Rural } & \multicolumn{3}{|c|}{2010 Urban } & \multicolumn{3}{|c|}{2010 National } \\
\hline & Formal & Informal & Total rural & Formal & Informal & Total urban & Formal & Informal & Total national \\
\hline Mining & 0.7 & 0.5 & 1.3 & 0.6 & 0.3 & 0.9 & 1.3 & 0.9 & 2.2 \\
\hline Manufacturing & 0.5 & 6.9 & 7.5 & 2.7 & 10.7 & 13.3 & 3.2 & 17.6 & 20.8 \\
\hline Utilities & 0.1 & 0.0 & 0.2 & 0.5 & 0.1 & 0.6 & 0.7 & 0.1 & 0.8 \\
\hline Construction & 0.4 & 1.1 & 1.5 & 1.3 & 3.1 & 4.3 & 1.7 & 4.2 & 5.9 \\
\hline Trade services & 0.8 & 10.3 & 11.1 & 4.9 & 30.9 & 35.8 & 5.7 & 41.3 & 46.9 \\
\hline Transport services & 0.8 & 1.0 & 1.7 & 3.3 & 2.5 & 5.9 & 4.1 & 3.5 & 7.6 \\
\hline Business services & 0.2 & 0.2 & 0.5 & 1.8 & 0.9 & 2.7 & 2.0 & 1.2 & 3.2 \\
\hline Personal services & 0.7 & 2.3 & 3.0 & 3.4 & 6.2 & 9.6 & 4.1 & 8.5 & 12.6 \\
\hline \multirow[t]{4}{*}{ Total } & 4.3 & 22.5 & 26.8 & 18.5 & 54.7 & 73.2 & 22.8 & 77.2 & 100.0 \\
\hline & \multicolumn{9}{|c|}{ Each sector in rural is 100} \\
\hline & \multicolumn{3}{|c|}{2010 Rural } & \multicolumn{3}{|c|}{2010 Urban } & \multicolumn{3}{|c|}{2010 National } \\
\hline & Formal & Informal & Total rural & Formal & Informal & Total urban & Formal & Informal & Total national \\
\hline Mining & 58.7 & 41.3 & 100 & 62.7 & 37.3 & 100 & 60.4 & 39.6 & 100 \\
\hline Manufacturing & 7.2 & 92.8 & 100 & 20.0 & 80.0 & 100 & 15.4 & 84.6 & 100 \\
\hline Utilities & 91.8 & 8.2 & 100 & 90.0 & 10.0 & 100 & 90.4 & 9.6 & 100 \\
\hline Construction & 26.1 & 73.9 & 100 & 29.1 & 70.9 & 100 & 28.3 & 71.7 & 100 \\
\hline Trade services & 6.9 & 93.1 & 100 & 13.6 & 86.4 & 100 & 12.0 & 88.0 & 100 \\
\hline Transport services & 43.9 & 56.1 & 100 & 56.9 & 43.1 & 100 & 53.9 & 46.1 & 100 \\
\hline Business services & 48.0 & 52.0 & 100 & 66.1 & 33.9 & 100 & 63.4 & 36.6 & 100 \\
\hline Personal services & 23.0 & 77.0 & 100 & 35.6 & 64.4 & 100 & 32.5 & 67.5 & 100 \\
\hline Total & 16.0 & 84.0 & 100 & 25.2 & 74.8 & 100 & 22.8 & 77.2 & 100 \\
\hline
\end{tabular}

Source: Authors' calculation using Census data of 2010 (GSS 2013). 
Table 2.6. Contribution of the informal and formal sectors to the national increase in total employment over 2000 to 2010 ; by sector and rural and urban (\%)

\begin{tabular}{|c|c|c|c|c|c|c|c|c|c|}
\hline & \multicolumn{3}{|c|}{ Rural } & \multicolumn{3}{|c|}{ Urban } & \multicolumn{3}{|c|}{ National } \\
\hline & Formal & Informal & Total rural & Formal & Informal & Total urban & Formal & Informal & Total national \\
\hline Mining & 1.2 & -0.1 & 1.1 & 0.0 & -0.5 & -0.5 & 1.2 & -0.6 & 0.6 \\
\hline Manufacturing & 0.2 & 4.9 & 5.1 & 1.6 & 7.0 & 8.6 & 1.7 & 12.0 & 13.7 \\
\hline Utilities & 0.3 & -0.3 & -0.1 & 0.9 & -0.2 & 0.7 & 1.2 & -0.5 & 0.6 \\
\hline Construction & 0.3 & 0.5 & 0.8 & 0.8 & 2.4 & 3.2 & 1.1 & 2.9 & 4.0 \\
\hline Trade services & 0.9 & 11.9 & 12.8 & 5.8 & 34.7 & 40.5 & 6.7 & 46.6 & 53.3 \\
\hline Transport services & 0.9 & 0.8 & 1.8 & 3.9 & 2.1 & 6.0 & 4.9 & 2.9 & 7.8 \\
\hline Business services & 0.2 & -0.1 & 0.1 & 1.7 & 0.8 & 2.5 & 1.9 & 0.7 & 2.6 \\
\hline Personal services & 1.1 & 2.5 & 3.6 & 5.4 & 8.4 & 13.8 & 6.5 & 10.9 & 17.5 \\
\hline Total & 5.0 & 20.2 & 25.2 & 20.2 & 54.6 & 74.8 & 25.2 & 74.8 & 100 \\
\hline
\end{tabular}

Source: Authors' calculation using data of Census 2000 and 2010 (GSS 2003, 2013). 
Nationally, 77.2 percent of all private sector, nonagricultural employment in 2010 was in the informal sector, and this share was higher in rural (84 percent) than in urban (74.8 percent) areas. Most of the private informal sector employment in 2010 was in manufacturing and trade services (17.6 percent and 41.3 percent, respectively), but more so in urban than rural areas. Between 2000 and 2010, the share of employment in formal manufacturing further declined while the share in trade services increased slightly, and this happened in both rural and urban areas.

Within individual nonagricultural sectors, informal employment was dominant in manufacturing, construction, trade services, and personal services in both rural and urban areas. It also dominated transport and business services in rural areas. Formal employment only dominated in mining in both rural and urban, and in utilities, transport and business services in urban areas. As we shall see in Section 2.3, labor productivity is generally higher in the formal than informal sectors, so the high shares of informal employment in key sectors like manufacturing and trade that provide most of the employment do not bode well for labor productivity.

Another perspective on the changes in employment can be obtained by computing the contributions informal and formal employment made to the increase in total employment between 2000 and 2010. This is reported by sector and separately for rural and urban areas in Table 2.6.

\subsection{Source of Growth in Productivity}

\subsubsection{Conceptual Framework}

In order to identify the main sources of growth in per capita income (PCI), we use a conceptual framework developed by Dani Rodrik in his papers on "The Past, Present and Future of Economic Growth" (Rodrik 2014), and more recently for Africa, in “An African Growth Miracle?” (Rodrik 2018). ${ }^{7}$ Rodrik identifies two broad development challenges: the "fundamentals" challenge, and the "structural transformation" challenge. Growth in productivity and PCI arises "within" sectors as a result of overcoming "fundamental" challenges by building fundamental capabilities, such as better institutions, healthier and

\footnotetext{
7 Rodrick's framework draws on the neoclassical growth theories of Solow (1956), Grossman and Helpman (1991), and Aghion and Howitt (1992), which essentially focus on the growth process within modern sectors, and the dual-economy theory initially formalized by Lewis (1954) and expanded upon by Ranis and Fei (1961) that focuses on relationships and flows among sectors. McMillan, Rodrik, and Sepúlveda (2016) further discuss the inter-connection of these two schools of economic theories in detail (see page 5 of McMillan et al. (2016)).
} 
Table 2.7. A typology of growth strategies, growth patterns, and outcomes Strategy focusing on structural transformation

Strategy focusing on investment in fundamentals

\begin{tabular}{|l|l|l|}
\multicolumn{2}{c}{ Strategy focusing on structural transformation } \\
\cline { 2 - 3 } \multicolumn{1}{c|}{} & Slow & Rapid \\
\hline Low & No or very little growth & Episodic growth \\
\hline High & (3) Slow growth & (4) Rapid, sustained growth \\
\hline
\end{tabular}

Source: Rodrik (2014).

better-educated workers, improved technologies, and more enabling policies. These are longer-term investments that are essential for sustaining economic growth over the long term, but which may have slow payoffs and contribute relatively little to short-term growth. Growth that arises from structural change involves investing in the rise of modern, highly productive industries like export manufacturing, and shifting workers from low-productivity sectors like traditional agriculture into the modern industrial and service sectors. This strategy requires significant capital and political investment, but can lead to more visible short- to medium-term benefits as well as setting the stage for longer-term growth. The two strategies can be summarized as in Table 2.7.

The rapid growth of China and several other Asian countries occurred at relatively low levels of fundamental capability, but with governments taking a strong proactive development state approach to promoting modern industry, especially export manufacturing, and facilitating the mass movement of workers from agriculture to industry. These countries have generally fallen into cell (2) in Table 2.1, experiencing rapid but episodic growth, and which if it is to be sustained, now requires more attention to complementary investments in fundamental capabilities. In Ghana, on the other hand, and as argued in Chapter 3, the emphasis since the Structural Adjustment Program (SAP) of the early 1980s has been more on investing in fundamental capabilities, with a rather benign state neglect of industry and the structural transformation issues. This has placed the country in cell (3), with a consistent pattern of slow growth and limited industrialization.

\subsubsection{Applying the Framework}

Rodrik formulized his two sources of growth into a growth decomposition model (Rodrik 2014). To apply this model to Ghana, we made several adaptations to better capture the reality of Ghana's recent structural transformation. We present these changes in two steps. 
The first step is conceptual, and involves changes to the model structure. First, we introduced agriculture as a separate sector in the model to reflect the fact that far from being a stagnant traditional sector, it has actually experienced significant productivity growth in recent years in Ghana, and part of this productivity growth in agriculture can be attributed to fundamentals. Second, we redefine the traditional sector without agriculture as the informal sector (I) and explicitly model labor mobility from agriculture into informal activities. Note that if labor productivity in agriculture should happen to exceed its productivity in the informal sector, then any structural change resulting from the movement of labor from agriculture to the informal sector would become growth-reducing instead of growth-enhancing.

The modified version of Rodrik's model we use is as follows:

$$
\begin{aligned}
y= & \alpha_{M} y_{M}+\alpha_{S} y_{S}+\alpha_{I} y_{I}+\left(1-\alpha_{M}-\alpha_{S}-\alpha_{I}\right) y_{A}, \\
\hat{y}= & \left(\alpha_{M} \pi_{M}+\alpha_{S} \pi_{S}+\alpha_{I} \pi_{I}+\alpha_{A} \pi_{A}\right) \gamma\left(\ln y^{\star}(\Theta)-\ln y\right) \\
& +\alpha_{M} \pi_{M} \beta\left(\ln y_{M}^{*}-\ln y_{M}\right) \\
& +\left(\pi_{M}-\pi_{A}\right) d \alpha_{M} \\
& +\left(\pi_{S}-\pi_{A}\right) d \alpha_{S} \\
& +\left(\pi_{I}-\pi_{A}\right) d \alpha_{I}
\end{aligned}
$$

where $y$ is the economy's aggregate labor productivity, and a " $\wedge$ " over a variable denotes proportional changes $(\hat{x}=d x / x) . y_{M^{\prime}}, y_{S}, y_{P}$, and $y_{A}$ are, respectively, value-added per worker for manufacturing, services, the informal economy and agriculture, $\pi_{M}, \pi_{S}, \pi_{I}$ and $\pi_{A}$ are the relative labor productivities $\left(y_{i} / y\right)$ for the same sectors, and $\alpha_{M}, \alpha_{S}$ and $\alpha_{I}$ are the employment shares of manufacturing, services and the informal sector, respectively.

Equation (2) identifies distinct channels for growth. First, there is a process of convergence that accompanies the accumulation of fundamental capabilities, such as skills and improved governance and institutions $(A)$. Rodrik calls this the "fundamentals" channel, as it depends on broad-based investments in human capital and institutional arrangements. Second, there are the forces of unconditional convergence operating within manufacturing $(B)$. These two dynamic effects are potentially augmented by two reallocation-of-labor effects, from agriculture to higher-productivity manufacturing $(C)$ and modern 
services $(D)$, but are also potentially negatively affected by reallocation of labor from agriculture to the informal economy $(E)$ if the productivity in the informal economy is lower than agriculture.

The second step involved empirical adjustments to the model to fit the available data. We had sufficient data to disaggregate the economy into ten sectors. Let $Y_{\mathrm{i}}$ denote the $\mathrm{i}^{\text {th }}$ sector's GDP at constant prices, and let $y$ and $y_{\mathrm{i}}$ denote to the economy's GDP per worker and $i^{\text {th }}$ sector's GDP per worker, respectively. Equation (1) thus can be rewritten as follows:

$$
y=\sum_{i}^{10} \alpha_{i} y_{i}, \sum_{i}^{10} \alpha_{i}=1 .
$$

Let $i=10$ represent the agricultural sector, and $i=1,2, \ldots, 9$ be the nine nonagricultural sectors. Totally differentiating equation (3), dividing through by $y$ and rearranging terms, we obtain the following equation similar to (2):

$$
\hat{y}=\sum_{i}^{10} \alpha_{i} \pi_{i} \hat{y}_{i}+\sum_{i}^{9}\left(\pi_{i}-\pi_{10}\right) d \alpha_{i}
$$

The first term in the right-hand side of equation (4) differs slightly from the first two terms of (2) in the following ways. First, we no longer explicitly distinguish the productivity growth that arises as a result of unconditional convergence in the modern manufacturing sector (Channel $(B)$ in equation (2)). Modern manufacturing in Ghana counts for only a small component of the manufacturing sector defined in the national account, and the growth contribution of its so-called unconditional convergence in manufacturing seems not to have been important. In addition, there is not enough data to allow us to define a modern manufacturing separately in equation (4). Second, $\hat{y}_{i}$ in equation (4) which measures the change in within-sector's labor productivity, can be different across sectors. This is a modification from equation (2) in which $\gamma$ is the same for all sectors. This modification allows equation (4) to be flexible enough in measuring the actual change in a sector's labor productivity. The second terms in the right-hand side of equation (4) is to capture the structural-change-led growth, which is the combination of Channels $(C)$ to $(E)$ in equation (2) in which the economy is aggregated into four sectors.

\subsubsection{Results}

The model was applied to Ghana using sector-level data obtained from GGDC (2015) for the period 1984 to 2011. Table 2.8 shows the key model coefficients used; namely, the relative labor productivity of each sector $\left(\pi_{i}\right.$ in equation (4)), 
Table 2.8. Key model coefficients: Sector-wise labor productivity, and GDP and employment shares, 1984, 2000 , and 2011

\begin{tabular}{|c|c|c|c|c|c|c|c|c|c|}
\hline & \multicolumn{3}{|c|}{ Relative labor productivity $\left(\pi_{i}\right)$} & \multicolumn{3}{|c|}{ GDP share } & \multicolumn{3}{|c|}{ Employment share $\left(a_{i}\right)$} \\
\hline & 1984 & 2000 & 2011 & 1984 & 2000 & 2011 & 1984 & 2000 & 2011 \\
\hline Agriculture & 0.67 & 0.61 & 0.67 & 40.9 & 32.9 & 26.2 & 61.1 & 53.6 & 38.9 \\
\hline Mining & 4.98 & 1.59 & 2.79 & 2.5 & 2.8 & 7.9 & 0.5 & 1.8 & 2.8 \\
\hline Manufacturing & 0.96 & 1.04 & 0.79 & 10.4 & 11.1 & 8.8 & 10.9 & 10.6 & 11.1 \\
\hline Utilities & 4.84 & 5.25 & 4.89 & 1.4 & 1.8 & 1.7 & 0.3 & 0.3 & 0.4 \\
\hline Construction & 5.24 & 1.85 & 2.92 & 6.3 & 5.4 & 9.1 & 1.2 & 2.9 & 3.1 \\
\hline Trade services & 0.60 & 0.66 & 0.46 & 8.8 & 11.2 & 11.5 & 14.6 & 17.0 & 25.1 \\
\hline Transport services & 5.83 & 5.33 & 4.59 & 13.2 & 15.4 & 15.5 & 2.3 & 2.9 & 3.4 \\
\hline Business services & 4.99 & 4.04 & 2.44 & 2.5 & 5.8 & 5.6 & 0.5 & 1.4 & 2.3 \\
\hline Government services & 1.86 & 1.80 & 1.48 & 11.4 & 9.4 & 9.3 & 6.2 & 5.2 & 6.3 \\
\hline Personal services & 1.02 & 0.98 & 0.64 & 2.6 & 4.0 & 4.2 & 2.6 & 4.1 & 6.6 \\
\hline Total Economy & 1.00 & 1.00 & 1.00 & 100 & 100 & 100 & 100 & 100 & 100 \\
\hline
\end{tabular}

Source: Authors' calculation using GGDC data (Timmer et al. 2015). 
and the employment shares ( $\alpha_{i}$ in equation (4)), as well the sector shares in GDP, for 1984, 2000 and 2011. Key observations here are: a) the low labor productivity of agriculture relative to all sectors except trade services in 1984 and 2011 and, in 2011, personal services; and b) the employment shares for all sectors except agriculture either increased over 1984-2011 or remained unchanged (utilities and government services). Clearly, there has been a net outflow of migrants from agriculture to most other sectors, which is consistent with structural change. However, whether this structural change contributed to raising national labor productivity depends on whether or not workers moved from agriculture to sectors with higher labor productivities. The last panel in Table 2.8 provides a cautionary note: the sectors whose employment shares grew the most over 1984-2011 were trade and personal services, yet these sectors had similar or lower labor productivities than agriculture. The movement of workers from agriculture to these sectors would have made a negative contribution to growth in national labor productivity, and this would have reduced the overall gain from structural change. The model decomposition results in Tables 2.9 and 2.10 clarify the situation.

The last panel of Table 2.9 shows the annual growth rates in labor productivity by sector, and for the total economy (which is the weighted sum of growth rates in labor productivity across sectors) for the periods of 1984-2011 and 2000-11. These growth rates are then disaggregated by sector to show the

Table 2.9. Decomposition of Ghana's economy-wide labor productivity growth in 1984-2011 and 2000-11 (results sum to total growth rate for economy each period)

\begin{tabular}{|c|c|c|c|c|c|c|}
\hline & \multicolumn{2}{|c|}{$\begin{array}{l}\text { Within sector } \\
\qquad\left(\alpha_{i} \pi_{i} \hat{y}_{i}\right)\end{array}$} & \multicolumn{2}{|c|}{$\begin{array}{l}\text { Structural change } \\
{\left[\left(\pi_{i}-\pi_{10}\right) d \alpha_{i}\right]}\end{array}$} & \multicolumn{2}{|c|}{$\begin{array}{c}\text { Total growth } \\
{\left[\alpha_{i} \pi_{i} \hat{y}_{i}+\left(\pi_{i}-\pi_{10}\right) d \alpha_{i}\right]}\end{array}$} \\
\hline & $1984-2011$ & $2000-11$ & 1984-2011 & $2000-11$ & 1984-2011 & $2000-11$ \\
\hline Agriculture & 1.03 & 1.11 & - & - & 1.03 & 1.11 \\
\hline Mining & 0.02 & 0.19 & 0.20 & 0.22 & 0.22 & 0.41 \\
\hline Manufacturing & 0.24 & 0.04 & 0.01 & 0.01 & 0.25 & 0.06 \\
\hline Utilities & 0.06 & 0.04 & 0.00 & 0.00 & 0.06 & 0.04 \\
\hline Construction & 0.07 & 0.41 & 0.16 & 0.07 & 0.23 & 0.48 \\
\hline Trade services & 0.17 & -0.04 & -0.03 & -0.07 & 0.14 & -0.10 \\
\hline Transport services & 0.30 & 0.22 & 0.20 & 0.21 & 0.51 & 0.43 \\
\hline Business services & -0.01 & -0.10 & 0.23 & 0.22 & 0.22 & 0.11 \\
\hline Government services & 0.21 & 0.10 & -0.03 & 0.10 & 0.19 & 0.20 \\
\hline Personal services & 0.05 & -0.04 & 0.03 & 0.03 & 0.08 & -0.01 \\
\hline Total Economy & 2.14 & 1.93 & 0.78 & 0.80 & 2.93 & 2.73 \\
\hline
\end{tabular}

Source: Authors' calculation using GGDC data (Timmer et al. 2015). 
part due to within-sector growth (panel 1), and the part due to structural change (panel 2). Table 2.10 shows the same results in percentage share form (taking the economy-wide labor productivity growth rate as 100).

A key result for the economy as a whole is that while labor productivity grew by 2.93 percent per year over 1984-2011, 73.2 percent of this was due to growth in "within-sector" labor productivity, while "structural change" contributed only 26.8 percent. These shares were little changed even in the more recent period 2000-11 (70.8 percent and 29.2 percent, respectively). Our finding is similar to that of Osei and Jedwab (2016), who used a similar data set but a slightly different decomposition approach.

In Rodrik's terminology, growth in Ghana has been predominantly led by the fundamentals rather than structural change, and this is unusual even in comparison to other African countries. Indeed, comparing Ghana's growth pattern with seven other low-income African countries available in the GGDC dataset, the contribution of structural change to the overall labor productivity growth in Ghana is among the lowest. For the eight low-income African countries together, structural change contributed 56 percent of economywide productivity growth in 2000-10, and it contributed more than 90 percent in four of the eight countries in the GGDC dataset (Diao, Harttgen, and McMillan 2017).

The reason for Ghana's poor performance on structural change has already been anticipated in our discussion of Table 2.8. The sectors that absorbed most of the labor that moved out of agriculture over 1984-2011, namely, trade services and personal services, had low labor productivities even compared to agriculture, hence the movements of labor to these sectors contributed little to the growth in national labor productivity. In fact, because labor productivity in trade services was lower than in agriculture, the movement of labor to this sector made a negative ( -2.5 percent) contribution to aggregate labor productivity in 2000-10 (panel 2 of Table 2.10).

Another striking result in Tables 2.9 and 2.10 is that labor productivity in agriculture grew more than in any other sector, accounting for the lion's share of the increase in the within-sector labor productivity of the entire economy, and for 35.3 percent of the increase in national labor productivity over 1984-2011. Labor productivity also grew in some nonagricultural sectors, but in most cases the growth was very modest, especially during 2000-11. Labor productivity even fell in trade, business and personal services in this later period. Thus, the overall gains from within-sector productivity slowed in the economy as a whole, led by a slowdown in most nonagricultural sectors during 2000-11. The most alarming decline was in manufacturing, whose 
Table 2.10. Contributions of each sector to Ghana's economy-wide labor productivity growth in 1984-2011 and 2000-11 (\% shares)

\begin{tabular}{|c|c|c|c|c|c|c|}
\hline & \multicolumn{2}{|c|}{ Within sector } & \multicolumn{2}{|c|}{ Structural change } & \multicolumn{2}{|c|}{ Total growth } \\
\hline & $1984-2011$ & $2000-11$ & 1984-2011 & $2000-11$ & 1984-2011 & $2000-11$ \\
\hline Agriculture & 35.3 & 40.6 & - & - & 35.3 & 40.6 \\
\hline Mining & 0.7 & 7.0 & 7.0 & 8.2 & 7.6 & 15.1 \\
\hline Manufacturing & 8.0 & 1.6 & 0.5 & 0.5 & 8.5 & 2.1 \\
\hline Utilities & 1.9 & 1.5 & 0.1 & 0.2 & 2.0 & 1.6 \\
\hline Construction & 2.5 & 15.0 & 5.3 & 2.5 & 7.8 & 17.5 \\
\hline Trade services & 5.9 & -1.4 & -1.1 & -2.5 & 4.8 & -3.8 \\
\hline Transport services & 10.4 & 8.2 & 6.9 & 7.6 & 17.3 & 15.8 \\
\hline Business services & -0.5 & -3.8 & 7.9 & 7.9 & 7.4 & 4.2 \\
\hline Government services & 7.3 & 3.5 & -1.0 & 3.8 & 6.3 & 7.3 \\
\hline Personal services & 1.7 & -1.4 & 1.1 & 1.0 & 2.8 & -0.3 \\
\hline Total Economy & 73.2 & 70.8 & 26.8 & 29.2 & 100 & 100 \\
\hline
\end{tabular}

Source: Authors' calculation using GGDC data (Timmer et al. 2015).

growth in within-sector labor productivity slowed from 0.24 percent during 1984-2011 to 0.04 percent during 2000-11.

Labor productivity in Ghana would have grown faster if more workers had moved into the highest productivity sectors. Why did this not happen? There are four non-traded nonagricultural sectors (utilities, construction, transport services, and business services), which all have labor productivities that are three to four times higher than the economy's average (Table 2.8). However, the expansion of these high-productivity sectors has been rather modest. Together they increased their employment share by less than 5 percentage points over 1984-2011. Their expansion is constrained by the fact that they produce mostly nontradables outputs/services, and hence their growth depends on growth in the rest of the economy.

Mining is another sector that has a much high labor productivity relative to the national average (Table 2.8), and which contributes significantly to Ghana's exports. However, large-scale modern mines, which dominate the sector, are extremely capital intensive and do not employ much labor, while informal small-scale mining is labor intensive but has low labor productivity. The emerging oil sector is also capital intensive and requires few workers.

One might expect manufacturing to have a relatively high labor productivity, but as shown in Table 2.8, it productivity was not much higher than agriculture in 2011. During 1984-2011, manufacturing also experienced little growth in its within-sector productivity (Table 2.9), or its employment share (Table 2.8), and its total contribution to the increase in national labor productivity was a mere 
8.5 percent in 1984-2011. This contribution fell to only 2.1 percent in $2000-11$ (Table 2.10). The problem is that while there are some formal manufacturing firms in Ghana that have reasonably high labor productivity, the sector is still dominated by many small and informal enterprises that have very low labor productivities. Ghana has not yet been able to achieve any significant growth in its formal manufacturing sector, nor in its manufacturing exports.

\subsection{Future Prospects}

Section 2.3 has shown that Ghana's economic growth since the SAP of the 1980s has been driven primarily by improvements in Rodrik's "fundamentals", which led to steady but modest growth in within-sector labor productivities, especially for agriculture, and thence steady but modest growth in national GDP per capita. Structural change has played only a modest role in raising labor productivity. Although there has been a significant shift of workers out of agriculture, they have mostly moved to jobs in informal services and manufacturing, where labor productivity is similar to or even lower than in agriculture. A shift to these kinds of jobs does little to raise average labor productivity, and in one case (movement to trade services), has even made a negative contribution.

Looking to the future, Ghana can expect to continue to gain from the longer-term impacts of past and ongoing improvements in its fundamentals, but these promise at best a modest if steady contribution to growth in GDP per capita. Their contribution may also slow as some important past sources of productivity growth run out of steam. For example, labor productivity growth in agriculture has depended on land expansion, but the land frontier is now approaching its limits, and unless other sources of productivity growth can be tapped, agriculture's labor productivity growth rate will slow (see Chapter 4).

How can Ghana sustain its current average annual GDP per capita growth rate of 2.8 percent? Better still, are there ways for Ghana to accelerate its growth rate to new highs? Additional growth of within-sector productivities will need to play a key role, and this requires a continued emphasis on fundamentals in national policy. But for faster growth, Ghana also needs to do a better job of tapping into the benefits of structural change, and this requires policies that can generate more rapid growth of modern sectors that can achieve a) high levels of labor productivity relative to agriculture, and b) absorb lots of workers from lower productivity sectors like agriculture. It is likely that the oil and mining sectors will provide an important, if volatile, source of GDP growth, but despite their high labor productivities, they are not likely to create much additional 
employment. More promising possibilities for creating productive employment lie in growing the more productive parts of the agricultural, manufacturing, and services sectors, and these options are reviewed below.

\subsubsection{Agriculture}

As shown in Section 2.3.2,the agricultural sector contributed the most to growth in economy-wide labor productivity during 1984-2011. This is a significant achievement given that agriculture is still the largest employer, and most of its workers are traditional, often poor, smallholders. However, the sector's labor productivity is still only about 60 percent of the national average (Table 2.8), which is lower than the productivity of all nonagricultural sectors except trade and personal services. This is good news in the sense that there ought to be significant opportunities to achieve greater productivity gains. There are also good prospects for growth in the demand for agricultural products in the national, West African regional, and world markets. A challenge is that past increases in labor productivity have come mainly from expanding the total crop area, which has been possible because Ghana was a relatively landabundant country. But this option is running out, and future productivity growth will increasingly depend on technology, management, and land-use changes that accelerate the growth in land as well as labor productivity. These issues are discussed in Part II of this book, where they are analyzed in some depth. An important finding is that while the agricultural sector has benefited from an enabling policy environment that has encouraged farmers to invest in expanding their production, still the sector has been constrained by low levels of public investment and, apart from cocoa, by limited success in developing the value chains for nontraditional export crops, or import substituting crops and livestock products like rice, tomatoes, and chicken. Had the government been more effective in partnering with the private sector, then perhaps there would have been a greater shift by now to faster growth in land productivity in Ghana, and an even faster rate of labor productivity growth.

\subsubsection{Manufacturing}

\subsubsection{Background}

Manufacturing played a crucial role in the development of China and most South East Asian economies, and as argued by Rodrik (2014), offers a shortcut 
for a developing country like Ghana to achieve rapid growth. The sector has two key advantages: a) it faces an elastic demand for its output, either through exports or import substitution, and b) it is relatively easy for modern manufacturing firms to achieve high levels of efficiency and labor productivity through the adoption of internationally available technologies and knowhow. Manufacturing can thus grow and expand rapidly in environments where the economy-wide capabilities in terms of human capital and institutions are still very limited. Manufacturing can also absorb a large number of less skilled workers coming directly out of agriculture, which makes the sector the most desirable destination for a majority of poor rural migrants, leading to large-scale structural changes and growth of economy-wide productivity. Sadly, the manufacturing sector has yet to play an important role in Ghana's economic development.

Ghana inherited a small manufacturing sector at Independence that comprised mostly small informal enterprises serving the domestic market (Rimmer 1992). Developing a formal industrial sector was an early government priority, and Ghana pursued a state-led industrialization program focused mainly on import-substitution industrialization (ISI). The result was a rapid expansion of the modern manufacturing sector in the 1960s and early 1970s, with many state-owned firms being set up (Steel 1972). But the sector never became that big in terms of its shares in national GDP or employment, and despite the many state-owned firms that were set up, the vast majority of manufacturing jobs remained in small, informal manufacturing units (Friedrich Ebert Foundation 1994: 53; Ball (1998: 87)). As shown in Table 2.6b, this is still the pattern; in 2010, 84.6 percent of total manufacturing jobs were in the informal sector.

As in many other countries that pursued similar industrialization policies, the ISI strategy was not a success. To promote industrialization in the formal sector, the government invested heavily in setting up state-owned manufacturing firms, and engaged in policies that protected and favored their development, such as trade protection, and privileged access to foreign exchange and finance. Most state-owned firms proved costly and inefficient, and were never able to compete with imports on a fair footing, or expand into export markets. Not only did the ISI waste resources in the stateowned sector, it crowded out the private sector, distorted the economy, and impeded growth, contributing importantly to the economic crises of the early 1980 s.

Correcting the legacy of ISI was a major priority of the SAP reforms, which involved unwinding the policy distortions, and privatizing most state enterprises. 
Even so, the manufacturing sector failed to take off and its share in national GDP was only 5.6 percent in 2016, down from 10.5 percent in 2006 (Table 2.3). It also remains a low-productivity sector. In 2011, labor productivity in manufacturing was only 80 percent of the national average (Table 2.8), and its within-sector labor productivity only grew by 0.24 percent per year over 1984-2011. Even then, most of this gain occurred during and immediately after the SAP reforms; its within-sector labor productivity grew by a mere 0.04 percent per year during 2000-11 (Table 2.9).

\subsubsection{A bifurcated sector}

One reason for the poor performance of the manufacturing sector is because of the split between a relatively small number of large-sized firms in the formal sector, and a much larger number of small and informal units, including many household enterprises and micro firms. Some insights into the relative productivity of formal and informal enterprises can be gleaned from an NIC report published by the government (GSS 2006), which provides value-added and employment information by firm size groups (Table 2.11).

The average firm size is about 164 workers for the medium and large $(\geq 30$ workers) firm size group, and 17.1 and 4.8 workers for the two smaller firm size groups. The larger firms provide 84 percent of the total manufacturing value-added in this NIC sample, but only 38 percent of total employment. The ratio of these two numbers provides an estimate of the relative labor productivity of the different firm size groups. Normalizing the average labor productivity for the entire sample to 1.0, the relative labor productivity of the larger firms is 2.2 , but only 0.3 and 0.2 for the two smaller firms. That is

Table 2.11. Shares of value-added and employment and labor productivity for three groups of manufacturing firms in Ghana

\begin{tabular}{lcrr}
\hline & \multicolumn{2}{l}{$\begin{array}{l}\text { Large firms } \\
\text { (employee number } \geq 30)\end{array}$} & \multicolumn{2}{l}{$\begin{array}{l}\text { Small firms } \\
\text { Employees number }\end{array}$} \\
\cline { 3 - 5 } & & $\mathbf{1 0 - 2 9}$ & $\mathbf{1 - 9}$ \\
\hline Share of value-added (\%) & 83.8 & 6.7 & 9.5 \\
Share of employment (\%) & 38.2 & 21.8 & 40.0 \\
Average firm size (person/per firm) & 163.9 & 17.1 & 4.8 \\
Relative labor productivity (total & 2.2 & 0.3 & 0.2 \\
$\quad$ manufacturing's labor productivity = 1.0) & & & \\
Ratio to the smallest firm group (small & 9.3 & 1.3 & 1.0 \\
$\quad$ firms with employees 1-9=1.0) & & & \\
\hline
\end{tabular}

Source: Authors' calculation using data of 2003 NIC (GSS 2006). 
to say, an average worker in a larger firm is about eight times more productive than an average worker in small manufacturing firms (Table 2.11). ${ }^{8}$

Although larger manufacturing units achieve higher labor productivities, they also require more capital, and that could affect their competitiveness. Again, insights can be gained from the published NIC report, which provides estimates of the value of fixed capital at the beginning of 2003 for individual industries and by two firm size groups (firms with more than ten employees, and those with less). Using such information, we can calculate capital and labor ratios across industrial sectors and by size group. ${ }^{9}$ At the national level, for all the manufacturers covered by the NIC, the average value of fixed capital is $\$ 7,155$ per worker, while for the larger firms ( $\geq 10$ workers) it is $\$ 11,908$, and for the small firms (less than ten workers) it is only $\$ 25.4$ per worker. Thus, although the labor productivity of small firms (1-9 workers) is only 1/9th that of the larger firms (Table 2.11), they are achieving this level of productivity using only 0.02 percent as much capital per worker as the large firms. Another problem is that the large firms pay much higher wages than small firms, which is in line with their higher labor productivity. But given than Ghana is now a relatively high-wage economy, this does undermine their competitiveness when competing against low-wage Asian competitors in Ghana's domestic or potential export markets.

\subsubsection{What is holding back manufacturing?}

Much has been written about the constraints on the manufacturing sector in Ghana. These include the business environment (see Chapter 3), high transport costs, inadequate and costly port facilities, unreliable power supplies, inadequate access to finance, difficulties in obtaining land rights, high labor costs, weak or ineffective industrial policies, and state-business relations, etc. (World Bank 2014; Owoo and Page 2017). These constraints appear to be more binding on the formal than informal sector, making it difficult for formal manufacturing firms to achieve a competitive edge against international competitors. On the other hand, the informal sector faces a more binding market constraint, because it produces mostly nontradables, the demand for which is constrained by growth in national demand. Demand for the products of the

\footnotetext{
8 Many workers in the small firms are not regular employees. For example, the regular employees accounted for 21 percent of total employment in the small firm group with employees 1-9. Thus, when all workers are treated equal, as we did in Table 2.11, it could significantly underestimate the labor productivity for small firms. Keeping this caveat in mind, the labor productivity gaps between small firms and large firms should still be significant.

9 According to 2003 NIC, value of fixed capital assets at the beginning the survey year include values of land, buildings, machinery and equipment (GSS 2006).
} 
informal manufacturing sector has grown rapidly with rising per capita incomes and urbanization, which explains why informal manufacturing employment grew by 12 percent per annum over 2000-10 (Table 2.7). The downside is that the jobs being created are still low-productivity jobs, so more attention needs to be given to improving the efficiency and productivity of some of the small and medium-sized units in this subsector.

The discovery and development of oil offers new opportunities for diversifying the economy into upstream and downstream industries, but this would require a coherent longer-term industrialization policy, key public investments, and effective management of the "resource-curse" or "Dutch disease" risks associated with oil revenues (Owoo and Page 2017). The agricultural processing sector would also seem to offer good prospects for growth, particularly given rapid growth in demand for processed and pre-cooked foods in urban areas. There is also some scope for expansion into the West African regional market as trade barriers are brought down. This sector is still dominated by many small and medium-sized firms, and has the potential to grow lots of reasonably productive jobs. However, firms face many of the same constraints as manufacturing firms in general, as well as challenges in obtaining reliable supplies of raw materials of the right qualities from farmers. These issues are explored in more detail in Chapter 8.

\subsubsection{Services}

As we have seen, services have been the fastest growing sector in Ghana since the SAP, and by 2016 they had become the largest sector in national GDP (Table 2.3). Most of this growth has been in trade and personal services, both of which are dominated by small informal enterprises. Services are predominantly nontradables, and their demand has grown with GDP per capita, but also with the rapid urbanization of the country. For example, trade services have grown with a greater need to move more agricultural commodities from rural to urban areas. However, not all the growth in services has arisen in the cities, and much has occurred in small and medium-sized towns, where it has created new off-farm income-earning opportunities for farm households (see Chapter 5).

The difficulty with the services sector is that it has low labor productivity, in some cases like trade and personal services, even lower than agriculture. Although there may be some opportunities for developing pockets of modern services that have higher labor productivity, it is unlikely that these 
can substitute for the development of more productive manufacturing and agricultural activities if Ghana is to benefit more from structural change.

\subsection{Conclusions}

Ghana's economic growth since the SAP reforms of the 1980s has been driven primarily by improvements in "fundamentals," which led to steady but modest growth in within-sector labor productivities, and thence steady but modest growth in national GDP per capita. Structural change has played only a modest role in raising labor productivity. While many workers have left agriculture, many of them have moved to sectors with similar or even lower labor productivity, so this has contributed little to raising the average labor productivity.

Ghana can expect to continue to gain from the longer-term impacts of past and ongoing improvements in its fundamentals, but these promise at best a modest if steady contribution to growth in GDP per capita. Their contribution may also slow as some important past sources of productivity growth run out of steam as, for example, the possibilities for further land expansion for agriculture. If Ghana is to sustain or even accelerate its average annual GDP per capita growth rate of 2.8 percent, then the country will need to do a better job of tapping into the benefits of structural change, and this requires policies that can generate more rapid growth of sectors that can achieve a) high levels of labor productivity relative to traditional agriculture, and b) absorb lots of workers from lower productivity sectors like traditional agriculture. While the oil and mining sectors will provide an important, if volatile, source of GDP growth, and they have high labor productivities, they are not likely to create much additional employment on their own. Although with the right industrial policies and investments, there is scope to use these sectors to help diversify the economy into more upstream and downstream industries. Other promising possibilities for creating productive employment lie in expanding and improving the more productive parts of the agricultural, manufacturing, and services sectors. Not only is there a growing national demand that offers new market opportunities in these sectors, but with increasing regional economic cooperation, Ghana should be able to increase its exports into the West African regional market.

In Rodrik's scheme of things, structural change led by improving such sectors requires a more proactive development state approach to drive it, and not just a focus on fundamentals. Ghana's earlier attempts to develop specific sectors through government-led initiatives like the ISI industrialization 
program failed badly. The relevant questions now are: a) whether there are better policies available today that might successfully drive lead sectors, and $b$ ) if so, does the government have the inclination or capacity to deliver on such an agenda? These questions are addressed in subsequent chapters, with special emphasis on the agricultural and food sectors.

\section{References}

Aghion, P., and P. Howitt. 1992. "A Model of Growth through Creative Destruction." Econometrica 60(2): 323-51.

Ball, Rajiv. 1998. “The 'Long Depression' and the Growth of Small-scale Industries in Ghana, 1970-mid1980s," in Gareth Austin (ed.), Industrial Growth in the Third Word, 1870-1990. LSE Working Papers in Economic History, 44/98. London: LSE, 73-87.

Collier, Paul, and Anthony J. Venables. 2007. "Rethinking Trade Preferences: How Africa Can Diversify its Exports." The World Economy 30(8): 1326-45.

Diao, X., K. Harttgen, and M. McMillan. 2017. "The Changing Structure of Africa's Economies." NBER Working Paper No. 23021. Cambridge, MA: National Bureau of Economic Research.

Friedrich Ebert Foundation. 1994. "Privatization of State-owned Enterprises in Ghana: Proceedings of a Workshop Organized for Members of the Finance Committee of Parliament on 18-20 of November." Accra: Friedrich Ebert Foundation.

Gollin, D., R. Jedwab, and D. Vollrath. 2016. "Urbanization with and without Industrialization." Journal of Economic Growth 21(1): 35-70.

Grossman, G., and E. Helpman. 1991. Innovation and Growth in the Global Economy. Cambridge, MA: MIT Press.

GSS (Ghana Statistical Service). 2003. "Population and Housing Census 2000." Census data. Accra.

GSS (Ghana Statistical Service). 2006. "National Industrial Census 2003.” Accra.

GSS (Ghana Statistical Service). 2010. "Rebasing of Ghana's National Accounts to Reference Year 2006." Accra.

GSS (Ghana Statistical Service). 2013. "Population and Housing Census 2010." Census data. Accra.

Japan External Trade Organization (JETRO). 2009. "Kakkoku Chiiki Betsu Joho" (information by country/region). Available at: http://www.go.jp/world/search/ compare.

Leite, Sergio Pereira, Anthony Pellechio, Luisa Zanforlin et al. 2000. "Ghana: Economic Development in a Democratic Environment." Occasional Paper No. 199. Washington, DC: International Monetary Fund. 
Lewis, W. A. 1954. "Economic Development with Unlimited Supplies of Labor." Manchester School of Economic and Social Studies 22(2): 139-91.

McMillan, Rodrik and Claudia Sepúlveda (eds). 2016. Structural Change, Fundamentals, and Growth: A Framework and Case Studies. Washington, DC: International Food Policy Research Institute.

Ministry of Trade and Industry (MoTI). 2002. "Study of the Textile Sub-sector, a Report Prepared by Brucks \& Associates for MoTI.” November. Accra: MoTI.

Mottaleb, Khondoker Abdul and Tetsushi Sonobe. 2011. "An Inquiry into the Rapid Growth of the Garment Industry in Bangladesh.” Economic Development and Cultural Change 60(1): 67-89.

Osei, Robert Darko and Rémi Jedwab. 2016. "Structural Change in a Poor African Country: New Historical Evidence from Ghana," in Margaret McMillan, Dani Rodrick, and Claudia Sepúlveda (eds). 2016. Structural Change, Fundamentals, and Growth: A Framework and Case Studies. Washington, DC: International Food Policy Research Institute.

Owoo, Nkechi and John Page. 2017. "Industrial Policy in Ghana: From Dominant State to Resource Abundance," in E. Aryeetey and R. Kanbur (eds), The Economy of Ghana Sixty Years after Independence. Oxford: Oxford University Press, 176-91.

Quartey, P. 2006. “The Textile and Clothing Industry in Ghana,” in H. Jauch and R. Traub-Marz (eds), The Future of the Textile and Clothing Industry in SubSaharan Africa. Buchdruckerei: Bub Bonner University, 135-16.

Ranis, G., and J. C. Fei. 1961. “A Theory of Economic Development.” American Economic Review 51(4): 533-58.

Rimmer, Douglas. 1992. Staying Poor: Ghana's Political Economy, 1950-1990. Oxford: Pergamon Press.

Rodrik, D. 2013. "Unconditional Convergence in Manufacturing." Quarterly Journal of Economics 128(1):165-204.

Rodrik, D. 2014. “The Past, Present, and Future of Economic Growth," in Franklin Allen et al., Towards a Better Global Economy: Policy Implications for Citizens Worldwide in the 21st Century. Oxford: Oxford University Press, 70-133.

Rodrik, D. 2018. “An African Growth Miracle?” Journal of African Economies 27(1): 10-27.

Steel, William F. 1972. "Import Substitution and Excess Capacity in Ghana." Oxford Economic Papers 24(2): 212-40.

Solow, R. M. 1956. “A Contribution to the Theory of Economic Growth.” Quarterly Journal of Economics 70(1): 65-94.

Timmer, M. P., G. J. de Vries, and K. de Vries. 2015. "Patterns of Structural Change in Developing Countries," in J. Weiss and M. Tribe (eds), Handbook of Industry and Development. London: Routledge, 65-83. 
World Bank. 2006. World Development Indicators. Available at: http://data. worldbank.org/indicator in 2006.

World Bank. 2014. “Ghana: Country Profile 2013”. Enterprise Surveys. Washington, DC: World Bank.

World Bank. 2017. World Development Indicators. Available at: http://data. worldbank.org/indicator in 2017. 


\title{
3
}

\section{Strong Democracy, Weak State \\ The Political Economy of Ghana's Stalled Structural Transformation}

\author{
Danielle Resnick
}

\subsection{Introduction}

What are the political and institutional factors that enable governments to pursue policies to promote economic and agricultural transformation? Sustaining growth, achieving inclusive development, and promoting structural transformation require qualitatively different, albeit not necessarily mutually distinct, economic policy interventions. In particular, respecting property rights, investing in broad-based public goods, such as infrastructure, education, and health, and adhering to macroeconomic stability, can be critical "fundamentals" for, or enablers of, sustainable growth, but they do not necessarily result in structural transformation (see Chapter 2 of this book, and Rodrik 2014). Instead, the latter may be more likely when specific industries are favored, firms are incentivized, and market failures within and across sectors are overcome (see Sen 2015). Hausmann et al. (2008) identify three different types of market failures that need to be overcome in order to achieve transformation: self-discovery externalities (identifying new products that can be produced profitably), coordination externalities (engaging in simultaneous investments upstream and downstream), and missing public inputs (legislation, accreditation, and infrastructure). Structural transformation therefore requires more activist government policies beyond providing an enabling environment.

However, some of the economic policy levers that are available for addressing these market failures may be more viable in certain political and institutional settings than others. By investing in the economic "fundamentals," peaceful, democratic societies are typically better at sustaining growth than conflict-ridden, autocratic ones (e.g., Acemoglu and Robinson 2012; Feng 1997; Gerring et al. 2005; Przeworski et al. 2000; Rodrik 2000). Yet, these same political virtues may not always be associated with the institutional 
environment and economic policies needed to generate structural transformation. Historically, structural transformation has not been uncommon in closed political regimes, ranging from Bismarkian Germany of the late 1800s, to the 1970s period of dictatorship in Brazil and South Korea, to oneparty regimes in Ethiopia and Rwanda from the 2000s onward (e.g., Holden 2012; Kelsall 2013; Kohli 2004; Leftwich 1995; Poulton 2014; Schneider 1999).

This chapter therefore argues that Ghana's sustained economic growth in recent decades reflects a concerted commitment to maintaining political fundamentals. Ghana is broadly lauded for its environment of political pluralism, respect for human rights, free and fair elections, and vocal civil society. According to multiple indicators, including Freedom House, the Ibrahim Index of African Governance (IIAG), and Polity IV, Ghana ranks near the top of the African region. A genuinely competitive multi-party system has resulted in the alternation of political parties in office and has classified the country as one of only a handful on the continent to have achieved democratic consolidation according to Huntington's (1991) two-turnover test. In fact, the two main political parties, the National Democratic Congress (NDC) and the New Patriotic Party (NPP), peacefully have handed over power to each other in 2000, 2008, and 2016. Party institutionalization and respect for the rule of law meant that the death in office of President John Atta Mills in 2012 did not result in the power vacuum or political chaos witnessed recently in African countries that have faced a similar fate, such as Malawi and Zambia. Despite the presence of ethnic divisions, they have not undermined the country's unity, and no group has ever attempted to secede (see Oduro et al. 2014). Indeed, while neighboring countries with similar economies, such as Côte d'Ivoire, were plunged into ethnic and religious conflict in recent years, Ghana has remained peaceful and avoided local conflicts from exploding into regional or national conflagrations. When Ghana became the only sub-Saharan African country besides South Africa to launch a $\$ 750$ million Eurobond in 2007, it was four times oversubscribed with political stability repeatedly identified by international investors as one reason for its success (Chung 2007; Rao 2007). ${ }^{1}$

Yet, despite these virtues, and as shown in Chapter 2, Ghana has been unable to achieve substantial structural transformation in the sense of accelerating the growth of high labor productivity sectors and shifting labor to them from low-productivity sectors, like traditional agriculture (see also Jebwab and Osei 2012; Killick 2000; Powell and Round 2000). Moreover, the

\footnotetext{
${ }^{1}$ Indeed, despite the country's growing external debt and ambiguity about oil reserves, the country has successfully launched three additional Eurobonds.
} 
country appears to face recurrent lapses of fiscal management. Public sector capacity and financial management indicators are often volatile, with a strong deviation from economic prudence close to elections. Public opinion surveys indicate low levels of trust in the government to deliver on its promises while constrained relationships between successive governments and the domestic business community have impeded long-term strategizing on priorities for growth and development.

Consequently, Ghana is strongly democratic but plagued by weak state capacity, and these politico-institutional characteristics have shaped the economic policies pursued, including in the agricultural sector, and the resultant development trajectory. Specifically, Rawlings, who oversaw the transition from the economic crisis years of the early 1980s, combined aspects of developmental neo-patrimonialism with a small but technocratic financial team to push through structural adjustment policies that helped stabilize the macro economy. After the country's democratic transition in the early 1990s, Ghana has witnessed broad investment in public goods and social welfare due to its competitive party system. However, this chapter argues that three political economy factors have undermined its ability to achieve substantive structural transformation. First, democracy has enabled a broader range of interest groups to permeate policymaking decisions, often resulting in policy backtracking and volatility as well as fiscal deficits around elections that, among other things, stifle credit access for domestic business through high interest rates. Secondly, public sector reforms were not pursued with the same vigor as macroeconomic reforms, meaning that the state has lacked the capacity typically necessary to identify winning industries or to actively facilitate the transition to higher value-added sectors. Thirdly, successive governments, regardless of party, have failed to actively invest in building strong, productive relationships with the private sector, which is a legacy of Rawlings' strong distrust and alienation of the sector during his tenure in office.

The chapter expounds on these arguments by first reviewing in Section 3.2 the extant scholarship on the linkages between governance, economic growth and structural transformation. Section 3.3 explores Ghana's initial investments in economic fundamentals before turning in Section 3.4 to the challenge of maintaining these fundamentals as the country democratized and as disparate interest group pressures became more pronounced. Then, Section 3.5 elaborates on the capacity constraints of Ghana's bureaucracy, which can be traced to insufficient attention to much-needed public sector reforms in recent decades. Weak business-state relationships are analyzed in Section 3.6 before 
exploring the broader implications of these political and governance dynamics for agricultural transformation. The final section concludes by discussing what this combination of a strong democracy and a weak state implies for feasible policy options in agriculture and beyond.

\subsection{Governance, Growth, and Transformation: Regime or State?}

The political and institutional characteristics that define countries can be broadly aligned according to the type of political regime and the capacity of the state. Regimes fall along a wide continuum, ranging from completely authoritarian with no space for competition to liberal democracy with multiparty competition, freedom of association, and rule of law (see Howard and Roessler 2006; Levitsky and Way 2010).

Regime types are not always correlated with state capacity. The archetypical view on state capacity originates from Weber (1978) who argued that a rational-legal bureaucracy guided by meritocracy, high levels of expertise, and respect for the law was most likely to promote prosperity. According to Sen (2015), the two main elements of state capacity are bureaucratic power (i.e., the ability of the state to implement policy decisions) and infrastructural power (i.e., the capacity of the state to exert full authority over national territory). In a cross-country analysis using proxies for Weberian state structures in thirty-five developing countries, Evans and Rauch (1999) find that meritocratic recruitment and career mobility are associated with higher economic growth, even after controlling for human capital and initial levels of GDP per capita (see also Rauch and Evans 2000).

The Weberian ideal is typically contrasted to patrimonial rule whereby government officials are driven more by allegiances and informal ties than by expertise. Van de Walle (2001) has used the term "neo-patrimonial" to refer to states with the outward trappings of a Weberian bureaucracy with rules, regulations, and formal procedures but are internally governed by clientelist practices. He refers to African administrations whereby "the top technocrats may be very competent and well trained, but they lead underfinanced state structures with very little data gathering, planning, and policy analysis capabilities" (van de Walle 2001: 55). The literature suggests that regime type plays an important role in determining investment in economic fundamentals while state capacity may play a larger part in shaping economic transformation. 


\subsubsection{Democracy}

Democratic governments may have an incentive to provide a more equitable distribution of resources (Acemoglu and Robinson 2006; Boix 2003), and invest more in public than private goods (Bueno de Mesquita et al. 2005; Baum and Lake 2003). In addition, research suggests that they spend more on education and social welfare (Ansell 2008; Brown and Hunter 1999; Huber et al. 2008), and do better than autocracies on important measures of well-being such as life expectancy and calorie consumption (Besley and Kudamatsu 2006; Blaydes and Kayser 2011). Bates and Block (2013) even find that the introduction of competitive presidential elections in Africa since the 1990s is correlated with improvements in total factor productivity in the agricultural sector.

There are various causal mechanisms underlying these relationships. Meltzer and Richard (1981) argued that where the median income is lower than the mean income, the majority of voters are poorer than their compatriots. In a poor democracy, politicians are therefore motivated to adopt policies favoring the less well-off in order to increase their chances at re-election. Lake and Baum (2001) further suggest that the accountability of the electoral process forces democracies to improve human capital as broadly as possible (see also Stasavage 2005). Rodrik (1999) emphasizes the value of political participation, arguing that democracies have higher manufacturing wages because they allow greater freedom of association and collective bargaining.

On the other hand, there have been suggestions that an emphasis on democracy can be counter-productive for development (e.g., Collier 2009; Sachs 2005) and that democracy can foment clientelism and undermine the effective delivery of services (see Booth 2012). Ross (2006) finds that social welfare spending in democracies disproportionately benefits middle- and upper-income groups, supporting other scholars' observations that elections result in targeted spending for organized constituents rather than broad welfare spending (see Keefer 2007 and Karakoc 2010). In the African agricultural sector in particular, Poulton (2014) suggests that democratization has resulted in governments favoring short-term policy options, especially input subsidy programs, rather than more long-term investments in research and development or extension.

Relatedly, the political budget cycle plays an important role in democracies. This view suggests that fiscal policy, especially government transfers for certain goods and services, is manipulated before elections by opportunistic incumbents (see Rogoff 1990). The pattern is especially strong in developing 
countries (see Brender and Drazen 2005). For instance, based on a sample of forty-four African countries, Block (2002) finds that a government's budget deficit increases by 1.2 percentage points in an election.

The collective implication from this literature is that the opportunities for political participation and accountability that accompany democracy can force governments to invest in economic fundamentals. However, economic policies may also favor those constituencies that are most powerful, either in numerical or material terms. This may result in policies that are not necessarily conducive to long-term growth or to achieving strategic development objectives.

\subsubsection{Developmental States}

The fact that democracies can become hostage to interest group pressures, and thereby distract from long-term strategic planning, has long bolstered the arguments of "developmental state" scholars. Historically, the term "developmental state" referred to those states, including Japan, Taiwan, South Korea, Singapore, and Hong Kong that engineered a transition from agrarian economies or island trading centers to industrial economies through industrial policy (see Evans 1995; Johnson 1982). Johnson's (1982) main insight from the study of the Japanese miracle was that economic development is plagued by market failures and depends on the government's ability to facilitate coordination of the private sector, offer selective and conditional support to particular firms through subsidies, and intervene in markets when necessary.

Solving these coordination problems required a specific set of political and institutional characteristics. Politically, these transformations occurred under authoritarian regimes that avoided capture by societal demands. Although these governments invested in education, their repression of labor allowed for export-oriented growth based on low wages and flexibility in hiring and firing (Deyo 1989; Haggard 1990). Institutionally, these developmental states were characterized by technocratic policymaking, the concentration of decisionmaking authority in just a few ministries or pilot agencies, and key reforms to bureaucratic routines and norms (see Amsden 1989; Chang 1994; Haggard 1990; Cheng et al. 1998; Wade 1990). Recruitment and compensation based on merit and career mobility were other key factors that precluded rent-seeking that might otherwise undermine commitment to long-term development strategies.

More recent studies have looked at the developmental state argument in other contexts, demonstrating that it may not have a natural affinity for a 
particular regime type. For example, Mauritius is frequently portrayed as a democratic developmental state (see Bräutigam 1997; Sandbrook 2005). Rodrik (2008) also discusses notable cases of state-led industrial policy in democracies, including South Africa and Uruguay. Botswana represents a more muted example whereby a capable state led by a cattle-elite was committed to development (Acemoglu et al. 2003). But repeated attempts to diversify the economy, even through multiple industrial policy plans, has failed to generate significant structural change since the 1990s (see McCaig et al. 2015). Notably, Mauritius' major period of transformation occurred during the thirty-four-year rule of same political party while both Botswana and South Africa's democratic periods have been one-party dominant. ${ }^{2}$

There are, however, critiques of the developmental state approach. Some have noted that there has been an overemphasis on successful cases of industrial policy (see Geddes 2003; Robinson 2009). The failed cases of ISI industrial policy in much of Latin America are an important caveat whereby governments did selectively intervene to favor an inward, rather than exportoriented, strategy. In other words, even states that have all the institutional prerequisites to oversee a long-term strategy may still choose policies that generate neither growth nor transformation. Secondly, developmental states cannot be shaped overnight to respond to development strategy imperatives but rather the product of long-term historical processes, including colonial lineages (Kohli 2004). A third critique, elaborated on more below, is that a technocratic Weberian state may be necessary but insufficient for transformation and that more attention is needed on the nature of the relationships between states and business.

\subsubsection{State Business Coalitions}

Relationships between the bureaucracy and the private sector need to be honed over time, generating credible commitments and trust, facilitating the flow of information and learning, and adapting to changing economic circumstances (e.g., Leftwich 2010; Maxfield and Schneider 1997). Consequently, some have claimed that complex and close networks between the public and private sector are the linchpin for economic transformation. In the context of explaining the East Asian miracle, Evans (1995: 59) coined the concept of

\footnotetext{
${ }^{2}$ From independence in 1968 until 1982, the Mauritian Labor Party was dominant in parliament and its leader, Sir Seewoosagur Ramgoolam, remained prime minister for those thirty-four years.
} 
"embedded autonomy," referring to the bureaucracy's ability to be embedded in society through "a concrete set of connections that link the state intimately and aggressively to particular social groups with whom the state shares a joint project of transformation."

Deliberation councils, which are consultative fora of business and government that discuss policy options and make recommendations to executive agencies, were one way of facilitating this relationship in Asia (see Campos and Root 1996). In assessing different "varieties of capitalism," Hall and Soskice (2001) observe a similar modality in the coordinated market economies of northern Europe whereby government, business, and labor frequently engage in a corporatist arrangement. Such corporatism has been based in turn on peak business associations having the ability to enforce commitments among their members to effect cooperation that helps address coordination failures (Katzenstein 1985). Schneider (2013) elaborates on the elements for the success in such councils, including smaller numbers of participants balanced across relevant stakeholders, frequent meetings that raise expectations of repeated interaction, high-level representation from the government, and clear mandates. Rodrik (2008) also concurs that the implementation of industrial policies requires governments to engage in "embeddedness" through not only deliberation councils but also public-private dialogue, or sectoral roundtables. Bräutigam et al. (2002) suggest that statebusiness relationships transform into growth coalitions when three criteria are met: equal capacity between the state and private sector, broad representation of business associations, and allocation of non-public benefits, such as export quotas, to selective members of the private sector.

The political context is not insignificant in shaping dynamics with the private sector. While authoritarian contexts can be much more predictable for the private sector than volatile democratic transitions, business groups can quickly resettle and adapt to a new status quo in consolidated democracies (see Schneider 2010). Schneider (2013) though, cautions that governments should not be hijacked by business interests. He makes the distinction between passive and active industrial policies, with the former referring to lowering business costs by removing red tape and the latter referring to public subsidies aimed at altering firms' incentives to export or focus on research and development. To ensure that activist policies aimed at transformation benefit society rather than just government or business alone, Rodrik (2008) emphasizes the need for not only incentives but also "sticks" through conditionalities and sunset clauses as well as accountability mechanisms for performance. 
In the African context, the nature of the business-state relationship often has wavered between crony capitalism, whereby the private sector is co-opted by ruling parties, and marginalization through active repression or passive disengagement with the business community. These patterns are particularly relevant to the African domestic private sector rather than to multi-national corporations, which may have more flexibility in their choice of government partners. According to Taylor, the nature of these relationships often depends how diversified the economy is, the relative contribution business makes to the economy, and the institutional strength of business vis-à-vis that of the state (Taylor 2007). For instance, Handley (2008) notes that Mauritius' export-led growth orientation was facilitated by a strong degree of organization among business associations clustered around sugar, export-processing zones (EPZs), and tourism. This facilitated a corporatist mode of policymaking that included government, business, and labor. Rodrik (2007) likewise documents how South Africa's Department of Trade and Industry worked with private sector associations to develop Customized Sector Programs to formulate policies for individual sectors and help expand into non-traditional areas.

\subsubsection{Neo-patrimonial Developmental State}

If strong states and a strong business sector are critical for transformation, then is there any option for countries that lack these ingredients? Those who believe that there is a neo-patrimonial developmental state model claim that there is room to be optimistic. In this model, states may be weak and characterized by clientelist practices but guided by a strong and visionary leader who prefers long-term, pro-capitalist policies and creates pockets of technocratic efficiency to achieve them. Rents, or excessive profits typically from monopoly trading or corruption (see Khan 2000), are managed centrally and directed to productive purposes. This view builds on Olson's (1993) distinction between roving and stationary bandits, whereby the latter refer to leaders who recognize that rents can be maximized in the long term if the economy is allowed to grow.

This stream of scholarship has been strongly influenced by a set of African cases. $^{3}$ Booth and Golooba-Mutebi (2014) point to the Rwanda case under Paul Kagame and the Rwandan Patriotic Front (RPF). The RPF's war reserves

\footnotetext{
${ }^{3}$ Much of the argument about neopatrimonial developmental states has emerged from the African Power and Politics Program at the Overseas Development Institute.
} 
were initially used in 1994 to rehabilitate state finances and institutionalized into the party's investment arm, currently known as Crystal Ventures, which invests in agro-processing, mobile phones, construction, road-building, and furniture. The company plays a significant role in campaign contributions during elections to prop up the RPF. Despite this obvious conflation of party and business interests, Kagame has remained committed to using Crystal Ventures and other public resources to achieve economic and social development via Rwanda Vision 2020 rather than padding the wallets of politicians. A similar dynamic has been observed in the Ethiopian context under the late Meles Zenawi and the EPRDF (see Berhanu and Poulton 2014). Other examples include Malawi under Hastings Banda's early tenure (1964-79) and Bingu wa Mutharika, as well as Côte d'Ivoire under the early years of Houphouët-Boigny (see Cammack et al. 2010; Kelsall 2011). The notable element under all these cases were that political leaders provided the leadership to guide specifically pro-rural development strategies.

The notable caveat of the developmental patrimonialism school of thought is that it is highly dependent on a particular leader or a well-organized dominant party. The contributors to this scholarship have not explained whether the visionary and long-term leadership that maintains this precarious balance between predation and development can be institutionalized when (and if) the leader or party is ousted.

\subsection{Ghana's Initial Investment in Economic Fundamentals}

How do these various schools of thought relate to Ghana's development trajectory? In many ways, Ghana's positive and sustained growth since the Structural Adjustment period starting in the 1980s validates the alternating importance of strong leadership to enforce commitment to economic fundamentals as well as the role of democracy in generating political incentives to invest in broad-based infrastructure and other public goods. Historically, however, neither of those features were prominent.

Shortly after Independence in 1957, Ghana descended into a repeated cycle of civilian government, military coups, and dictatorship for three decades (see Table 3.1). The political instability resulted in macroeconomic chaos as each successive regime reversed their predecessors' policies and attempted to chart a new economic course. For instance, Kwame Nkrumah's attempts at Big Push modernization relied on an import-substitution industrialization approach that resulted in overvaluing the exchange rate, lacked planning, and involved 
Table 3.1. Timeline of political regimes and governments since Ghana's Independence

\begin{tabular}{|c|c|c|c|}
\hline Government & Political regime & Ruling party & Leader \\
\hline $1957-64$ & Civilian democracy & Convention People's Party & Kwame Nkrumah \\
\hline $1964-6$ & One-party state & Convention People's Party & Kwame Nkrumah \\
\hline 1966-9 & $\begin{array}{l}\text { "Caretaker" } \\
\text { military regime }\end{array}$ & $\begin{array}{l}\text { National Liberation } \\
\text { Council }\end{array}$ & $\begin{array}{l}\text { Joseph Ankrah (1966-9); } \\
\text { Akwasi Afrifa (1969) }\end{array}$ \\
\hline 1969-72 & Civilian democracy & Progress Party & Kofi Busia \\
\hline 1972-9 & Military regime & $\begin{array}{l}\text { National Redemption } \\
\text { Council }\end{array}$ & Ignatious Acheampong \\
\hline $1979-81$ & Civilian democracy & Convention People's Party & Hilla Limann \\
\hline 1981-3 & Military regime & $\begin{array}{l}\text { Provisional National } \\
\text { Defense Council }\end{array}$ & Jerry Rawlings \\
\hline $1983-92$ & One-party state & $\begin{array}{l}\text { Provisional National } \\
\text { Defense Council }\end{array}$ & Jerry Rawlings \\
\hline 1992-2000 & Civilian democracy & $\begin{array}{l}\text { National Democratic } \\
\text { Congress }\end{array}$ & Jerry Rawlings \\
\hline $2000-8$ & Civilian democracy & New Patriotic Party & John Kufuor \\
\hline $2008-16$ & Civilian democracy & $\begin{array}{l}\text { National Democratic } \\
\text { Congress }\end{array}$ & $\begin{array}{l}\text { John Atta Mills (2008-11); } \\
\text { John Mahama (2011-16) }\end{array}$ \\
\hline $\begin{array}{l}2016- \\
\text { present }\end{array}$ & Civilian democracy & New Patriotic Party & Nana Akufo-Addo \\
\hline
\end{tabular}

negligible engagement from the private sector. Under Busia's tenure, there were disproportionate investments in Asante-dominated regions of Ashanti and Brong-Ahafo and the expulsion of migrant cocoa workers on sharecropping contracts under the Alien Compliance Orders Act, which severely undermined cocoa production. Under Colonel Acheampong, more than 20 million cedis were allocated to Operation Feed Yourself to increase production of rice, maize, and other goods for domestic consumption. Bad rains coupled with the overvalued exchange rate and a collapse in the cocoa sector mean that by 1975 , food actually had to be imported, but there was a lack of foreign exchange to do so.

The turning point, both politically and economically, emerged in 1983, two years after Flight Lieutenant Jerry Rawlings took over in a coup and established the Provisional National Defense Council (PNDC). A severe drought and the expulsion of more than one million Ghanaians from Nigeria prompted Rawlings to agree to an Economic Recovery Program (ERP) with the IMF that year. Between 1983 and 1992, Ghana's structural adjustment experience was actually characterized by six IMF programs. ${ }^{4}$ The first

\footnotetext{
4 These included three standby agreements $(1984,1985,1986)$, an Extended Fund Facility combined with a Structural Adjustment Facility (SAF) (1987) an enhanced SAF (1988-91), and a Fund Monitored Program from 1992 (see Martin 1993).
} 
program, the ERPI, was signed in 1983 and implemented in 1984-7 under standby agreements. The ERPI focused on "getting the prices right" through stabilization policies aimed at halting the decline in Ghana's industrial production and commodity exports. The emphasis of the IMF was on restoring external balances by rehabilitating exports via devaluation through a foreign exchange auction and creating a private foreign exchange bureau (Kraus 1991). Other key aspects of policy conditionality involved increasing the producer price of cocoa by lowering the export tax, reducing the marketing costs of Cocobod, removing subsidies and price controls, restricting pay increases for public sector employees, liberalizing trade, divesting from stateowned enterprises, and introducing cost recovery in health and education sectors through user fees (e.g., Bawumia 1998; Rimmer 1992). About thirtytwo state-owned enterprises were put up for sale and the government claimed it would accept bids on any of the 185 SOEs, except for eighteen that were considered "strategic" (Rothchild 1991). ${ }^{5}$

The second phase of the Economic Recovery Plan, ERPII, launched in 1987-91, aimed to deepen these policies and further stimulate economic development (Nugent 1995). To do so, the government received net aid disbursements ranging from $\$ 370$ million in 1984 to $\$ 488$ million by 1990 , which were targeted at, among other things, rehabilitating the cocoa, mining, and timber industries (Kraus 1991; Nugent 1995). By 1990, the Ghana Stock Exchange opened in order to mobilize greater domestic resources for capital investment and to attract foreign direct investment, a new investment code was established, and more restrictive decrees were repealed (Aryeetey and Harrigan 2000). ${ }^{6}$

With respect to agriculture, the World Bank and other donors supported the Agricultural Services Rehabilitation Project under ERPI and helped establish the Policy Planning, Monitoring and Evaluation Directorate in the Ministry of Agriculture to improve the ministry's capacity to design and implement agricultural projects. Through the Public Investment Program launched in 1984, an emphasis was placed on improving roads, highways, water, and electricity, with a particular concentration on export-producing rural regions (see Bawumia 1998). As part of the ERPII, the minimum guaranteed price for maize and rice was increased and the supply of agricultural inputs temporarily improved, even as subsidies for fertilizers and machinery gradually were

\footnotetext{
5 Nugent (1995) notes however that while about forty companies had been removed from the public domain by mid-1991, only seventeen of those had actually been sold to private investors.

${ }^{6}$ For instance, the 1971 Manufacturing Industries Act, the 1974 Price Control Decree, and the 1976 Control of Sale of Specific Goods Decree were all removed.
} 
reduced. The cocoa sector Rehabilitation Project aimed to improve efficiency in marketing and production in the sector and an Agricultural Policy Coordinating Committee was established to help bring together all the various institutions dealing with agricultural policy (see Nyanteng and Seini 2000).

While many other African governments also pursued such programs at the time, Rawlings' government actually remained committed to the program and avoided the half-hearted implementation that exacerbated economic conditions in countries such as Malawi, Senegal, and Zambia (see Devarajan et al. 2001; Martin 1993). Indeed, as Herbst (1993: 30-1) observed, other African governments that faced economic crisis simply "limped by" while Ghana underwent a major economic overhaul. Rawlings' ability to stay committed to economic reform relied on a careful balancing act between technocratic implementation and authoritarian practices.

This approach manifested in a number of ways. First, interest group demands did not hijack the government's reform agenda. A number of scholars observed that the state's autonomy from interest group pressures were a key feature of this era (see Jeffries 1992; MacLean 2010; Rothchild 1991). For instance, anti-austerity opponents within the PNDC were expelled by Rawlings (Martin 1993). In addition, while the ERPs' short-term impacts made livelihoods more difficult for all strata of society, it is widely believed that they were more beneficial to the rural sector than to urbanites (see Callaghy 1990; Herbst 1993; Mikell 1989). Agricultural producers concentrated in export crop production, especially cocoa, benefited from the currency devaluation and improved producer prices. In 1984, the party published a Rural Manifesto that emphasized the importance of accelerating rural development in the country (Gyimah and Jeffries 2000). In 1986, the PNDC also tried to promote the registration of agricultural titles in order to secure tenants' land rights (Boone 2014).

By contrast, urbanites, who had actually been Rawlings' main supporters in 1981, suffered from the rising cost of imports, lower wages, retrenchments, and the introduction of user service fees. By 1989, the PNDC had retrenched approximately 53,000 civil servants (Rothchild 1991). Some urban discontent manifested in clashes on university campuses and protests by the Trade Union Congress (TUC) and urban workers. However, government repression of the labor unions deterred large-scale urban protests (see Herbst 1993). In addition, those who were hurt most by the reforms had become relatively disorganized and leaderless, lacking clear lobbying channels as a consequence of so much policy and political instability in the preceding decades (Martin 1993). 
As Callaghy (1990: 277) notes, "A key characteristic of the Rawlings regime was its relatively narrow organizational base... Insulation from important sociopolitical veto groups, themselves weakened by the shredding of the previous fifteen years, allowed the PNDC to do more than other more constrained regimes."

Secondly, Ghana benefited from a relatively well-trained and capable technocratic team, led by the minister of finance and university professor, Dr. Kwesi Botchwey, Dr. Joseph Abbey, and the head of cabinet, P. V. Obeng. Unlike Nkrumah, Rawlings did not meddle in the economic policymaking of his technocratic team. Critically, much of this economic team remained intact throughout the structural adjustment period, allowing for policy continuity, credibility with the donors, and implementation experience (e.g., Jeffries 1992; Kraus 1991). A majority of the policy making structure was concentrated around this core economic team and a few pragmatic military leaders, compared with a much more complex policymaking structure at the time of countries such as Zambia (see Martin 1993). Thirdly, the PNDC could capitalize on being a rather new government that needed to rectify the abuses and mismanagement of previous regimes. Ruling governments in countries such as Tanzania and Zambia, which essentially had been under one-party rule for decades, could not as easily defer blame (Martin 1993).

During this period, Ghana witnessed a growth in foreign direct investment (FDI) that was facilitated by the promulgation of an Investment Code in 1985 and restructuring of the Ashanti Goldfields Company, which opened up opportunities for joint ventures with foreign investors in the mining sector (Tsikata 1995). FDI increased from only $\$ 2$ million in 1984 to $\$ 22.5$ million a decade later (Tsikata et al. 2000). Gold production increased fivefold in the decade after 1984, leading it to supersede cocoa in exports (Nugent 2004). Inflation declined from 123 percent in 1983 to 10 percent a decade later, while average GDP per capita growth reversed from hovering around negative 3.5 percent between 1973 and 1983, to 2.2 in the ten years after the ERP began (WDI 2016). At the same time, as seen in Figure 3.1, the level of taxation of agriculture decreased substantially during the latter half of Rawlings' tenure. Despite receiving large shares of foreign aid, including to agriculture, during this period, Wiggins and Leturque (2011: 17) strongly credit economic reform for this revival: "Funding to agriculture (narrowly defined), however, may not be quite the point: much of what benefited the farmers, and cocoa growers in particular, came from economic reform, macroeconomic stability and public investments in highways-rather than from programs implemented by the Ministry of Food and Agriculture." 


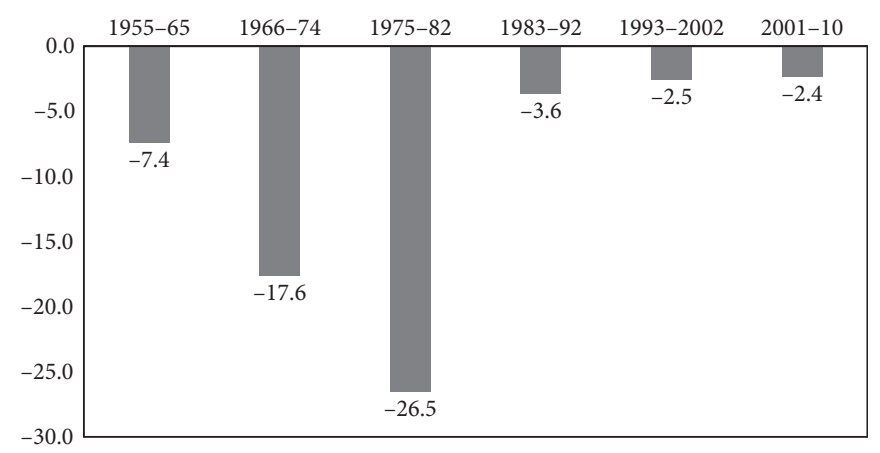

Figure 3.1. Average nominal rates of assistance for all agriculture in Ghana (\%) Notes: These rates indicate net taxation levels and obscure differences in protection and taxation across imports and exports and among products.

Source: Anderson, Kym, and Signe Nelgen (2013).

By investing in the economic fundamentals that benefited a large portion of the rural population, Rawlings felt comfortable enough to allow multi-party elections in 1992. As LeVan (2015: 190-1) notes, the ultimate success of this structural adjustment period was the ability to hold elections and debate policy outcomes. By the time of the democratic transition in 1992, policy change no longer required regime change. Notably, in the elections that year, the PNDC transformed into the National Democratic Congress (NDC) and Rawlings was the party's candidate. He won 58.3 percent of the vote compared with 30.4 percent for the main opposition candidate, Professor Adju Boahen of the New Patriotic Party. One distinct pattern to the election outcomes was that Rawlings' share of votes was higher in all rural constituencies than urban ones in almost every region, emphasizing that he had established a rural support base as a consequence of the orientation of many of the structural adjustment policies (see Bawumia 1998; Gyimah-Boadi and Jeffries 2000). ${ }^{7}$

\subsection{Democracy's Double-edged Sword}

Much like Rawlings' acquiescence to the ERP in 1983, Ghana's transition to democracy in the early 1990s represented a critical juncture in the country's political economy that shifted incentive structures and interest group dynamics. On the one hand, the need to attract votes every four years in a highly

\footnotetext{
${ }^{7}$ He had also obtained an overwhelming majority in the Volta region, reflecting support from his own regional stronghold and Ewe constituents.
} 
competitive two-party system has had positive impacts on the welfare of citizens through the provision of public goods. ${ }^{8}$ On the other hand, catering to a broad array of pluralist pressures has had some negative implications for government coffers and indirectly hurt the domestic private sector.

As much of the democratization literature discussed earlier has posited, Ghana observers find that political parties and elites now provide public goods, such as rural roads, that benefit large constituencies rather than narrowly targeted private goods (e.g., Gyimah-Boadi and Prempeh 2012; Harding 2015; Weghorst and Lindberg 2009). A key reason for this is that elections between the NDC and NPP are always incredibly close, especially in key regions of the country, and therefore winning votes requires courting a broad range of voters. Williams (2009: 144) argues that political motivations also explain why the government has continued to support producer prices for cocoa under the Fourth Republic: "Given the large share of Ghanaians involved in the cocoa industry, cocoa interests have noticeable political weight in democratic politics. The producer price is frequently an issue of discussion of Ghana's main political parties. Thus, Ghana's democracy has helped to protect the producer price increases over time."

In addition, Ghana has demonstrated impressive progress towards meeting key development objectives since transitioning to democracy. These may partially be attributed to its formal commitment to the Millennium Development Goals (MDGs) in 2001, which were subsequently integrated into the Ghana Poverty Reduction Strategy (2003-5) and the Growth and Poverty Reduction Strategy (2006-9). In turn, Ghana benefited from financial assistance through HIPC, Multilateral Debt Relief Initiative, MDBS, as well as initiatives such as the United States Millennium Challenge Account (UNDP 2015). Figure 3.2 illustrates that commitment to the MDGs corresponded with greater expenditures in the education and health sectors, as a share of GDP, from 2000 onwards. By contrast, infrastructure investment in communications and transportation and as well as agricultural expenditures were much more modest (see also Chapter 5).

The MDGs were an important policy driver in many countries regardless of political regime type. But, Ghana has been a top performer in Africa with regards to its progress towards achieving the MDG targets, particularly with respect to the poverty and social welfare targets. For instance, literacy rose from 58 to 71 percent of the population between 1999 and 2014 while net

\footnotetext{
${ }^{8}$ In the 2000, 2008, and 2012 elections, the margins of victory in the presidential elections for the first (or only) round were 4,2 , and 3 percentage points, respectively.
} 


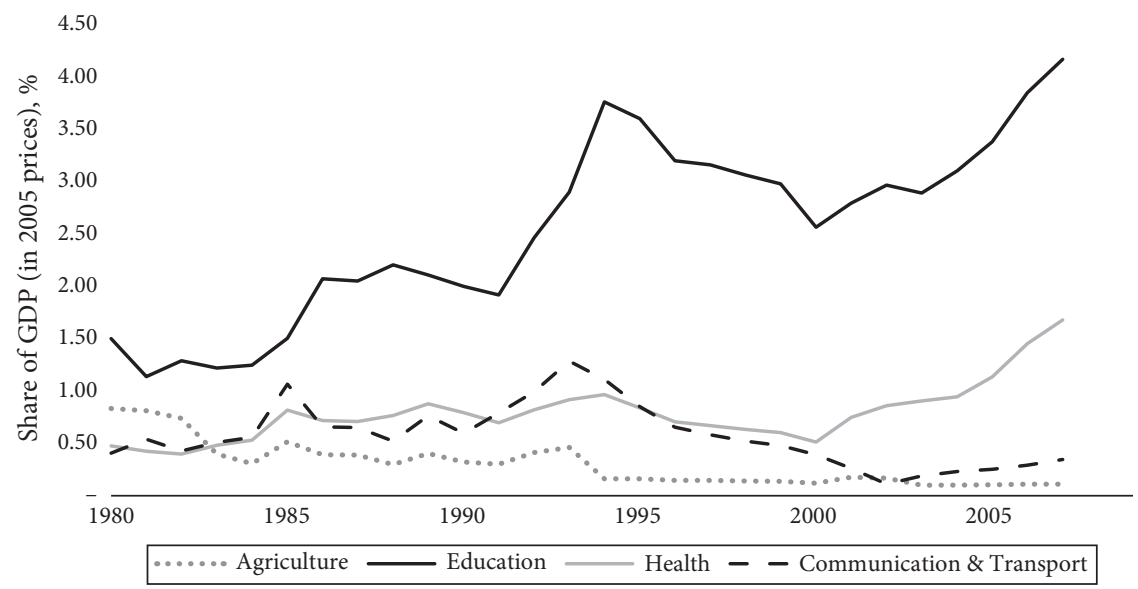

Figure 3.2. Shifts in sectoral public expenditures, 1980-2007

Source: Calculated from Statistics for Public Expenditure for Economic Development (SPEED) database, available at: http://dx.doi.org/10.7910/DVN/INZ3QK.

female enrollment in primary school increased from 60 to 89 percent during the same period. The equivalent increase for secondary school was 32 to 54 . The share of the population now having access to an improved water sources is particularly notable, increasing from 56 percent in 1992 to 87 percent by $2015 .^{9}$

Beyond the impetus of the MDGs, successive democratic regimes in Ghana invested in a number of broad-based social welfare schemes. Notable among these includes the National Health Insurance Scheme, which was established in 2003 and represents one of Africa's few attempts to implement a universal healthcare program (Blanchet et al. 2012). In 2005, the government also abolished primary school fees and provided schools with a small grant (capitation grant) for each pupil enrolled. Another example includes the Livelihood Empowerment Against Poverty Program (LEAP), which was launched in 2008 and now expanded to all ten regions of the country with more than 70,000 beneficiaries. LEAP is a cash transfer program that provides beneficiaries with direct cash payments and free health insurance (Handa et al. 2013). While all three programs began under the NPP, they were scaled up under the NDC tenure of Presidents Mills and Mahama, indicating a broad consensus across parties about their importance.

\footnotetext{
${ }^{9}$ Data is from the World Bank's World Development Indicators.
} 
However, these and other programs clearly can be manipulated for political gain, especially for the incumbent party. For instance, Rawlings and the NDC publicly rejected becoming a HIPC country in 1999. When the NPP came to power, it reversed this policy and agreed to join HIPC. Subsequently, the construction of schools and public toilets were clearly labeled "HIPC Benefits" as a visual reminder to voters that these public goods were the consequence of the NPP's actions (see Abdulai and Hulme 2014). Likewise, Ghana abolished primary school fees in 2004 (World Bank 2009), which Stasavage (2005) has attributed to an effort to win over rural voters.

At the same time, democracy has enabled a broader range of interest groups to permeate policymaking decisions compared with the PNDC. While the use of repression significantly weakened protest activity during the one-party regime of Rawlings' PNDC, the transition to a multi-party democracy created the space for popular resistance, and elections every four years generated an incentive for politicians to respond. Thus, when the government attempted to introduce a 17 percent value-added tax (VAT) in 1995, industrial workers and civil servants launched the Kume Preko ("You Might as Well Kill Me") demonstrations in Accra and Kumasi. A component of its economic reform program with the IMF, the VAT was intended to replace sales tax and provide the government with a much more reliable and equitable revenue source. But a coalition of interest groups, led by Nana Akufo-Addo of the opposition NPP, forced the government to reverse the policy (Osei 2000). ${ }^{10} \mathrm{~A}$ similar set of policy reversals was witnessed with respect to increasing petrol and electricity prices in the wake of popular protests in urban areas (Hutchful 2002).

Catering to particularly urban interest groups was also reflected in the "political budget cycle." As noted earlier, the political business cycle refers to the expansion of spending in the run-up to an election in order for an incumbent party to improve its chances at re-election, only to reduce spending after the election period has ended (see Rogoff 1990). Ghana has actively followed this cycle since democratization, with observers claiming that the 1992, 1996, and 2008 elections were especially destabilizing (see Mosley and Chiripanhura 2016; Prempeh and Kroon 2012) and that the four increases in the wage bill have been suspiciously timed to take effect around elections (STAR-Ghana 2011). ${ }^{11}$

\footnotetext{
${ }_{10}$ The government was though then able to successfully implement the VAT in 1998 and this has since provided a significant share of revenue (see Williams 2009, footnote 20).

11 The introduction of the Single Spine Salary Structure in 2010 was actually intended to stop the tendency of labor strikes among different unions to mobilize for higher pay increases in response to the demands of other unions (see STAR-Ghana 2011).
} 
More specifically, in 1991, Ghana had a surplus of 1.5 percent of GDP but by 1992, the year of the elections, it then had a fiscal deficit of 5 percent of GDP (Block 2002). As the 1996 elections approached, additional fiscal "slippages" were apparent as the NDC increased capital spending in rural areas on roads and hospitals to maintain the support it gained from the previous elections while responding with salary increases after a set of successive strikes by doctors, nurses, workers of the Cocoa Board, railway employees, and civil servants (see Leite et al. 2000). In fact, Kwesi Botchwey, the technocratic finance minister who helped oversee Ghana's structural adjustment, resigned from cabinet as a result of disagreeing with Rawlings over the use of public finances to win the 1996 elections (Africa Confidential 2016). The overall fiscal deficit amounted to 9.5 percent of GDP that year, and the IMF and World Bank temporarily halted their aid disbursements (Tsikata 2001). ${ }^{12}$ A World Bank's (2011) public expenditure review also emphasized that fiscal deficits as a share of GDP were found to be significantly higher during election years.

By around 2000, the gains from the ERPs had been eroded and the government began negotiations for debt forgiveness under the Heavily Indebted Poor Countries Initiative (HIPC). But, the political budget cycle fueled by Ghana's intensely close democratic competitions did not cease with the NDC and continued under the NPP. During its 2000-8 tenure, the NPP also backtracked on removing subsidies from public utilities and petroleum products, as well as reducing the public sector wage bill (Gyimah-Boadi 2009). As the 2008 elections drew near, the government provided higher wages and salaries to civil servants, increased energy sector subsidies, and invested in a set of highly visible prestige projects (see Whitfield 2010). After the 2012 elections, the government announced a deficit of 12 percent of GDP, exceeding its original projection of 6 percent (Oduro et al. 2014). These deficits have contributed to high interest rates ranging around 16 to 19 percent between 2009 onwards that make credit costly and deter domestic private sector investment (see Quartey and Afful-Mensah 2014). ${ }^{13}$

By the end of 2016, Ghana's debt stock was 74 percent of GDP and the fiscal deficit estimated at 9 percent of GDP (IMF 2017). Poor macroeconomic management, coupled with frequent electricity outages, are both credited with the defeat of the NDC in the December 2016 elections. Nana AkufoAddo of the NPP was elected president with some of the largest vote margins

\footnotetext{
12 They resumed disbursements, even though Ghana was still off track with its macroeconomic indicators, due to pressure from three bilaterals: the United Kingdom, Canada, and Japan (see Tsikata 2001).

${ }^{13}$ Quartey and Afful-Mensah (2014) find that the spread between lending and savings rates averaged at least 20 percent between 1997 and 2012, which discouraged both savings and investment.
} 
in the country's history of democratic elections. While President Akufo-Addo acknowledged the dire situation of the economy in his First State of the Nation address, he also promised large-scale programs that would put additional pressure on the already limited fiscal space. These included offering free secondary school education to all Ghanaians, creating four new regions out of the current ten, building a new factory in every one of the country's 254 districts under the "One District, One Factory" policy, and a campaign entitled "Planting for Food and Jobs" that intended to expand agricultural extension serves and increase the availability and accessibility of improved seed and fertilizer (Akufo-Addo 2017).

\subsection{Ghana's Lame Leviathan: Limitations to Public Sector Reform}

In addition to regime dynamics, relatively weak state capacity, measured by public sector management and civil service, is a second political economy factor that has undermined Ghana's structural transformation. ${ }^{14}$ As Booth et al. (2005) observe, "Everyone seems to agree that the public service, particularly the civil service, has reached a very low ebb. Incentive structures within the civil service actively discourage initiative and pro-activity. For individuals, the way to move up the system is to avoid mistakes, maintain a low profile and let seniority work its magic." Likewise, Whitfield (2010: 735) observes that "the result today is a public administration system that does not work and which severely reduces the ability of the government to implement reforms and programs." The complete decimation of the quality civil service during the politically volatile decades preceding Rawlings' tenure, combined with the overwhelming influence and dependence on the donors and their parallel institutional structures in the two subsequent decades, are key reasons for these outcomes (see Whitfield and Jones 2009).

This state of affairs is even more disappointing given how much effort has been invested into public sector reform. The weakness of the public sector was identified as one of the bottlenecks to better implementation of Ghana's stabilization policies in the 1980s. In fact, in 1987, the World Bank provided a $\$ 100$ million credit for a Structural Adjustment Institutional Support Project (SAIS) in order to reform public sector management through improving the management and policy capacities of key ministries. The project resulted in

14 The term "lame leviathan" was coined by Callaghy (1987). 
the retrenchment of approximately 50,000 civil servants (IMF 1999). When the project end in 1993, auditors concluded that SAIS had had little impact on economic policy planning and the government had resisted change (see Hutchful 2002). Around the same time, a Civil Service Reform Program was implemented with the aim of re-examining the salary structure while also improving motivation and performance. By 1997, Ghana had one of the highest ratios of civil servants to population, with 84,000 in central government and 123,000 in local government (IMF 1999).

A series of other programs then followed, facilitated by a Ministry of Public Sector Reform that was established in 2005 to coordinate all of these reform efforts. These included the Civil Service Performance Improvement Program (CSPIP), which ran from 1995 until 2006 and involved senior bureaucrats within ministries, departments, and agencies signing performance contracts with the president (Larbi 1999). This too failed to transform the public sector's organizational culture, with insufficient incentives, lack of political will, and high levels of institutional fragmentation representing some of the main hindrances (Ohemeng 2011).

Around the same time in the mid-1990s, the Public Services Commission began reviewing the salary structure to assess and address wage disparities. In 1997, the government also aimed to improve budgetary planning and implementation through the Public Financial Management Reform Program (PUFMARP). In the same year, it also attempted to implement a ten-year strategy entitled the Public Sector Reinvention and Modernization Strategy (PUSERMOS) that intended to, among other objectives, reduce the civil service to just 2,500 staff by reallocating most staff either to the Metropolitan, Municipal, and District Assemblies (MMDAs) or to subvented agencies, such as universities, health services, and the highways authority (IMF 1999). An Economic Management Capacity Building Project-Public Sector Reform Program from 2005 to 2011 funded by the World Bank and DfID was also rated "unsatisfactory" by its conclusion (World Bank 2010). Public sector reform was again on the agenda in 2010 with a proposed Presidential Delivery Unit Model (see World Bank 2010) as well as in 2014 as Ghana began negotiating with the IMF to secure financial assistance (Bigg and Kpodo 2014).

A number of indicators confirm that Ghana's state capacity, measured by public sector performance and management, remains sub-standard. For instance, Figure 3.3 focuses on some of the governance variables underlying the Ibrahim Index of African Governance (IIAG). Although there are many governance datasets, the advantage of the IIAG is that it builds on more than thirty independent African and global databases, including from the World 


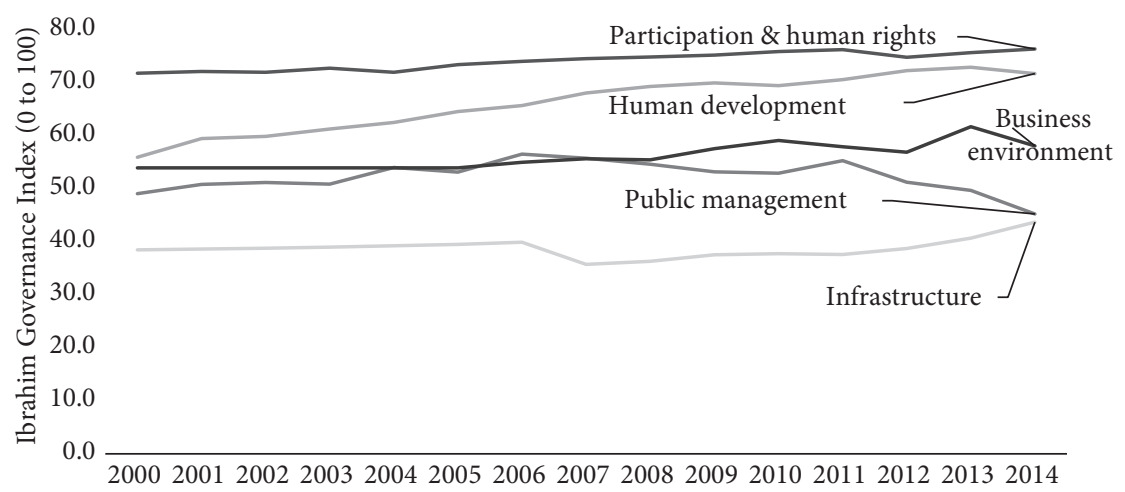

Figure 3.3. Trends in Ghana's governance profile, 2000-14

Source: Mo Ibrahim Foundation, Ibrahim Index of African Governance (IIAG). Available at: http:// mo.ibrahim.foundation/iiag/downloads/.

Bank and the African Development Bank. Using a scale ranging from 0 to 100, with higher scores indicating better performance, Ghana's does well with respect to participation and human rights, confirming the country's democratic strengths. Moreover, as already noted, there have been clear improvements in education, health, and social protection throughout the 2000s, which accounts for the positive "human development" performance. While the business environment and infrastructure are lower, the most striking trend is with regards to "public management," which is the only indicator that has actually declined over the last fourteen years. ${ }^{15}$

Table 3.2 below also indicates that Ghana performs worse on this indicator than a number of other Africa countries. The Table includes a mixture of wellrecognized high-capacity African countries (e.g., Botswana, Rwanda, and South Africa), countries that underwent democratic transitions in the early 1990s (e.g., Benin, Senegal), countries that underwent SAPs at the same time as Ghana (e.g., Malawi, Tanzania, Uganda, Zambia), and other West African economies (e.g., Côte d'Ivoire, Nigeria). As of 2014, Ghana was the worst ranked for this indicator among this sample. Moreover, Ghana was only one of

\footnotetext{
15 "Public management" includes statistical capacity, budget management, ratios of revenues to expenditures, fiscal policy, external debt service to exports, revenue collection, access to financial records of state companies, and quality of public administration according to the extent to which civilian government is structured to design and implement government policy effectively. When the latter category is disaggregated even more, this captures policy coordination and responsiveness, service delivery and operational efficiency, merit and ethics, pay adequacy, and management of the wage bill (see the metadata explanations found at the Mo Ibrahim Foundation IIAG website: http:// mo.ibrahim.foundation/iiag/).
} 
Table 3.2. Comparisons of public management across selected African countries (Ibrahim Index of African Governance, ranging from 0-100)

\begin{tabular}{lccr}
\hline Country & \multicolumn{3}{c}{ IIAG Index } \\
\cline { 2 - 4 } & $\mathbf{2 0 0 0}$ & $\mathbf{2 0 1 4}$ & Change \\
\hline Benin & 53.5 & 55.9 & 2.4 \\
Botswana & 66.5 & 67.6 & 1.1 \\
Côte d'Ivoire & 37.6 & 47.0 & 9.4 \\
Ghana & $\mathbf{4 8 . 9}$ & 45.1 & -3.8 \\
Kenya & 51.9 & 56.5 & 4.6 \\
Malawi & 39.6 & 47.9 & 8.3 \\
Mozambique & 42.3 & 56.6 & 14.4 \\
Nigeria & 42.8 & 51.8 & 9.0 \\
Rwanda & 45.2 & 60.7 & 15.5 \\
Senegal & 56.8 & 58.7 & 1.9 \\
South Africa & 74.7 & 71.6 & -3.1 \\
Tanzania & 53.5 & 55.3 & 1.8 \\
Uganda & 45.7 & 49.2 & 3.5 \\
Zambia & 38.1 & 51.3 & 13.2 \\
\hline
\end{tabular}

Source: Mo Ibrahim Foundation, Ibrahim Index of African Governance (IIAG). Available at: http://mo.ibrahim.foundation/iiag/downloads/.

two countries to have experienced a decline in its public sector management between 2000 and $2014 .^{16}$

This is particularly notable given that Ghana's civil service is relatively large compared with other African countries. For instance, based on the 2000 census, the number of public employees in administration, defense, education, and health as a share of the population was 2.1 percent while the equivalent average for the African region was 1 percent (see also WB 2011). A decade later, the number of people working in the formal public sector had doubled from 388,020 to 639,260 people, equivalent to approximately 1 public servant for every 40.6 people. ${ }^{17}$ According to a World Bank public expenditure review, a large share of expenditures in the social sectors, including up to 80 percent in the education sector, was actually allocated to personal emoluments and administration (WB 2011).

Why is this important? One key reason is that stronger public sector management can provide a bulwark against corruption and misuse of public

\footnotetext{
${ }^{16}$ Ghana has performed relatively well in raising taxes as a share of GDP. However, the main tax agencies, including the National Revenue Secretariat, the Customs, Excise, and Preventive Services (CEPS), and the Internal Revenue Service have recruitment, training, and promotion policies that are separate from those used in the main civil service (see Terkper 1995).

17 This was calculated from the 2010 Census population, which was $24,658,823$.
} 
resources that could be better invested in stimulating productive economic activities, including infrastructure. A second reason is that it is reflective of the degree of policy coordination within the civil service, which can help determine whether there are large gaps between policy formulation and implementation. In addition to these oversight and coordination roles, the developmental state literature discussed earlier emphasized the importance of a more capable bureaucracy for proactively selecting sectors and industries to prioritize in order to generate economic transformation.

\subsection{Weak State-Business Relationships}

A third governance hindrance to structural transformation in Ghana is the persistent inability of the government to engage with the private sector in a manner that in other contexts has facilitated the identification of sectoral priorities and helped overcome bottlenecks to performance (see, e.g., Maxfield and Schneider 1997; Rodrik 2008). Under Rawlings' PNDC regime, the government ignored the private sector and during the first decade of democracy, he actively politicized it through the selective distribution of SOEs. While the NPP rhetorically committed to a more interactive relationship with business, signified by President Kufuor's call for a Golden Age of Business, observers suggest that this ultimately resulted in more superficial overtures than substantive outcomes.

More specifically, during the PNDC's regime from 1983 to 1992, businessmen in sectors as diverse as textiles, timber, tobacco, and pharmaceuticals actively were harassed and targeted for arrest or property confiscation since any sign of capital accumulation suggested potential violation of state regulation of the economy (Kraus 2002). In fact, many businessmen had been charged with economic sabotage before the National Public Tribunal, which is outside the normal judicial system (Tangri 1999). As Opoku (2010: 86) notes, "One reason for the lack of consultation between government and business between 1983 and 1991 was Rawlings' self-proclaimed role as the defender of the 'common man'; his need to periodically reaffirm his commitment to the poor gave rise to continuing denunciations of business." In fact, Rawlings even refused to meet publicly with private sector representatives until 1988, five years after the ERP had been signed (Handley 2007). The government provided little support to businesses that had to repay loans to foreign banks even as the ERP was causing the currency to devalue. In addition, the stabilization policies involved tight credit and high interest 
rates, which resulted in denying capital to the indigenous private sector despite the protests of Ghanaian business associations (Kraus 2002). Trade liberalization exacerbated the weakness of the private sector, contributing to the collapse of 1,200 local industries between 1983 and 1992 and an additional 400 each year between 1995 and 1999 (Nugent 2004; Opoku 2010). ${ }^{18}$

The onset of democracy facilitated greater interaction between the NDC and the private sector. For instance, in 1995, the Private Enterprise Foundation (PEF) was established with members from the Federation of Associations of Ghana Exporters, Ghana Chamber of Mines, and the Association of Ghana Industries and it had credible levels of engagement with the government. When the NDC published its development strategy document in 1995, entitled Ghana Vision 2020, it emphasized that poverty reduction and transformation to middle-income status needed to rely on agro-processing and light manufacturing (Aryeetey and Fosu 2007). Soon thereafter, an act of parliament established the Ghana Free Zones Board (GFZB) to promote economic development.

On the other hand, Rawlings' democratic tenure also coincided with a partisan bias in economic decision-making. When the World Bank began pushing divestiture of SOEs, the government ensured that many of the beneficiaries from these sales were NDC party members (see Gyimah-Boadi 1997; Handley 2008; Kraus 2002; Opoku 2010). In fact, the Divestiture Implementation Committee was almost completely staffed by NDC loyalists (Pitcher 2012), and all final sales had to be approved by the President's Office (see Leite et al. 2000). While the NDC established the Council of Independent Business Associations, it was regarded as a "creature of government" aimed at distributing patronage to partisan supporters (see Opoku 2010). More generally, the NDC preferred engaging with multinational business, which was considered apolitical, rather than the domestic private sector, which was assumed to be more aligned with supporting the avowedly pro-business NPP (see Kraus 2002). ${ }^{19}$

When the NPP acceded to the presidency under the leadership of John Kufuor, the new administration attempted to reverse some of the key policies and tendencies of the NDC. For instance, it rejected Ghana Vision 2020.

\footnotetext{
${ }^{18}$ Indeed, over the course of the reforms in the 1980s, the rate of growth in manufacturing valueadded had fallen from 13 to 1 percent (Opoku 2010).

${ }_{19}$ The NPP is the modern incarnation of the liberal and elitist political traditions of Kofi Busia and J. B. Danquah who in turn came from the Ashanti region and established the United Gold Coast Convention in 1947. The prominence of cocoa and timber sectors in Ashanti resulted in Akan-speakers having a relatively large presence in the modern-day business community.
} 
Instead, it inserted its own priorities from the NPP manifesto into the Poverty Reduction Strategy (PRS) needed to access HIPC support at the time, including an emphasis on modernizing agriculture, promoting agro-processing and strengthening the private sector through access to long-term credit (see Whitfield and Jones 2009). Moreover, in 2001, Kufour established a Ministry of Private Sector Development (MPSD) that was tasked with catalyzing a "Golden Age of Business" by providing a liberalized trade and investment environment as well as promoting an industrial policy to attract manufacturers and establish value-added jobs. The MPSD was also tasked with creating a Captains of Industry program to match university students with Ghanaian businessmen and women. In addition, the NPP government reinforced the export zones approached initiated by the NDC by establishing an Export Development and Investment Fund (EDIF) in 2001 in order to develop and promote the country's exports (Asem et al. 2013).

During the same year, the Kufour launched the President's Special Initiatives (PSIs), which were aimed at boosting investment in targeted areas such as cassava starch, salt, textiles, garments, and oil palm (Arthur 2006). Another contrast from the Rawlings' era was that Kufuor held biannual meetings with the Ghana Investors Agency Council, which consisted of members of various business associations. These meetings allowed the business community to provide feedback on how policies affected the investor climate, with one concrete outcome being the reduction of corporate taxes in 2003 (Arthur 2006). In addition, under Kufuor, the private sector was often given the opportunity to review the annual proposed budget and provide input accordingly before it was presented to parliament (see Ackah et al. 2010).

Figure 3.4 provides one indication that the Kufuor regime signaled a more positive policy environment for the business community in at least one regard, i.e., domestic credit. As a share of GDP, this measure captures whether financial institutions provide resources to the private sector through, for example, loans and trade credits, and its generally used as a measure of the size and health of the private sector. Under the NPP, domestic credit to the private sector almost doubled from the time of Rawlings' presidency and was four times higher than under his one-party regime.

Nevertheless, Table 3.3 still suggests that from a comparative standpoint, Ghana ranks relatively poorly on this measure both within Africa and from a global perspective. In fact, as recently as 2010, major fruit-processing and agricultural-export companies faced interest rates as high as 32 percent when seeking loans from commercial banks in Ghana (see McMillan 2013). According to Ghana's most recent enterprise survey, which surveyed 720 private 


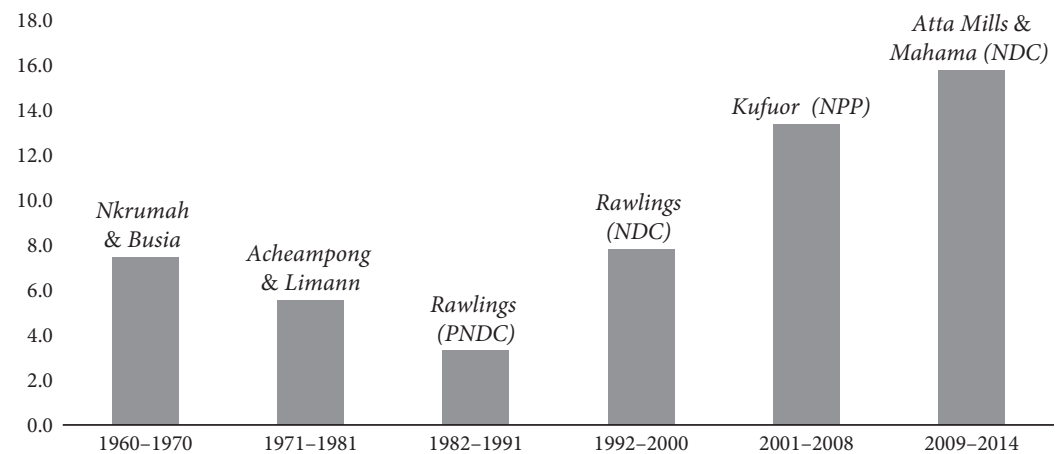

Figure 3.4. Domestic credit to the private sector (average \% of GDP)

Notes: The best score on the index is a 100. See descriptions of what the indicators encompass in the footnote 15 , this chapter.

Source: Calculated from World Development Indicators database (2016).

Table 3.3. Comparisons of domestic credit to the private sector (\% of GDP), 2014

\begin{tabular}{llr}
\hline Category & Country & $\mathbf{2 0 1 4}$ \\
\hline Africa & Benin & 22.9 \\
& Botswana & 31.9 \\
& Ghana & 19.9 \\
& Kenya & 34.4 \\
& Malawi & 16.2 \\
& Mozambique & 31.8 \\
& Nigeria & 14.5 \\
& Senegal & 33.2 \\
& Tanzania & 13.8 \\
& Uganda & 14.4 \\
& Zambia & 17.1 \\
Emerging Markets & Brazil & 62.6 \\
& China & 130.0 \\
& Mexico & 27.6 \\
& South Africa & 151.5 \\
High Income & Turkey & 57.9 \\
& Germany & 83.5 \\
& Japan & 178.4 \\
& United Kingdom & 165.4 \\
& United States & 180.7 \\
\hline
\end{tabular}

Source: World Development Indicators database, 2016. 
sector firms, access to finance was overwhelmingly identified as the main obstacle to growth (World Bank 2014).

More generally, despite the efforts of the NPP, the anticipated expansion of the private sector and transformation of the economy did not materialize to a significant degree. One challenge was that the PSI Secretariat, which was tasked with implementing the PSIs, received minimal public financing in practice. Whitfield et al. (2015) note that the minister of finance at the time opposed the PSIs because he felt such an undertaking should be instead financed by the private sector rather than the government. This, along with competing demands for several other government programs and an energy crisis reduced the budgets requested for it by the Ministry of Trade and Industry. ${ }^{20}$ The PSIs, along with a strategy to modernize agriculture through support from the Millennium Challenge Corporation, were never informed by significant input from key actors within the industry, undermining the substantive commitment of the government to involve the private sector (Whitfield 2010). Perhaps as a consequence of the Rawlings' era legacy, Booth et al. (2005) found that under the NPP, the business community increasingly preferred to lobby for special treatment through informal channels with individual politicians rather than to press for better conditions for the private sector more broadly via institutionalized business associations.

\subsection{Implications for Agricultural Transformation}

The dynamics noted above, including a preoccupation with the short-term goal of winning votes, insufficient public sector capacity, and politically biased linkages with the private sector, have had an impact not only on the broad economic transformation but also on Ghana's repeated attempts to pursue high value-added agriculture. This has manifested in at least four ways.

First, the government hesitates to pursue reforms that could alienate stakeholders who are powerful in either financial or political terms. For instance, there has been reluctance to tackle land reform, which would have substantial implications for the government's relationship with powerful traditional authorities. Typically, the central government, whether NDC or NPP, has followed a policy of non-interference in chieftancy affairs, particularly over

\footnotetext{
${ }^{20}$ There may have also been a political motive as well since both the minister of finance and the head of the PSI secretariat were competing against each other in the 2004 NPP party primaries (see Whitfield et al. 2015).
} 
Table 3.4. Sources of communal conflict in Ghana

\begin{tabular}{lc}
\hline What is the major source of conflict in your community? & Percentage \\
\hline Indebtedness & 4.5 \\
Ethnic/tribal conflict & 9.9 \\
Political differences & 9.5 \\
Marriage & 6.2 \\
Land disputes & 31.9 \\
Chieftancy & 30.9 \\
Religion & 0.7 \\
Other & 6.4 \\
Total observations & 1,410 \\
\hline
\end{tabular}

Notes: The sample is only for those who noted that there is tension/conflict in their respective communities

Source: GLSS 6, conducted in 2012-13.

land allocation under customary tenure, which is the tenancy system for approximately 80 percent of Ghana's land (Lavers and Boamah 2016; Ubink 2008). One key reason is that chiefs in many parts of Ghana can mobilize large numbers of rural voters during election periods (see Bonoff 2016). Nevertheless, land tenure security is a major constraint in Ghana. As seen in Table 3.4, land disputes are the overriding cause of conflict in Ghanaian communities. When further disaggregated by regions, land disputes are the top source of conflict in six of Ghana's regions (Central, Greater Accra, Volta, Eastern, Upper East, and Upper West). Goldstein and Udry (2008) find that insecure land rights in Ghana have significant effects on discouraging smallholders to invest in soil fertility. In the aftermath of the 2008 food crisis, when approximately twenty foreign companies attempted to acquire land in Ghana to produce jatropha and sugarcane for biofuels, the lack of clarity on land tenure created a very confusing environment for both smallholders and foreign investors (see Ahwoi 2010; Boamah 2014; Schoneveld et al. 2010).

More generally, Throup et al. (2014) observe that large-scale commercial farming investment, by both domestic and foreign investors, will not proceed at scale in Ghana until investors are assured that no new stakeholders will emerge to claim the land after a deal is completed. This is a critical observation given that the government views enhancing commercial agriculture and strengthening value chains as a major route towards modernizing agriculture, evidenced by the Ghana Commercial Agricultural Project launched in 2012. ${ }^{21}$

21 See: http://mofa.gov.gh/site/?page_id=7036. 
For instance, Amanor (2013) points to a number of delays for agro-processing investors linked to ongoing land disputes between chiefs or held up in the courts. McMillan (2013) also points to the challenge of land tenure insecurity for the Blue Skies processed-fruit company in Ghana. Due to land tenure disputes, many commercial investors prefer to rely on outgrower schemes or nucleus schemes with smallholders rather than invest in new land, but these arrangements are also fraught with risks (Throup et al. 2014). The government certainly recognizes the problem of tenure insecurity, and even noted this as a binding constraint within its Food and Agriculture Sector Development Policy (FASDEP II). Yet, some of the modalities for addressing the challenge, such as the introduction of Customary Land Secretariats, have not gone far enough in achieving good land governance (see Biitir and Nara 2016; Lavers and Boamah 2016).

Secondly and relatedly, the government hesitates to pursue the preferences of those actors who are numerically small and insignificant for winning elections, even if they have essential technical and business knowledge. This has been apparent in a number of cases. For instance, the NPP government actively tried to push Ghana into cocoa processing rather than just cocoa production. Thus, it reached out to various multinational cocoa processors and promised them a 20 percent discount on "light" cocoa beans, which are smaller beans from a second harvest, in exchange for establishing processing facilities in Ghana. Three firms, Cargill, Callebaut, and Archer Daniels Midland accepted the offer, which in turn also spurred domestic investments in processing factories. Due to low output in the 2000s, Cocobod often was unable to uphold its contract for light beans to processors. Since Cocobod sells its beans on forward contracts, losing a portion of its output to the processors can hurt its ability to finance the management of the company as well as eat into the resources it uses to stabilize the producer price for smallholders. While processing coincided with the NPP's belief in economic nationalism, it decided that it would be politically suicidal to alienate the interests of thousands of smallholders in favor of the demands of just a handful of processors (see Whitfield and Buur 2014).

A similar dynamic was apparent with respect to the Palm Oil PSI, which began in 2002. Domestic demand was rising for palm oil and domestic production appeared a possible solution for decreasing imports. In addition, a senior NPP member was aware of the success of Felda in Malaysia, one of the world's largest palm oil estates, and encouraged Kufuor to visit that country to learn how to strengthen the sector back in Ghana (Whitfield et al. 2015). A palm oil committee was established by the PSI secretariat, which included 
individuals experienced in the sector as well as representatives from Ghana's existing palm oil estates. They emphasized that the PSI would need to involve investments in infrastructure and energy, incentive schemes to encourage private investment, and various land tenure reform modalities to expand existing plantations. However, the PSI Secretariat ultimately decided to follow the policy design recommendations of a small coterie of NPP politicians rather than the sector experts and estate owners, an outcome that Whitfield et al. (2015) attribute to the latter's small numbers and weak influence. ${ }^{22}$ More broadly, an extensive in-depth study of agro-processing firms in Ghana revealed that successful agro-enterprises were more likely to be politically connected, resulting in unfair information advantages and disproportionate credit opportunities (see Brüntrup et al. 2014).

The experience of the oil palm PSI is also reflective of a third dynamic, which is a lack of long-term commitment to initiatives that require a high level of implementation capacity. Oil palm production typically involves large tracts of contiguous land, which was not possible to organize in Ghana due to overlapping claims to land tenure. Instead, smallholders were aggregated into larger plots, known as Corporate Village Enterprises (COVEs), in various locations. Twentynine nurseries were also established to produce oil palm seedlings that would then be bought by the Secretariat and distributed to COVEs (Asante 2012). Credit initially was provided to smallholders in order for them to hire labor on these larger plots. Yet, despite the anticipated 300,000 hectares of land that were to be devoted to oil palm, only 30,000 hectares were under cultivation by 2008 . Moreover, by the time the PSIs were shut down, very few of the nurseries were sustainable. Asante (2012) found that smallholders were overstretched after government financial support to hire labor had dried up, resulting in oil palm that could not be cultivated, and that the drip irrigation system used in the nurseries broke down frequently and was not replaced by the government. The only successful nurseries were those that belonged to already established estates that had installed a different type of irrigation system.

Finally, the government has shied away from taking on a more proactive and anticipatory role in promoting particular agro-industrial sectors. The case of pineapples is instructive in this regard. In the 1980s, a handful of Ghanaian investors, who were mostly urban professionals or public sector workers, recognized the potential of pineapple exports to Europe based on the success in this sector by neighboring Côte d'Ivoire. As Ghana began to demonstrate

\footnotetext{
${ }^{22}$ There were only four large-scale oil palm estates and four medium-sized private estates (Asante 2012).
} 
success in the industry, these investors focused on meeting volume demands and gave minimal attention to production processes that improve quality or to institutionalizing formal quality control measures. They accorded little regard for investing in technological innovation, skilled labor, infrastructure, and export marketing, and they failed to engage in collective action to ensure national competitiveness within the sector. Aside from a few ad hoc programs, neither the government nor the donors gave much support to the industry due to their preferred interest in supporting smallholder production (Whitfield 2012). While pineapples remain one of Ghana's major horticultural exports, the country's export potential has declined over the 2000s, from a zenith of 71,000 tons in 2004 to approximately 35,000 per year since then. The weakness of the sector is attributed to the inability of Ghana to quickly adapt a new variety, MD2, which was developed by Costa Rica and is now the preference among European consumers (Fisher 2013). Whitfield (2012:319) contrasts the Ghanaian experience with Costa Rica's where the government supported the pineapple industry by providing tax credits, export incentives, access to land, and investment in agricultural research and development: "The pineapple case shows that competitive horticulture export industries cannot be made from the efforts of individual entrepreneurs alone."

The exception proves the norm, and this is perhaps most apparent with respect to cassava. The Cassava PSI model from the mid-2000s focused on creating a cassava starch industry for export. Consequently, a starch processing factory was built and an outgrower model was used for smallholder cassava producers to supply it with raw cassava. However, smallholders reneged on their contracts whenever prices in traditional domestic markets were high (Gatune 2016). Moreover, since the raw cassava needed to be sent for processing within twenty-four hours after being uprooted, having only one factory (in the Central Region) proved insufficient given the state of road infrastructure, resulting in a huge littering of cultivated cassava on the country's roadways (Arthur 2006). The Cassava PSI was "liquidated" and shut down in 2006 (Asante 2012). However, in 2012, the government sought to revive cassava processing by providing a 10 percent reduction in excise taxes to companies that used raw material inputs. Guinnness Ghana Breweries Limited took advantage of this incentive to create a beer based on cassava (Oxford Business Group 2013). ${ }^{23}$ In this case, the government pursued activist policies for attracting business that require relatively low maintenance or outlays of scarce resources. This proved more successful than simply launching a highly

\footnotetext{
${ }^{23}$ This is called Ruut Extra Premium Beer.
} 
visible and political initiative, such as the PSIs, which had minimal private sector input in design and implementation.

\subsection{Conclusions}

This chapter has shown that Ghana's reputation for upholding political rights and civil liberties since the country's democratic transition in 1992 is well deserved. As Africa's only institutionalized two-party system, competitive elections have enforced a commitment to the poor and a broad swathe of voters, evidenced by an impressive national health insurance scheme and an extensive social transfer program. Resources also have been heavily invested in health and education, resulting in substantial improvements in social outcomes. Foreign direct investment is attracted by the country's political stability and openness. Compared to the country's years of political instability prior to the 1980s, when ideological differences resulted in high levels of policy volatility, substantive partisan differences between the NDC and NPP have narrowed on key issues. As Throup et al. (2014: 155) note with respect to agriculture, there is now a bi-partisan consensus on key policies: "the peasantry must be encouraged, nontraditional crops must be promoted, development must be brought to the North [through the Savannah Accelerated Development Authority], and investment on infrastructure should be prioritized."

At the same time, the imperative of winning elections has sometimes resulted in a layering of new priorities onto existing development strategies in order for the party in office to show its imprint, as witnessed with the NPP's disposal of Vision 2020 and the creation of the PSIs. Moreover, deficit spending around elections has often increased interest rates, weakened the currency, and increased the cost of credit which, along with the absence of reliable electricity, all undermine private sector activity (see Arze del Granado and Daal 2014). Whitfield (2010: 734) further argues that the absence of strong coalitions for structural transformation, in agriculture and more broadly, has reduced successive government's incentive to prioritize facilitating policies:

General voter concerns also place stress on the provision of social services and infrastructure much more than on agricultural policies, except for requests for fertilizer subsidies. In contrast, not much pressure is exerted on government by organized interest groups, and especially not in the area of productive sector policies... In an economy where much of the economic elite are in construction, real estate, financial services, and trading (import and distribution), there are few large and organized trade associations... 
Thus there has not been a big pull within society to deliver a strategy for economic transformation.

While the public may want the government to provide more employment, there is little popular understanding or pressure for the types of policies that would facilitate that outcome.

To achieve more substantive transformation in general and within the agricultural sector in particular, the government needs to learn from its own history and from some of the positive lessons of developmental states in other regions of the world. Under Rawlings' tenure of the 1980s, a technocratic set of bureaucrats in the Ministry of Finance was insulated from popular pressures and able to push through difficult reforms with long-term gains but shortterm challenges. The authoritarian regime may have facilitated these dynamics but given the disastrous outcomes under previous autocratic presidents in Ghana, the more essential component was Rawlings' leadership and commitment. Both authoritarian and democratic developmental states in East Asia, Mauritius, South Africa, and Botswana, have been characterized by a much broader degree of technocratic capacity throughout the public sector and a higher level of "embedded autonomy" vis-à-vis the business community. The latter two qualities have been largely absent in Ghana, despite repeated efforts at public sector reform and rhetorical commitments to the private sector.

Consequently, achieving transformation in Ghana will require more activist economic policies within the confines of the state's capacity, without forfeiting commitments to human rights and free and fair political competition. These options may address at least two of Hausmann et al.'s (2008) three market failures, namely addressing coordination externalities and providing missing public inputs while leaving the task of addressing self-discovery externalities for high capacity contexts. Concretely, this may translate into providing tax incentives, credit support schemes to key sectors, land tenure reforms, and institutional modalities to help solve coordination problems that inhibit Ghana's competitiveness in promising industries. To be effective, these policies would need to depart from past tendencies to favor partisan private sector actors and instead prioritize efficiency and innovation.

\section{References}

Abdulai, Abdul-Gafaru, and David Hulme. 2014. "The Politics of Regional Inequality in Ghana: State Elites, Donors and PRSPs." Effective States and Inclusive Development (ESID) Working Paper No. 41, University of Manchester. 
Acemoglu, Daron, and James Robinson. 2006. Economic Origins of Dictatorship and Democracy. New York: Cambridge University Press.

Acemoglu, Daron, and James Robinson. 2012. Why Nations Fail: The Origins of Power, Prosperity, and Poverty. New York: Crown Publishers.

Acemoglu, Daron, Simon Johnson, and James Robinson. 2003. "An African Success Story: Botswana," in Dani Rodrik (ed.), In Search of Prosperity: Analytic Narratives on Economic Growth. Princeton, NJ: Princeton University Press, 80-120.

Ackah, Charles, Ernest Aryeetey, Joseph Ayee, and Ezekiel Clottey. 2010. "StateBusiness Relations and Economic Performance in Ghana." Institutions for Propoor Growth (IPPG) Discussion Paper Series No. 35. University of Manchester.

Africa Confidential. 2016. "It's the Contract Election." March 4. Available at: http://www.africa-confidential.com.

Ahwoi, Kwesi. 2010. “Government's Role in Attracting Viable Agricultural Investment: Experiences from Ghana." Paper presented at the World Bank Annual Conference on Land Policy and Administration, April 26-27, Washington, DC.

Akufo-Addo, Nana. 2017. "Message on the State of the Nation by the President of the Republic, Nana Addo Dankwa Akufo-Addo, on the Occasion of the State Opening of Parliament on Tuesday, February 21, 2017.” Available at: https:// www.ghanabusinessnews.com/wp-content/uploads/2017/02/State-of-the-NationAddress_2017.pdf.

Amanor, Kojo Sebastian. 2013. "Expanding Agri-business: China and Brazil in Ghanaian Agriculture." IDS Bulletin 44(4): 80-90.

Amsden, Alice. 1989. Asia's Next Giant: South Korea and Late Industrialization. Oxford: Oxford University Press.

Anderson, Kym and Signe Nelson. 2013. "Updated Database of National and Global Distortions to Agricultural Incentives, 1955-2011.” Available at: www. worldbank.org/agdistortions.

Ansell, Ben. 2008. "Traders, Teachers, and Tyrants: Democracy, Globalization, and Public Investment in Education.” International Organization 62(2): 289-322.

Arthur, Peter. 2006. “The State, Private Sector Development, and Ghana's 'Golden Age of Business.'” African Studies Revie. 49(1): 31-50.

Aryeetey, Ernest, and Augustin Fosu. 2007. "Economic Growth in Ghana, 1960-2000," in Benno Ndulu, Stephen O’Connell, Jean-Paul Azam et al. (eds), The Political Economy of Economic Growth in Africa, 1960-2000, Volume 2: Country Case Studies. New York: Cambridge University Press, 289-321.

Aryeetey, Ernest, and Jane Harrigan. 2000. "Macroeconomic and Sectoral Development since 1970," in Ernest Aryeetey, Jane Harrigan, and Machiko Nissanke (eds), Economic Reforms in Ghana: The Myth and the Mirage. Trenton, NJ: Africa World Press, 5-31. 
Arze del Granado, Francisco Javier, and Wendell Daal. 2014. "High Twin Deficits Pose Risks to Ghana's Growth Outlook.” IMF Survey Magazine, May 13.

Asante, Elizabeth. 2012. “The Case of Ghana's President's Special Initiative on Oil Palm (PSI-Oil Palm).” DIIS Working Paper 2012: 11. Danish Institute for International Studies, Copenhagen, Denmark.

Asem, Freda, Matthias Busse, Robert Osei, and Magdalene Silberberger. 2013. "Private Sector Development and Governance in Ghana." International Growth Centre Working Paper.

Bates, Robert, and Steven Block. 2013. "Revisiting African Agriculture: Institutional Change and Productivity Growth." Journal of Politics 75(2): 372-84.

Baum, Matthew, and David Lake. 2003. "The Political Economy of Growth: Democracy and Human Capital." American Journal of Political Science 47(2): 333-47.

Bawumia, Mahamudu. 1998. "Understanding the Rural-Urban Voting Patterns in the 1992 Ghanaian Presidential Election: A Closer Look at the Distributional Impact of Ghana's Structural Adjustment Programme.” Journal of Modern African Studies 36(1): 47-70.

Berhanu, Kassahun, and Colin Poulton. 2014. "The Political Economy of Agricultural Extension Policy in Ethiopia: Economic Growth and Political Control.” Development Policy Review 32(S2): S197-S213.

Besley, Timothy, and Masayuki Kudamatsu. 2006. "Health and Democracy." American Economic Review 96(2): 313-18.

Bigg, Matthew Mpoke, and Kwasi Kpodo. 2014. "Ghana Starts Talks with IMF with Public Sector Reform on Agenda.” Reuters, September 16. Available at: http://www.reuters.com/article/ghana-economy-imf-idUSL3N0RH4SN20140916.

Biitir, Samuel, and Baslyd Nara. 2016. "The Role of Customary Land Secretariats in Promoting Good Local Land Governance in Ghana." Land Use Policy 50: 528-36.

Blanchet, N. J., G. Fink, and I. Osei-Akoto. 2012. “The Effect of Ghana's National Health Insurance Scheme on Health Care Utilization." Ghana Medical Journal 46(2): 76-84.

Blaydes, Lisa, and Mark Andreas Kayser. 2011. "Counting Calories: Democracy and Distribution in the Developing World." International Studies Quarterly 55: 887-908.

Block, Steven. 2002. "Political Budget Cycles, Democratization, and Economic Reform: The Case of Africa." Journal of Development Economies 67: 205-28.

Boamah, Festus. 2014. "How and Why Chiefs Formalize Land Use in Recent Times: The Politics of Land Dispossession through Biofuels Investment in Ghana." Review of African Political Economy 41(141). 
Boix, Carles. 2003. Democracy and Redistribution. New York: Cambridge University Press.

Bonoff, Nicole. 2016. "Traditional Authority in the State: Chiefs, Elections and Taxation in Ghana." PhD dissertation, University of California, San Diego.

Boone, Catherine. 2014. Property and Political Order in Africa: Land Rights and the Structure of Politics. New York: Cambridge University Press.

Booth, David. 2012. Development as a Collective Action Problem: Addressing the Real Challenges of African Governance. London: ODI for Africa Power and Politics Programme.

Booth, David, and Frederick Golooba-Mutebi. 2014. "Policy for Agriculture and Horticulture in Rwanda: A Different Political Economy?” Development Policy Review 32(S2): S173-S196.

Booth, David, Richard Crook, E. Gyimah-Boadi et al. 2005. "What Are the Drivers of Change in Ghana?" CDD/ODI Policy Brief 1. Accra and London: CDD and ODI.

Bräutigam, Deborah. 1997. "Institutions, Economic Reform, and Democratic Consolidation in Mauritius.” Comparative Politics 30(1): 45-62.

Bräutigam, Deborah, Lise Rakner, and Scott Taylor. 2002. "Business Associations and Growth Coalitions in Sub-Saharan Africa." Journal of Modern African Studies 40(4): 519-47.

Brender, A. and A. Drazen. 2005. "Political Budget Cycles in New versus Established Democracies.” Journal of Monetary Economics 52: 1271-95.

Brown, David, and Wendy Hunter. 1999. "Democracy and Social Spending in Latin America, 1980-1992.” The American Political Science Review 93(4): 779-90.

Brüntup, Michael, Tony Swetman, Mirja Michalscheck, and Felix Asante. 2014. "Factors of Success and Failure of Large Agro-enterprises (Production, Processing, and Marketing) a Pilot Study in Ghana: Results of Case Studies in the Fruit, Maize, and Palm Oil Sub-sectors." African Journal of Food, Agriculture, Nutrition and Development 13(5).

Bueno de Mesquita, Bruce, Alastair Smith, Randolph Siverson, and James Morrow. 2005. The Logic of Political Survival. Cambridge, MA: MIT Press.

Callaghy, Thomas. 1990. "Lost between State and Market: The Politics of Economic Adjustment in Ghana, Zambia, and Nigeria," in Joan Nelson (ed.), Economic Crisis and Policy Choice: The Politics of Adjustment in the Third World. Princeton, NJ: Princeton University Press, 257-320.

Callaghy, Thomas. 1987. "The State as Lame Leviathan: The PatrimonialAdministrative State in Africa," in Z. Ergas (ed.), The African State in Transition. London: Macmillan Press: 423-42.

Cammack, Diana, Tim Kelsall, and David Booth. 2010. "Developmental Patrimonialism? The Case of Malawi.” Working Paper No. 12. APPP, ODI. 
Campos, J. E., and H. L. Root. 1996. The Key to the Asian Miracle: Making Shared Growth Credible. Washington, DC: Brookings Institution.

Chang, Ha-Joon. 1994. The Political Economy of Industrial Policy. Basingstoke: Macmillan.

Cheng, Tun-Jen, Stephan Haggard, and David Kang. 1998. "Institutions and Growth in Korea and Taiwan: The Bureaucracy." Journal of Development Studies 34(6): 87-111.

Chung, Joanna. 2007. “Ghana Makes International Bond Debut.” Financial Times, September 27.

Collier, Paul. 2009. War, Guns, and Votes: Democracy in Dangerous Places. New York: Harper Collins.

Devarajan, Shantayanan, David Dollar, and Torgny Holmgren (eds). 2001. Aid and Reform in Africa. Washington, DC: The World Bank.

Deyo, Frederic. 1989. "Labor and Development Policy in East Asia." The Annals of the American Academy of Political and Social Sciences 505(September): 152-61.

Evans, Peter. 1995. Embedded Autonomy: States and Industrial Transformation. Princeton, NJ: Princeton University Press.

Evans, Peter, and James Rauch. 1999. "Bureaucracy and Growth: A Cross-national Analysis of the Effects of the 'Weberian' State Structures on Economic Growth." American Sociological Review 64(5): 748-65.

Feng, Yi. 1997. “Democracy, Political Stability, and Economic Growth.” British Journal of Political Science 27: 391-418.

Fisher, Martyn. 2013. “Ghana Endures Major Pineapple Slump.” Fresh Produce Journal, October 15. Available at: http://www.fruitnet.com/fpj/article/159652/ ghana-endures-major-pineapple-slump.

Gatune, Julius. 2016. "Cassava as a Driver of Innovation-The Case of Ghana and Nigeria," in Olugbenga Adesida, Geci Karuri-Sebina, and João Resende-Santos (eds), Innovation Africa: Emerging Hubs of Excellences. Bingley: Emerald Group: 239-82.

Geddes, Barbara. 2003. Paradigms and Sand Castles: Theory Building and Research Design in Comparative Politics. Ann Arbor, MI: University of Michigan Press.

Gerring, John, Philip Bond, William Barndt, and Carola Moreno. 2005. "Democracy and Economic Growth: A Historical Perspective." World Politics 57: 323-64.

Goldstein, Markus, and Christopher Udry. 2008. "The Profits of Power: Land Rights and Agricultural Investment in Ghana." Journal of Political Economy 116(6): 981-1022.

Gyimah-Boadi, E. 2007. “The Challenges Ahead.” Journal of Democracy 8(2): 78-91. 
Gyimah-Boadi, E. 2009. “A 'Liberal’ Developmental State in Ghana: An Emerging Paradigm for Democracy and Economic Growth?” Paper presented at the conference From Asymmetry to Symmetry? The West, Non-West and the Idea of Development as Conceptual Flow." University of Heidelberg, Germany, 13-16 July.

Gyimah-Boadi, E., and Richard Jeffries. 2000. “The Political Economy of Reform,” in Ernest Aryeetey, Jane Harrigan, and Machiko Nissanke (eds), Economic Reforms in Ghana: The Myth and the Mirage. Trenton, NJ: Africa World Press, 32-50.

Gyimah-Boadi, E., and H. Kwasi Prempeh. 2012. "Oil, Politics, and Ghana's Democracy." Journal of Democracy 23(3): 94-108.

Haggard, Stephan. 1990. Pathways from the Periphery: The Politics of Growth in the Newly Industrializing Countries. Ithaca, NY: Cornell University Press.

Haggard, Stephan, and Robert R. Kaufman. 2008. Development, Democracy, and Welfare States: Latin America, East Asia, and Eastern Europe. Princeton, NJ: Princeton University Press.

Hall, Peter, and David Soskice. 2001. Varieties of Capitalism: The Institutional Foundations of Comparative Advantage. New York: Oxford University Press.

Halperin, Morton, Joseph Siegle, and Michael Weinstein. 2005. The Democracy Advantage. New York: Routledge.

Handa, S., M. J. Park, R. O. Darko et al. 2013. "Livelihood Empowerment against Poverty Impact Evaluation." Carolina Population Center, University of North Carolina.

Handley, Antoinette. 2007. "Business, Government, and the Privatization of the Ashanti Goldfields Company in Ghana." Canadian Journal of African Studies 41(1): 1-37.

Handley, Antoinette. 2008. Business and the State in Africa: Economic Policymaking in the Neo-Liberal Era. New York: Cambridge University Press.

Harding, Robin. 2015. "Attribution and Accountability: Voting for Roads in Ghana." World Politics 67(4): 656-89.

Hausmann, Ricardo, Dani Rodrik, and Charles Sabel. 2008. "Reconfiguring Industrial Policy: A Framework with an Application to South Africa." CID Working Paper No. 168, Harvard University, Cambridge, MA.

Herbst, Jeffrey. 1993. The Politics of Reform in Ghana, 1982-1991. Berkeley, CA: University of California Press.

Holden, Joseph. 2012. "Rwanda: Overcoming the Industrial Policy Taboo," in M. Campioni and P. Noack (eds), Rwanda Fast Forward. London: Palgrave Macmillan, 126-44.

Howard, Marc Morjé, and Philip Roessler. 2006. "Liberalizing Electoral Outcomes in Competitive Authoritarian Regimes." American Journal of Political Science 50(2): 365-81. 
Huber, Evelyne, Thomas Mustillo, and John Stephens. 2008. "Politics and Social Spending in Latin America." The Journal of Politics 70(2): 420-36.

Hutchful, Eboe. 2002. Ghana's Adjustment Experience: The Paradox of Reform. Geneva: United Nations Research Institute for Social Development (UNRISD).

IMF. 1999. "Ghana: Selected Issues." IMF Staff Country Report No.99/3. Washington, DC: IMF.

IMF. 2017. "IMF Staff Concludes Visit to Ghana.” Washington, DC: IMF. Available at: https://www.imf.org/en/News/Articles/2017/02/10/pr1743-IMF-StaffConcludes-Visit-to-Ghana.

Jedwab, R., and R. D. Osei. 2012. “Structural Change in Ghana, 1960-2012.” IIEP Working Paper. Washington, DC: George Washington University, Institute for International Economic Policy.

Jeffries, Richard. 1992. "Urban Popular Attitudes towards the Economic Recovery Programme and the PNDC Government in Ghana." African Affairs 91(363): 207-26.

Johnson, Chalmers. 1982. MITI and the Japanese Miracle: The growth of industrial policy, 1925-1975. Stanford, CA: Stanford University Press.

Karakoc, Ekrem. 2010. “The Democracy and Equality Paradox: How Democracy has Increased Income Disparities in Postcommunist and Southern Europe.” $\mathrm{PhD}$ dissertation, The Pennsylvania State University.

Katzenstein, Peter. 1985. Small States in World Markets: Industrial Policy in Europe. Ithaca, NY: Cornell University Press.

Kaufman, Robert, and Alex Segura-Ubiergo. 2001. "Globalization, Domestic Politics, and Social Spending in Latin America: A Time-series Cross-section Analysis, 1973-1997." World Politics 53(4): 553-87.

Keefer, Philip. 2007. "Clientelism, Credibility, and the Policy Choices of Young Democracies.” American Journal of Political Science 51: 804-21.

Kelsall, Timothy. 2011. "Rethinking the Relationship between Neo-patrimonialism and Economic Development in Africa," IDS Bulletin. Vol. 42(2): 76-87.

Kelsall, Timothy. 2013. Business, Politics, and the State in Africa: Challenging the Orthodoxies on Growth and Transformation. London: Zed Books.

Khan, Mustaq. 2000. "Rents, Efficiency and Growth," in M. H. Khan and J. K. Sundaram (eds), Rents, Rent-Seeking and Economic Development: Theory and Evidence in Asia. Cambridge: Cambridge University Press, 21-69.

Killick, Tony. 2000. “Fragile Still: The Structure of Ghana's Economy 1960-94," in E. Aryeetey, J. Harrigan, and M. Nissanke (eds), Economic Reforms in Ghana: The Miracle and the Mirage. Oxford: James Currey: 51-67.

Kohli, Atul. 2004. State-Directed Development: Political Power and Industrialization in the Global Periphery. New York: Cambridge University Press. 
Kraus, Jon. 1991. "The Political Economy of Stabilization and Structural Adjustment in Ghana," in Donald Rothchild (ed.), Ghana: The Political Economy of Recovery. Boulder, CO: Lynne Rienner Publishers, 119-55.

Kraus, Jon. 2002. "Capital, Power and Business Associations in the African Political Economy: A Tale of Two Countries, Ghana and Nigeria." Journal of Modern African Studies 40(3): 395-436.

Lake, David, and Matthew Baum. 2001. "The Invisible Hand of Democracy: Political Control and the Provision of Public Services." Comparative Political Studies 34(6): 587-621.

Larbi, G. 1999. "The New Public Management Approach and Crisis States." UNRISD Discussion Paper No. 112. Geneva: United Nations Research Institute for Social Development.

Lavers, Tom, and Festus Boamah. 2016. “The Impact of Agricultural Investments on State Capacity: A Comparative Analysis of Ethiopia and Ghana." Geoforum 72: 94-103.

Leftwich, Adrian. 2010. "Beyond Institutions: Rethinking the Role of Leaders, Elites and Coalitions in the Institutional Formation of Developmental States and Strategies." Forum for Development Studies 37(1): 93-111.

Leftwich, Adrian. 1995. "Bringing Politics Back in: Towards a Model of the Developmental State." Journal of Development Studies 31(3): 400-27.

Leite, Sérgio, Anthony Pellechio, Luisa Zanforlin et al. 2000. Ghana: Economic Development in a Democratic Environment. Washington, DC: IMF.

Levitsky, Steven, and Lucan Way. 2010. Competitive Authoritarianism: The Emergence and Dynamics of Hybrid Regimes in the Post-Cold War Era. New York: Cambridge University Press.

LeVan, Carl. 2015. Dictators and Democracy in African Development. New York: Cambridge University Press.

MacLean, Lauren. 2010. Informal Institutions and Citizenship in Rural Africa: Risk and Reciprocity in Ghana and Côte d'Ivoire. New York: Cambridge University Press.

Martin, Matthew. 1993. "Neither Phoenix nor Icarus: Negotiating Economic Reform in Ghana and Zambia, 1983-1992," in Thomas Callaghy and John Ravenhill (eds), Hemmed In: Responses to Africa's Economic Decline. New York: Columbia University Press, 130-79.

Maxfield, Sylvia, and Ben Ross Schneider. 1997. Business and the State in Developing Countries. Ithaca, NY: Cornell University Press.

McCaig, Brian, Margaret McMillan, Inigo Verduzco-Gallo, and Keith Jefferis. 2015. "Stuck in the Middle? Structural Change and Productivity Growth in Botswana," NBER Working Paper No. 21029. Cambridge, MA: NBER. 
McMillan, Margaret. 2013. "Blue Skies: How One Firm Overcame 'Binding Constraints." Ghana Strategy Support Program (GSSP) Discussion Note No. 21. Washington, DC: IFPRI.

Meltzer, Allen, and Scott Richard. 1981. "A Rational Theory of the Size of Government." Journal of Political Economy 89(5): 914-27.

Mikell, Gwendolyn. 1989. "Peasant Politicisation and Economic Recuperation in Ghana: Local and National Dilemmas." The Journal of Modern African Studies 27(3): 455-78.

Mosley, Paul, and Blessing Chiripanhura. 2016. "The African Political Business Cycle: Varieties of Experience." Journal of Development Studies 52(7): 917-32.

Nordhaus, W. 1975. “The Political Business Cycle," Review of Economic Studies 42: 169-90.

Nugent, Paul. 1995. Big Men, Small Boys and Politics in Ghana: Power Ideology and the Burden of History. London: Pinter.

Nugent, Paul. 2004. Africa since Independence. London: Palgrave McMillan.

Nyanteng, V. K., and A. Wayo Seini. 2000. "Agricultural Policy and the Impact on Growth and Productivity, 1970-1995," in Ernest Aryeetey, Jane Harrigan, and Machiko Nissanke (eds), Economic Reforms in Ghana: The Myth and the Mirage. Trenton, NJ: Africa World Press, 267-83.

Oduro, Franklin, Mohammed Awal, and Maxwell Agyei Ashon. 2014. “A Dynamic Mapping of the Political Settlement in Ghana." Effective States and Inclusive Development (ESID) Working Paper No. 28. University of Manchester.

Ohemeng, Frank Louis Kwaku. 2011. "Institutionalizing the Performance Management System in Public Organizations in Ghana.” Public Performance of Management Review 34(4): 467-88.

Olson, Mancur. 1993. “Dictatorship, Democracy and Development.” American Political Science Review 87(3): 567-76.

Opoku, Darku. 2010. The Politics of Government-Business Relations in Ghana, 1982-2008. New York: Palgrave Macmillan.

Osei, Philip. 2000. "Political Liberalization and the Implementation of Value Added Tax in Ghana." The Journal of Modern African Studies 38: 255-78.

Oxford Business Group. 2013. The Report: Ghana. London: Oxford Business Group.

Pitcher, Anne. 2012. Party Politics and Economic Reform in African Democracies. New York: Cambridge University Press.

Poulton, Colin. 2014. "Democratization and the Political Incentives for Agricultural Policy in Africa.” Development Policy Review 32(S2): S101-S122.

Powell, M., and J. Round. 2000. "Structure and Linkage in the Economy of Ghana: A SAM Approach," in E. Aryeetey, J. Harrigan, and M. Nissanke (eds), Economic Reforms in Ghana: The Miracle and the Mirage. Oxford: James Currey: 68-87. 
Prempeh, H. K., and C. Kroon. 2012. The Political Economy Analysis of the Oil and Gas Sector in Ghana: The Implication for STAR-Ghana. Accra: STAR Ghana.

Przeworski, Adam, Michael Alvarez, Jose Antonio Cheibub, and Fernando Limongi. 2000. Democracy and Development. Cambridge: Cambridge University Press.

Quartey, Peter and Gloria Afful-Mensah. 2014. "Financial and Monetary Policies in Ghana: A Review of Recent Trends." Review of Development Finance 4(2): 115-25.

Rao, Sujata. 2007. "Ghana Sees Huge Demand for Debut 10-year Eurobond.” Reuters.

Rauch, James, and Peter Evans. 2000. "Bureaucratic Structure and Bureaucratic Performance in Less Developed Countries." Journal of Public Economics 75: 49-71.

Riedl, Rachel, and Tyler Dickovick. 2014. "Party Systems and Decentralization in Africa." Studies in Comparative International Development 49: 321-42.

Rimmer, Douglas. 1992. Staying Poor: Ghana's Political Economy, 1950-1990. New York: Pergamon Press.

Robinson, James. 2009. "Industrial Policy and Development: A Political Economy Perspective." Paper prepared for the 2009 World Bank ABCDE Conference in Seoul, Korea, June 22-24.

Rodrik, Dani. 1999. "Democracies Pay Higher Wages.” Quarterly Journal of Economics 114(3): 707-38.

Rodrik, Dani. 2000. "Institutions for High-Quality Growth: What They Are and How to Acquire Them." Studies in Comparative International Development 35 (3): 3-31.

Rodrik, Dani. 2008. "Normalizing Industrial Policy." Commission on Growth and Development, Working Paper No. 3. Washington, DC: The World Bank.

Rodrik, Dani. 2014. "The Past, Present, and Future of Economic Growth," in Franklin Allen, Jere Behrman, Nancy Birdsall et al. Towards a Better Global Economy: Policy Implications for Citizens Worldwide in the 21st Century. Oxford: Oxford University Press, 70-137.

Rogoff, Kenneth. 1990. “Equilibrium Political Budget Cycles.” American Economic Review 80(1): 21-36.

Ross, Michael. 2006. "Is Democracy Good for the Poor?" American Journal of Political Science 50(4): 860-74.

Rothchild, Donald. 1991. Ghana: The Political Economy of Recovery. Boulder, CO: Lynne Rienner Publishers.

Sachs, Jeffrey. 2005. The End of Poverty: Economic Possibilities for our Time. New York: Penguin Books.

Sandbrook, Richard. 2005. "Origins of the Democratic Developmental State: Interrogating Mauritius.” Canadian Journal of African Studies 39(3): 549-81. 
Schneider, Ben Ross. 1999. The Developmental State. Ithaca, NY: Cornell University Press.

Schneider, Ben Ross. 2010. "Business Politics in Latin America: Patterns of Fragmentation and Centralization," in D. Coen, W. Grant, and G. K. Wilson (eds.), The Oxford Handbook of Business and Government. New York, United States: Oxford University Press.

Schneider, Ben Ross. 2013. "Institutions for Effective Business-Government Collaboration: Micro Mechanisms and Macro Politics in Latin America.' InterAmerican Development Bank (IDB) Working Paper Series No. IDB-WP-418. Washington, DC: IDB.

Schoneveld, G., L. German, and E. Nutakor. 2010. “Towards Sustainable Biofuel Development: Assessing the Local Impacts of Large-scale Foreign Land Acquisitions in Ghana." Paper presented at the Annual World Bank Conference on Land Policy and Administration.

Sen, Kunal. 2015. “The Political Determinants of Economic Growth: An Analytical Review," in Sam Hickey, Kunal Sen, and Badru Bukenya (eds), The Politics of Inclusive Development: Interrogating the Evidence. Oxford: Oxford University Press, 35-59.

STAR-Ghana (Strengthening Transparency, Accountability, and Responsiveness in Ghana). 2011. Political Economy of Ghana and Thematic Strategy Development for STAR-Ghana. Accra: STAR and DfID.

Stasavage, David. 2005. "Democracy and Education Spending in Africa." American Journal of Political Science 49(2): 343-58.

Tangri, Roger. 1999. The Politics of Patronage in Africa: Parastatals, Privatization and Private Enterprise. Oxford: James Currey.

Terkper, Seth. 1995. “Ghana Tax Administration Reforms (1985-1993).” Harvard Development Discussion Papers. Cambridge, MA: Harvard Institute for International Development.

Taylor, Scott. 1999. "Race, Class and Neopatrimonial Politics in Zimbabwe," in Richard A. Joseph (ed.), State, Conflict, and Democracy in Africa. Boulder, CO: Lynne Rienner, 239-66.

Taylor, Scott. 2007. Business and the State in Southern Africa: The Politics of Economic Reform. Boulder, CO: Lynne Rienner Publishers.

Throup, David, Chris Jackson, Katherine Bain, and Rachel Ort. 2014. "Developing Commercial Agriculture in Ghana," in Verena Fritz, Brian Levy, and Rachel Ort (eds), Problem-Driven Political Economy Analysis. Washington, DC: World Bank, 143-74.

Tsikata, G. Kwaku. 1995. The Gold Sub-Sector and Economic Growth and Development in Ghana. Washington, DC: The World Bank. 
Tsikata, G. Kwaku, Yaw Asante, and E. M. Gyasi. 2000. Determinants of Foreign Direct Investment in Ghana. London: Overseas Development Institute.

Tsikata, Yvonne. 2001. "Ghana," in Shanta Devarajan, David Dollar, and Torgny Holmgren (eds), Aid and Reform in Africa: Lessons from Ten Case Studies. Washington, DC: The World Bank.

Ubink, Janine. M. 2008. "Struggles for Land in Peri-urban Kumasi and their Effects on Popular Perception of Chiefs and Chieftaincy," in J. M. Ubink and K. Amanor (eds), Contesting Land and Custom in Ghana: State, Chief, and the Citizen. Leiden: Leiden University Press, 155-82.

United Nations Development Program (UNDP). 2015. Ghana Millennium Development Goals, 2015 Report. New York: UNDP.

van de Walle, Nicolas. 2001. African Economies and the Politics of Permanent Crisis, 1979-1999. New York: Cambridge University Press.

Wade, Robert. 1990. Governing the Market: Economic Theory and the Role of Government in East Asian Industrialization. Princeton, NJ: Princeton University Press.

Weber, Max. 1978. Economy and Society. Berkeley, CA: University of California Press.

Weghorst, Keith and Staffan Lindberg. 2013. "What Drives the Swing Voter in Africa?” American Journal of Political Science 57(3): 717-34.

Whitfield, Lindsay. 2010. "The State Elite, PRSPs, and Policy Implementation in Aid-Dependent Ghana." Third World Quarterly 31(5): 721-37.

Whitfield, Lindsay. 2011. "Competitive Clientelism, Easy Financing and Weak Capitalists: The Contemporary Political Settlement in Ghana,” DIIS Working Paper 2011:27. Copenhagen: Danish Institute for International Studies.

Whitfield, Lindsay. 2012. "Developing Technological Capabilities in AgroIndustry: Ghana's Experience with Fresh Pineapple Exports." Journal of Development Studies 48(3): 308-21.

Whitfield, Lindsay, and Lars Buur. 2014. “The Politics of Industrial Policy: Ruling Elites and their Alliances." Third World Quarterly 35(1): 126-44.

Whitfield, Lindsay, and Emily Jones. 2009. "Ghana: Breaking out of Aid Dependence? Economic and Political Barriers to Ownership," in Lindsay Whitfield (ed.), The Politics of Aid: African Strategies for Dealing with Donors. Oxford: Oxford University Press, 185-216.

Whitfield, Lindsay, Ole Therkildsen, Lars Buur, and Anne Mette Kjær. 2015. The Politics of African Industrial Policy: A Comparative Perspective. New York: Cambridge University Press.

Wiggins, Steven, and Henri Leturque. 2011. “Ghana's Sustained Agricultural Growth: Putting Underused Resources to Work.” London: Overseas Development Institute. 
Williams, Tracy. 2009. An African Success Story: Ghana's Cocoa Marketing System. IDS Working Paper No. 318. Brighton: University of Sussex.

World Bank. 2009. Abolishing School Fees in Africa: Lessons from Ethiopia, Ghana, Kenya, Malawi, and Mozambique. Washington, DC: World Bank.

World Bank. 2010. Ghana's New Approach to Public Sector Reform: Focusing on Delivery. Global Expert Team, Public Sector Performance. Washington, DC: The World Bank.

World Bank. 2011. Republic of Ghana: Joint Review of Public Expenditure and Financial Management. Washington, DC: World Bank.

World Bank. 2014. Ghana: Country Profile 2013. Enterprise Surveys, Washington, DC: The World Bank.

World Development Indicators (WDI). 2016. Washington, DC: The World Bank. 


\section{PART II AGRICULTURE'S ROLE IN GHANA'S TRANSFORMATION}





\title{
4 \\ Ghana's Agricultural Transformation
}

\author{
Past Patterns and Sources of Change
}

Peter Hazell, Xinshen Diao, and Eduardo Magalhaes

Ghana's agriculture has performed reasonably well by African standards since the 1980s in terms of its growth, labor productivity, farm incomes, and the decline in rural poverty. Yet it has not exploited its potential to become a more important source of export earnings beyond cocoa, or to reduce the country's growing dependence on many imported foods. As noted in Chapter 2, agriculture needs to become a more powerful engine of growth in the future if Ghana is to sustain its economic transformation and continue to grow its national per capita income. There are also concerns about the sustainability of the recent pattern of agricultural growth with its heavy dependence on expanding the cropped area rather than shifting to more intensive farming practices that can increase land productivity. Given the importance of agriculture in the Ghanaian economy, this chapter and Chapters 5-9 aim to provide a comprehensive review of the agricultural transformation that has occurred, the underlying reasons for why it has evolved the way it has, and to identify options for future growth.

This chapter is structured as follows. Section 4.1 describes the main features of the agricultural transformation that has occurred since the policy reforms of the 1980s, focusing on changes in: a) production (area, yield, output, crop mix); b) technology (fertilizer, seeds, pesticides, mechanization); c) land and labor (employment, wages, productivity, farm size distribution); and d) rural incomes (farm income, nonfarm income diversification, total income, expenditure). We provide regional as well as national insights. Then in Section 4.2 we examine important factors that may have driven this pattern of transformation: the policy environment; growing population pressure on the land base; and rapid urbanization. Section 4.3 contains our conclusions. 


\subsection{Patterns of Agricultural Growth}

\subsubsection{Production}

From a production perspective, Ghana's agriculture has been a success story. Agricultural gross output in real terms grew by 4.5 percent per annum on average between 1994 and 2013 (Table 4.1). Cocoa grew by 5.6 percent, but the noncocoa crop sector also grew well, particularly roots and tubers and other crops (4.9 percent and 5.6 percent, respectively).

The overall performance of the noncocoa sector, and particularly of food staple crops, is favorable by African standards. Food staple crops have successfully grown to keep pace with population growth (about 2.5 percent per annum) and rising per capita incomes (about 2.9 percent), and apart from some modest imports of wheat (which cannot be grown domestically) and growing imports of rice, the country has remained largely self-sufficient in food staple crops. However, livestock production has grown more modestly (3.2 percent) and imports of poultry, other meats, and skimmed milk have grown rapidly.

Although cocoa accounts for the largest share of the crop area (22.8 percent) and for most of Ghana's agricultural exports, it only accounts for about 12 percent of the total value of agricultural production (Table 4.2). Cassava and yams are twice as important in terms of the value of their output, and bananas and plantains together are equally as important as cocoa. On the other hand, livestock (not shown in Table 4.2) accounts for only about 12 percent of the total value of agricultural production.

Table 4.1. Annualized growth rates of value of output by commodity groups, 1994-2013

\begin{tabular}{lc}
\hline & Annual growth rate (\%) \\
\hline Cereals & 2.9 \\
Roots and tubers & 4.9 \\
Cocoa & 5.6 \\
Other crops & 5.6 \\
Livestock & 3.2 \\
Agriculture total & 4.5 \\
\hline
\end{tabular}

Note: According to MOFA, staples include the following crops: maize, rice, cassava, yam, cocoyam, plantain, cowpea, and groundnut. In the table, we included plantain in roots and tubers, while cowpea and groundnut in other crops.

Source: Author's calculations using gross production value at constant 2004-6 US\$ (FAO 2016). 
Table 4.2. Composition of crop agriculture, 2012

\begin{tabular}{lrrrr}
\hline Crop & Land area (ha) & $\begin{array}{c}\text { Share of crop } \\
\text { land }(\%)\end{array}$ & VOP $\left(\mathbf{1 0 ^ { 3 } )}\right.$ & $\begin{array}{c}\text { Share of } \\
\text { VOP }(\%)\end{array}$ \\
\hline Cassava & 875,185 & 12.5 & $1,519,652$ & 23.6 \\
Cocoa, beans & $1,600,300$ & 22.8 & 913,192 & 12.3 \\
Groundnuts & 328,940 & 4.7 & 202,446 & 2.4 \\
Maize & $1,023,459$ & 14.6 & 147,642 & 1.9 \\
Yams & 421,558 & 6.0 & $1,693,203$ & 25.5 \\
Other tree crops & 645,514 & 9.2 & 194,307 & 2.8 \\
Pulses & 430,000 & 6.1 & 145,959 & 1.9 \\
Rice, paddy & 215,905 & 3.1 & 130,764 & 2.2 \\
Taro (cocoyam) & 193,998 & 2.8 & 269,407 & 3.8 \\
Banana+plantain & 346,860 & 4.9 & 756,803 & 11.1 \\
Vegetables & 64,466 & 0.9 & 378,508 & 5.6 \\
Sorghum+millet & 386,556 & 5.5 & 75,027 & 0.9 \\
Fruits & 408,427 & 5.8 & 378,183 & 5.7 \\
Others & 86,050 & 1.2 & 21,680 & 0.3 \\
Total & $7,027,218$ & 100.0 & $6,826,775$ & 100.0 \\
\hline
\end{tabular}

Source: Authors' calculation using FAO data.

For most food crops, increases in the area harvested since 1995 have been a more important source of production growth than increases in yields (Table 4.3). Also, yield growth rates for many crops have slowed since the early 1990s. For example, yield growth rates for cocoa, maize, rice, and yams in 1995-2012 were about one quarter the growth rates achieved in 1980-94 (Table 4.3). The higher growth rates achieved during 1980-94 may simply reflect a period of yield catch-up after the disastrous pre-reform period, while the more recent growth rates are in line with the Africa-wide average for the same period (ReSAKSS.org, accessed in 2018).

Changes in the crop mix have also contributed to agricultural growth. The crops whose area expanded faster than average during 1995-2013 typically either already had high value of output per hectare (VOP/ha) or experienced more rapid growth than average in VOP/ha over that period (Table 4.4). These crops included groundnuts, yams, pulses, and vegetables.

\subsubsection{Regional Diversity}

Ghana spans several agroclimatic zones, and this leads to clear geographic patterns in crop production. MoFA identifies three main agroecological zones defined on the basis of climate, natural vegetation, and soils. These are the forest zone (which includes the rain and deciduous forests), the savanna zone (including the coastal and northern savannas), and the transitional zone (Map 4.1). 
Table 4.3. Growth in crop area, output, and yield, by period (\%/year)

\begin{tabular}{|c|c|c|c|c|c|c|}
\hline & \multicolumn{3}{|c|}{ 1980-94 } & \multicolumn{3}{|c|}{$1995-2012$} \\
\hline & $\begin{array}{l}\text { Area } \\
\text { harvested }\end{array}$ & Production & Yield & $\begin{array}{l}\text { Area } \\
\text { harvested }\end{array}$ & Production & Yield \\
\hline Cassava & 7.9 & 9.8 & 1.8 & 2.6 & 4.7 & 2.0 \\
\hline Cocoa, beans & -3.4 & 2.4 & 6.1 & 2.6 & 5.1 & 2.5 \\
\hline Groundnuts & 2.9 & 0.0 & -2.8 & 4.6 & 7.0 & 2.3 \\
\hline Maize & 3.1 & 8.3 & 5.0 & 2.6 & 3.8 & 1.2 \\
\hline Yams & 3.4 & 10.0 & 6.3 & 5.0 & 6.5 & 1.5 \\
\hline Other tree crops & 3.0 & 0.1 & -2.9 & 3.4 & 4.6 & 1.2 \\
\hline Pulses & 0.3 & 0.1 & -0.2 & 8.1 & 21.5 & 12.4 \\
\hline Rice, paddy & -0.1 & 7.6 & 7.8 & 3.5 & 5.4 & 1.9 \\
\hline Taro (cocoyam & 1.0 & 5.3 & 4.2 & -0.4 & -0.9 & -0.5 \\
\hline Plantain & 1.1 & 3.4 & 2.3 & 2.6 & 5.2 & 2.5 \\
\hline Vegetables & 1.2 & 2.9 & 1.6 & 4.4 & 4.5 & 0.1 \\
\hline Sorghum \& millet & 2.0 & 5.3 & 3.2 & -1.6 & -0.7 & 0.9 \\
\hline Fruits & 0.5 & 2.6 & 2.1 & 2.0 & 5.9 & 3.8 \\
\hline Others & 1.7 & 1.2 & -0.5 & 5.0 & 2.5 & -2.4 \\
\hline Total & 1.1 & 5.8 & 4.1 & 2.7 & 5.1 & 2.4 \\
\hline
\end{tabular}

Source: Authors' calculation using FAO data.

Table 4.4. Growth in value added/ha and crop area, by commodity, 1995-2013 (\%/year)

\begin{tabular}{lccc}
\hline & $\begin{array}{c}\text { VOP/ha } \\
\text { in 2012 }\end{array}$ & $\begin{array}{l}\text { Growth in VOP/ha } \\
\text { 1995-2013 }\end{array}$ & $\begin{array}{l}\text { Growth in crop area } \\
\text { 1995-2013 }\end{array}$ \\
\hline Cassava & 1.7 & 2.0 & 2.6 \\
Cocoa, beans & 0.6 & 2.7 & 2.6 \\
Groundnuts & 0.6 & 3.2 & 4.6 \\
Maize & 0.1 & 1.0 & 2.6 \\
Yams & 4.0 & 1.8 & 5.0 \\
Other tree crops & 0.3 & -1.5 & 3.4 \\
Pulses & 0.3 & 15.3 & 8.1 \\
Rice, paddy & 0.6 & 1.6 & 3.5 \\
Taro (cocoyam & 1.4 & 0.4 & -0.4 \\
Banana+plantain & 2.2 & 2.7 & 2.6 \\
Vegetables & 5.9 & -4.1 & 4.4 \\
Sorghum+millets & 0.2 & 1.2 & -1.6 \\
Fruits & 0.9 & 7.4 & 2.0 \\
Others & 0.3 & -0.1 & 5.0 \\
Total & 1.0 & 2.1 & 2.7 \\
\hline
\end{tabular}

Note: The aggregation of agricultural production takes into consideration the weight for each crop, which is in 2004-6 international constant prices.

Source: Authors' calculation using FAO data. 


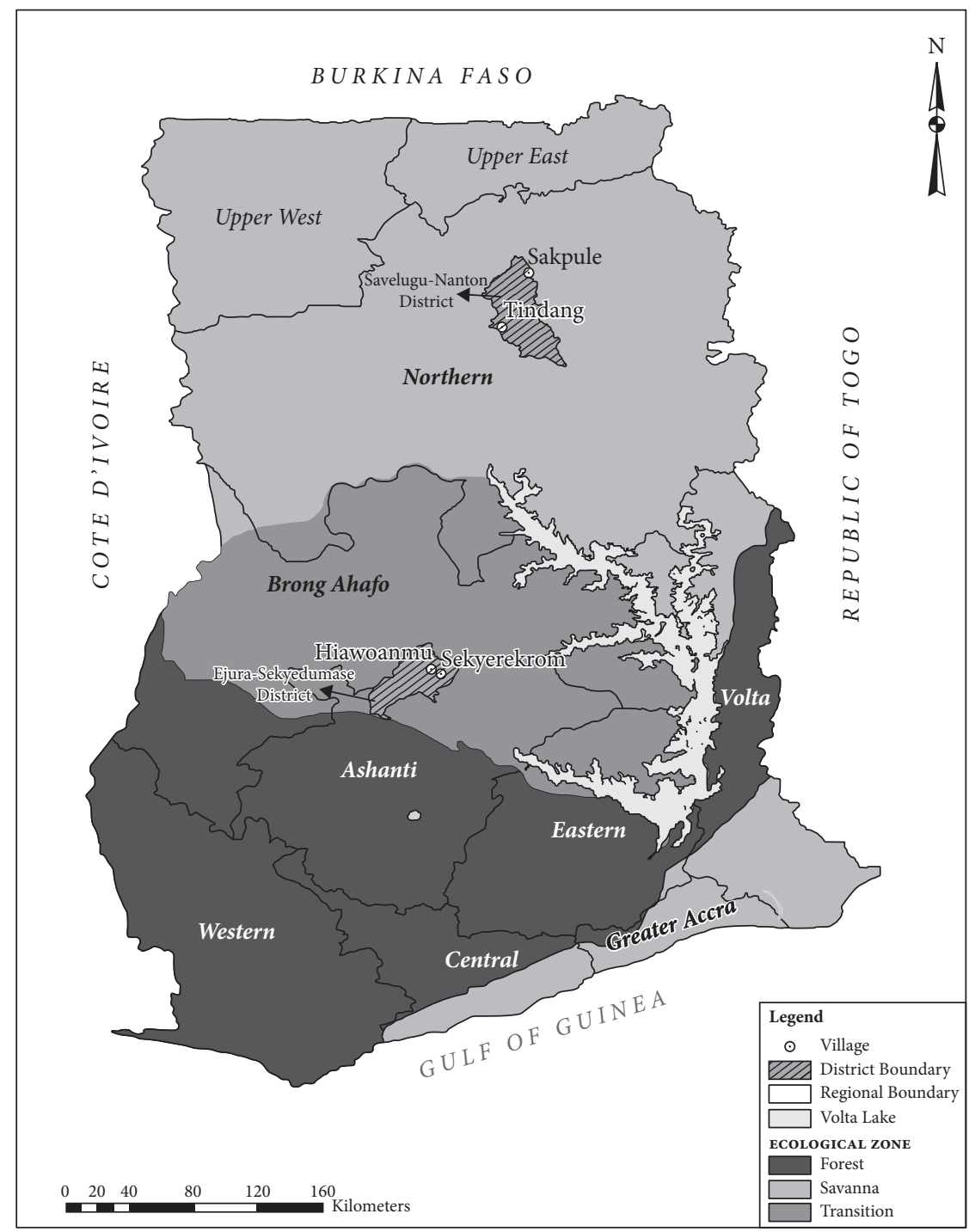

Map 4.1. Ecological zones of Ghana

Source: Compiled from Harvest Choice and GADM data (2015). Map reprinted with permission from Springer.

The distribution of major food crops by agroecological zone is shown in Table 4.5, using average production data for 2010-12. Maize and yams are the only major crops that are grown widely throughout the country, while millet, sorghum, groundnut, and cowpea are grown almost exclusively in the savannah zone, and cassava, plantain, and cocoyam are grown mostly in the transition and forest zones. Rice is most important in the savannah and forest 
Table 4.5. Production of major food crops by agroecological zone, 2010-12 averages

\begin{tabular}{lcccr}
\hline & $\begin{array}{c}\text { Savannah } \\
\%\end{array}$ & $\begin{array}{c}\text { Transition } \\
\%\end{array}$ & $\begin{array}{c}\text { Forest } \\
\%\end{array}$ & $\begin{array}{r}\text { National } \\
\mathbf{1 0 0 0 s} \text { mt }\end{array}$ \\
\hline Cassava & 9.0 & 20.8 & 70.2 & 14,098 \\
Yam & 35.7 & 36.9 & 27.4 & 6,152 \\
Plantain & 0 & 28.0 & 72.0 & 3,571 \\
Cocoyam & 0 & 36.2 & 63.8 & 926 \\
Maize & 20.3 & 27.8 & 51.9 & 1,835 \\
Rice & 63.2 & 4.8 & 32.0 & 479 \\
Millet & 100.0 & 0 & 0 & 194 \\
Sorghum & 98.2 & 0 & 1.8 & 297 \\
Groundnut & 88.1 & 7.1 & 4.8 & 290 \\
Cowpea & 94.3 & 3.3 & 2.4 & 226 \\
Total & & & & \\
$\quad$ 1000 mt & 5,303 & 7,083 & 16,263 & 28,649 \\
$\quad \%$ & 18.5 & 24.7 & 56.8 & 100 \\
\hline
\end{tabular}

Source: Authors' calculation using MoFA SRID data (accessed in 2015).

zones, and cocoa is grown almost exclusively in the forest zone. In aggregate, the forest zone produces 57 percent of the total tonnage of food crops, the transition zone produces 25 percent, and the savannah produces 18 percent.

MoFA reports cultivated area and production for eight major food crops (maize, rice, cassava, yam, cocoyam, plantain, cowpea, and groundnut) at the regional level and data is available for 1992-2012. During that period, the cultivated areas of these eight major food crops increased from 2.4 million ha in 1992 to almost 4 million ha by 2012. The land expansion predominantly occurred in the transition zone and part of the savannah zone, particularly in the BrongAhafo and Northern regions, which became the two largest food-producing regions. More than 40 percent of the increase in the food crop area occurred in these two regions, with annual growth rates of 6.0 percent and 2.6 percent, respectively (Figure 4.1), while the national annual growth rate was 2.9 percent.

\subsubsection{Technology}

Fertilizer use has grown rapidly in Ghana, from a meagre average of $3.7 \mathrm{~kg}$ NPK/ha arable land in 2002 to $35.8 \mathrm{~kg} / \mathrm{ha}$ in 2013 (Table 4.6), and the share of rural agricultural households using fertilizer increased from 22.4 percent to 33.4 percent between 2005/6 and 2012/13 (Table 4.7). About half the largersized farms used fertilizer in 2012/13, while only a quarter of small farms $(<2 \mathrm{ha})$ used it (Table 4.7). It is surprising that yields have not increased more with fertilizer use. However, as discussed in Chapter 6, fertilizer is used not so 


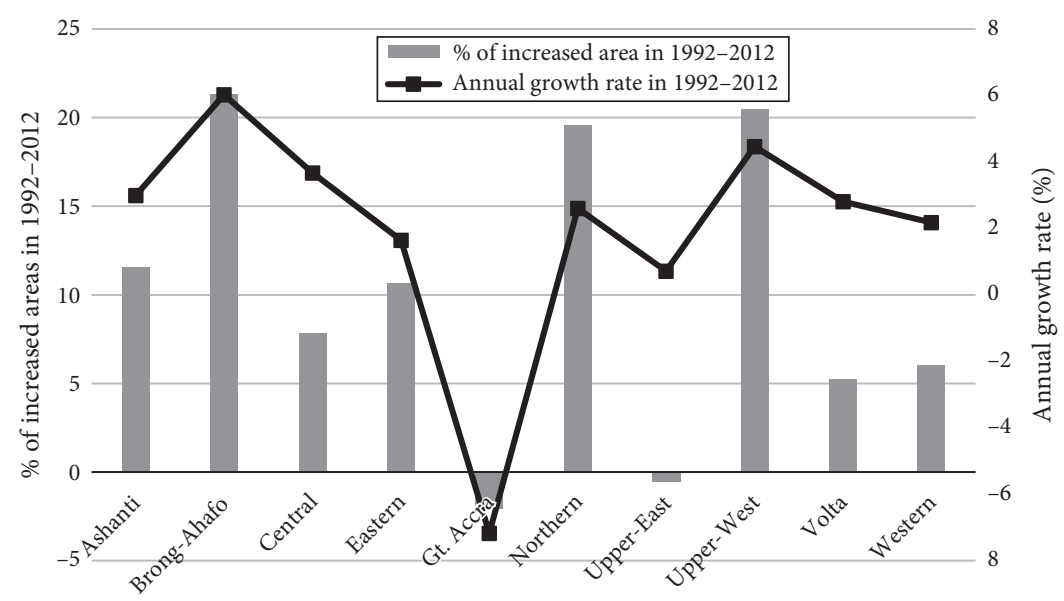

Figure 4.1. Distribution of increases in food crop areas and annual growth rates by region

Source: Authors' calculation using MoFA SRID data (accessed in 2016).

Table 4.6. Fertilizer use (tons of nutrients)

\begin{tabular}{rrrrrc}
\hline & N & P & K & Total NPK & $\begin{array}{c}\text { Application rate kg } \\
\text { NPK/ha of arable land }\end{array}$ \\
\hline 2002 & 4,330 & 120 & 11,120 & 15,570 & 3.7 \\
2013 & 61,922 & 55,628 & 50,823 & 168,373 & 35.8 \\
\hline
\end{tabular}

Source: FAOSTAT.

much to increase yields as to offset declining yields due to loss of soil fertility as fallow periods have been shortened. The adoption of improved seed varieties that might have enhanced the yield response to fertilizer has also been modest. For example, based on a recent farm survey, Ragasa et al. (2013) found that there has been very little increase in the adoption of improved varieties of maize since a 1997 survey, and although 61 percent of the maize area was planted with modern varieties, only 15 percent was planted with certified seed.

In recent years, many farmers have also adopted herbicides and insecticides, and shifted to tractors for land preparation (Table 4.7). As shown in Chapter 6, these labor-saving technologies have enabled many farmers in the savannah and transition zones to expand their cropped area, while substantially reducing hired labor use per hectare, which has become more expensive with rapid urbanization. However, the increased labor needs associated with larger cropped areas has more than offset reductions in labor use per ha, and the share of farm households using hired labor about doubled between 2005/6 and 2012/13 (Table 4.7). 
Table 4.7. Share of rural households using modern inputs and hired labor (\%)

\begin{tabular}{|c|c|c|c|c|c|}
\hline \multirow[t]{2}{*}{ Input } & \multicolumn{4}{|c|}{ Farm size } & \multirow[t]{2}{*}{ Total } \\
\hline & $<2$ ha & $2-5$ ha & $5-20$ ha & $>20$ ha & \\
\hline \multicolumn{6}{|c|}{ Fertilizer: } \\
\hline $2005 / 6$ & 17.0 & 26.4 & 30.8 & 49.3 & 22.4 \\
\hline $2012 / 13$ & 24.6 & 40.6 & 44.8 & 52.5 & 33.4 \\
\hline \multicolumn{6}{|c|}{ Pesticides: } \\
\hline $2005 / 6$ & 26.2 & 36.3 & 46.3 & 37.7 & 32.2 \\
\hline $2012 / 13$ & 59.6 & 79.3 & 86.3 & 83.7 & 70.6 \\
\hline \multicolumn{6}{|c|}{ Mechanization: } \\
\hline $2005 / 6$ & 12.9 & 20.3 & 27.0 & 34.4 & 17.5 \\
\hline $2012 / 13$ & 22.0 & 37.8 & 53.6 & 72.8 & 32.5 \\
\hline \multicolumn{6}{|c|}{ Hired labor: } \\
\hline $2005 / 6$ & 19.2 & 34.6 & 40.3 & 28.8 & 27.7 \\
\hline $2012 / 13$ & 43.1 & 53.2 & 64.6 & 74.1 & 50.0 \\
\hline
\end{tabular}

Source: Authors' calculation using GLSS5 and GLSS6.

\subsubsection{Land and Labor}

The total cropped area grew by 2.7 percent per year over 1999-2014 (Table 4.4) as farmers brought virgin land into production and shortened fallow periods. FAO estimates that the agricultural labor force also grew at about the same rate over a similar period (Table 4.8). However, this estimate may be high; GGDC (Timmer et al. 2016) estimates that agricultural employment grew by only 0.7 percent per year during $2000-10$, and this estimate is consistent with our own estimates based on the Ghana Living Standard Survey data. Census data also show that the rural population has peaked in size, in which case the pressure on the land base should be easing. ${ }^{1}$

Labor also became more expensive as real wage rates were pulled up by competition from rural nonfarm jobs (Chapters 2 and 5), growing by nearly 7 percent per year on average over 1991 to 2012 at both national and regional levels (Table 4.9). However, the value of agricultural production has grown faster than land and labor ( 4.5 percent per year), leading to increases in both land and labor productivity. Figure 4.2 plots the changes in land and labor productivity since 1991, and shows that while both have increased, labor productivity has grown considerably faster than land productivity, a reflection

\footnotetext{
1 The land pressure on the rural population will also have been affected by loss of land to urban-based entrepreneurs who are reportedly venturing into farming (Jayne et al. 2016), but there has also been an offsetting pattern with some rural households giving up their land to focus on nonfarm occupations (see Chapter 5).
} 
Table 4.8. Growth in national and agricultural labor forces

\begin{tabular}{|c|c|c|c|c|c|c|c|}
\hline & \multicolumn{4}{|c|}{ Millions } & \multicolumn{3}{|c|}{ Annual growth rate $\%$} \\
\hline & 1999 & 2004 & 2009 & 2014 & 1999-2004 & 2004-9 & 2009-14 \\
\hline National population & 18.38 & 20.84 & 23.69 & 26.44 & 2.54 & 2.60 & 2.22 \\
\hline Rural population & 10.44 & 11.05 & 11.71 & 12.20 & 1.01 & 1.01 & 1.00 \\
\hline National labor force & 8.07 & 9.20 & 10.75 & 12.43 & 2.66 & 3.16 & 2.95 \\
\hline $\begin{array}{l}\text { Agricultural labor } \\
\text { force }\end{array}$ & 4.62 & 5.15 & 5.87 & 6.63 & 2.20 & 2.65 & 2.50 \\
\hline
\end{tabular}

Source: FAOSTAT.

Table 4.9. Agricultural wages in Ghana, 1991-2012, by type of work (new cedis, deflated by CPI)

\begin{tabular}{lccc}
\hline Year & Men clearing & Women harvesting & Men harvesting \\
\hline 1991 & 1.18 & 0.94 & 1.11 \\
1998 & 1.39 & 1.03 & 1.35 \\
2005 & 2.30 & 1.84 & 2.38 \\
2012 & 4.55 & 3.60 & 4.24 \\
Growth rate & 6.70 & 6.78 & 6.78 \\
\hline
\end{tabular}

Note: Annualized growth rates over 1991-2012.

Source: Authors' calculation using GLSS3 to GLSS6.

of a switch to labor-saving technologies and crops. This is consistent with Chapter 2 where it is shown that labor productivity growth within agriculture was an important source of growth in national labor productivity.

\subsubsection{Land distribution}

Ghanaian agriculture is still dominated by small farms of less 2 ha in size, but one consequence of the changes in land area and population has been a shift in the farm size distribution (Table 4.10). Nationally, about three quarters of all rural households had land in 2012/13, and of these about half farmed 2 ha or less (i.e., about 4.5 million small farms). The share of rural households with no cultivated land increased from 16.8 percent in 2005/6 to 23.2 percent in $2012 / 13$, while amongst those households who do have land, there has been an increase in the share of middle-sized farms at the expense of small $(<2 \mathrm{ha})$ and large (> 20 ha) farms. This change masks important differences at regional levels. In the northern regions (comprising most of the savannah and part of transition zones), the changes are similar to but more modest than the changes 


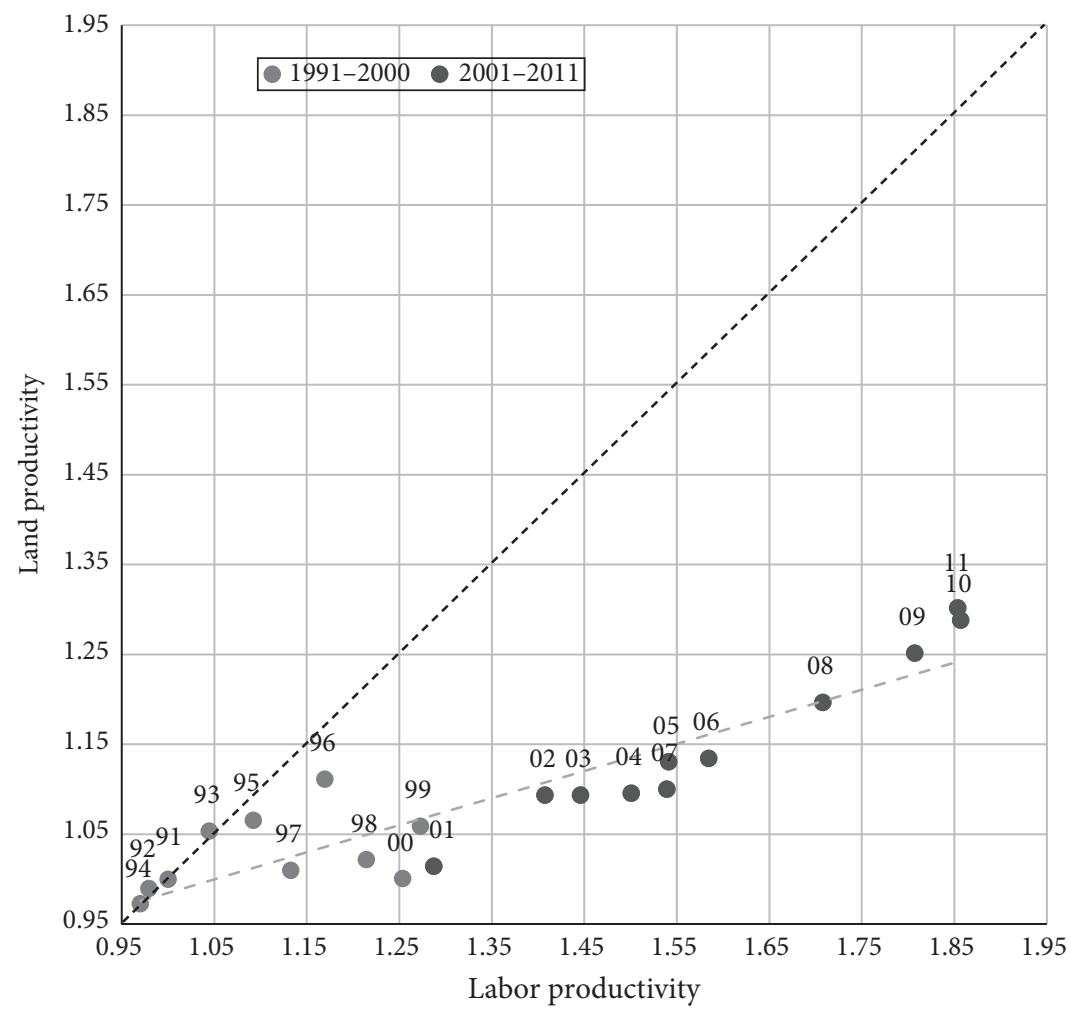

Figure 4.2. Trends in land and labor productivity, 1991-2011

Note: Each dot in the chart represents an individual year.

Source: Authors' calculation using data from GGDC (2016) for agricultural value added and agricultural employment, and from FAO (2016) for cultivated agricultural land.

Table 4.10. Changes in the size distribution of farms amongst rural households (\%)

\begin{tabular}{|c|c|c|c|c|c|c|}
\hline & No land & $<2$ ha & $2-5$ ha & $5-20$ ha & $>20$ ha & Some land \\
\hline \multicolumn{7}{|l|}{ National } \\
\hline $2012 / 13$ & 23.2 & 49.3 & 35.6 & 14.2 & 0.9 & 76.8 \\
\hline \multicolumn{7}{|c|}{ Northern regions (savannah and transition zones) } \\
\hline $2005 / 6$ & 12.8 & 44.3 & 36.6 & 15.9 & 3.2 & 87.2 \\
\hline $2012 / 13$ & 14.9 & 38.6 & 41.2 & 18.8 & 1.4 & 85.1 \\
\hline \multicolumn{7}{|c|}{ Southern regions (forest and coastal zones) } \\
\hline $2005 / 6$ & 16.8 & 53.3 & 31.8 & 12.9 & 1.9 & 83.2 \\
\hline 2012/13 & 29.1 & 58.4 & 30.8 & 10.3 & 0.5 & 70.9 \\
\hline
\end{tabular}

Source: Authors' calculations using GLSS5 and GLSS6 data. Land is defined as cultivated land. 
in national aggregates. In the southern regions (comprising the forest and coastal zones), there has been a much sharper increase in no-land households, and the share of small farms $(<2$ ha) has actually increased by 10 percent at the expense of all the other size groups.

The GLSS data can also be used to calculate the share of the total operated land farmed by different farm size groups. Jayne et al. (2016) provide the estimates in Table 4.11. According to their estimates, small farms of less 5 ha accounted for 84.5 percent of all farms in 2012 (down from 92.1 percent in 1992), and for 48.9 percent of the total operated area (down from 60.7 percent in 1992). On the other hand, the share of farms in the 5-100 ha range about doubled between 1992 and 2012 (up 97 percent) while their share of the operated land area increased by 45.5 percent. This confirms the growing importance of middle-sized farms. Further confirmation is to be found from village studies in the savannah zone (in Chapter 6). In the 1980s there were very few farms greater 5 acres in the four study villages, but by 2015 half or more of the farms in all the villages were larger than 5 acres.

A problem with representative household surveys like the GLSS is that, because they are sampled to represent households and not agricultural area, they can seriously understate the importance of large farms, and hence distort estimated land shares (Lowder et al. 2016). Jayne et al. (2016) used census and other area based data to estimate a more accurate picture for Ghana, and found that while there were very few farms greater then 100 ha in the GLSS surveys, nevertheless they account for about 22 percent of the total farmed area. This group is missing in estimates like those in Table 4.10, which are based only on GLSS data.

Table 4.11. Distribution of farms and operated area by farm size groups, 1992 and 2012

\begin{tabular}{|c|c|c|c|c|c|c|}
\hline \multirow[t]{2}{*}{ Farm size } & \multicolumn{3}{|c|}{ Percent of farms } & \multicolumn{3}{|c|}{ Percent of operated land area } \\
\hline & 1992 & 2012 & $\%$ change & 1992 & 2012 & $\%$ change \\
\hline $0-5$ ha & 92.1 & 84.5 & -8.3 & 60.7 & 48.9 & -19.4 \\
\hline $5-10$ ha & 5.3 & 9.2 & 73.6 & 17.2 & 19.5 & 13.4 \\
\hline $10-20$ ha & 1.7 & 4.0 & 135.3 & 11.0 & 16.0 & 45.5 \\
\hline 20-100 ha & 0.9 & 2.4 & 166.7 & 11.1 & 15.6 & 40.5 \\
\hline $5-100$ & 7.9 & 15.6 & 97.4 & 39.3 & 51.1 & 30.0 \\
\hline
\end{tabular}

Source: Jayne et al. (2016) based on GLSS data. 


\subsubsection{Rural Livelihoods, Incomes, and Poverty}

Rural households have benefited directly from the changes in the agricultural sector, but they have also benefited from new opportunities in the rural nonfarm economy. Nonfarm opportunities have grown rapidly in urbanizing areas, especially in districts with medium and small-sized towns, leading to considerable diversification of farm household livelihoods into nonfarm sources of income and employment (see Chapter 5). Table 4.12 summarizes some of the main changes in terms of incomes sources by farm size groups. About half of all farm households (51.3 percent) received less than one third of their total income from nonfarm sources in 2012/13 and can be considered to have been primarily dependent on farming. This share was down from 55.8 percent in 2005/6. Moreover, the share of farm households receiving two thirds or more of their total income from nonfarm sources was 41.4 percent in 2012/13, up from 32.1 percent in 2005/6. Proportionally, more small farms ( $\leq 2 \mathrm{ha}$ ) obtain two thirds or more of their income from nonfarm sources than medium and large farms; 42.7 percent versus 35.7 percent.

The combined impact of changes in the agricultural sector plus diversification into nonfarm sources of income has led to substantial increases in rural incomes, which, because of data problems, we proxy here by household expenditures (Table 4.13). For rural households as a group, per household and per capita real expenditures increased by 2.4 percent and 2.2 percent annually between $2005 / 6$ and $2102 / 13$. These increases compare favorably

Table 4.12. Composition of farm household by type of livelihood strategy

\begin{tabular}{lccr}
\hline $\begin{array}{l}\text { Nonfarm income as share } \\
\text { total income }\end{array}$ & \multicolumn{3}{c}{ Farm size } \\
\cline { 2 - 4 } & $\begin{array}{c}\text { Small } \\
(\leq 4 \text { ha })\end{array}$ & $\begin{array}{c}\text { Medium and large } \\
(>4 \text { ha })\end{array}$ & Total \\
\hline $2012 / 13(n=9,111)$ & & & \\
Low $(\leq 1 / 3)$ & 41.0 & 10.3 & 51.3 \\
Medium $(1 / 3-2 / 3)$ & 5.8 & 1.5 & 7.3 \\
High $(>2 / 3)$ & 35.0 & 6.5 & 41.4 \\
Total & 81.8 & 18.2 & 100.0 \\
2005/6 $(n=5,200)$ & & & \\
Low $(\leq 1 / 3)$ & 41.5 & 14.3 & 55.8 \\
Medium $(1 / 3-2 / 3)$ & 9.7 & 2.4 & 12.1 \\
High $(>2 / 3)$ & 27.2 & 4.9 & 32.1 \\
Total & 78.4 & 21.6 & 100.0 \\
\hline
\end{tabular}

Note: Includes rural and urban households that have some operated farm land.

Source: Calculations by Melanie Bacou using GLSS data. 
Table 4.13. Changes in household and per capita expenditure, 2005/6 and 2012/13

\begin{tabular}{lccccc}
\hline \multicolumn{7}{c}{ Type household } \\
\cline { 2 - 6 } & National & Rural & Rural agriculture & $\begin{array}{c}\text { Rural } \\
\text { nonagriculture }\end{array}$ & Rural mixed \\
\hline Per household & $(2012 / 13$ & cedi) & & & \\
$2005 / 6$ & 7,511 & 6,015 & 5,648 & 6,658 & 7,641 \\
$2012 / 13$ & 9,014 & 7,078 & 6,435 & 7,762 & 8,939 \\
Ratio & 1.20 & 1.18 & 1.14 & 1.17 & 1.17 \\
Per capita & $(2012 / 13$ cedi) & & & & 1,299 \\
$2005 / 6$ & 1,872 & 1,376 & 1,251 & 1,929 & 1,504 \\
$2012 / 13$ & 2,259 & 1,586 & 1,389 & 2,260 & 1.16 \\
Ratio & 1.21 & 1.16 & 1.11 & 1.17 & \\
\hline
\end{tabular}

Source: Authors' calculation using GLSS5 and GLSS6 data.

with the national average increases in household and per capita expenditure of 2.6 percent and 2.7 percent per annum, respectively. Although the differences in rates of increase are small, they are sufficient to prevent any convergence in household expenditures (or incomes) between rural and urban households, and between agricultural and nonagricultural households in rural areas. In 2012/13, rural households still had average per capita expenditures that were 70 percent of the national average, and agricultural households had per capita expenditures that were only 61 percent as large as the rural average.

Along with income growth, rural poverty has declined. The national poverty rate fell from 52 percent in 1991/2 to 32 percent by 2005/6, and to 24 percent by $2012 / 13$. The rural poverty rate has remained higher than the national rate, but it also fell sharply-from about 65 percent in 1991/2 to 44 percent in 2005/6, and to 38 percent in 2012/13. As shown in Chapter 5, there is a clear relationship between poverty and rural livelihood opportunities, particularly the participation in rural nonfarm activities, and which varies with the level of urbanization.

\subsection{Explaining the Trends}

Ghana's agricultural performance has been better than in most other African countries, but it has not been outstanding, nor has it exploited its potential to become a more important source of export earnings beyond cocoa, or to reduce the country's growing dependence on many imported foods. Moreover, despite continuing rural population growth, agricultural growth has depended 
mainly on expanding the cropped area, and there has been little agricultural intensification of the Green Revolution type. In this section we attempt to explain why agriculture has developed the way it has, and to assess the implications for the future.

The observed patterns of change reflect the summation of the decisions of some 6 million farmers, who have responded over time to a changing political and economic environment. Key drivers of change to explore are:

- Government policy, including the political and economic environment, public investment, and pro-active state interventions to further the development of particular value chains, regions, or groups of farmers.

- Population pressure and land expansion

- Rapid urbanization, which can impact on agriculture through changes in market access, infrastructure, population pressure, rural nonfarm opportunities, and higher wages.

\subsubsection{Policy}

\subsubsection{An enabling economic environment}

As discussed in Chapter 3, apart from cocoa, the value chain for which the government has intervened actively through Cocobod (a parastatal), and trade and tax policies, the government has generally shown benign neglect of the agricultural sector since the SAP reforms of the 1980s, relying more on creating a stable and enabling economic environment than on direct interventions that favored particular commodities. As discussed in Chapter 2, this improvement in what Rodrik calls "fundamentals" led to significant growth in labor productivity in agriculture after the SAP, to the point where it has been a major factor in the growth of national per capita income since the 1980s.

The improvement in the enabling economic environment for agriculture is reflected in a sustained shift in the sector's domestic terms of trade. Real farm gate prices increased modestly over 1998-2012 (Table 4.14), while farm input prices, including fertilizer, declined substantially (Table 4.15). Against this, agricultural wage rates grew by nearly 7 percent per year on average over 1991 to 2012 (Table 4.9), and labor costs are now a major production cost for most farmers (Diao et al. 2014). There was also a general decline in the level of taxation of agriculture, as reflected by changes in average nominal rates of assistance for agriculture (see Chapter 3). 
Table 4.14. Annualized growth rates in crop prices, 1998-2012 (\%)

\begin{tabular}{lcc}
\hline Crop & Current Prices & Constant 2005 prices \\
\hline Cassava & 18.49 & -0.41 \\
Yam & 16.77 & -1.86 \\
Plantain & 21.84 & 2.41 \\
Cocoyam & 19.25 & 0.23 \\
Maize & 21.06 & 1.75 \\
Sorghum & 21.29 & 1.94 \\
Groundnut & 22.98 & 3.37 \\
Millet & 19.65 & 0.57 \\
Rice & 20.94 & 1.65 \\
Tomato & 23.15 & 3.51 \\
\hline
\end{tabular}

Source: Authors using data from the Ministry of Agriculture of Ghana.

Table 4.15. Annualized growth rates in input prices, 1998-2012 (\%)

\begin{tabular}{lcc}
\hline Input & Current prices & Constant 2005 prices \\
\hline NPK 15-15-15 & 7.80 & -7.17 \\
Sulphate of Ammonia & 7.37 & -7.54 \\
Urea & 5.15 & -9.45 \\
Round Up & 3.99 & -10.45 \\
Karate & -0.20 & -14.06 \\
Actellic & -2.67 & -16.18 \\
Hoe & 18.52 & 2.06 \\
Cutlass & 14.38 & -1.50 \\
Jute Sac & 25.61 & 8.17 \\
\hline
\end{tabular}

Source: Authors using data from the Ministry of Agriculture of Ghana.

\subsubsection{Direct government interventions}

The lack of direct support for agriculture is reflected in low levels of public spending on agriculture and limited and often ineffective interventions for promoting value chain development for commodities other than cocoa.

The government has underinvested in agriculture by the norms of other African countries, and by its own commitment under the Maputo Declaration to spend at least 10 percent of its total budget on agriculture. As shown in Chapter 7, public spending on agriculture averaged only 2.1 percent of total government spending during 2001-8, and 2.8 percent during 2009-12. Furthermore, about two thirds of this spending went to the cocoa subsector, leaving the noncocoa subsector even more neglected. When expenditures of 
the Ghana Cocoa Board are included as part of public expenditures on agriculture, and expenditures of other public corporations are included as part of total public expenditure, then, as shown in Chapter 7, the budget share is about 3.8-5.3 percent, which still falls far short of the 10 percent Maputo Declaration target. ${ }^{2}$ Ghana also spends relatively little on rural roads and other infrastructure important to agriculture (Chapter 7), and spending on agricultural R\&D has averaged 0.6-0.7 percent of agricultural GDP since 2000, which is barely above the Africa-wide average, and well below the African Union (AU) target of 1 percent (Stads 2016).

Apart from cocoa, whose value chain is tightly controlled by Cocobod, and which generally does a good job (see Chapter 8), the government has made few direct interventions along the value chains of other commodities since the economic reforms, and the few attempts that have been made were mostly unsuccessful (Chapters 3 and 8). For example, the public sector attempts to promote domestic cocoa processing, palm oil production, and the export of pineapples (Chapter 3). This lack of effective value chain interventions may not have adversely affected many of the markets for nontradable agricultural products, but Ghana has not done well in developing additional exports crops like pineapple, in competing with imports like rice and tomatoes, or in developing agroprocessing industries, despite strong demand. Weak public sector support has contributed to the poor availability of appropriate technologies, especially improved seeds, weak rural infrastructure like roads, transport systems, and cold storage, lack of grading systems for quality control, and limited export promotion (Chapter 8). However, as discussed in Chapter 3, for government to play more proactive roles along value chains requires overcoming inherently weak public sector capacities, and a greater willingness to engage with the domestic as well as the international private sectors.

In 2007, the government started paying more attention to the noncocoa subsector with some proactive interventions. These included the reintroduction of a fertilizer subsidy, the establishment of subsidized Agricultural Mechanization Service Centers (AMSECs), the setting up of Block Farms that benefit from a range of subsidized inputs and extension, and the stabilization of output prices via the establishment of the National Food Buffer Stock Company (NAFCO). The cost of these programs was initially modest at GHS7.5 million per year in 2007 and 2008, but had escalated to 25 percent

${ }^{2}$ Offsetting to some extent this neglect in public spending has been some off-budget spending by a number of donors that is channeled directly to partners in the private and NGO sectors. 
of MoFA's budget in 2010, and were on track to increase to about half MoFA's total budget by 2020 (Chapter 7).

A key question is whether these public sector interventions will be any more effective than past attempts, or whether public sector capabilities are still too weak and disengaged from the private sector. While there is some preliminary evidence that these programs are leading to higher yields for some farmers, still growth in average land productivity for the noncocoa subsector was only marginally higher during 2009-12 (3.6 percent per annum) than during 2001-8 (3.2 percent per annum) (see Chapter 7). There is also little evidence that the AMSECs are effective in promoting agricultural mechanization and may if anything be distorting more efficient private sector initiatives (Chapter 9). Recent turmoil in the government's fertilizer subsidy policy also raises doubts about the effectiveness of its interventions. Rather than staying with a well-defined objective for the subsidy, the government's objectives and the program's design have changed almost yearly in response to changing political and financial pressures. There have also been serious problems in containing the total cost of the subsidy (see Chapter 7), and problems implementing the program in ways that ensure dealers are able to import required amounts of fertilizer each year and that farmers receive their fertilizer in time for each crop season (Resnick and Mather 2016).

In short, there is little evidence to suggest that proactive government policies and investments in agriculture and along value chains have been a major driver of agricultural growth in Ghana since the economic reforms, other than in the cocoa subsector. However, by creating and sustaining a favorable enabling environment and improved terms of trade for agriculture, the government has encouraged farmers and other private sector players to invest in agriculture and along value chains, leading to sustained agricultural growth and gains in labor productivity.

\subsubsection{Population Pressure on the Land Base}

The rural population has grown steadily over the years, adding to the population pressure on the land base, and an 18 percent decline over 1981-2013 in the available agricultural land area per rural person (Table 4.16). However, because more land has been brought into crop production by clearing virgin land and reducing the length of fallow periods, the arable land area grew fast enough to enable the arable land area per rural person to increase by 52 percent over 1981-2013 (Table 4.16). Nearly all this increase occurred 
Table 4.16. Changes in rural population density, 1991-2013

\begin{tabular}{lccccc}
\hline & $\begin{array}{l}\text { Agricultural } \\
\text { area (m ha) }\end{array}$ & $\begin{array}{l}\text { Arable } \\
\text { area } \\
(\mathbf{m} \text { ha) }\end{array}$ & $\begin{array}{l}\text { Rural } \\
\text { population } \\
(\mathbf{m})\end{array}$ & $\begin{array}{l}\text { Agricultural } \\
\text { land/rural } \\
\text { person (ha) }\end{array}$ & $\begin{array}{l}\text { Arable } \\
\text { land/rural } \\
\text { person (ha) }\end{array}$ \\
\hline 1981 & 12.00 & 1.90 & 7.628 & 1.57 & 0.25 \\
1991 & 12.72 & 2.84 & 9.452 & 1.34 & 0.30 \\
1999 & 14.18 & 3.85 & 10.445 & 1.36 & 0.37 \\
2013 & 15.70 & 4.70 & 12.244 & 1.28 & 0.38 \\
Percent change & & & & & \\
$1981-1999$ & 18.17 & 102.63 & 36.93 & -13.38 & 48.00 \\
$1999-2013$ & 10.72 & 22.08 & 17.22 & -5.89 & 2.70 \\
$1981-2013$ & 30.83 & 147.37 & 60.51 & -18.47 & 52.00 \\
\hline
\end{tabular}

Source: FAOSTAT.

before 1999, with only a 2.7 percent increase since 1999 . The most recent census data suggests that the rural population size has now peaked. As shown in Chapter 5, there has been considerable spatial variation in these patterns, with much of the rural population growth occurring in the more urbanized and population dense areas, and much of the arable land expansion occurring in the more sparsely settled rural areas, particularly in the savannah and transition zones.

Early advocates of induced innovation (Boserup 1965; Ruthenberg 1980) argued that as rural population densities increase, there ought to be increasing farmer demand for yield-enhancing technologies to raise land productivity. A complication for this theory in Ghana is that it ignores the elastic nature of the land constraint, which has contributed to an increase in the cropped area per rural person even as the agricultural land area per rural person has declined (Table 4.16). However, as noted above, these national figures mask important regional variations, so there could still be pockets of induced innovation, especially in some of the more urbanized areas. There have, for example, been cases of rice intensification in some irrigated areas, but one study suggests these are driven more by market opportunity and new technology than population pressure (Takeshima et al. 2013; Otsuka and Larson 2013).

Nin-Pratt and McBride (2014) analyzed the relationship between population density and the purchase of modern inputs and the value of output/ha in different ecological zones in Ghana, using GLSS5 data. They focused on the 30 percent most efficient farmers in the sample as measured through a data envelop analysis (DEA), on the grounds that the more efficient farmers are the most likely ones to be adopting modern inputs in response to any changes in factor prices. They found no consistent relationships in the coastal, forest, and 
savannah zones to support the induced innovation theory, except for some increase in hired labor costs and value of output/ha in the top two population density deciles of the forest zone (which may reflect an emerging land constraint). This analysis has now been updated using GLSS6 data, and the results for the forest and savannah zones are shown in Figures 4.3a and $4.3 \mathrm{~b} .{ }^{3} \mathrm{We}$ report results for the full GLSS6 sample as well as the 25 percent most efficient and inefficient farmers using the DEA approach. Again, there are few systematic relationships between input use and population density, and whereas the induced innovation theory would predict that the value of production/ha should increase as the population density increases, the reality is the reverse. Limiting the analysis to the more efficient farmers does not make much difference.

\subsubsection{Urbanization}

If proactive government policies and increasing population density do not adequately explain past patterns of agricultural growth in Ghana, then what does? We explore a third hypothesis that attributes an important part of Ghana's agricultural success to the impact of rapid urbanization. Chapter 5 examines this hypothesis in detail for Ghana, and finds that urbanization has led many rural households to move into nonfarm occupations as their primary jobs, with a corresponding decline in the share of households that depend primarily on agriculture. Not surprisingly, this shift into nonfarm occupations is positively correlated with the degree of urbanization of a district and the proximity to large urban centers. Chapter 5 also finds that farming in the most urbanized districts is increasingly undertaken by small-scale units, often on a part-time basis. On the other hand, in the agriculturally important north where there are less nonfarm job opportunities, there has been a more pronounced trend towards a larger share of medium-sized farms. Finally, Chapter 5 finds that there is little evidence that urbanization has led to more intensive farming practices in terms of the use of modern inputs or choice of technology in the more urbanized areas.

Although Chapter 5 finds that there has been substantial uptake of fertilizers, herbicides, and mechanization in Ghana in recent years, this does not seem to have been driven by urbanization. In fact, the use of fertilizer is greater in the north of the country than the more urbanized south, and higher

\footnotetext{
3 The authors are grateful to Alejandro Nin-Pratt for his help in updating this analysis.
} 

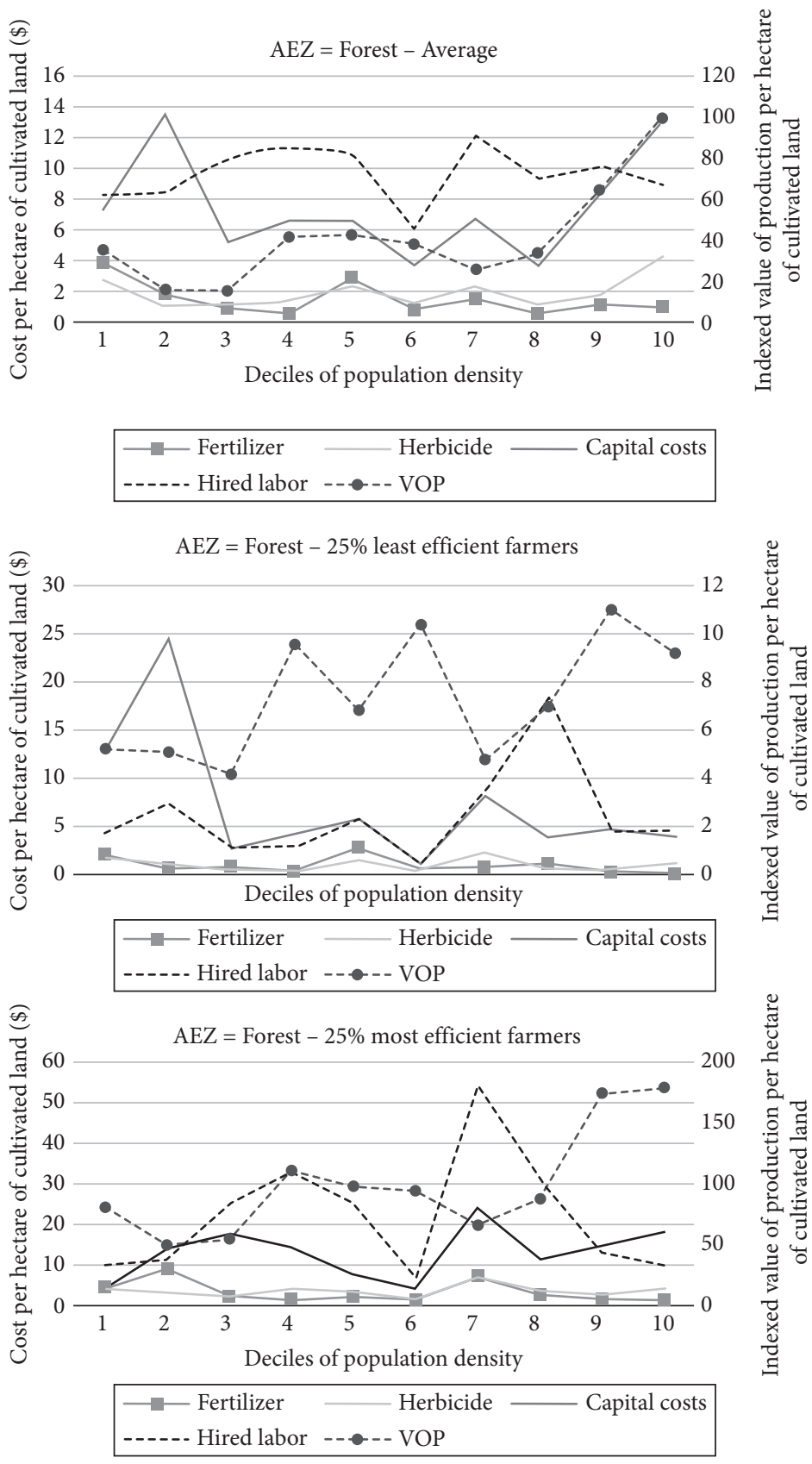

Figure 4.3a. Patterns of intensification against population density in the forest zone comparing full sample with least and most cost-efficient farmers Source: Calculations by Alejandro Nin-Pratt and authors, using GLSS6 data. 

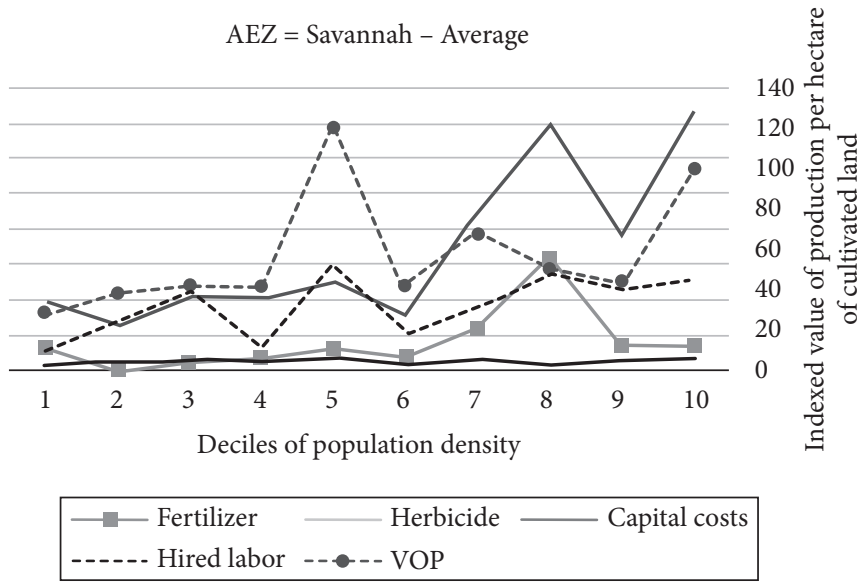

है

$\mathrm{AEZ}=$ Savannah $-25 \%$ least efficient farmers

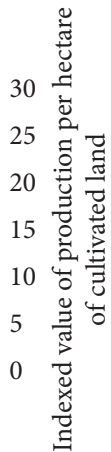

Deciles of population density
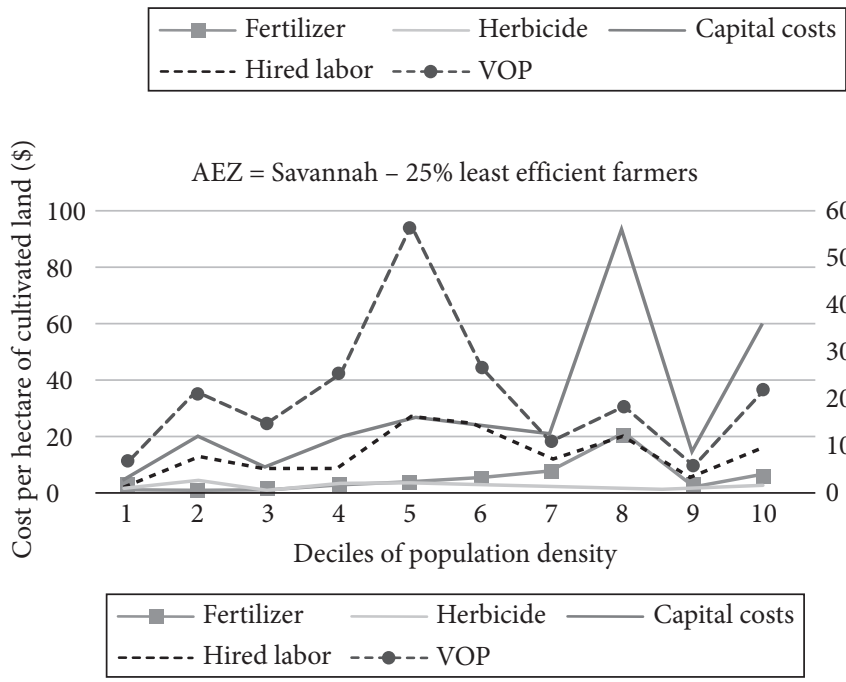

Figure 4.3b. Patterns of intensification against population density in the savannah zone comparing full sample with least and most cost-efficient farmers Source: Calculations by Alejandro Nin-Pratt and authors, using GLSS6 data. 
amongst medium- and large-sized farms than small farms. These patterns are consistent with the finding from the village narratives in Chapter 6 that fertilizer is used mainly for offsetting declining soil fertility rather than intensification. Overall, the evidence suggests that intensification is only taking place to a limited extent even in areas near urban centers. Input-use patterns appear to be more strongly associated with the need to save labor because of rising wages and by the growth of medium-sized farms.

\subsection{Conclusions}

Past patterns of agricultural growth have been associated with an elastic land frontier that has enabled agricultural production to grow by expanding the cropped area. This was initially achieved by bringing more virgin land into production, but as the land frontier tightened farmers increased their cropped area by shortening fallow periods, and using fertilizer to compensate for the soil fertility problems that followed. At the same time, farmers in the transition and savannah regions have responded to rising labor costs, urbanization, and new market opportunities, by increasing their farm sizes with the aid of mechanization and herbicides, and changing their crop mixes to better meet market demand. The result has been substantial increases in farm production and incomes, but more from increases in the cropped area and crop mix than from increased yields. Land productivity has increased only modestly, but labor productivity has increased substantially in line with wages.

The pattern of transformation has been different in the southern parts of the country that have been more affected by rapid urbanization. Here many farm households have taken advantage of urban-rural linkages to diversify into nonagricultural sources of income, and farms have become smaller at the expense of larger farms. Despite having greater access to urban markets, services, infrastructure and an increasing population pressure on the land base, there is little evidence of any agricultural intensification leading to higher yields and land productivity in these areas. As in the northern parts of the country, the transition has been towards labor-saving farming practices and increased labor productivity. These livelihood patterns seem likely to be sustained into the future as long as the nonagricultural economy, especially in middle- and small-sized cities, continues to flourish. There must be pockets of agricultural intensification, e.g., high-value agriculture near urban centers, but if so they are still at too small a scale to be captured in the level of household aggregation used in Chapter 5, or indeed in the GLSS household surveys. 
Although the agricultural sector has benefited from an enabling policy environment that has encouraged farmers to invest in expanding their production, still the sector has been constrained by low levels of public investment and a lack of proactive public sector interventions to develop the value chains for important export crops (other than cocoa) or import-substituting crops like rice and tomatoes. Had the government done more to help farmers access improved seeds, irrigation, roads, credit, markets, etc., then perhaps there would have been a greater shift by now to agricultural intensification in Ghana, and even faster rates of agricultural growth. Induced innovation is hypothesized to happen as an endogenous response to increasing population pressure and urbanization, but it can only work if there are intensification technologies available to farmers that are profitable to use, and markets to absorb their additional production.

The future sustainability of the current patterns of agricultural growth is constrained by the availability of remaining virgin and fallow land for future expansion of the cropped area. As the land frontier runs out, farmers will need to shift towards more intensive modes of production, and options will need to include higher-yielding technologies and a greater focus on high-value products. The economic viability of these options will depend on government policies towards agricultural $\mathrm{R} \& \mathrm{D}$, infrastructure, and value chain interventions that condition access to modern inputs and urban markets and their costs, and trade policies that condition the level of competition farmers must face in their domestic markets. These policies will need to be cognizant of the needs of the changing nature of Ghanaian agriculture. As more small farm households are attracted into nonfarm activities, farms become more consolidated, rural wages rise, and rural youth become better educated, more emphasis will be needed on the development of technologies and commercial farming practices that raise land as well as labor productivity, are attractive to young farmers, and meet the needs of Ghana's increasingly urbanized food system. We return to these issues in Chapter 10.

\section{References}

Boserup, E. 1965. The Conditions of Agricultural Growth. New York: Aldine Publishing.

Diao, X., F. Cossar, N. Houssou, and S. Kolavali. 2014. "Mechanization in Ghana: Emerging Demand, and the Search for Alternative Supply Models." Food Policy 48: 168-81. 
Jayne, T. S., J. Chamberlin, L. Traub et al. 2016. “Africa’s Changing Farm Size Distribution Patterns: The Rise of Medium-scale Farms." Agricultural Economics 47: 197-214.

Lowder, S. K., J. Skoet, and T. Raney. 2016. “The Number, Size, and Distribution Farms, Smallholder Farms, and Family Farms worldwide.” World Development 87: 16-29.

Nin-Pratt, A., and L. McBride. 2014. "Agricultural Intensification in Ghana: Evaluating the Optimist's Case for a Green Revolution." Food Policy 28: 153-67.

Otsuka, K., and D. Larson. 2013. An African Green Revolution: Finding Ways to Boost Productivity on Small Farms. Dordrecht: Springer.

Ragasa, C., A. Dankyi, P. Acheampong et al. 2013. "Patterns of Adoption of Improved Maize technologies in Ghana." Ghana Strategy Support Program Working Paper (GSSP) No. 35. Washington, DC: IFPRI.

Resnick, Danielle, and David Mather. 2016. “Agricultural Inputs Policy under Macroeconomic Uncertainty: Applying the Kaleidoscope Model to Ghana's Fertilizer Subsidy Programme (2008-2015).” IFPRI Discussion Paper No. 01551, Washington, DC: IFPRI.

Ruthenberg, Hans. 1980. Farming Systems in the Tropics. 3rd edition. Oxford: Oxford University Press.

Stads, G.-J. 2016. "Investment in Agricultural Research and Development: An Account of Two-speed Growth, Underinvestment, and Volatility," in J. Lynam, N. Beintema, J. Roseboom et al. (eds), Agricultural Research in Africa: Investing in Future Harvests. Washington, DC: IFPRI, 85-108.

Takeshima, H., K. Jimah, S. Kolavalli et al. 2013. "Dynamics of Transformation: Insights from an Exploratory Review of Rice Farming in the Kpong Irrigation Project.” IFPRI Discussion Paper No. 01272. Washington, DC: IFPRI.

Timmer, M. P., G. J. de Vries, and K. de Vries. 2015. "Patterns of Structural Change in Developing Countries," in J. Weiss and M. Tribe (eds), Handbook of Industry and Development. London: Routledge, 65-83. 


\title{
5
}

\section{Urbanization and its Impact on Ghana's Rural Transformation}

\author{
Xinshen Diao, Eduardo Magalhaes, and Jed Silver
}

\subsection{Introduction}

Ghana has rapidly urbanized in recent years and more than half the total population now lives in urban areas. However, urbanization in Ghana has not followed the typical historical pathway for the economic transformation of an agrarian country. As discussed in earlier chapters, urbanization in Ghana has not been driven by an agricultural revolution and the development of a laborintensive manufacturing sector but by rapid growth in the services sector. Moreover, urbanization has involved growth in medium and small towns as well as large cities, perhaps bringing more local opportunities to rural-based households. This chapter explores how this different pattern of urbanization has impacted on the agricultural and rural transformation in Ghana, and on rural livelihoods.

The chapter addresses three broad questions. First, are patterns of rural employment in Ghana changing with urbanization and are those changes related in any systematic way with proximity to urban centers of different sizes? Second, does proximity to different-sized urban centers have any impact on patterns of agricultural intensification? Finally, what are the impacts on household livelihoods and welfare outcomes? To answer these questions the analysis goes beyond the usual agroecological breakdown (Chapter 4 ) and uses a spatial typology of rural areas based on work by Berdegue et al. (2015) and others in Latin America.

The rest of the chapter is structured as follows: Section 5.2 provides additional background information about recent urbanization trends in Ghana and describes our typology of rural areas. Section 5.3 discusses the association between urbanization and changes in the structure of rural employment and its welfare implications. Section 5.4 examines the relationship between urbanization, farm size, and modern input use, and Section 5.5 concludes. 


\subsection{Urbanization Trends in Ghana}

Ghana has always been relatively urbanized compared to other African countries. This is partially due to the post-Independence expansion of the cocoa sector (Jedwab and Moradi 2011), and the promotion of state-owned industries in the late 1960s and early 1970s (Ackah, Adjasi, and Turkson 2014). However, urbanization has been especially rapid in the past two decades, as shown in Figure 5.1. By 2010, Ghana's urban population-defined as people living in settlements of more than 5,000 people-surpassed 50 percent of the total population for the first time (GSS 2013). Urbanization has involved the growth of large cities, but more so the development of small cities and towns throughout the country. There has been substantial migration of workers from rural to urban areas, alongside substantial employment growth in the rural nonfarm economy, leading to a decline in the share of workers remaining in agriculture (Figure 5.2).

\subsubsection{A Spatial Typology of Rural Areas}

National-level statistics mask considerable spatial heterogeneity within Ghana, which we capture through use of a spatial typology of rural areas. Specifically,

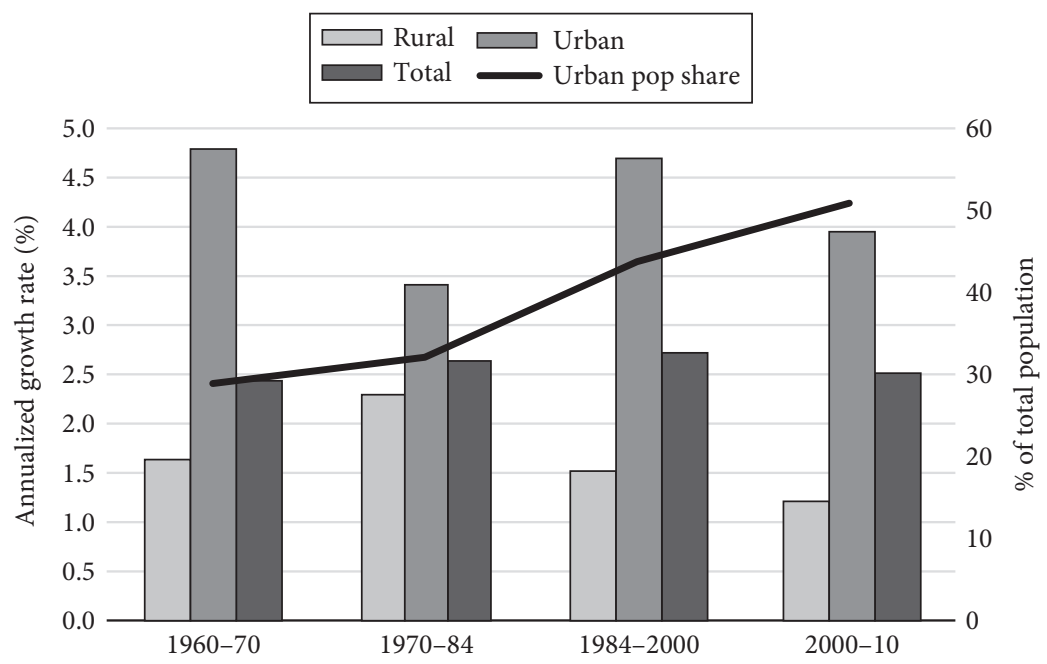

Figure 5.1. Annual growth rate in the population between census years, and urban population share in census years, 1960-2010

Note: Urban population share is for the census years, which is the ending year of each period along the $\mathrm{x}$-axis. Source: Authors' calculation using data from the five rounds of censuses (GSS 2013). 


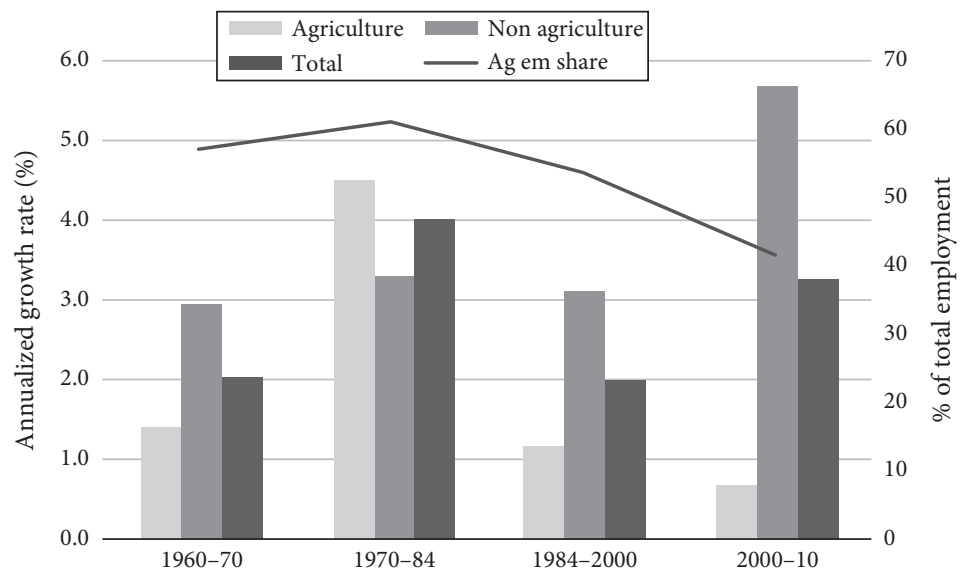

Figure 5.2. Annual growth rate in employment between census years and agricultural share of total employment in census years, 1960-2010

Note: Agricultural employment share is for the census years, which is the ending year of each period along the x-axis.

Source: Authors' calculation using data from the five rounds of censuses (GSS 2013).

we take districts as our primary spatial unit, and classify districts by the size of their largest city. Similar studies have found correlations between the size of a city and its impact on the surrounding rural areas (e.g., Berdegue et al. 2015; Deichmann, Shilpi, and Vakis 2008). An alternative approach would be to capture the effect of proximity to cities using a gravity model as done by Binswanger-Mkhize et al. (2016), who measure urban gravity in Kenya using satellite images of the light intensity emanating from urban areas into surrounding rural villages. However, this approach requires data that is not available for Ghana.

Ghana has a well-defined south-north divide, which, amongst other things, reflects spatial differences in agroecological conditions, population density, rural infrastructure, and levels of urbanization. As a first step in our typology, we therefore differentiate between two major regions based on both the northsouth divide and agroecological conditions. We distinguish between the agriculturally dominant north, comprising the regions of Brong Ahafo, Northern, Upper East, and Upper West, which we call the North. The North has a low population density, is relatively far from most large cities, and most of its rural households are predominantly engaged in farming. The North also corresponds closely to the savanna and transition agroecological zones, and hence has its own well-defined farming systems (Chapter 4). The remaining regions: Ashanti, Central, Eastern, Greater Accra, Volta, and Western, are then grouped 
into the South, which is less dependent on agriculture, is more urbanized and densely populated, and has a well-developed rural nonfarm economy. The South corresponds closely to the forest and coastal agroecological zones, which also have their own well-defined farming systems (Chapter 4).

Taking districts as our primary spatial unit using 2010 census data, each of the two regions is subdivided into four groups based on the proximity of each district to cities of different sizes. Big city districts are those that contain parts of Accra and Kumasi, and hence are only in the South, 2nd-tier city districts are those with cities of between 100,000 and 500,000 people, which are located in both the North and South, 3rd-tier city districts are those with cities containing between 40,000 and 100,000 people, and non-city districts are those with no settlement of over 40,000 people. This leads to a total of seven groups of districts in Ghana, three in the North and four in the South. These are mapped in Figure 5.3.

Although the South covers a much smaller land area than the North, the 2010 census shows that 73 percent of the total population and 63 percent of the rural population live in the South. Moreover, the majority of the total population lives in districts with cities of at least 40,000 people in both regions; 40 percent of the rural population also lives in such districts.

Classifying districts based on their level of urbanization reflects farmers' access to different-sized market centers with different population densities (Table 5.1). As such, more recent interpretations of the induced innovation theory (Pingali et al. 1987; Binswanger and McIntire 1987; McIntire et al. 1992), which emphasize the role of market access as well as population pressure (resulting in decreased access to land) in driving agricultural intensification, suggest that farmers in more urbanized areas will be more likely to adopt agricultural intensification practices and technologies.

\subsection{Changing Patterns of Rural Employment and Welfare Outcomes}

\subsubsection{Changes in Employment}

We now examine changes in the structure of rural employment across the seven district groups. Unlike other studies, we focus on employment at the household rather than individual level in order to distinguish between changing employment patterns that involve entire households shifting sectors, and farm household diversification that involves employment of members in multiple sectors including agriculture. We classify rural households into 


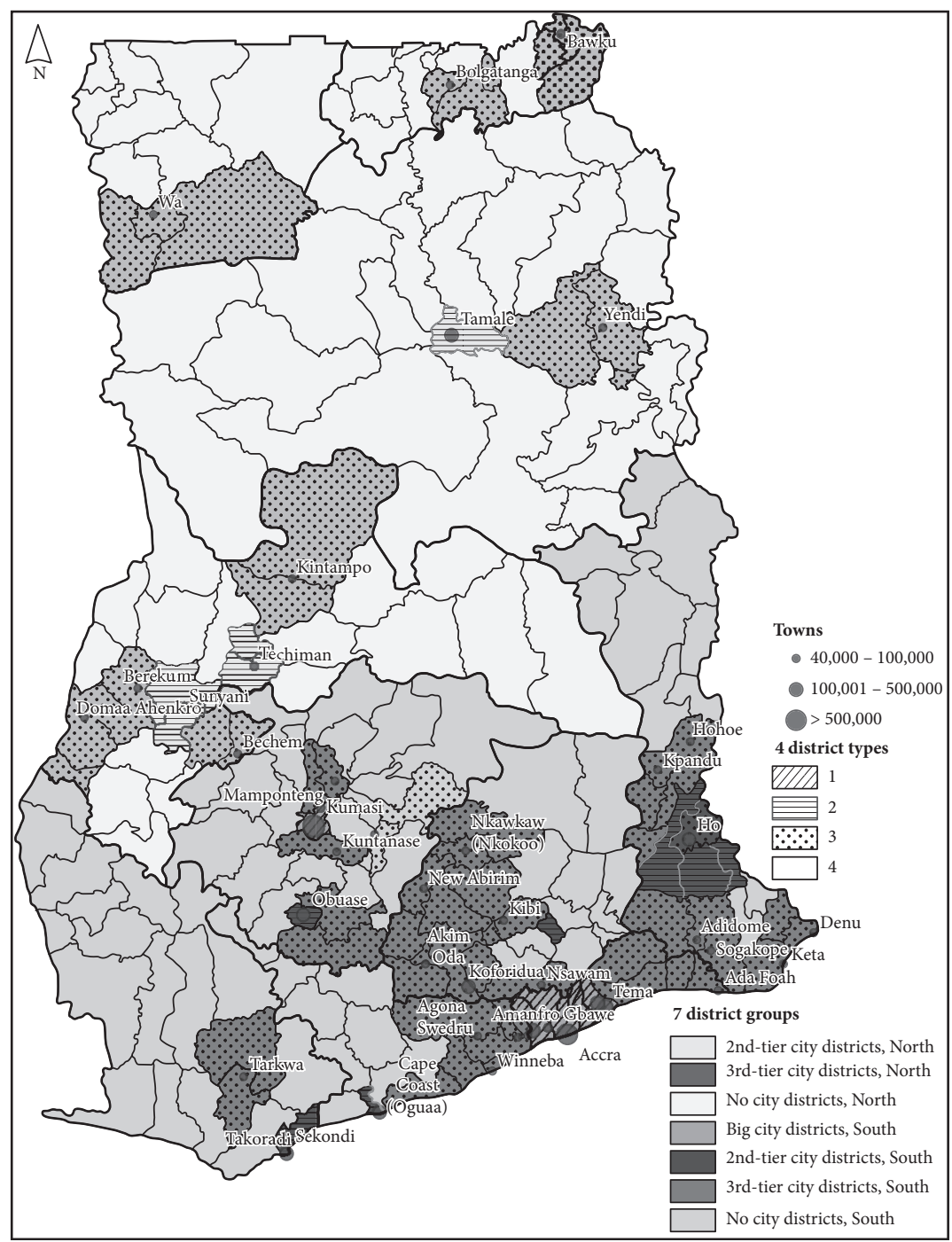

Figure 5.3. Ghana map showing the different types of districts

Source: The map was created by Mekamu Kedir Jemal (IFPRI) who combines 2010 Census data with other spatial data including cities and road networks. Spatial data of cities, towns and road network are from University of Ghana Remote Sensing \& Geographic Info Systems website (http://www.ug.edu.gh/ rsgislab/rs-gis-geonode-app.html).

three types based on members' reported primary occupations in the census or GLSS data: (1) agricultural households that have members whose primary employment is in agriculture and that have no family members primarily engaged in non-agriculture-called agriculture-only households; (2) nonagricultural households that have members whose primary employment is in 
Table 5.1. Population densities by district group, 2000 and 2010 (people $/ \mathrm{km}^{2}$ )

\begin{tabular}{lrrrrrrr}
\hline District Group & \multicolumn{3}{c}{ 2000 } & & & 2010 \\
\cline { 2 - 3 } \cline { 7 - 8 } & Total & Rural & Urban & & Total & Rural & Urban \\
\hline North: & & & & & & \\
2nd-tier city districts & 210 & 72 & 138 & & 257 & 73 & 184 \\
3rd-tier city districts & 57 & 40 & 17 & & 69 & 45 & 24 \\
No city districts & 28 & 23 & 5 & & 37 & 28 & 9 \\
North total & 38 & 27 & 10 & & 48 & 33 & 16 \\
South: & & & & & & \\
Big city districts & 2,410 & 127 & 2,283 & & 3,577 & 129 & 3,448 \\
2nd-tier city districts & 753 & 133 & 620 & & 1,023 & 119 & 904 \\
3rd-tier city districts & 136 & 89 & 48 & & 177 & 100 & 77 \\
No city districts & 71 & 56 & 15 & & 84 & 62 & 22 \\
South total & 135 & 68 & 68 & & 178 & 75 & 102 \\
\hline
\end{tabular}

Source: Authors' calculation using Population and Housing Census 2000 and 2010.

non-agriculture and having no members whose primary employment is in agriculture-called non-agriculture-only households; and (3) households that have members with primary employment in both agriculture and non-agriculture-called mixed households. We ignore a small percentage of rural households that do not report any primary employment. Table 5.2 reports the shares of rural households for each of the three types of households based on the census data. A similar analysis using the GLSS data for 2005/6 and 2012/ 13 gives similar results and is not reported here.

In both the South and North, rural households' exit from agriculture has been highly correlated with proximity to cities and their population sizes. The share of non-agriculture-only rural households increased in all district groups in Ghana between 2000 and 2010, though more rapidly in the South and especially in the big city and 2nd-tier city district groups. This was mirrored by an almost equivalent pattern of decline in the shares of agriculture-only rural households in the South and the district group with 2nd-tier cities in the North. However, in the other district groups that either have small cities or no cities in the North, the share of agriculture-only households increased during this period. Thus, there has been a sizeable movement of household from agriculture to the rural nonfarm economy in the South and in districts with secondary cities in the North. Despite this exit, the share of rural agricultureonly households remains high in district groups without big and secondary cities in both the North and South, averaging 46 percent even in the South in 2010. Only in the areas with relatively larger cities did non-agriculture-only households dominate in the rural areas in 2010. 
Table 5.2. Distribution of rural households by agricultural, nonagricultural, and mixed occupations across district groups (each type of district's total rural households $=100$ )

\begin{tabular}{|c|c|c|c|c|c|c|}
\hline \multirow[t]{2}{*}{ District group } & \multicolumn{3}{|c|}{ North } & \multicolumn{3}{|c|}{ South } \\
\hline & Agri. only & $\begin{array}{l}\text { Non-agri. } \\
\text { only }\end{array}$ & Mixed & $\begin{array}{l}\text { Agri. } \\
\text { only }\end{array}$ & $\begin{array}{l}\text { Non-agri. } \\
\text { only }\end{array}$ & Mixed \\
\hline \multicolumn{7}{|l|}{ Census 2000} \\
\hline Big city districts & & & & 27.7 & 50.3 & 12.3 \\
\hline 2nd-tier city districts & 53.8 & 18.2 & 20.3 & 38.3 & 32.4 & 14.9 \\
\hline 3rd-tier city districts & 58.2 & 11.2 & 19.1 & 50.1 & 21.1 & 18.8 \\
\hline Non-city districts & 62.6 & 8.2 & 19.0 & 61.5 & 13.9 & 17.9 \\
\hline Regional total & 60.9 & 9.7 & 19.1 & 55.3 & 18.4 & 18.0 \\
\hline \multicolumn{7}{|l|}{ Census 2010} \\
\hline Big city districts & & & & 9.0 & 74.1 & 6.6 \\
\hline 2nd-tier city districts & 37.7 & 34.9 & 20.4 & 14.9 & 59.7 & 10.2 \\
\hline 3rd-tier city districts & 63.7 & 14.5 & 17.8 & 39.4 & 34.1 & 17.4 \\
\hline Non-city districts & 67.5 & 10.5 & 18.6 & 53.4 & 23.0 & 17.0 \\
\hline Regional total & 64.7 & 13.0 & 18.5 & 45.6 & 29.7 & 16.7 \\
\hline \multicolumn{7}{|l|}{ Difference in 2000-10 } \\
\hline Big city districts & & & & -18.7 & 23.8 & -5.8 \\
\hline 2nd-tier city districts & -16.1 & 16.6 & 0.0 & -23.4 & 27.4 & -4.7 \\
\hline 3rd-tier city districts & 5.5 & 3.2 & -1.3 & -10.7 & 12.9 & -1.4 \\
\hline Non-city districts & 4.9 & 2.3 & -0.4 & -8.0 & 9.1 & -0.9 \\
\hline Regional total & 3.8 & 3.3 & -0.6 & -9.6 & 11.3 & -1.3 \\
\hline
\end{tabular}

Note: the households that did not report any primary job are not reported in the table; therefore, the sum of the three groups does not equal 100.

Source: Authors calculation using data from the 2000 and 2010 Census (GSS 2003, 2013).

There has been a modest but surprising decline in the shares of agriculture/ non-agriculture mixed rural households in both North and South (Table 5.2). Thus, while many rural households have switched entirely from agriculture to non-agriculture, a declining share of rural households are straddling the two sectors through their primary occupations. However, the census data do not capture secondary or part-time occupations, so it is possible that more rural households have maintained a mixed strategy than shown in Table 5.2, but on a part-time basis.

Some insights about this can be gained from the GLSS data. Figure 5.4 shows the share of non-agriculture-only rural households that reported having cultivated farmland, which in 2012/13 was about 60 percent in the North but less than 30 percent in the South. The size of the land area held by such households is small, mostly less than 2 hectares. However, it does seem that many households whose members' primary occupations lie outside agriculture are still engaged in farming as a secondary or part-time occupation. 


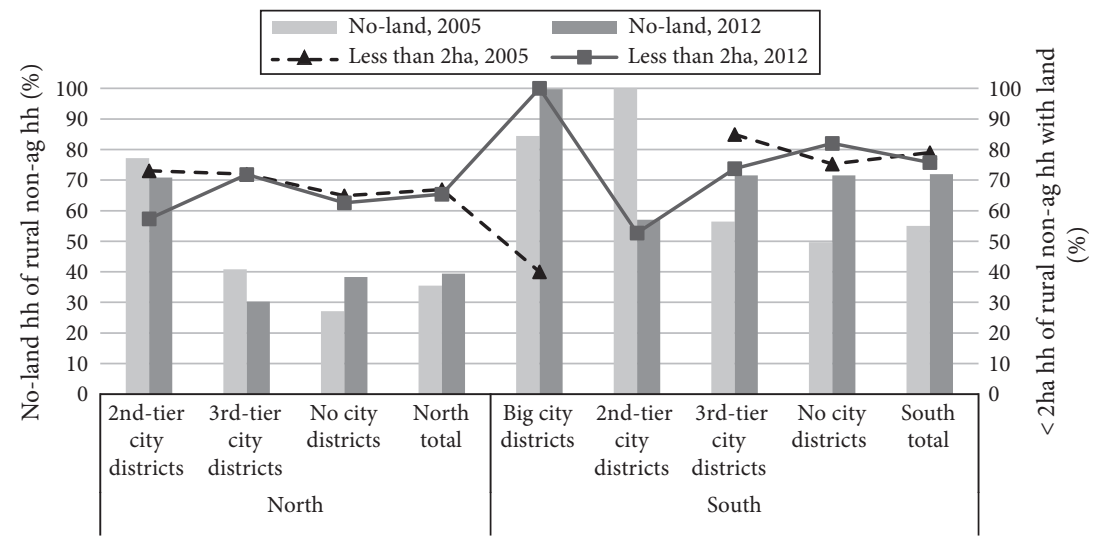

Figure 5.4. Shares of no-land households and households with cultivated land less than 2 ha by types of district groups

Source: Authors' calculations using data from GLSS5 for 2005 and GLSS6 for 2012 (GSS 2008, 2014).

Additionally, some rural households classified as agriculture-only also report having nonfarm household enterprises, though these are likely to be seasonal or part-time activities. This phenomenon was more prevalent in the relatively less urbanized districts, though its importance fell between 2005/6 and 2012/13 (GSS 2008; 2014-not pictured in Figure 5.4).

The census data also provides detailed insights into the types of primary employment, and we focus on non-agriculture-only households in Table 5.3 for such information. By far the largest share of nonagricultural employment in the rural areas is in informal activities, and this is true for all district groups in both census years. Informal trade is more prevalent than informal manufacturing, and more so in 2010 than in 2000. Between the North and South informal manufacturing is also more prevalent in less urbanized areas in the North, as much of it involves small-scale food processing for the local market. The growing importance of informal trade suggests increasing integration of rural areas with urban areas and the broader economy (Haggblade, Hazell, and Brown 1989).

\subsubsection{Changes in Welfare Outcomes}

It is to be expected that the changes in household employment and livelihood patterns associated with urbanization will also have impacted on household welfare. We know from earlier chapters that average per capita incomes have 
Table 5.3. Types of primary employment amongst non-agriculture-only households, by district type, 2000 and 2010

\begin{tabular}{|c|c|c|c|c|c|c|}
\hline & \multicolumn{6}{|c|}{$\begin{array}{l}\% \text { of rural nonagricultural households with family members } \\
\text { engaging in: }\end{array}$} \\
\hline & $\begin{array}{l}\text { Formal } \\
\text { only }\end{array}$ & $\begin{array}{l}\text { Inf. } \\
\text { mfg } \\
\text { only }\end{array}$ & $\begin{array}{l}\text { Inf. } \\
\text { trade } \\
\text { only }\end{array}$ & $\begin{array}{l}\text { Inf. mfg } \\
\text { \& trade }\end{array}$ & $\begin{array}{l}\text { Inf. } \\
\text { others }\end{array}$ & $\begin{array}{l}\text { Formal \& } \\
\text { informal } \\
\text { combined }\end{array}$ \\
\hline \multicolumn{7}{|c|}{2000} \\
\hline \multicolumn{7}{|l|}{ North: } \\
\hline 2nd-tier city districts & 30.1 & 10.5 & 21.6 & 4.3 & 9.7 & 23.7 \\
\hline 3rd-tier city districts & 16.1 & 27.5 & 14.0 & 5.0 & 18.0 & 19.3 \\
\hline No city districts & 21.7 & 25.6 & 18.7 & 2.7 & 15.6 & 15.7 \\
\hline North total & 21.0 & 24.4 & 17.6 & 3.6 & 15.6 & 17.8 \\
\hline \multicolumn{7}{|l|}{ South: } \\
\hline Big city districts & 27.7 & 6.3 & 15.5 & 2.9 & 13.0 & 34.5 \\
\hline 2nd-tier city districts & 24.8 & 10.1 & 22.7 & 3.3 & 12.0 & 27.1 \\
\hline 3rd-tier city districts & 19.4 & 16.2 & 23.6 & 4.9 & 13.7 & 22.1 \\
\hline No city districts & 23.6 & 16.8 & 22.1 & 4.1 & 12.5 & 20.9 \\
\hline South total & 22.1 & 15.3 & 22.2 & 4.3 & 13.1 & 22.9 \\
\hline National total & 21.9 & 16.9 & 21.4 & 4.2 & 13.5 & 22.0 \\
\hline \multicolumn{7}{|c|}{2010} \\
\hline \multicolumn{7}{|l|}{ North: } \\
\hline 2nd-tier city districts & 29.2 & 5.4 & 20.8 & 4.9 & 9.7 & 30.0 \\
\hline 3rd-tier city districts & 24.0 & 14.7 & 21.2 & 4.1 & 14.5 & 21.5 \\
\hline No city districts & 22.9 & 19.0 & 22.0 & 4.2 & 11.4 & 20.4 \\
\hline North total & 24.3 & 15.6 & 21.6 & 4.3 & 12.0 & 22.3 \\
\hline \multicolumn{7}{|l|}{ South: } \\
\hline Big city districts & 24.0 & 6.0 & 19.5 & 3.0 & 10.9 & 36.6 \\
\hline 2nd-tier city districts & 25.4 & 8.8 & 20.0 & 3.8 & 10.1 & 31.9 \\
\hline 3rd-tier city districts & 20.5 & 14.5 & 24.1 & 4.2 & 12.0 & 24.5 \\
\hline No city districts & 23.6 & 13.3 & 25.3 & 3.8 & 11.6 & 22.4 \\
\hline South total & 22.3 & 13.2 & 24.1 & 3.9 & 11.7 & 24.8 \\
\hline National total & 22.6 & 13.5 & 23.7 & 4.0 & 11.7 & 24.4 \\
\hline
\end{tabular}

Source: Authors' calculation using data of Census 2000 and 2010 (GSS 2003; 2013).

grown significantly in Ghana with the economic transformation, that the national poverty rate has fallen, and that a variety of other social welfare indicators (e.g., literacy, mortality rates) have also improved (Chapters 2 and 4). But how have these welfare gains been spatially distributed, and how do they relate to urbanization? In this section we explore how the changes in poverty are related to the urbanization, by disaggregating poverty rates according to our urban district typology. Table 5.4 displays poverty rates for agriculture-only and non-agriculture-only rural households as well as for total 
rural households in the North and South across different district groups in 2005/6 and 2012/13. We were not able to include the mixed households because the sample sizes in the GLSS surveys for this group were too small.

Table 5.4 confirms a widely held view that the rural poverty rate is much higher in the North than in the South; in fact the poverty rate was nearly twice as high in the North as in the South in in 2012/13 (54.4 percent compared to 28.9 percent). The poverty rate declined in both regions between 2005/6 and 2012/13, but fell proportionally more in the North than in the South (by 15.3 percent and 9.1 percent, respectively). So although the poverty rate is still much higher in the North, at least the regional gap is closing. Another general result is that households are poorer than nonagricultural households in both regions, a pattern that did not change between $2005 / 6$ and 2012/13. Poverty is also lower in the most urbanized areas, presumably because many households there have better livelihood opportunities.

Table 5.4. Rural poverty rate in the north and south across district groups

\begin{tabular}{|c|c|c|c|c|c|c|}
\hline \multirow[t]{2}{*}{ District group } & \multicolumn{3}{|c|}{ North } & \multicolumn{3}{|c|}{ South } \\
\hline & $\begin{array}{l}\text { Agri. } \\
\text { only }\end{array}$ & $\begin{array}{l}\text { Non-agri. } \\
\text { only }\end{array}$ & $\begin{array}{l}\text { North } \\
\text { total }\end{array}$ & $\begin{array}{l}\text { Agri. } \\
\text { only }\end{array}$ & $\begin{array}{l}\text { Non-agri. } \\
\text { only }\end{array}$ & $\begin{array}{l}\text { South } \\
\text { total }\end{array}$ \\
\hline \multicolumn{7}{|l|}{$2005 / 2006$} \\
\hline Big city districts & & & & - & - & 11.4 \\
\hline 2nd-tier city districts & 44.7 & - & 39.3 & - & - & 41.3 \\
\hline 3rd-tier city districts & 64.1 & 32.3 & 61.6 & 31.3 & 19.5 & 27.7 \\
\hline Non-city districts & 65.6 & 62.4 & 66.8 & 39.7 & 14.5 & 35.5 \\
\hline Regional total & 64.4 & 50.4 & 64.2 & 36.6 & 16.0 & 31.8 \\
\hline \multicolumn{7}{|l|}{$2012 / 2013$} \\
\hline Big city districts & & & & - & 10.7 & 24.8 \\
\hline 2nd-tier city districts & 40.4 & 10.4 & 38.7 & 5.4 & 5.3 & 4.2 \\
\hline 3rd-tier city districts & 64.8 & 39.2 & 55.3 & 32.8 & 19.7 & 28.6 \\
\hline Non-city districts & 58.4 & 49.6 & 55.2 & 32.7 & 14.2 & 29.9 \\
\hline Regional total & 59.2 & 42.3 & 54.4 & 32.7 & 16.1 & 28.9 \\
\hline \multicolumn{7}{|c|}{ Difference, 2012/13-2005/06 } \\
\hline Big city districts & & & & - & - & 13.5 \\
\hline 2nd-tier city districts & -4.2 & - & -0.5 & - & - & -37.1 \\
\hline 3rd-tier city districts & 0.7 & 6.9 & -6.3 & 1.5 & 0.2 & 0.9 \\
\hline Non-city districts & -7.2 & -12.8 & -11.6 & -6.9 & -0.3 & -5.5 \\
\hline Regional total & -5.2 & -8.1 & -9.8 & -3.9 & 0.1 & -2.9 \\
\hline
\end{tabular}

Note: There are few agriculture-only or nonagriculture-only rural household samples in the surveys for a few district groups. " - " represents such a situation in a particular type of district, where the weighted rural population is less than 100,000 and we therefore did not report the poverty rate.

Source: Authors' calculation using data from GLSS5 for 2005/6 and GLSS6 for 2012/13 (GSS 2008 and 2014). 
Looking at the changes between 2005/6 and 2012/13, the biggest decline in the North was in the rural districts without cities, where it fell proportionally more among nonagricultural than agricultural households. It would seem that the growth in nonfarm employment opportunities for rural households has been a step out of poverty for many. In the South the biggest poverty reduction was in districts with 2nd-tier cities, whilst poverty worsened in districts with big cities. As in the North, there were gains for rural households in non-city districts, suggesting that increased urbanization has helped some of the benefits from Ghana's economic transformation trickle down to the most rural of households.

\subsection{Urbanization and Agricultural Intensification}

\subsubsection{Farm Size Distribution}

Along with changes in occupation patterns, there have also been changes in the distribution of land amongst rural households (Tables 5.5a and 5.5b). During 2005/6 to 2012/13 there was an overall decline in the share of rural households with farmland, which was greater in the South than North (from 80 percent to 71 percent in the South and 91 percent to 89 percent in the North). The decline was most marked in Southern big city districts (from 42 percent to 12 percent). However, despite these changes, the majority of rural households still held cultivated land in 2012/13 in all types of districts except big city districts (Table $5.5 \mathrm{~b}$ ).

Nationally, the share of small farms with less than 2 ha declined from 53.3 percent in 2005/6 to 49.3 percent in $2012 / 13$. This was offset by some increase in the shares of medium-sized farms (2-5 ha and 5-20 ha), while the share of farms larger than 20 ha remained at about 1 percent. Similar patterns of change occurred on average in both the North and South. However, there was a reverse trend in the most urbanized districts of the South, where the shares of small farms increased from 77 percent to 90 percent in big city districts and from 52.6 percent to 61.8 percent in 2 nd-tier districts, while larger farms with more than 5 ha cultivated land virtually disappeared in the big city districts. Apparently, the trend is for farming in the most urbanized districts to be undertaken by small-scale units. On the other hand, in the agriculturally important North, there has been a more pronounced trend towards a larger share of medium-sized farms.

However, these changes in the distribution of rural households by farm size seem not to have affected the average farm sizes of small, medium, and large 
Table 5.5a. Shares of rural households by farm size and district group, 2005/6

\begin{tabular}{|c|c|c|c|c|c|c|}
\hline \multirow[t]{2}{*}{ District Group } & \multirow{2}{*}{$\begin{array}{l}\text { Percent } \\
\text { landless } \\
\text { house-holds }\end{array}$} & \multicolumn{4}{|c|}{$\begin{array}{l}\text { Percent landed households by farm } \\
\text { size }\end{array}$} & \multirow{2}{*}{$\begin{array}{l}\text { Percent } \\
\text { landed } \\
\text { households }\end{array}$} \\
\hline & & $<2$ ha & $2-5$ ha & $5-20$ ha & $>20$ ha & \\
\hline \multicolumn{7}{|l|}{ North } \\
\hline 2nd-tier city districts & 27.0 & 55.5 & 39.0 & 5.6 & - & 73.0 \\
\hline 3rd-tier city districts & 7.9 & 49.6 & 28.9 & 17.8 & 3.8 & 92.1 \\
\hline No city districts & 8.1 & 40.7 & 42.0 & 14.3 & 3.1 & 91.9 \\
\hline Total North & 9.0 & 43.9 & 38.0 & 16.2 & 3.2 & 91.0 \\
\hline \multicolumn{7}{|l|}{ South } \\
\hline Big city districts & 57.9 & 77.2 & 16.2 & 3.1 & 3.5 & 42.1 \\
\hline 2nd-tier city districts & 29.4 & 52.6 & 34.6 & 12.7 & - & 70.6 \\
\hline 3rd-tier city districts & 22.6 & 65.9 & 25.8 & 7.6 & 0.7 & 77.4 \\
\hline No city districts & 16.5 & 52.0 & 31.1 & 15.1 & 1.2 & 83.5 \\
\hline Total South & 20.2 & 58.0 & 28.8 & 11.8 & 1.3 & 79.8 \\
\hline National total & 16.8 & 53.3 & 31.8 & 12.9 & 1.9 & 83.2 \\
\hline
\end{tabular}

Note: Land is defined as cultivated farmland.

Source: Authors' calculation using data of GLSS6 (GSS 2014).

Table 5.5b. Shares of rural households by farm size and district group, 2012/13

\begin{tabular}{lcccccc}
\hline District group & $\begin{array}{l}\text { Percent landless } \\
\text { households }\end{array}$ & $\begin{array}{l}\text { Percent landed households by } \\
\text { farm size }\end{array}$ & $\begin{array}{l}\text { Percent landed } \\
\text { households }\end{array}$ \\
\cline { 3 - 5 } & & $<$ 2 ha & 2-5 ha & 5-20 ha & > 20 ha & \\
\hline North & & & & & & \\
2nd-tier city districts & 22.8 & 40.5 & 37.7 & 20.6 & 1.2 & 77.2 \\
3rd-tier city districts & 7.7 & 49.3 & 35.3 & 13.1 & 2.3 & 92.3 \\
No city districts & 10.2 & 32.5 & 44.4 & 21.7 & 1.4 & 89.8 \\
Total North & 10.3 & 37.3 & 41.7 & 19.4 & 1.7 & 89.7 \\
South & & & & & & \\
Big city districts & 87.8 & 90.3 & 9.7 & - & - & 12.2 \\
2nd-tier city districts & 42.7 & 61.8 & 24.5 & 12.9 & 0.8 & 57.3 \\
3rd-tier city districts & 35.0 & 61.6 & 29.2 & 8.4 & 0.8 & 65.0 \\
No city districts & 22.3 & 52.2 & 34.5 & 13.1 & 0.2 & 77.7 \\
Total South & 28.8 & 55.8 & 32.3 & 11.4 & 0.4 & 71.2 \\
National total & 23.2 & 49.3 & 35.6 & 14.2 & 0.9 & 76.8 \\
\hline
\end{tabular}

Note: Land is defined as cultivated farmland.

Source: Authors' calculation using data of GLSS6 (GSS 2014). 


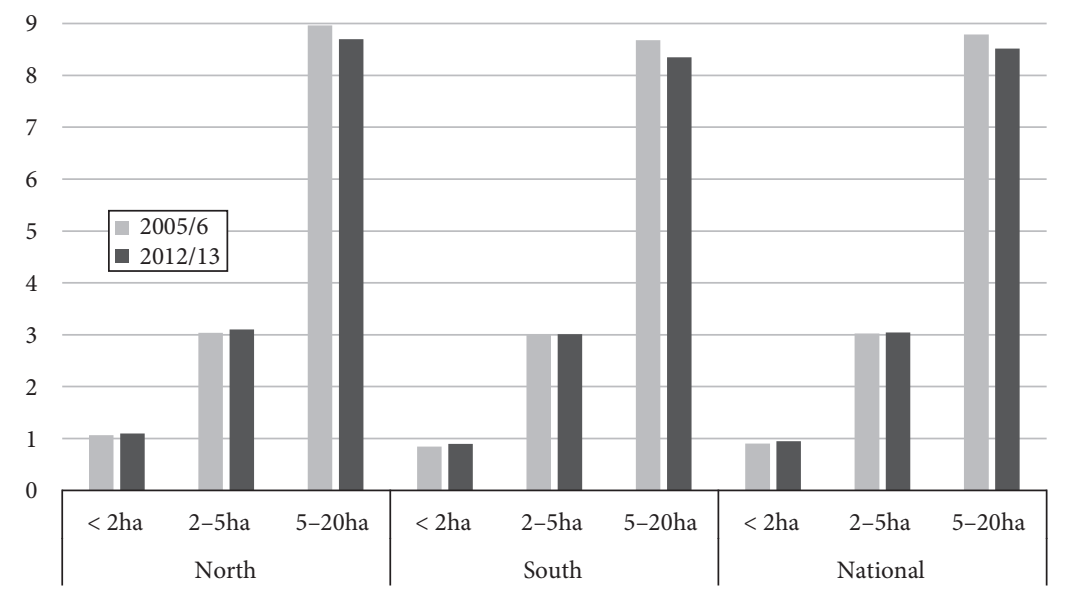

Figure 5.5. Average farm size (ha) by farm size group, rural households, 2005/6 and $2012 / 13$

Note: Farm size is defined according to cultivated farmland and only rural households with cultivated farmland are counted.

Source: Authors' calculation using GLSS5 and GLSS6 (GSS 2008, 2014).

farms (Figure 5.5). The average farm size for the small farms with less than 2 ha is about 0.91 and 0.95 ha in 2005/6 (GLSS5) and 2012/13 (GLSS6), respectively, at the national level, and 3.02 ha and 3.05 ha for the farm size group of 2-5 ha in these two rounds of the surveys, while farms of 5-20 ha in size have become marginally smaller on average. These trends are similar in both the North and South.

\subsubsection{Farming Practices}

Urbanization has had important impacts on rural livelihoods, increasing the share of rural households engaged in the nonfarm economy. It has also contributed to an increase in the share of small, part-time farms in urbanized areas, and a shift towards more medium-sized farms in the agriculturally important areas of the North. The induced innovation hypothesis predicts that urbanization and associated increases in population density and market access should lead to more intensive farming practices, both in terms of landuse patterns and the choice of technologies. We examine these relationships in this section. 
Table 5.6. Share of rural farm households using organic and inorganic fertilizer, 2012/13

\begin{tabular}{llrrrrr}
\hline Type district & $<\mathbf{2 ~ h a}$ & $\mathbf{2 - 5}$ ha & $\mathbf{5 - 2 0}$ ha & $>\mathbf{2 0}$ ha & Total \\
\hline \multirow{2}{*}{ North } & 2nd-tier city districts & 38.7 & 59.1 & 70.3 & 82.0 & 53.4 \\
& 3rd-tier city districts & 55.5 & 67.2 & 63.9 & 84.5 & 61.4 \\
& No city districts & 48.3 & 69.0 & 73.1 & 93.5 & 63.5 \\
& Total North & 50.3 & 68.2 & 71.3 & 89.8 & 62.4 \\
\multirow{2}{*}{ South } & Big city districts & 3.6 & & & & 3.3 \\
& 2nd-tier city districts & 15.7 & 36.4 & 50.4 & 0.0 & 25.1 \\
& 3rd-tier city districts & 23.3 & 42.3 & 58.6 & 48.7 & 32.0 \\
& No city districts & 28.6 & 47.6 & 56.1 & 29.2 & 38.8 \\
& Total South & 26.2 & 45.7 & 56.6 & 40.4 & 36.1 \\
\multirow{2}{*}{ National } & Total & 32.7 & 55.0 & 63.7 & 73.7 & 45.4 \\
\hline
\end{tabular}

Source: Authors calculations using GLSS6.

Fertilizer use, particularly inorganic fertilizer, has increased significantly in Ghana from $3.7 \mathrm{~kg} \mathrm{NPK} / \mathrm{ha}$ arable land in 2002 to $35.8 \mathrm{~kg} / \mathrm{ha}$ in 2013 (Chapter 4). Still, only 45 percent of farmers were using either organic or inorganic fertilizer in 2012/13 (GLSS6), and the share of farmers using fertilizer was nearly twice as high in the less-urbanized North than in the more-urbanized South (Table 5.6), which can be explained by problems with declining soil fertility in the North (Chapters 4 and 6) rather than urbanization. Table 5.6 also shows an inverse relationship between the degree of urbanization of a district and the share of farmers using fertilizer in both the North and South, i.e., the lower the level of urbanization for a district group, the higher percentage of farmers that use fertilizer. Thus, rather than any pattern of induced fertilizer adoption from urbanization, these data suggest that the main drivers of increased fertilizer use may have been a) the need to maintain soil fertility and crop yields in the North as fallow periods were shortened, and b) possibly the introduction the government's fertilizer subsidy policy in 2007/8.

Herbicide and insecticide use in Ghana has also increased sharply in recent years, from less than 2 percent of all farm households in 1998 to about 55 percent in 2013 (Grabowski and Jayne 2016). Nationally, about 70 percent of farm households used herbicides or/and insecticides in 2012/13 (GLSS6), and with the big city district group in the South as an exception (possibly due to few observations covered by the survey), the use of herbicides/insecticides is more evenly distributed between the North and South than is fertilizer use (Table 5.7). In both the North and South, small farms are less likely to use herbicides or insecticides than medium-sized or large farms (with 
Table 5.7. Share of rural farm households using herbicides or insecticides, 2012/13

\begin{tabular}{llccccc}
\hline Type district & $<\mathbf{2}$ ha & $\mathbf{2 - 5}$ ha & $\mathbf{5 - 2 0}$ ha & $>\mathbf{2 0}$ ha & Total \\
\hline \multirow{2}{*}{ North } & 2nd-tier city districts & 85.6 & 93.8 & 78.5 & 100.0 & 87.4 \\
& 3rd-tier city districts & 43.1 & 73.3 & 88.1 & 96.1 & 60.9 \\
& No city districts & 59.0 & 81.4 & 92.4 & 93.8 & 76.7 \\
& Total North & 55.0 & 80.2 & 90.9 & 94.8 & 73.1 \\
\multirow{2}{*}{ South } & Big city districts & 7.3 & & & & 6.6 \\
& 2nd-tier city districts & 56.3 & 62.9 & 94.1 & & 62.4 \\
& 3rd-tier city districts & 59.1 & 79.1 & 84.1 & 69.5 & 67.1 \\
& No city districts & 63.4 & 78.9 & 80.8 & 50.9 & 71.0 \\
& Total South & 61.5 & 78.7 & 82.0 & 60.7 & 69.4 \\
National & & 59.6 & 79.3 & 86.3 & 83.3 & 70.6 \\
\hline
\end{tabular}

Source: Authors' calculations using GLSS6 data.

Table 5.8. Share of rural households using mechanization, 2012/13

\begin{tabular}{llccccc}
\hline & $<\mathbf{2}$ ha & $\mathbf{2 - 5}$ ha & $\mathbf{5 - 2 0}$ ha & $>\mathbf{2 0}$ ha & Total \\
\hline \multirow{2}{*}{ North } & 2nd-tier city districts & 42.3 & 54.2 & 62.3 & 100.0 & 51.6 \\
& 3rd-tier city districts & 20.5 & 43.6 & 51.9 & 96.1 & 34.5 \\
& No city districts & 26.5 & 40.1 & 59.4 & 66.6 & 40.3 \\
& Total North & 25.3 & 41.6 & 58.2 & 78.6 & 39.3 \\
\multirow{5}{*}{ South } & Big city districts & 28.8 & & & & 26.0 \\
& 2nd-tier city districts & 17.1 & 0.0 & 0.0 & 0.0 & 10.6 \\
& 3rd-tier city districts & 23.1 & 36.9 & 50.4 & 69.5 & 29.8 \\
& No city districts & 19.2 & 35.1 & 50.5 & 51.4 & 28.9 \\
& Total South & 20.7 & 35.1 & 49.3 & 60.9 & 28.8 \\
National & & 22.0 & 37.8 & 53.6 & 72.8 & 32.6 \\
\hline
\end{tabular}

Source: Authors' calculations using GLSS6.

exceptions for larger-than-20-ha size group in the South, (again possibly due to few observations in the survey). However, there is no consistent pattern of increased use of herbicides with levels of urbanization within the North or South, suggesting that urbanization is not inducing greater use.

Mechanization. The share of farmers using mechanization (mostly tractors for land preparation) doubled from 17 percent in 2005/6 to 33 percent in 2012/13 (based on GLSS5 and GLSS6 data). About 40 percent of farm households used mechanization in 2012/13 in the North, compared to less than 30 percent in the South (Table 5.8). The lower use in the South is possibly due to the problems with tree stumps in the forest zone. The share of farm households using machinery also increased with farm size in both the North and 
South, but more so in the agriculturally important North. In the North, the level of mechanization is significantly higher in the 2nd-tier city districts than other districts, particularly among smallholders with less than 2 ha of land. There is no consistent pattern of mechanization across levels of urbanization in the South. The factors driving mechanization are explored more fully in Chapter 9.

\subsubsection{Regression Analysis of the Links between Urbanization and Modern Input Adoption}

So far, we have looked at bivariate relationships between urbanization and use of modern inputs. Further insights can be obtained by using regression techniques to unravel more complex multivariate relationships. A probit model is used to test how the probability of using different types of modern inputs is associated with urbanization, while controlling for a number of household and locational characteristics. The latter included farm size group, type of household head (youth, gender, level of education), the degree of urbanization of the districts in which the households live (using our district typology), and a set of infrastructural variables such as access to markets, public transportation, or electricity at the rural community level. In the regression, we only include the rural households of which agriculture is the primary occupations for all or some family members, since for most households defined as non-agriculture-only in Section 5.3any agricultural activity appears to be part-time.

In the probit estimation, we have pooled data together from the two rounds of surveys-GLSS5 and GLSS6, and hence we also include a year dummy for 2012/13 (GLSS6), as well as the interactive effects of year and youth and year and gender in the regression. Still, there are too many missing variables in the regressions to test any causal relationships (e.g., we are unable to control for wages or missing household effects), but they do reveal some interesting patterns of association. We only report the marginal effects of the probit estimation in Table 5.9.

Urbanization, as captured through our typology, has some significant but complex links with agricultural intensification. Rural households in all the three district groups in the agriculturally important North have a higher predicted probability of using fertilizers than households in the South, which as we mentioned above, may be driven by increasing soil fertility problems in the North. However, contrary to the bivariate relationship of Table 5.5, in 
Table 5.9. Probit model regressions for input use, pooled data of GLSS5 and GLSS6

\begin{tabular}{|c|c|c|c|c|}
\hline Independent variable & $\begin{array}{c}(1) \\
\text { Fertilizer }\end{array}$ & $\begin{array}{c}(2) \\
\text { Herbicides/ } \\
\text { Insecticides }\end{array}$ & $\begin{array}{c}(3) \\
\text { Hiring } \\
\text { labor }\end{array}$ & $\begin{array}{c}(4) \\
\text { Mechanization }\end{array}$ \\
\hline \multicolumn{5}{|l|}{ Farm size } \\
\hline Less than 2 ha & $\begin{array}{l}-0.278^{\star * *} \\
(0.0461)\end{array}$ & $\begin{array}{l}-0.147^{* * *} \\
(0.0449)\end{array}$ & $\begin{array}{l}-0.223^{\star * *} \\
(0.0501)\end{array}$ & $\begin{array}{l}-0.286^{* * *} \\
(0.0389)\end{array}$ \\
\hline $2-5$ ha & $\begin{array}{l}-0.140^{* * *} \\
(0.0463)\end{array}$ & $\begin{array}{l}-0.0236 \\
(0.0447)\end{array}$ & $\begin{array}{l}-0.116^{\star *} \\
(0.0503)\end{array}$ & $\begin{array}{l}-0.187^{\star * *} \\
(0.0388)\end{array}$ \\
\hline 5-20 ha & $\begin{array}{l}-0.0842^{\star} \\
(0.0475)\end{array}$ & $\begin{array}{r}0.0709 \\
(0.0462)\end{array}$ & $\begin{array}{r}-0.00961 \\
(0.0519)\end{array}$ & $\begin{array}{l}-0.0869^{* *} \\
(0.0399)\end{array}$ \\
\hline \multicolumn{5}{|l|}{ Base is $>20$ ha } \\
\hline \multicolumn{5}{|l|}{ Types of district groups } \\
\hline 2nd-tier city districts, North & $\begin{array}{c}0.250^{\star * *} \\
(0.0452)\end{array}$ & $\begin{array}{l}0.174^{* * *} \\
(0.0522)\end{array}$ & $\begin{array}{l}0.177^{\star * *} \\
(0.0508)\end{array}$ & $\begin{array}{l}0.0803^{\star *} \\
(0.0383)\end{array}$ \\
\hline 3rd-tier city districts, North & $\begin{array}{l}0.187^{\star * *} \\
(0.0184)\end{array}$ & $\begin{array}{l}-0.172^{\star * *} \\
(0.0181)\end{array}$ & $\begin{array}{l}-0.0150 \\
(0.0205)\end{array}$ & $\begin{array}{r}-0.000881 \\
(0.0172)\end{array}$ \\
\hline No city districts, North & $\begin{array}{c}0.139^{\star * *} \\
(0.0138)\end{array}$ & $\begin{array}{l}-0.0827^{\star * *} \\
(0.0137)\end{array}$ & $\begin{array}{r}0.0103 \\
(0.0154)\end{array}$ & $\begin{array}{r}-0.00338 \\
(0.0128)\end{array}$ \\
\hline Big city districts, South & $\begin{array}{l}0.0217 \\
(0.107)\end{array}$ & $\begin{array}{r}-0.0730 \\
(0.109)\end{array}$ & $\begin{array}{c}0.180^{*} \\
(0.103)\end{array}$ & $\begin{array}{c}0.175^{\star *} \\
(0.0857)\end{array}$ \\
\hline 2nd-tier city districts, South & $\begin{array}{r}-0.00633 \\
(0.0621)\end{array}$ & $\begin{array}{l}-0.159^{* * *} \\
(0.0587)\end{array}$ & $\begin{array}{r}0.0604 \\
(0.0669)\end{array}$ & $\begin{array}{l}-0.0807 \\
(0.0630)\end{array}$ \\
\hline 3rd-tier city districts, South & $\begin{array}{l}-0.0693^{* * *} \\
(0.0156)\end{array}$ & $\begin{array}{l}-0.0404^{* * *} \\
(0.0150)\end{array}$ & $\begin{array}{l}-0.0254 \\
(0.0166)\end{array}$ & $\begin{array}{r}-0.00712 \\
(0.0140)\end{array}$ \\
\hline Base is no city districts, So & & & & \\
\hline
\end{tabular}

Notes: Farm size is based on cultivated area. Rural households defined as agricultural only or agricultural and nonagricultural mixed households in GLSS5 are included in the regressions. ${ }^{*} \mathrm{p}<0.1,{ }^{* *} \mathrm{p}<0.05,{ }^{* * *} \mathrm{p}<0.01$.

Source: Authors' own estimation using GLSS5 and GLSS6 data.

which we could not find a consistent pattern of increased use of fertilizer with levels of urbanization within each of the two regions, the probit estimation shows that in the North, the higher the urbanization level-measured by the size of cities in different district groups, the higher the predicted probability of using fertilizer. For example, compared with households in the South's districts without cities, the predicted probability of using fertilizer increases by 25 percent in the North's districts with secondary cities, while the marginal effects are smaller in Northern districts with 3rd-tier cities or without cities, at 18.7 percent and 13.9 percent, respectively.

The probit estimates show a similar relationship between farm size and use of fertilizer as we observe in Table 5.6, i.e., the smaller the farm size is for a rural household, the less likely for it to use fertilizer. For example, the predicted probability of using fertilizer is 27.8 percent lower for households 
Table 5.9. Probit model regressions for input use, pooled data of GLSS5 and GLSS6 (cont.)

\begin{tabular}{|c|c|c|c|c|}
\hline Independent variable & $\begin{array}{c}(1) \\
\text { Fertilizer }\end{array}$ & $\begin{array}{l}\text { (2) } \\
\text { Herbicides/ } \\
\text { Insecticides }\end{array}$ & $\begin{array}{l}\quad(3) \\
\text { Hiring } \\
\text { labor }\end{array}$ & $\begin{array}{c}(4) \\
\text { Mechanization }\end{array}$ \\
\hline Year dummy for 2013 & $\begin{array}{l}0.156^{\star * *} \\
(0.0108)\end{array}$ & $\begin{array}{c}0.346^{* * *} \\
(0.00876)\end{array}$ & $\begin{array}{l}-0.0743^{* * *} \\
(0.0124)\end{array}$ & $\begin{array}{c}0.149^{* * *} \\
(0.00993)\end{array}$ \\
\hline Youth-headed household & $\begin{array}{r}0.00104 \\
(0.0134)\end{array}$ & $\begin{array}{c}0.0234^{*} \\
(0.0134)\end{array}$ & $\begin{array}{l}-0.0433^{* * *} \\
(0.0147)\end{array}$ & $\begin{array}{l}0.00602 \\
(0.0123)\end{array}$ \\
\hline Female-headed household & $\begin{array}{l}-0.0695^{\star * *} \\
(0.0159)\end{array}$ & $\begin{array}{l}-0.0842^{* * *} \\
(0.0155)\end{array}$ & $\begin{array}{l}0.0612^{* * *} \\
(0.0168)\end{array}$ & $\begin{array}{l}-0.0385^{* * *} \\
(0.0144)\end{array}$ \\
\hline Year dummy* Youth & $\begin{array}{l}0.0596^{\star *} \\
(0.0266)\end{array}$ & $\begin{array}{l}-0.0663^{\star *} \\
(0.0269)\end{array}$ & $\begin{array}{r}-0.0200 \\
(0.02904)\end{array}$ & $\begin{array}{r}0.0295 \\
(0.0245)\end{array}$ \\
\hline Year dummy ${ }^{\star}$ Female & $\begin{array}{r}-0.00362 \\
0.02845\end{array}$ & $\begin{array}{l}-0.0440 \\
(0.0286)\end{array}$ & $\begin{array}{l}-0.0184 \\
(0.0303)\end{array}$ & $\begin{array}{l}-0.0773^{* *} \\
(0.0261)\end{array}$ \\
\hline \multicolumn{5}{|l|}{ Education level } \\
\hline Primary completed & $\begin{array}{l}0.0265^{* *} \\
(0.0134)\end{array}$ & $\begin{array}{l}0.0647^{\star * *} \\
(0.0131)\end{array}$ & $\begin{array}{l}0.0609^{* * *} \\
(0.0144)\end{array}$ & $\begin{array}{l}0.0601^{* * *} \\
(0.0121)\end{array}$ \\
\hline Secondary completed & $\begin{array}{l}0.0828^{* * *} \\
(0.0267)\end{array}$ & $\begin{array}{l}0.0961^{\star * *} \\
(0.0276)\end{array}$ & $\begin{array}{l}0.0833^{\star * *} \\
(0.0303)\end{array}$ & $\begin{array}{l}0.0863^{* * *} \\
(0.0241)\end{array}$ \\
\hline University and above & $\begin{array}{r}0.0130 \\
(0.0894)\end{array}$ & $\begin{array}{l}0.352^{\star * *} \\
(0.148)\end{array}$ & $\begin{array}{r}0.184 \\
(0.142)\end{array}$ & $\begin{array}{r}0.136 \\
(0.143)\end{array}$ \\
\hline \multicolumn{5}{|l|}{ Base is no education } \\
\hline Access to markets & $\begin{array}{l}-0.0335^{\star *} \\
(0.0145)\end{array}$ & $\begin{array}{l}-0.0276^{*} \\
(0.0143)\end{array}$ & $\begin{array}{c}0.0314^{*} \\
(0.0161)\end{array}$ & $\begin{array}{l}-0.0278^{* *} \\
(0.0126)\end{array}$ \\
\hline $\begin{array}{l}\text { Access to public } \\
\text { transportation }\end{array}$ & $0.0418^{* * *}$ & $0.103^{* * *}$ & $0.0769^{* * *}$ & $0.0904^{\star * *}$ \\
\hline Access to electricity & $\begin{array}{r}(0.0125) \\
-0.00848 \\
(0.0124)\end{array}$ & $\begin{array}{l}(0.0124) \\
-0.0381^{\star * \star} \\
(0.0122)\end{array}$ & $\begin{array}{c}(0.0138) \\
0.0284^{\star *} \\
(0.0134)\end{array}$ & $\begin{array}{r}(0.0116) \\
-0.00746 \\
(0.0116)\end{array}$ \\
\hline Observations & 13,388 & 13,340 & 13,340 & 13,340 \\
\hline
\end{tabular}

Notes: Agricultural only or agricultural and nonagricultural mixed rural households in GLSS5 are included in the regressions. ${ }^{\star} \mathrm{p}<0.1,{ }^{* *} \mathrm{p}<0.05,{ }^{* *} \mathrm{p}<0.01$.

Source: Authors' own estimation using GLSS5 and GLSS6 data.

with less than 2 ha of land compared to households with 20 ha or more, but the probability is only 14.0 percent and 8.4 percent lower for those with land of 2-5 ha and 5-20 ha, respectively. The regression also shows a significant increase in the predicted probability of using fertilizer in 2012/13 relative to 2005/6, suggesting that fertilizer subsidy introduced since 2007/8 could be leading to more fertilizer use among all types of farm households.

The probit results for the use of herbicides/insecticides, hiring labor and use of mechanization also show that the smaller the farm size, the less likely they are to be used. As with fertilizer, their use also increases with the education level of the household head. 
While predicted probabilities of fertilizer, herbicide/insecticide and mechanization use are higher in 2012/13, they are lower for hired labor use. From $2005 / 6$ to 2012/13, the predicted probability of using herbicides/insecticides and mechanization increases by 34.6 percent and 14.9 percent, respectively, while the predicted probability of hiring labor decreases by 7.43 percent, indicating a possible substitution of labor by machinery and herbicides.

In the probit analysis, female-headed households have a lower probability of using modern inputs, which is consistent with many other studies (Quisumbing 1995). However, the marginal effect is positive for hiring labor among female-headed households, possibly due to the labor constraints such households face. The sign of the marginal effect for the youth dummy is not consistent and often insignificant in the regressions. This result is somewhat surprising, since younger farmers might be expected to be more open to new technologies and knowledge than older adults.

The marginal effect of urbanization on the use of other inputs is not always consistent with that for fertilizer use. Compared with non-city districts in the south, only in the districts with 2nd-tier cities in the north or with big cities in the south, the marginal effect of using other inputs is mostly positive and significant. The sign of marginal effect tends to be negative, if significant, for the other types of district groups in both North and South.

Among the three variables related to market access or public infrastructure, the marginal effect of input use is positive only for the access to public transportation variable. The probability for any modern input use or labor hiring increases by $4.18-10.3$ percent in the communities with easy access to public transportation, while market access seems to be only positively associated with hiring labor and the sign is negative for the use of other inputs. Market access is measured by whether a rural community has a daily or periodic market. It is also possible that better access to public transportation allows farmers to get access to market through traders who can come to villages directly.

\subsection{Conclusions}

Ghana has rapidly urbanized in recent decades, through the development of many secondary and small cities as well as through growth of large cities, particularly in the South of the country. Urbanization has diversified rural livelihood opportunities, leading to significant growth in the share of rural households engaged primarily in the nonfarm economy. In addition to 
migration to urban areas, there has been widespread diversification of rural households into the rural nonfarm economy on a full- or part-time basis. The result has been a substantial decline in the share of households who depend primarily on agriculture. Urbanization has also contributed to an increase in the share of small, part-time farms in the more urbanized areas, and a shift towards more medium-sized farms in the agriculturally important areas of the North. These patterns of change in household employment have also led to spatial patterns of change in the incidence of poverty. Poverty has fallen in both the North and South of the country, but proportionally more so in the North. And while the impacts are mixed in districts with larger cities, poverty rates have fallen for all household types in the non-city districts. It would seem that increased urbanization has helped some of the benefits from Ghana's economic transformation trickle down to the most rural of households.

The induced innovation hypothesis predicts that urbanization and associated increases in population density and market access should lead to more intensive farming practices, both in terms of the land-use patterns and the choice of technologies. Although there has been substantial uptake of fertilizers, herbicides, and mechanization in recent years, we find only limited support for the hypothesis that this has been driven by urbanization, and this support is mainly in the North and in some districts with big cities in the South. More generally, fertilizer appears to be used mainly for offsetting declining soil fertility rather than intensification. Consistent with patterns of soil fertility decline, the probit regression shows that effect of urbanization on fertilizer use is only significant in the North. This is also consistent with findings in Chapter 6.

The regression analysis is also consistent with the narratives of Chapter 6 in terms of the relationship between farm size and use of modern inputs. Chapter 6 describes how farmers in the savanna and transition zones are cropping larger areas and using mechanization to reduce labor requirements in the face of increasing wages. In the probit regressions here, the probability of fertilizer use and using other inputs and mechanization and hiring labor increases significantly with farm size.

Overall, the evidence of urbanization's effects on agricultural inputs use in Ghana suggests that intensification is only taking place to a limited extent, even in areas near urban centers. Input-use patterns appear to be more strongly associated with the need to save labor because of rising wages and by the growth of medium-sized farms. 


\section{References}

Ackah, C., C. Adjasi, and F. Turkson. 2014. "Scoping Study on the Evolution of Industry in Ghana". Learning to Compete Working Paper No. 18. Washington: Africa Growth Initiative (AGI) at Brookings.

Berdegue, J., F. Carriazo, B. Jara et al. 2015. "Cities, Territories and Inclusive Growth: Unraveling Urban-Rural Linkages in Chile, Colombia, and Mexico." World Development 73: 56-71.

Binswanger, Hans P., and John McIntire. 1987. "Behavioral and Material Determinants of Production Relations in Land-abundant Tropical Agriculture." Economic Development and Cultural Change 36(1): 73-99.

Binswanger-Mkhize, H., T. Johnson, P. Samboko, and L. You. 2016. “The Impact of Urban Growth on Agricultural and Rural Nonfarm Growth in Kenya." Rome: International Fund for Agricultural Development.

Deichmann, U., F. Shilpi, and R. Vakis. 2008. "Urban Proximity, Agricultural Potential and Rural Non-farm Employment: Evidence from Bangladesh." World Development 37(3): 645-60.

Grabowski, P., and Jayne, T. 2016. "Analyzing Trends in Herbicide Use in SubSaharan Africa." East Lansing: Food Security and International Development Working Paper No. 142. Department of Agricultural, Food, and Resource Economics, Michigan State University.

GSS (Ghana Statistical Service). 2003. Population and Housing Census 2000. Census data. Accra.

GSS (Ghana Statistical Service). 2008. Ghana Living Standards Survey Round 5 (GLSS 5). Survey Data. Accra.

GSS (Ghana Statistical Service). 2013. Population and Housing Census 2010. Accra.

GSS (Ghana Statistical Service). 2014. Ghana Living Standards Survey Round 6 (GLSS 6). Survey data. Accra.

Haggblade, S., P. Hazell, and J. Brown. 1989. "Farm-Nonfarm Linkages in Rural Sub-Saharan Africa." World Development 17(8): 1173-201.

McIntire, John, Daniel Bourzat, and Prabhu Pingali. 1992. “Crop Livestock Interaction in Sub-Saharan Africa.” Washington, DC: World Bank.

Pingali, Prabhu, Yves Bigot, and Hans P. Binswanger. 1987. Agricultural Mechanization and the Evolution of Farming Systems in Sub-Saharan Africa. Baltimore, MD: Johns Hopkins University Press.

Quisumbing, Agnes. 1995. "Gender Differences in Agricultural Productivity: A Survey of Empirical Evidence.” FCND Discussion Paper No. 5. Washington, DC: IFPRI. 


\title{
6 \\ Agricultural Transformation in the Savannah
}

\author{
Perspectives from the Village
}

Michael Johnson, Nazaire Houssou, Shashidhara Kolavalli, and Peter Hazell

\subsection{Introduction}

Most of the evidence presented in this book about changes in the agricultural sector draws on secondary data and nationally representative household surveys like the GLSS. This chapter seeks to ground the truth of some of the key findings by providing village and farmer perspectives on important changes that have impacted on their livelihoods since the 1980s, and how they have adapted their farming systems and practices. The chapter also addresses several key questions. What were the key factors driving farmers' adaptation decisions, including the roles of changes in population density and the availability of additional land for cultivation, improved access to markets, changing market demands, increased competition for labor from the rural nonfarm economy, and higher wages? Why, despite continuing rural population growth, have farmers generally chosen to adopt technologies and farming practices that increase labor productivity relative to land productivity? Finally, what happens once options for bringing more land into production become exhausted? As discussed in Chapter 4, how well farmers adjust to increasing land scarcity will be critical for the future sustainability of agricultural growth in Ghana.

The study draws on two sources of evidence. First, the results from interviews conducted during 2015 with focus groups and key informants in four representative villages in the transition and Guinea savannah zones. Villages were selected that provide contrasting situations about the availability of additional land. This study is reported in Section 6.2. Second, a farm modeling exercise was undertaken to simulate the changes in farming practices that have 
occurred in the villages since the 1980s to help identify what have been the main drivers of the adaptations farmers have made. This study is reported in Section 6.3.

\subsection{Village and Farmer Perspectives of Change}

Given limited resources, the village study was undertaken in the Guinea savannah and transition zones. ${ }^{1}$ These zones were chosen because they produce the bulk of Ghana's cereal and legume crops (Chapter 4) and because they are also the zones that have experienced the fastest growth in cultivated area since 1992, which is germane to concerns about the sustainability of past patterns of agricultural growth as the land frontier becomes exhausted.

\subsubsection{Selection of Villages}

The study was conducted in two villages in the transition zone and two in the Guinea savannah zones. In each zone, one village was selected that has reached its land frontier (Type I) and one that still has virgin land left (Type II). The villages (Table 6.1) were selected based on discussions with local officials to represent the typical transformations that have occurred in the two zones.

Interviews were conducted in each village during 2015. These involved focus group discussions, as well as individual interviews with selected farmers, village leaders, and local extension and government officials. Interviews followed a loosely structured format in which interviewees were encouraged to identify important changes and to suggest reasons, rather than trying to test many preconceived hypotheses.

Table 6.1. Location and names of the selected villages

\begin{tabular}{llll}
\hline Agroecological zone & District & \multicolumn{2}{c}{ Village } \\
\cline { 3 - 4 } & & Type I & Type II \\
\hline Transition & Ejura-Sekyedumase & Hiawoanwu & $\begin{array}{l}\text { Sekyerekrom } \\
\text { Guinea savannah }\end{array}$ \\
\hline
\end{tabular}

Note: Sekyekrom and Sakpule are also known as Sakiryiakura and Saakpuli, respectively. Source: Authors' village studies.

\footnotetext{
1 This section draws on a more detailed paper by Houssoul et al. (2017).
} 


\subsubsection{Village Characteristics}

Both Type I villages are connected by tarred roads, whereas the Type II villages are connected by sandy/gravel roads. This suggests that land frontier has been reached first in villages that are better connected to urban centers and markets. None of the villages had good roads in the 1980s, and the tarred roads have been constructed since 2000 .

There have been some improvements in education, potable water, and electrification, though not all villages have progressed evenly. All have benefited since 2005 from massive changes in communication with the introduction of mobile phones. In Sekyerekrom, for example, nine out of ten adults have mobile phones.

There have been changes in access to credit as well. During the 1980s and the 1990s, people borrowed from informal sources such as family, relatives, and friends who did not charge any interest. Now they borrow from formal sources paying interest ranging from 30 to 50 percent-even credit from informal family and friends now comes only with interest.

Population sizes have grown in all four villages since the 1980s, often through in-migration. Census data for 2000 and 2010 show that population growth has slowed in recent years (Table 6.2), except in Sapules where it has increased significantly despite this being one of the poorest villages lacking a school and mains electricity. This was basically because of in-migration attracted by the availability of land.

Apart from farming, other sources of income have emerged, such as petty trading, provision of transport services, and firewood and charcoal production. In the two transition zone villages, which are closer to urban centers in the South, youth are also migrating to urban areas to work as electricians, mechanics, and drivers among other occupations.

Table 6.2. Changes in village population, 2000 to 2010

\begin{tabular}{lrr}
\hline Village & \multicolumn{2}{c}{ Census } \\
\cline { 2 - 3 } & $\mathbf{2 0 0 0}$ & $\mathbf{2 0 1 0}$ \\
\hline Hiawoanwu & 2,582 & 2,718 \\
Tindan & 452 & 451 \\
Sekyerekrom & 524 & 523 \\
Sakpule & 186 & 854 \\
\hline
\end{tabular}

Source: Ghana Statistical Service (2000, 2010). 


\subsubsection{Local Perceptions of Change about Farming Practices}

\subsubsection{Land Use}

Farmers report that land was more abundant (and available closer to homesteads) in the 1980s, and cultivated land was allowed to revert to long-term fallow after three to four years of cropping and replaced by clearing virgin or mature fallow land. Today there is little or no virgin land left in any of the villages, and fallow land is also getting scarce, particularly in the Type I villages. In Sekyerekrom, farmers reported that in the 1990s, virgin land accounted for 60 percent of their farmland, but this had declined to 40 percent by the 2000 s, and today there is none left.

There are also more larger farms today than in the 1980s. In the 1980s, only Sekyerekrom had any farms greater 5 acres, but by 2015 half or more of the farms in all four villages were larger than 5 acres (Table 6.3). The emergence of local land constraints has not prevented farmers from expanding their operations; they are expanding by cultivating lands in other villages that still have available land. For example, more than one half of the farmers in Tindang cultivate lands outside their village boundaries. By 2015, there were higher shares of farms in the largest size group in the Type I villages than in the Type II villages. However, this does not mean that many small farms are being consolidated; rather fallow periods are being shortened and farmers are acquiring additional land away from their villages.

Fallowing is still practiced as part of the farming system, but larger farms tend to fallow a smaller portion of their lands than small farms, probably

Table 6.3. Changes in cultivated farm size distribution (\%)

\begin{tabular}{llcrc}
\hline Village & & Size group (acres) & 1980s & 2015 \\
\hline Type I & Hiawoanwu & $1-5$ & 100 & 20 \\
& & $5-15$ & 0 & 30 \\
& \multirow{2}{*}{ Tindang } & $>15$ & 0 & 50 \\
& & $1-10$ & 100 & 30 \\
\multirow{2}{*}{ Type II } & Sekyerekrom & $>-25$ & 0 & 20 \\
& & $1-5$ & 0 & 50 \\
& & $5-15$ & 50 & 30 \\
& \multirow{2}{*}{ Sakpule } & $>15$ & 30 & 40 \\
& & $1-5$ & 100 & 30 \\
& & $5-30$ & 0 & 20 \\
& & $>30$ & 0 & 30 \\
\hline
\end{tabular}

Source: Authors' village studies. 
because they have greater access to tractors. Farmers in one village suggested that smallholders fallow 80 percent of their land compared to 70 and 30 percent on medium- and large-sized holdings.

\subsubsection{Crop Dynamics}

In the 1980s, farmers produced primarily for their own subsistence needs, and the amount of land they could cultivate was limited by the use of hoes and cutlasses for clearing and preparing land. In Tindang, for example, yellow maize and yams were widely grown, though there was no market for either crop at the time. Women in Sakpule indicated that they used to cultivate groundnuts on a single acre of land given to them by their husbands to complement the grains that the males produced for the family pot. Today farm families have greater need for cash to meet the costs of schooling their children and other essentials like mobile phones. To generate more cash income they farm a larger crop area, and hire tractor services from local providers to plow the fields for them. They pay for this service after harvest. Nearly all farm households market some produce today, though the extent of their participation in markets depends on their farm size.

The changes in cropping choices can be summarized as follows:

Transition zone: In Hiawoanwu during the 1980s and 1990s, the crops grown included maize, cowpea, cassava, yam, tomato, groundnut, cotton, and tobacco. In 2010, tomato, cotton, and tobacco had disappeared, and yam, cassava, and groundnuts had declined to subsistence levels. The main cash crops now are maize and cowpeas. A similar trend is observed in Sekyerekrom. Guinea savannah zone: In Tindang, yams and cassava were important crops in the 1980s, but have now disappeared. The main cash crops today are maize, rice, groundnuts, and soybean. A similar trend is observed in Sakpule, where important crops in the 1980s like yams, cassava, millets, and sorghum have all but disappeared today and the main crops today (in order of importance) are soybeans, cotton, rice, and maize.

In general, farmers have moved from root-based subsistence crops (such as yam and cassava) to grain-legume-based crops (such as maize and groundnuts) that have market value. Yams, which require rich soils, are grown immediately after clearing forests. As soil fertility declines, farmers switch to other crops like maize that are more tolerant of the declining soil fertility. The cropping mix has changed from a subsistence-driven system of intercropping based on multiple crops to a mixed subsistence-commercial system based on a few crops, in which commercialized crops are mostly grown as monocrops, such as maize, cowpea, groundnut, and soybean. 
The crop mix also varies by farms size, in part because of labor and capital constraints. For example, in Tindang, small farmers specialize more in laborintensive and capital-extensive crops like soybeans while larger farms specialize more in capital-intensive but labor-extensive crops like rice. The difference in cropping by farm size in Tindang is as follows:

- Large-scale farmers: 50 percent rice, 30 percent maize, and 20 percent groundnut

- Medium-scale farmers: 50 percent maize, 30 percent rice, and 20 percent groundnut, and

- Small-scale farmers: 30 percent maize, 60 percent soybean, and 10 percent groundnut.

In Hiawoanwu, large scale farmers are not cultivating yams because they require special care and labor-intensive husbandry practices.

Farmers explained that their cropping patterns and farm sizes have been influenced by a number of factors, but especially by their household needs for staple foods and cash, soil fertility problems, the location of their lands relative to their houses, and market opportunities. Changes in rainfall patterns have also induced some changes in the crops and varieties that farmers grow.

\subsubsection{Labor Use}

Back in the 1980s, farmers relied on family and communal labor, which was relatively abundant, and adequate to meet their needs. Land preparation and weeding were undertaken manually. Today communal labor has declined significantly, and farmers are cultivating larger areas. This has increased their dependence on hired labor, and at a time when real wages have been rising.

Hired labor has become scarcer and more expensive in the villages, especially during weeding and harvesting operations. Local workers are often insufficient to meet the demand and as a result, migratory workers are helping to fill the gap. In Tindang, laborers migrate from West Mamprusi and Savalegu to the village to offer their services during the farming season. Laborers also migrate from the Guinea savanna zone in the north to the transition zone in the south.

Labor constraints affect different sized farmers differently. Large farms are particularly affected because they need to mobilize more laborers than small farms, and who may not be available at the time needed. On the positive side, large farmers can afford to bring labor from as far as the Northern region, and small farms can access such laborers after they have worked on the large farms. With increasing labor scarcity (and cost), other technologies such as herbicides and tractors for land preparation have emerged as substitutes. 


\subsubsection{Mechanization}

Tractor plowing and maize shelling have increasingly become standard farming practices in the villages. This trend is broadly consistent with regional patterns (Table 6.4). However, access to these technologies differs depending on farm size. Whereas access to tractors is relatively easy for medium- and large-scale farmers, smallholder farmers need to organize to secure tractor services, especially in communities where there is a limited number of locally owned tractors. Some medium- and large-scale farmers also own machines. Increasingly, mechanized farming seems to have shifted labor bottlenecks from land preparation to weeding and harvesting operations.

\subsubsection{Herbicides}

An important labor-saving innovation has been the introduction of herbicides in the villages. The use of herbicides has led to a drastic reduction in the use of hoes, cutlasses, and manual labor for weeding. Herbicide use has also replaced the practice of slash-and-burn cultivation. Weed problems seem to have increased as soil fertility has declined. The uptake of herbicides for land preparation (nonselective) and weed control (selective) occurred in the early 1990s in Hiawoanwu and the early 2000s in Sekyerekrom. Today, the use of herbicides to clear lands before plowing is widespread in the villages. One of the farmers suggested that plowing to clear lands without first applying herbicide lowers germination, limits plant growth, and leads to lower yields. They believe that plowing in dead weeds enriches the soils. However, on-farm weed control by resource-constrained smallholder farmers is still sometimes done manually using family labor. A farmer in Sekyerekrom indicated that in the absence of herbicides, many medium- and small-scale farms would have to scale down their operations.

Table 6.4. Trends in the share of farmers renting mechanical equipment, by farm size

\begin{tabular}{|c|c|c|c|c|c|c|}
\hline \multirow[t]{2}{*}{ Farm category } & \multicolumn{3}{|c|}{ Transition zone } & \multicolumn{3}{|c|}{ Guinea savannah zone } \\
\hline & 1998 & 2005 & 2012 & 1998 & 2005 & 2012 \\
\hline \multicolumn{7}{|c|}{ Percent of farms } \\
\hline$<5$ acres & 0.0 & 4.7 & 7.6 & 6.9 & 3.1 & 12.5 \\
\hline$\geq 5-12$ acres & 4.5 & 2.4 & 9.6 & 6.0 & 4.8 & 25.6 \\
\hline$\geq 12-25$ acres & 0.0 & 12.1 & 18.1 & 12.5 & 6.5 & 38.4 \\
\hline$\geq 25$ acres & 3.7 & 22.5 & 9.0 & - & 7.7 & 35.8 \\
\hline Average & 1.5 & 5.3 & 9.8 & 6.8 & 4.6 & 23.3 \\
\hline
\end{tabular}

Source: Ghana Statistical Service $(1998,2005,2012)$. 


\subsubsection{Fertilizer Use}

Little inorganic fertilizer was used in the 1980s, but today its use is widespread, largely because the fertility of most of the farmed lands has declined. However, farmers use less than the recommended rate of fertilizer for many reasons, including financial constraints, risk management, outdated recommendations, knowledge of their own soils, and the availability of fallow lands. For example, in Sakpule, only 50 percent of farmers in the village applied ammonia in addition to the compound fertilizer, while 75 percent of farmers applied only half of the recommended rate of NPK per acre. Without chemical fertilizers, it seems clear that yields could not have been maintained as lands were more continuously cropped. Organic fertilizers, such as manure are rarely used, except in Tindang, where it is used on a limited scale by cattle owners.

In Hiawoanwu and Sekyerekrom in the transition zone, a standard practice for maintaining soil fertility is the use of a maize-cowpea rotation between major and minor seasons. Likewise in Tindang, farmers practice a soybeanmaize rotation. The nitrogen fixed in the soil by a legume crop like cowpea or soybean benefits the maize crop that follows, enabling farmers to apply less or no chemical fertilizers and to save on their production costs.

\subsubsection{Seeds}

Local and late-maturing varieties of crops were planted in the early 1980s, but many of these have been replaced over time by improved varieties. In Sakpule, farmers indicated that the pattern of rainfall has changed in the past thirty to forty years, and they have switched from local to improved and early-maturing varieties of maize such as Okomasa and Obtampa, and to new crops such as soybean and cotton. Soybean varieties like Jenguma have also been adopted by farmers in the Guinea savannah zone owing to the crop's resistance to shattering, which helps reduce yield losses resulting from late harvesting. Although farmers have adopted improved and early maturing varieties, most of them do not purchase seeds on the market but rely instead on recycled seeds selected from the previous season, a pattern also reported by Ragasa et al. (2013). Furthermore, with declining soil fertility and exhaustion of virgin lands, the major varieties of yam grown have also changed. Modern cultivars are more tolerant of drier conditions and can thrive in less fertile soils, producing big tubers that are consumed domestically but have limited market potential. Amanor and Pabi (2007) also note that yams cultivated with inorganic fertilizers grow to be large but they develop an unpleasant hairy appearance that repels urban consumers. 


\subsubsection{Structure of Farm Input Costs}

The structure of farm input costs has changed over the years in the two zones as shown in Table 6.5. The share of hired labor in total crop expenditure declined between 1998 and 2012, while the shares of fertilizers, herbicides, and insecticides increased. Interestingly, the cost share for mechanical inputs (rented equipment) changed little in the Guinea savannah zone, and remained small in the transition zone despite some increase. The cost share of purchased seeds declined during the same period.

\subsubsection{Productivity}

Farmers were unanimous in their views about yield trends, indicating that land was very fertile in the 1980s, no fertilizer was used, and yields were very good, and at least sufficient to meet their subsistence needs. Currently, in order to obtain comparable yields, farmers indicated that they must apply fertilizer, though they use it sparingly. Table 6.6 also shows that reported yields have been maintained or have increased only slightly, except in Hiawoanwu where farmers claim maize yields have doubled with the use of fertilizer. The generally modest growth in yields is consistent with national data on cereal yields, especially of maize and rice (see Chapter 4 ).

Table 6.5. Selected farm input costs ( $\%$ of total crop expenditure)

\begin{tabular}{|c|c|c|c|c|c|c|}
\hline \multirow[t]{2}{*}{ Input type } & \multicolumn{3}{|c|}{ Transition zone } & \multicolumn{3}{|c|}{ Guinea savannah zone } \\
\hline & 1998 & 2005 & 2012 & 1998 & 2005 & 2012 \\
\hline Hired labor & 43.3 & 39.6 & 31.6 & 18.4 & 23.3 & 13.4 \\
\hline Inorganic fertilizer & 2.8 & 8.5 & 12.5 & 6.9 & 16.2 & 26.2 \\
\hline Seed & 6.2 & 4.9 & 3.2 & 4.2 & 7.7 & 2.3 \\
\hline Insecticides & 0.9 & 2.3 & 2.7 & 1.0 & 1.8 & 3.0 \\
\hline Herbicides & 0.3 & 6.0 & 22.1 & 0 & 0.3 & 12.1 \\
\hline Rented equipment & 0.1 & 0.4 & 1.9 & 11.4 & 4.6 & 10.8 \\
\hline
\end{tabular}

Source: Ghana Statistical Service $(1998,2005,2012)$.

Table 6.6. Trends in maize yields ( $\mathrm{t} / \mathrm{ha})$

\begin{tabular}{|c|c|c|c|c|c|}
\hline & & Hiawoanwu & Sekyerekrom & Tindang & Sakpule \\
\hline \multicolumn{2}{|c|}{ 1980s (without fertilizer) } & 0.8 & 1.0 & 1.0 & 1.3 \\
\hline Current yield & $\begin{array}{l}\text { Without fertilizer } \\
\text { With fertilizer }\end{array}$ & $\begin{array}{l}- \\
1.6\end{array}$ & $\begin{array}{l}0.5 \\
1.3\end{array}$ & $\begin{array}{l}0.4 \\
1.0\end{array}$ & $\begin{array}{l}0.6 \\
1.4\end{array}$ \\
\hline
\end{tabular}

Source: Authors' village studies. 
Table 6.7. Value of agricultural production, income, and consumption expenditures (real US\$)

\begin{tabular}{|c|c|c|c|c|c|c|}
\hline \multirow[t]{2}{*}{ Indicators } & \multicolumn{3}{|c|}{ Transition zone } & \multicolumn{3}{|c|}{ Guinea savannah zone } \\
\hline & 1998 & 2005 & 2012 & 1998 & 2005 & 2012 \\
\hline $\begin{array}{l}\text { Estimated value of agricultural } \\
\text { production (real US\$/ha) }\end{array}$ & 168 & 219 & 353 & 128 & 187 & 297 \\
\hline Share of nonfarm income (\%) & 16.8 & 20.2 & 28.4 & 11.3 & 14.6 & 20.8 \\
\hline $\begin{array}{l}\text { Annual per capita } \\
\text { expenditure (real US\$) }\end{array}$ & 284 & 320 & 734 & 156 & 219 & 512 \\
\hline
\end{tabular}

Source: Ghana Statistical Service (1998, 2005, 2012).

Land productivity (value of production per ha) more than doubled between 1998 and 2012 in both the transition and savannah zones, even though cereal yields did not increase by much (Table 6.7). This reflects changes in the cropping pattern (with increases in crops oriented for the market), as well as changes in real farm gate prices.

\subsubsection{Incomes}

With increases in the average cropped area per farm and land productivity, farm incomes have increased. At the same time, farm households have about doubled their nonfarm sources of income (Table 6.7), which now accounts for 20-30 percent of their household income. The net result has been a substantial increase in household welfare, as measured by real per capita expenditure (Table 6.7). This increased by 260 percent between 1998 and 2012 in the transition zone, and by 328 percent in the Savannah zone.

\subsubsection{Conclusions from the Village Narratives}

Since the 1980s, farmers in the savannah and transition zones have responded to increasing population pressure, changing household needs and expanding market opportunities, by increasing the size of their farms and growing more market-oriented crops. This adjustment has been complicated by an increasing scarcity of virgin land, which has compelled farmers to reduce fallow periods or acquire land in other more distant communities that still have a virgin land frontier. With shortened fallow periods, there has been a decline in soil fertility, and farmers have had to adjust by using inorganic fertilizeressentially to maintain rather than increase yields, introduce soil fertility 
management practices like legume-cereal rotations, and adopt new crops and crop varieties that are more tolerant of less fertile soils and to changing rainfall patterns. Another factor complicating farmers' adaptation has been the increasing cost of labor and growing difficulties in accessing it at critical times of the agricultural season. Farmers have adjusted to this problem by adopting labor-saving technologies like tractors and herbicides, and by growing less labor-using crops.

One result of all these changes is that the composition of outputs has changed from root-based crops for local consumption to grain-legumebased cash crops that are increasingly commercialized. However, because farmers have invested more in labor-saving technologies like mechanization and herbicides than in land-saving technologies like improved seeds and fertilizers, yields have increased only marginally. Yet with the increase in the average cropped area per farm, changes in the crop mix, and an increase in nonfarm incomes, most farm households have managed to make substantial welfare gains since the 1980s, whether measured by the value of agricultural production or household consumption expenditure.

\subsection{A Farm Model Analysis}

In order to better understand the factors driving changes at the farm level and how well farmers have adapted, a mathematical programming model was constructed for farms in a typical village in the transition zone and used to simulate farming practices in 1990, 2000, and 2010. The model is solved for different assumptions about changes in land and labor supplies, technology, wages, and commodity prices, which allows the contributions of different drivers of change to be unraveled.

Three models representing small, medium, and large farms were constructed and results derived for each farm size and for the average village farm. The model assumes rational choice behavior, and in particular that farmers are risk averse and maximize an expected income standard deviation utility function as described in Hazell and Norton (1986). Decisions are made subject to three types of land constraints (virgin, fallow, and continuously cropped lands) and seasonal labor constraints. The total crop area available to the village each year and its allocation between virgin, fallow, and continuously cropped land, are exogenously fixed in the model for each sized farm using data from the village narratives. The model allows farmers to choose which crops to grow and which technologies to use in each of two seasons, where the 
technologies reflect the options for improved seeds, fertilizer, herbicides, and tractors that were available in different decades. Tractor services and seasonal labor can be hired in, and family labor can be hired off farm up to seasonal limits. Some crops, such as vegetables, are excluded from the model due to their small area allocation (primarily to meet subsistence needs) relative to cereals, legumes, and root crops. As in Hazell and Norton (1986), model solutions corresponding to different degrees of risk aversion were compared to actual cropping patterns to select a "best fitting" value of the risk-aversion coefficient.

\subsubsection{Results for Average Farm}

The model was parameterized using data collected during the interviews in Hiawoanwu and Sekyerekrom villages in the transition zone, and from a variety of secondary sources. Additional details of the model and parameter assumptions are presented in the Appendix to this chapter. Table 6.8 presents key results for the average village farm in 1990, 2000, and 2010. This is a weighted average of the results for the small-, medium- and large-sized farms, where the weights are the shares of the three groups in total farms in 1990, 2000, and 2010.

The model results replicate many of the changes in farming practices reported in the village narratives, and provide quantitative estimates about aspects of those practices that could not be elicited during the interviews. Some of the changes were imposed on the model through the resource constraints, most notably the increases in the cultivated farm sizes between 1990 and 2010, and the declining importance of fallow and virgin land and the increasing use of continuously cropped land. In particular, the assumed changes led to the average farm more than doubling its crop area (from 8.8 to 20.7 ha between 1990 and 2010, which was achieved by increasing its continuously cropped area from 2.1 to 13.7 ha, while the fallow and virgin land under cultivation increased modestly; from 4.93 to 5.59 ha and 1.76 to 2.9 ha, respectively, but fell sharply as shares of the total cropped area. Changes in the farm size distribution used to calculate the average farm each year were also exogenous. But most other changes are endogenous to the model. Some key results are as follows:

- Expected farm income more than tripled between 1990 and 2010. This is in line with the increases in annual per capita expenditure reported by the Ghana Statistical Service in Table 6.7. The higher income was achieved without any apparent increase in risk, as measured by the coefficient of variation of income $(\mathrm{CV})$. 
Table 6.8. Model results for the average farm in the representative transition zone village, 1990, 2000, and 2010

\begin{tabular}{|c|c|c|c|c|c|}
\hline & 1990 & 2000 & 2010 & $\begin{array}{c}\text { Ratio } \\
2010 / 2000\end{array}$ & $\begin{array}{c}\text { Ratio } \\
2010 / 1990\end{array}$ \\
\hline Expected income $(\$, 000)$ & 6.2 & 11.1 & 20.2 & 1.82 & 3.25 \\
\hline CV income (\%) & 0.1 & 0.1 & 0.1 & 0 & 0 \\
\hline Cultivated area (ha) & 8.8 & 14.1 & 20.7 & 1.46 & 2.35 \\
\hline \multicolumn{6}{|l|}{ Type land (\%) } \\
\hline Continuously cropped & 24 & 45 & 66 & 1.47 & 2.75 \\
\hline Fallow & 56 & 37 & 27 & 0.73 & 0.48 \\
\hline Virgin & 20 & 18 & 14 & 0.78 & 0.70 \\
\hline \multicolumn{6}{|l|}{ Crop mix (\%) } \\
\hline Yam/cassava & 34 & 22 & 10 & 0.45 & 0.29 \\
\hline Maize based & 66 & 78 & 90 & 1.15 & 1.36 \\
\hline \multicolumn{6}{|l|}{ Crop output (Kg) } \\
\hline Cassava & 20,002 & 9,024 & 10,652 & 1.18 & 0.53 \\
\hline Cowpeas & 0 & 7,307 & 17,324 & 2.37 & - \\
\hline Groundnuts & 6,220 & 5,163 & 3,969 & 0.77 & 0.64 \\
\hline Maize & 12,794 & 33,278 & 53,607 & 1.61 & 4.19 \\
\hline Yams & 17,860 & 9,191 & 10,078 & 1.10 & 0.56 \\
\hline \multicolumn{6}{|l|}{ Labor use (days) } \\
\hline Family labor & 577 & 776 & 878 & 1.13 & 1.52 \\
\hline Hired labor & 690 & 630 & 1,138 & 1.81 & 1.65 \\
\hline Total labor & 1,267 & 1,406 & 2,016 & 1.43 & 1.59 \\
\hline Total labor (days/ha) & 145 & 100 & 97 & 0.97 & 0.67 \\
\hline \multicolumn{6}{|l|}{ Labor and land productivity } \\
\hline Total labor (\$/day) & 3.0 & 5.5 & 8.0 & 1.45 & 2.67 \\
\hline Land productivity (\$/ha) & 626 & 695 & 886 & 1.27 & 1.42 \\
\hline \multicolumn{6}{|l|}{ Technology adoption } \\
\hline Fertilizer (kg/ha) & 16.4 & 28.0 & 33.9 & 1.21 & 2.07 \\
\hline Total fertilizer (kg) & 143 & 396 & 703 & 1.77 & 4.92 \\
\hline Fertilizer (\% maize area) & 49 & 63 & 82 & 1.32 & 1.67 \\
\hline Land under tractors (\%) & 7 & 45 & 86 & 1.91 & 12.29 \\
\hline Seeds (\% farm area) & 65 & 100 & 100 & 1.00 & 1.54 \\
\hline
\end{tabular}

Source: Authors' model results.

- As in the farm narratives, there is a marked shift from a root-based cropping system based on yams and cassava to a grain-based cropping system based on maize and legumes. The preferred legumes are groundnuts and cowpeas.

- The output of cassava, groundnuts, and yams declined by 47,36 , and 44 percent, respectively, between 1990 and 2010 while there was a fourfold increase in maize production, and cowpeas production went from zero to $17,324 \mathrm{~kg}$. 
- Total labor use per hectare declined by one third due to greater use of labor-saving technologies and less labor-intensive crops, but total labor use on the farm increased by 60 percent, mainly because of the increased cropped area. Family and hired labor use increased by 52 and 65 percent, respectively, but all the increase in the use of hired labor occurred between 2000 and 2010 .

- The percentage of the cropped area plowed with tractors increased from 7 percent in 1990 to 86 percent in 2010.

- Fertilizer use per hectare doubled between 1990 and 2010, but its use still remained moderate at $33.9 \mathrm{~kg} / \mathrm{ha}$ in 2010 . Total fertilizer use increased much more, by about 400 percent, because of the increased crop area as well as more intensive use of fertilizer. Much of the fertilizer is applied to the maize crop, 82 percent of which was fertilized in 2010, up from 49 percent in 1990.

- The use of improved maize seeds increased from 65 percent of the maize area in 1990 to 100 percent in 2000, and remained at full adoption through 2010. Even higher yields might have been obtained with hybrid maize, but this was not included as an option in the model because hybrid seeds were virtually unattainable in the study area over the period modeled.

- While labor productivity increased by 167 percent between 1990 and 2010 , land productivity (income per hectare) increased by a more modest 42 percent. These increases translate into annualized growth rates of 1.7 percent for labor productivity and 3.9 percent per annum for land productivity. The growth in land productivity is primarily the result of a larger cropped area, a shift towards higher value crops, and the adoption of labor-saving technologies, as also reported from the village narratives.

\subsubsection{Differences by Farm Size}

Table 6.9 and Figure 6.1 highlight some important differences in the results by farm size.

Small farms increased their cropped area by 92 percent between 1990 and 2010, compared to 51 percent for medium-sized farms and 27 percent for large farms. These changes were exogenous to the model, but importantly small farm income increased proportionally more than the incomes of the medium and large farms; by 222 percent verses 134 percent and 85 percent, 
Table 6.9. Selected model results by farm size group, representative village in the transition zone, 1990, 2000, and 2010

\begin{tabular}{|c|c|c|c|c|c|c|c|c|c|}
\hline \multirow[t]{2}{*}{ Variable } & \multicolumn{3}{|c|}{ Small farm } & \multicolumn{3}{|c|}{ Medium farm } & \multicolumn{3}{|c|}{ Large farm } \\
\hline & 1990 & 2000 & 2010 & 1990 & 2000 & 2010 & 1990 & 2000 & 2010 \\
\hline Expected income $(\$ 000)$ & 2.2 & 4.0 & 7.1 & 5.6 & 7.9 & 13.1 & 18.6 & 23.8 & 34.5 \\
\hline CV income (percent) & 19 & 16 & 9 & 17 & 17 & 9 & 11 & 13 & 7 \\
\hline Cropped area (ha) & 1.3 & 1.8 & 2.5 & 6.4 & 7.9 & 9.7 & 33.0 & 37.1 & 41.8 \\
\hline \multicolumn{10}{|l|}{ Crop mix (percent) } \\
\hline Yam/cassava & 42.1 & 44.8 & 23.8 & 30.2 & 12.0 & 8.7 & 17.0 & 1.2 & 1.5 \\
\hline Maize based & 57.9 & 55.2 & 76.2 & 69.8 & 88.0 & 91.3 & 83.0 & 98.8 & 98.5 \\
\hline \multicolumn{10}{|l|}{ Labor use (days) } \\
\hline Total labor & 241 & 306 & 323 & 1,028 & 982 & 991 & 4,519 & 3,335 & 3,970 \\
\hline Hired & 0 & 0 & 0 & 173 & 0 & 114 & 3,260 & 2,099 & 2,744 \\
\hline Total (days/ha) & 185 & 170 & 129 & 160 & 124 & 102 & 137 & 90 & 95 \\
\hline \multicolumn{10}{|l|}{ Technology adoption } \\
\hline Fertilizer (kg/ha) & 14.5 & 20.7 & 28.6 & 17.5 & 29.2 & 34.2 & 20.7 & 37.0 & 36.9 \\
\hline Total fertilizer (kg) & 19 & 37 & 71 & 112 & 231 & 332 & 685 & 1,374 & 1,544 \\
\hline Fertilizer (\% maize area) & 41 & 38 & 62 & 54 & 78 & 84 & 71 & 98 & 97 \\
\hline Land under tractors (\%) & 0 & 5 & 60 & 8 & 47 & 91 & 27 & 98 & 99 \\
\hline Seeds ( $\%$ of farm area) & 80 & 100 & 100 & 58 & 100 & 100 & 28 & 100 & 100 \\
\hline
\end{tabular}

Source: Authors' model results.

respectively. Although small farms followed medium and large farms in shifting from a root-based to a maize-based cropping system, the shift was more muted, in part because of their own consumption needs for these crops.

Total labor use increased by 34 percent (from 241 to 323 days) on small farms between 1990 and 2010, but declined by 4 percent and 12 percent, respectively, on medium and large farms. This reflects changes in the labor intensity of their different cropping patterns and differences in the uptake of tractor mechanization. Small farms also use more labor per hectare than medium and large farms in all three years. Hired labor is used mostly on large farms but their total use fell by 16 percent between 1990 and 2010 . Small farms do not use any hired labor in the model results, and medium-sized farms used only moderate amounts. Small farms use less fertilizer per hectare than larger farms in all three years, but they also fully adopt improved maize seeds by 2000 .

Finally, while there is a more than doubling of labor productivity for all sized farms, land productivity (income per hectare) increases more modestly, by 53 percent, 46 percent, and 45 percent for small, medium, and large farms. These translate into annualized growth rates in labor productivity of 


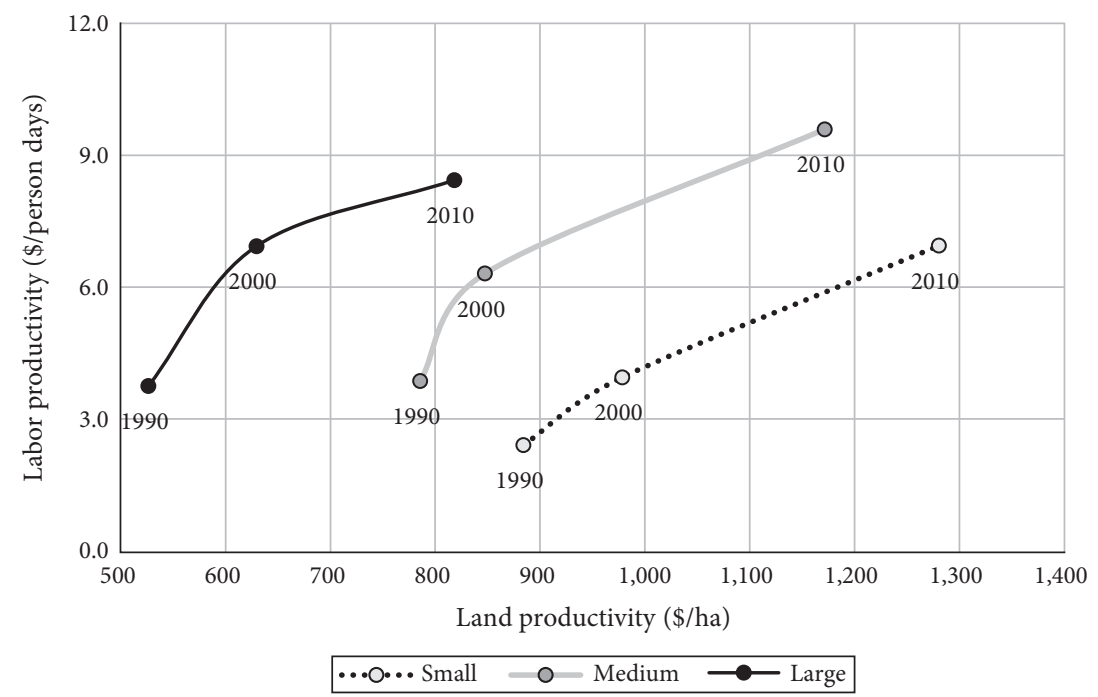

Figure 6.1. Changes in labor and land productivity by farm size, representative village in the transition zone, 1990-2010 Source: Authors' model results.

7.8, 5.6, and 4.5 percent for small, medium, and large farms, respectively, over 1990-2010, but only about 2 percent per annum in land productivity for all farms. As might be expected, smaller farms experience higher values of land productivity than medium and large farms, as illustrated in Figure 6.1.

\subsubsection{A Decomposition Analysis of the Changes, 1990-2010}

The model was used to identify the contributions of different drivers of change between 1990 and 2010 for each farm size group using a decomposition analysis. Specifically, model simulations were undertaken to decompose changes in key endogenous variables like expected income, input use, crop choice and production into parts due to exogenous changes over 1990 to 2010 in available land and improved seeds, and changes in wages, input and output prices, and a residual measuring interactions between these components. This was done by first solving the 1990 and 2010 models to calculate the total change in key endogenous variables, and then solving the 1990 model with 2010 land constraints and everything else set at 1990 values; solving again for 2010 seeds with everything else set at 1990 values; solving again for 2010 wages 
with everything else set at 1990 values; etc. Then for each endogenous variable of interest calculate:

$\mathrm{Y}_{2010}=\mathrm{Y}_{1990}+\mathrm{Y}_{1990}$ (given 2010 land) $+\mathrm{Y}_{1990}$ (given 2010 wage) $+\mathrm{Y}_{1990}$ (given 2010 seeds) $+\mathrm{Y}_{1990}$ (given 2010 price ratios) + Residual (equals interaction terms).

Where the residual is calculated as the difference to balance the equation. The results can then be used to assess the relative importance of changes in the exogenous variables in explaining the changes between 1990 and 2010 .

Table 6.10 shows the decomposition results. Some key points are as follows:

- The exogenous increase in farm sizes between 1990 and 2010 accounts for about 10 percent of the increase in expected incomes for all sized farms. Increases in farm size are also an important driver of the increases in total labor use for all sized farms, and for hired labor on medium and large farms. Increases in farm size are also an important driver of fertilizer use for all sized farms.

- Increases in farm size had a negligible impact on the use of tractor plowing. The latter was more affected by increases in the wage rate and, in the case of large farms, by reductions in input (presumably herbicide) costs.

- Increases in wages acted to reduce labor use on all sized farms, and encouraged greater use of tractor plowing. Wage increases also had a positive impact on the incomes of small and medium-sized farms, but a negative impact on the incomes of large farms. This is because large farms are net buyers of labor, whereas small and medium farms sell more labor off farm over the year than they hire in.

- Improved seeds made an important contribution to incomes, especially for medium and large farms, but acted to reduce total fertilizer use. This is surprising; seeds seem to be used as a substitute for fertilizer rather than as a complementary input, perhaps because they are used on more fertile land.

- Changes in output prices contributed little to incomes, but encouraged greater use of fertilizer, a pattern that was reinforced by reductions in input prices. Changes in input prices also encouraged greater mechanization and reduced labor use. This is partly the impact of less costly herbicides. 
Table 6.10. Decomposition of changes in selected variables by farm size group, representative village in the transition zone, 1990-2010

\begin{tabular}{|c|c|c|c|c|c|c|c|c|}
\hline \multirow[b]{2}{*}{$\begin{array}{l}\text { Endogenous variable (by farm } \\
\text { type) }\end{array}$} & \multicolumn{7}{|c|}{ Percentage share of 2010 value attributed to } & \multirow[b]{2}{*}{$\begin{array}{l}2010 / 1990 \\
\text { value }\end{array}$} \\
\hline & 1990 value & $\begin{array}{l}\text { Change } \\
\text { in land }\end{array}$ & $\begin{array}{l}\text { Change } \\
\text { in wages }\end{array}$ & $\begin{array}{l}\text { Change } \\
\text { in seeds }\end{array}$ & $\begin{array}{l}\text { Change in } \\
\text { output prices }\end{array}$ & $\begin{array}{l}\text { Change in } \\
\text { input prices }\end{array}$ & $\begin{array}{l}\text { Interaction } \\
\text { terms }\end{array}$ & \\
\hline \multicolumn{9}{|l|}{ Expected income (\$) } \\
\hline Small farm & 31.5 & 11.6 & 41.1 & 9.6 & 0.1 & 1.6 & 4.4 & 3.2 \\
\hline Medium farm & 42.8 & 13.6 & 8.7 & 23.0 & 3.1 & 4.9 & 3.9 & 2.3 \\
\hline Large farm & 53.9 & 10.8 & -25.1 & 45.8 & 5.0 & 13.3 & -3.6 & 1.9 \\
\hline \multicolumn{9}{|l|}{ Total fertilizer use (kg) } \\
\hline Small farm & 26.4 & 37.4 & 18.0 & -9.3 & 14.5 & 38.8 & -25.8 & 3.8 \\
\hline Medium farm & 33.7 & 22.4 & -12.4 & -13.9 & 10.0 & 29.0 & 31.3 & 3.0 \\
\hline Large farm & 44.4 & 16.3 & -25.7 & -10.6 & 5.3 & 35.9 & 34.4 & 2.3 \\
\hline \multicolumn{9}{|l|}{ Tractorized land area (ha) } \\
\hline Small farm & 0.0 & 0.0 & 42.5 & 0.0 & 0.0 & 3.3 & 54.2 & - \\
\hline Medium farm & 6.1 & -3.1 & 40.7 & -2.9 & -5.5 & 3.2 & 61.3 & 16.3 \\
\hline Large farm & 21.3 & 3.5 & 28.0 & -9.4 & -9.0 & 34.2 & 31.4 & 4.7 \\
\hline \multicolumn{9}{|l|}{ Labor use (days)_family } \\
\hline Small farm & 74.6 & 54.3 & -31.3 & 4.0 & -11.3 & -9.5 & 19.2 & 1.3 \\
\hline Medium farm & 97.5 & 22.7 & -25.9 & -0.9 & 11.0 & -4.5 & 0.0 & 1.0 \\
\hline Large farm & 102.6 & 0.0 & -27.1 & 0.0 & 9.3 & -12.5 & 27.7 & 1.0 \\
\hline \multicolumn{9}{|l|}{ Labor use (days)-Hired } \\
\hline Small farm & 0.0 & 0.0 & 0.0 & 0.0 & 0.0 & 0.0 & 0.0 & 1.0 \\
\hline Medium farm & 151.7 & 251.2 & -138.7 & 82.9 & -134.0 & -32.2 & -81.0 & 0.7 \\
\hline Large farm & 118.8 & 35.3 & -92.2 & 31.4 & -8.9 & -39.9 & 55.4 & 0.8 \\
\hline \multicolumn{9}{|l|}{ Labor use (days)_Total } \\
\hline Small farm & 75.9 & 55.2 & -31.9 & 4.1 & -11.5 & -9.7 & 19.5 & 1.3 \\
\hline Medium farm & 84.8 & 40.1 & -31.8 & 7.2 & -4.7 & -6.2 & -7.6 & 1.0 \\
\hline Large farm & 100.2 & 21.5 & -63.5 & 19.1 & -2.9 & -27.7 & 41.3 & 0.9 \\
\hline
\end{tabular}

Source: Authors' model results. 


\subsection{Conclusions}

The village narratives and the farm model results tell a consistent story of change since the 1980s in the savannah and transition zones. Farmers have responded rationally to increasing population pressure, changing household needs and expanding market opportunities, by increasing the size of their farms and growing more market-oriented crops. This adjustment has been complicated by an increasing scarcity of virgin land, which has compelled farmers to reduce fallow periods or acquire land in other more distant communities that still have a virgin land frontier. With shortened fallow periods there has been a decline in soil fertility and farmers have had to apply more inorganic fertilizer to maintain rather than increase yields, introduce soil fertility management practices like legume-cereal rotations, and adopt new crops and crop varieties that are more tolerant of less fertile soils and to changing rainfall patterns. Also, higher wages and difficulties in accessing hired labor at critical times of the agricultural season have led farmers to adopt labor-saving technologies like tractors and herbicides, and to switch to crops that require less labor.

As a result, the composition of farm output has changed from root-based crops for local consumption to grains and legumes (especially maize, cowpeas, and groundnuts) that are increasingly commercialized. Given the emphasis on labor-saving technologies like mechanization and herbicides, labor productivity has risen faster than land productivity, and yields of many crops have increased only marginally. However, because of the increase in the average cropped area per farm, changes in the crop mix, and some increase in nonfarm incomes, most farm households have managed to substantially increase their incomes since the 1980s, whether measured by income, the value of agricultural production, or household consumption expenditure.

Although farmers have adjusted to increasing land scarcity, it is not clear that they have found a sustainable solution for future agricultural growth. They are still exploiting remaining opportunities to shorten fallows and offset declining soil fertility with fertilizers and crop rotations, and seeking additional land in other villages. But there is little evidence that they are successfully switching to yield enhancing technologies that will be essential for future agricultural growth. This is true even in the villages that have already reached their land limit. Such intensification may require a more proactive policy agenda, especially promoting hybrid seeds and the like. We return to these issues in Chapter 10. 


\section{Appendix 6A: Description of the Ghana Farm Model}

\section{The Model}

The model was developed using the general algebraic modeling system, or GAMS (Brooke et al. 1998), using nonlinear programming approaches. The choice variables in the model (to be capitalized) include land area $\left(X_{i j k}\right)$ allocated by farmer type $i$ (small, medium, and large) to activities $j$ (by crop and technology type) and land type $k$. Labor can be own family labor $\left(L_{i t}^{f i n}\right)$ and/or hired labor $\left(L_{i t}^{h}\right)$ at the going wage rate $\left(w_{t}\right)$. Additionally, because we assume the existence of a labor market, we also permit each farmer type to sell their own labor at any time of the year $\left(L_{i t}^{\text {fout }}\right)$ but at a fraction of the going wage rate $\left(w_{t}^{*}\right)$. Five major crop rotation activities $j$ are included with assumed area allocation to those activities. Because of bimodal rainy seasons in the Ejura area, farmers typically rotate their cropping activities between legumes and cereals (in this case, cowpeas, groundnuts, and maize). The exceptions are root crops, such as yam and cassava, as these are single annual crops. Table 6A.1 summarizes these crop activities, as well as a description of the various parameters, indices, and endogenous variables defined in the model.

Mathematically, the objective for each average farmer type $i$ is represented by $z_{i}$ in equation 1 below-to maximize net profits $\left(\pi_{i}\right)$ minus its standard deviation $\left(\sigma_{i}\right)$ across activities $\left(X_{i j k}\right)$ multiplied by a risk parameter $(\rho)$ whose values can be adjusted to reflect the degree of risk aversion among farmers in each location. Specifically:

$$
\operatorname{Max} z_{i}=\pi_{i}-\rho_{i} \sigma_{i}, \forall i
$$

Where:

$$
\pi_{i}=\sum_{j} \sum_{k}\left[\mu_{i j k}-\sum_{t} c_{i j t} X_{i j k}(1+\tau)\right]+\sum_{t}\left(w_{t}^{*} L_{i t}^{o u t}-w_{t} L_{i t}^{i n}\right), \forall i
$$

[Expected income]

$$
\sigma_{i}=\sqrt{v_{i}}, \text { and } v_{i}=\sum_{j} \sum_{k} \sum_{j^{\prime}} \sum_{k^{\prime}} \operatorname{cov}_{j k j^{\prime} k^{\prime}}
$$

[Standard deviation of gross margins]

And where:

$$
\mu_{i j k}=\frac{1}{N} \sum_{n=1}^{N} p_{i j}^{n} y_{i j l}^{n}, \forall i j
$$

[Gross margins by crop activity]

$$
v_{j k j^{\prime} k^{\prime}}=\frac{1}{N} \sum_{n=1}^{N}\left(p_{i j}^{n} y_{i j k}^{n}-\mu_{i j k}\right)\left(p_{i j^{\prime}}^{n} y_{i j^{\prime} k^{\prime}}^{n}-\mu_{i j^{\prime} k^{\prime}}\right), \forall i
$$

[Variance-covariance of gross margins by crop activity]

For the risk parameter values $\left(\rho_{i}\right)$ in equation (1), we use the risk premium value of $\rho_{i}=1.485$ for all farmer types (small, medium, and large). This was derived as the bestfitting value for aligning the model results with the actuals as revealed through the farmer narratives using the approach suggested by Hazell and Norton (1986). The model considers 
Table 6A.1. Summary description of model parameters and variables

a) Indices and subscripts

$\begin{array}{ll}\text { Index } & \text { Description } \\ i & \text { Farmer type } i=\text { small, medium, and large } \\ j & \text { Crop rotations and technology type, } j=\text { CPMZ, GNMZ, MZCP, MZGN, and } \\ & \text { YMCS with improved or traditional variety seed, mechanized with chemicals, } \\ & \text { with fertilizer or not. YMCS=yam-cassava single intercrop. For the maize- } \\ & \text { based crops, the crop activities are sequenced by the bimodal season (1st crop } \\ & \text { is cultivated in the major season, and 2nd in the minor season later in the year } \\ & \text { as a rotation on the same area plot-see Figure } 6 \text { A.1 below): CPMZ=cowpea- } \\ & \text { maize rotation; GNMZ=groundnut-maize rotation; MZCP=maize-cowpea } \\ & \text { rotation; MZGN=maize-groundnut rotation. Technology type are two seed } \\ & \text { varieties (traditional or local and improved), inorganic fertilizer (with four } \\ & \text { application rates: } 1 / 4,1 / 2,3 / 4, \text { and full, based on a maximum recommended } \\ & \text { dosage), and tractor and chemical use for cultivating and clearing land. } \\ & \text { Land type } k=\text { continuously cropped, previously fallowed, and cleared virgin } \\ & \text { land } \\ & \text { Primes of indices of } j \text { and } k . \\ j^{\prime}, k^{\prime} & \text { Seasons by month of the year, } t=1, \ldots, 12 \\ t & \text { Years within each decade } n=1, \ldots, \mathrm{N}(\mathrm{N}=10) \\ n & \end{array}$

b) Exogenous or fixed parameters

\begin{tabular}{|c|c|}
\hline Parameter & Description \\
\hline$\rho_{i}$ & Risk parameter of farmer type $i, 0<\rho_{i} \leq 1.65$ \\
\hline$w_{t}$ & Seasonal going wage rate (monthly), $t=1, \ldots, 12$ \\
\hline$w_{t}^{*}$ & $\begin{array}{l}\text { Seasonal wage earned for hiring out family labor (as a fraction of } w_{t} \text { ), } \\
t=1, \ldots, 12\end{array}$ \\
\hline$p_{i j}^{n}$ & $\begin{array}{l}\text { Annual average commodity prices at farm gate for each decade, } \mathrm{n}=1, \ldots, \mathrm{N} \\
(\mathrm{N}=10)\end{array}$ \\
\hline $\begin{array}{l}y_{i j k}^{n} \\
\tau\end{array}$ & $\begin{array}{l}\text { Annual average commodity yields and by land type } k, \mathrm{n}=1, \ldots, \mathrm{N}(\mathrm{N}=10) \\
\text { Average interest rate }\end{array}$ \\
\hline$c_{i j t}$ & $\begin{array}{l}\text { Per hectare cost of purchasing inputs: seeds, fertilizer, chemicals, and the use } \\
\text { of a tractor }\end{array}$ \\
\hline$f_{i t}$ & Total adult equivalent family labor available each month $t$ for farmer type $i$. \\
\hline$\alpha_{j k t}$ & $\begin{array}{l}\text { Per hectare labor requirements for land preparation, planting, weeding, } \\
\text { applying chemicals and operating a tractor or each activity } j \text { and land type } k\end{array}$ \\
\hline$\alpha_{j k t}^{h}$ & $\begin{array}{l}\text { Per hectare labor requirements for harvesting of crop activity } j \text { and with land } \\
\text { type } k \text { in month } t \text { and as a function of average yield, i.e., } a_{j t}^{h}=f\left(\bar{y}_{i j k}\right) \text { for a } \\
\text { month of harvesting. }\end{array}$ \\
\hline
\end{tabular}

c) Endogenous or choice variables

Parameter Description

$\pi_{i} \quad$ Annual income or net profits per farmer type $i$ and for each decade

$\mu_{i j k} \quad$ Gross margins of farmer type $i$, crop activity $j$, and by land type $k$

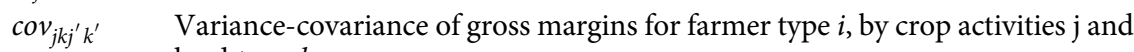
land type $k$. 
$v_{i}$

$\sigma_{i}$

$X_{i j k}$

$L_{i t}^{\text {in }}$

$L_{i t}^{f}$

$L_{i t}^{\text {out }}$

Total variance of gross margins across activities and land types for farmer type $i$

Total standard deviation of gross margins across activities and land types for farmer type $i$

Area located by each farmer type $i$ to each crop activity $j$ (including technology type) and by land type $k$.

Hired in labor for farmer type $i$ and by season $t$

Own family labor used by farmer type $i$ in season $t$, where $L_{i t}^{f i n} \leq f_{i t}$

Own family labor hired out by farmer type $i$ in season $t$, where $L_{i t}^{\text {fout }} \leq f_{i t}$

two growing seasons and we assume that the covariance of income between the two seasons is zero. This implies that expected utility for the year is simply the sum of the expected utilities generated each season.

The symbols $\mu_{i j k}$ and $\operatorname{cov}_{j k j^{\prime} k^{\prime}}$ in equations $2^{\prime}$ and $3^{\prime}$ above are the expected mean and covariance of on-farm gross margins, respectively, for each cropping activity $j$ and by type of land $k$ based on annual observations over each decade. The prime of $j$ (or $k$ ) associates the covariants between all activities adopted in the choice set, respectively. The subscripts $i$ in the mean profits $\left(\pi_{i}\right)$ and standard deviation of gross margins $\left(\sigma_{i}\right)$ represent the three farm types: small, medium, and large. The $j$ cropping activities include the five choice crop activities and by technology types available (see Table 6A.1).

$X_{i j k}, L_{i t}^{\text {fout }}$ and $L_{i t}^{h}$ are choice variables as follows: $X_{i j k}$ is the acreage allocation to each cropping activity and by land type; $L_{i t}^{\text {fout }}$ is own family labor hired out by farmer type $i$ and in month $t$; and $L_{i t}^{h}$ is labor hired in by farmer type $i$ and in month $t$. Fixed parameters include the following: $w_{i t}$ is the going wage rate for hiring in labor, while $w_{i t}^{*}$ is a fraction of the going wage rate for hiring out own family labor by farmer type. We assumed this changed over the decades as increasingly more off-farm employment options grew over time. As such, the value of $w_{i t}^{\star}$ was set at 40 percent, 50 percent, and 60 percent for the 1990, 2000, and 2010 decades across the months; $p_{i j}$ represents the average farm-gate price of each crop by activity $j$ (all in constant 2015 Ghanaian cedi values); $y_{i j}$ represents crop yields by activity $j$ (crop and by technology type). Finally, $c_{i j t}$ represents per unit costs for purchased inputs under each activity $j$ in month $t$ (also in constant 2015 Ghanaian cedi values).

The objective function in equation 1 is subjected to three resource constraints representing an upper bound on the supply of labor, land, and a minimum amount of production to satisfy own consumption for maize, yam, and cassava. In mathematical terms, the resource constraints are as follows:

$$
\sum_{j} \sum_{k}\left[a_{j k t}+a_{j k t}^{h}\left(\bar{y}_{i j k}\right)\right] X_{i j k} \leq L_{i t}^{f}+L_{i t}^{i n}, \forall i t
$$

Where:

$$
L_{i t}^{f} \leq f_{t}-L_{i t}^{\text {out }}
$$

[Labor supply constraint in month $t$ ]

$$
\sum_{j} X_{i j k} \leq a_{i k}, \forall i k
$$

[Land availability constraint by land type] 
Equation (4) is the main labor demand and supply equation-that is, labor required across all production activities and land clearing for new land can be sourced only from own family labor used $\left(L_{i t}^{f}\right)$ and labor hired in $\left(L_{i t}^{i n}\right)$. The term $\alpha_{j t}$ represents labor-use coefficients (person hours) under each cropping activity for land preparation, planting, and weeding. Harvesting and shelling in the field is captured in the separate term $\alpha_{j k t}^{h}$, which is a function of average annual yields $\bar{y}_{i j k}$ each decade by crop, technology, and land type. In the model we also restrict the YMCS (yam-cassava) activity to virgin land only, based on the observed practice of growing yam during the process of clearing land-burning the trees stumps around the yam mounds. These do not change over the decades. Most of the parameter values do not vary by land type except for land-clearing labor (not shown in the table). For virgin land, this is set at fifty-one man-days per hectare for non-yam-cassava crops and none for the YMCS crop mix as this is cultivated without clearing land. The clearing of a previous plot in fallow for three years is assumed to be a quarter of the time required to clear virgin land.

Equation (5) implies that own labor used on the farm each month $\left(L_{i t}^{f}\right)$ cannot exceed the residual of each farm type's adult equivalent household size $\left(f_{t}\right)$ and labor hired out off the farm each month $\left(L_{i t}^{\text {fout }}\right)$. A typical household size was assumed fixed over the decades and equal across the three farm types. Assuming four adults (two males and two females) and two youth, who work 26 days per month, their adult equivalent are calculated as $f_{t}=114.4\left(\right.$ i.e. $26^{\star}\left(2+0.7^{\star} 2+0.5^{\star} 2\right)$ in person days. For simplicity, we assume there is no upper bound for hired labor $\left(L_{i t}^{i n}\right){ }^{2}$

Equation (6) is a simple land constraint that imposes upper limits on total land available on the farm - that is, total cultivated area cannot exceed what the farmer already has access to on the farm as $a_{i k}$ and by land type. The assumption on fixed availability of land type permits us to impose the local circumstances of declining access to virgin and fallowed lands as observed in the Ejura area. Table 6A.2 presents the share of land type to total area cultivated across the decades based on an earlier IFPRI/SARI survey undertaken in the target area in 2013 (IFPRI/SARI 2013). From the table, use of fallowed land has declined significantly over time as farmers increasingly faced a land frontier by the 2010 decade. Only 10 to 27 percent of area cultivated is previously fallowed land, and only 6 to 25 percent is recently cleared virgin land.

While access to credit is often considered as a limiting factor to adoption in developing countries, we chose not to include it except to introduce a cost for using cash to

Table 6A.2. Percent shares in the type of land available by farm type and for each decade (1990-2010)

\begin{tabular}{|c|c|c|c|c|c|c|c|c|c|}
\hline \multirow[t]{2}{*}{ Farm type } & \multicolumn{3}{|c|}{ Large } & \multicolumn{3}{|c|}{ Medium } & \multicolumn{3}{|c|}{ Small } \\
\hline & 1990 & 2000 & 2010 & 1990 & 2000 & 2010 & 1990 & 2000 & 2010 \\
\hline Con & $22 \%$ & $44 \%$ & $65 \%$ & $29 \%$ & $47 \%$ & $66 \%$ & $23 \%$ & $45 \%$ & $67 \%$ \\
\hline Fallon & $37 \%$ & $24 \%$ & $10 \%$ & $56 \%$ & $41 \%$ & $27 \%$ & $62 \%$ & $45 \%$ & $27 \%$ \\
\hline Virgin land & $41 \%$ & $33 \%$ & $25 \%$ & $16 \%$ & $12 \%$ & $8 \%$ & $15 \%$ & $11 \%$ & $6 \%$ \\
\hline
\end{tabular}

Source: IFPRI/SARI Survey (2013).

\footnotetext{
${ }^{2}$ Earlier attempts to restrict it proved redundant given the small-size acreages and thus the small quantity of hired labor demanded when own family labor becomes binding.
} 
purchase inputs, valued here at the current interest rate or $\tau$ in equation (2). The value of $\tau$ varies by farmer type to capture the variance in access based on wealth and farm size: small -30 percent, medium -25 percent, and large- 20 percent. This is kept constant across the decades and is only meant to emphasize the greater difficulty for accessing cash among poorer or small-farm-size households. We chose to ignore access to credit in its traditional form as we are more interested in adoption patterns when land type conditions change, rather than restricting the ability to pay for inputs altogether.

Among the improved technology types in the model, four are introduced across all farm types and across the decades (not shown in the equations), including: improved seeds only (T1); improved seeds and chemical application, e.g., inorganic fertilizer and herbicides (T2); improved seeds, chemical application, and mechanization (T3); and mechanization and improved seeds only (T4). Traditional technologies will be referred to as T0. Although pesticides (or insecticides) can be considered as a chemical application-we impose these across all technology packages for cowpeas (with the exception of traditional technologies) because these are required regardless of the technology type. Additionally, while mechanization in T3 and T4 refers to the use of tractors during land preparation, we also include chemical herbicides under both packages to represent agricultural extensification (as both are labor-saving technologies). Agricultural intensification, on the other hand, refers to improved seeds and fertilizer use only in T1 and $\mathrm{T} 2$, respectively.

Other restrictions on technology use are imposed on yam, cassava, cowpea, and groundnuts based on local practice. For example, the YMCS activity does not use any chemical inputs or mechanization while groundnuts and cowpeas within their respective rotations do not use any fertilizer. Maize is the only crop using fertilizer in its rotation with legumes. From the field interviews, mechanization was very minimal in the 1990s due to its unavailability and high relative cost. Finally, the maize-legume crop rotations are also affected by rotations across the two growing seasons based on the field interviews on local practices. Farmers claimed that typically they would halve the total area allocated to the rotation as illustrated in Figure 6A.1. Basically, farmers break down their area allocated to the rotation in half, growing maize in one plot and a legume in the other half. For the next season, they rotate but sticking to the same legume and cereal (maize in this case). According to them, this helps recover some soil nutrient losses by following such a cereal-and-legume rotation.

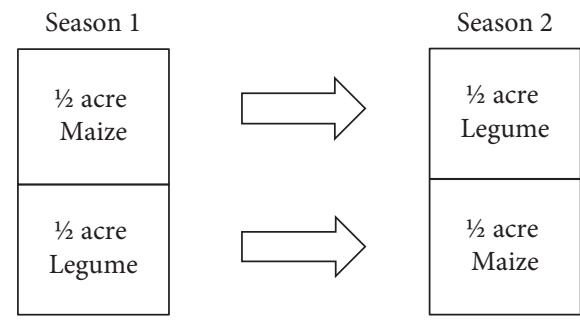

Figure 6A.1. Crop rotations between maize and legume (groundnuts or cowpeas) for a one-acre plot example and between two growing seasons in the Ejura area Source: Based on field interviews by the authors in Ejura. 


\section{Data Sources and Calculations}

Based on an extensive literature review and data sources, including one of the author's own past work in Ghana (see Johnson et al. 2006), input and output coefficients, population, land-use patterns, prices, and crop area allocations, were compiled and reviewed for each of the four decades being analyzed. The data and parameters used in the model are only for the transitional zone and can be made available by the author upon request (johnsonphiri@gmail.com). Here we only present a few key parameters we wish to highlight-yields, means, and co-variance of gross margins.

For yields, a number of assumptions and calculations had to be undertaken in order to not only capture changes in yield variability across decades, but yield differences according to both technology (seeds and fertilizer) and land type (continuous, fallowed, and virgin lands), and accounting for the general decline in yields due to degradation in soil fertility over time.

To capture the effect of technologies such as fertilizer (applied only to maize), a simple quadratic crop response function was specified, calculated from maize yield estimates in the Ejura area by Adjei-Nsiah et al. (2007):

$$
y_{t}(N)=\alpha_{t}+\beta N+\gamma N^{2}, \forall t=1990, \ldots, 2015
$$

Where, $\alpha_{t}=$ is an intercept (known annual base yield), $\beta=$ is a constant slope parameter valued at 33.2, and $\gamma=$ a negative quadratic term valued at -0.185 . For each decade, the baseline yields also vary by the land on which they are being cultivated (continuous, fallowed, or on previous virgin lands) and by the type of seed (traditional or improved). The $N$ variable is weight of inorganic fertilizer applied at five different rates up to a maximum recommended dosage of $90 \mathrm{~kg}$ per hectare: $N=0$ (no fertilizer application such that $y_{t}(0)=\alpha_{t}$ ); $N=0.25$ (one quarter the maximum dosage, or $22.5 \mathrm{~kg} / \mathrm{ha}$ ); $N=0.50$ (one half the maximum dosage, or $45.0 \mathrm{~kg} / \mathrm{ha}$ ); $N=0.75$ (three quarters the maximum dosage, or $67.5 \mathrm{~kg} / \mathrm{ha}$ ); and, $N=1.00$ (the full recommended maximum dosage, or $90.0 \mathrm{~kg} / \mathrm{ha}$ ). Because we also wished to capture declining levels of soil fertility over time, we assumed the base yields in $\alpha_{t}$ declined over time at about 7.2 percent per decade on average.

To allow for a time-series trend in yields and their variability, we had to rely on national level trends given the absence of sufficient time-series data at the local level in Ejura. These trends were adjusted to their base levels in the Ejura region. Combining this information with the fertilizer to yield the response function described above, we estimated the pattern of yield changes over time by the type of seed used and from fallowed lands only. These were then compared with actual observed yields based on interviewee estimates in the field and secondary data sources from the Ministry of Food and Agriculture (MoFA) and United Nations' Food and Agricultural Organization statistical database (FAOSTAT) for consistency.

Final averaged yields across the decades are reported in Table 6A.3. From the table, yields for local seeds are shown to decline over time under a continuous cropping system and reduced fallow as nutrients are mined from the soil. This has actually been occurring in Ejura as fallowed and virgin lands have become increasingly scarce. On the other hand, we assumed the average yield from improved varieties will still rise some (although very slightly) under continuous cropping as new higher-yielding varieties are introduced each year and in spite of the decline in soil fertility. Both seeds perform quite well with the 
Table 6A.3. Maize yields by type of seed and responses to fertilizer

\begin{tabular}{|c|c|c|c|c|c|c|c|c|}
\hline & \multicolumn{2}{|c|}{$\begin{array}{l}\text { No fertilizer } \\
\text { application }\end{array}$} & \multicolumn{4}{|c|}{$\begin{array}{l}\text { S2, with fertilizer (application } \\
\text { rates-\% of maximum dosage } \\
\text { recommended) }\end{array}$} & \multirow{2}{*}{$\begin{array}{l}\text { Ratio } \\
\text { (Seeds) } \\
\text { S2/S1 }\end{array}$} & \multirow{2}{*}{$\begin{array}{l}\begin{array}{l}\text { Ratio } \\
\text { (Fertilizer) }\end{array} \\
100 \% \text { app/ } \\
\text { No app }\end{array}$} \\
\hline & $\mathrm{S} 1$ & S2 & $25 \%$ & $50 \%$ & $75 \%$ & $100 \%$ & & \\
\hline & a & b & & & & c & $\mathrm{b} / \mathrm{a}$ & $c / b$ \\
\hline \multicolumn{9}{|c|}{ Continuously cropped } \\
\hline 1990 & 793 & 1,025 & 1,554 & 1,931 & 2,156 & 2,229 & 1.29 & 2.18 \\
\hline 2000 & 736 & 1,213 & 1,795 & 2,210 & 2,458 & 2,538 & 1.65 & 2.09 \\
\hline 2010 & 683 & 1,402 & 1,984 & 2,399 & 2,647 & 2,727 & 2.05 & 1.94 \\
\hline \multicolumn{9}{|c|}{ Previously fallowed } \\
\hline 1990 & 855 & 1,104 & 1,634 & 2,011 & 2,236 & 2,309 & 1.29 & 2.09 \\
\hline 2000 & 834 & 1,276 & 1,858 & 2,273 & 2,521 & 2,601 & 1.53 & 2.04 \\
\hline 2010 & 794 & 1,439 & 2,021 & 2,435 & 2,683 & 2,763 & 1.81 & 1.92 \\
\hline \multicolumn{9}{|c|}{ Cleared virgin land } \\
\hline 1990 & 855 & 1,104 & 1,634 & 2,011 & 2,236 & 2,309 & 1.29 & 2.09 \\
\hline 2000 & 855 & 1,308 & 1,890 & 2,304 & 2,552 & 2,632 & 1.53 & 2.01 \\
\hline 2010 & 855 & 1,512 & 2,093 & 2,508 & 2,756 & 2,836 & 1.77 & 1.88 \\
\hline \multicolumn{9}{|c|}{ Annual growth (\%) } \\
\hline Continuous & -0.6 & 1.5 & 1.1 & 1.0 & 0.9 & 0.9 & n.a. & n.a. \\
\hline Fallowed & -0.3 & 1.2 & 0.9 & 0.8 & 0.8 & 0.8 & n.a. & n.a. \\
\hline Virgin land & 0.0 & 1.5 & 1.1 & 1.0 & 0.9 & 0.9 & n.a. & n.a. \\
\hline
\end{tabular}

Source: Authors' calculations from model data.

introduction of fertilizer-although the improved variety always outperforms local seeds' response to fertilizer as would be expected. We assume yields on virgin lands to not change over the years for local seeds.

For prices, local prices were cross-checked with those from the Ministry of Food and Agriculture (MoFA) for Ejura. Because prices of vegetables were only a proxy using tomatoes, the prices subsequently were adjusted during model calibration. It was also observed that local prices for yams and cassava fluctuated a lot, and are often lower than the numbers reported. The same is true with yields for both crops, as these are inherently difficult to measure (as tubers). As such, prices for these two commodities were also adjusted during model calibration-especially for the 1980s and 1990s decades. The final prices used in the model are shown in Figure 6A.2, including corresponding estimates of gross margins. The variations in gross margins and prices appear to be quite similar, implying that price variation has been more volatile than yields.

One thing that stands out immediately in Figure 6A.2 is the higher variance in price and gross margins for most of the commodities in the 2000 decade (aside from cowpeas, yams, and cassava). This was a period when food prices rose sharply in the latter half of the 2000 decade. The volatility in prices remained higher than in the 1990s during the more recent decade (2010) for cassava only. Among the five commodities, maize and groundnuts recorded the highest volatility in gross margins in 2000-which explains some of the shifting away from groundnuts to cowpea cultivation in the farm 

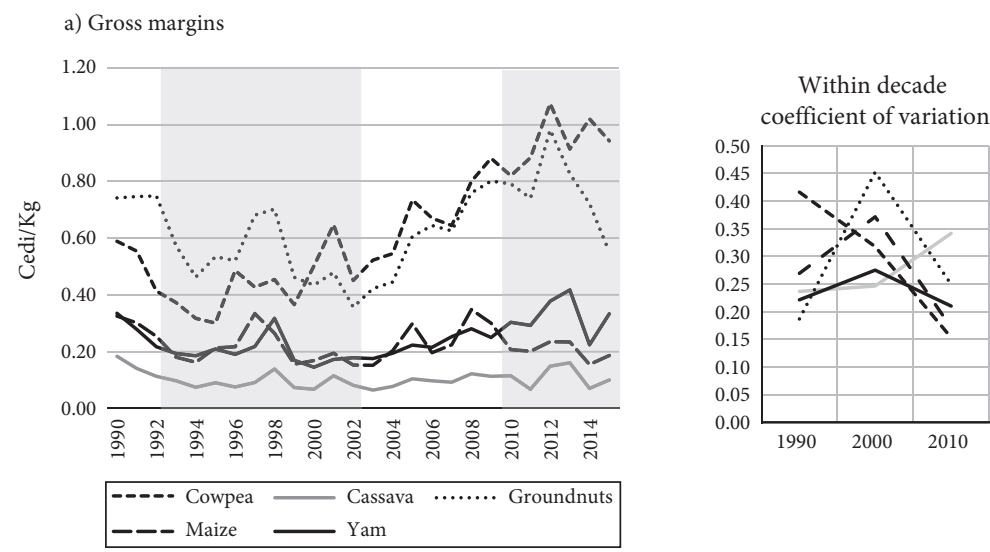

b) Prices
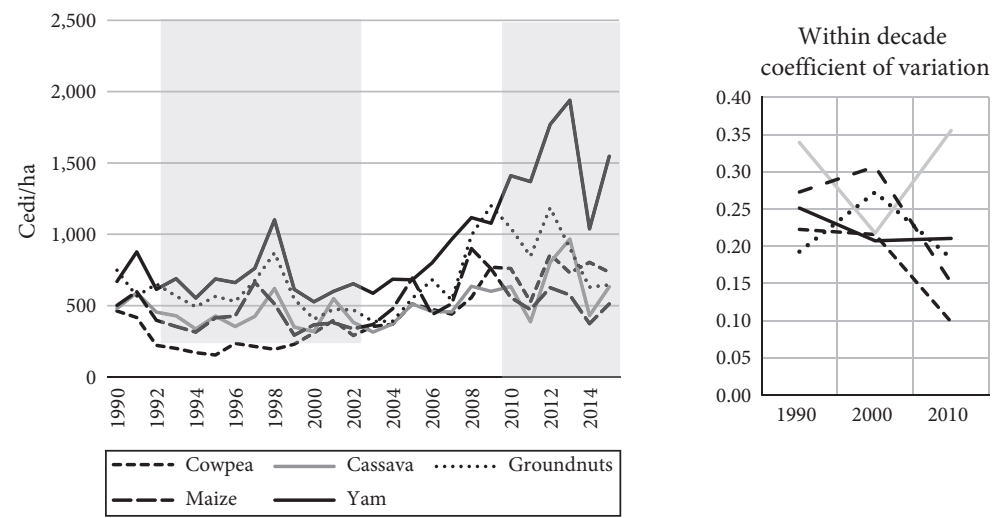

Figure 6A.2. Gross margins and annual price trends in Ejura, 1980-2015 (constant 2015 US\$/kg)

Source: MoFA national monthly price data, 1980-2010. For the more recent years, 2011-15, these are taken from monthly recorded prices in Ejura and adjusted with previous national trends.

model solutions. In general, expected gross margins and their variances also rise with higher-yielding technology and/or land type combinations-which can affect the rate of adoption each decade under risk-averse behavior.

With regard to input costs, wages have grown more significantly since 2000 , essentially more than doubling. We assumed off-farm wages are typically less than the cost of hiring in labor, due to either search costs, or as is more common, leasing out labor at a period when demand for labor is lower and pays less. Nevertheless, to capture recent improvements in road infrastructure and transportation, and therefore access to off-farm employment opportunities in the Ejura area, we allow this wage to rise until it is about equal to the wage for hiring in labor by 2010. Base values for farm sizes and area allocations to crops was derived from both the group interviews of farmers in the Ejura area and data collected by IFPRI in 2012 in the same area. 


\section{References}

Adjei-Nsiah, S., T. W. Kuyper, C. Leeuwis et al. 2007. "Evaluating Sustainable and Profitable Cropping Sequences with Cassava and Four Legume Crops: Effects on Soil Fertility and Maize Yields in the Forest/Savannah Transitional AgroEcological Zone of Ghana.” Field Crops Research 103(2): 87-97.

Amanor, K. S., and O. Pabi. 2007. "Space, Time, Rhetoric and Agricultural Change in the Transition Zone of Ghana.” Human Ecology 35: 51-67.

Brooke, A., D. Kendrick, and A. Meeraus. 1998. GAMS: A User's Guide. Redwood City: The Scientific Press.

Ghana Statistical Service. 1998. Ghana living standards survey data 1998. Accra.

Ghana Statistical Service. 2000. Ghana living standards survey data 2000. Accra.

Ghana Statistical Service. 2005. Ghana living standards survey data 2005. Accra.

Ghana Statistical Service. 2010. Ghana living standards survey data 2010. Accra.

Ghana Statistical Service. 2012. Ghana living standards survey data 2012. Accra.

Hazell, P. B. R., and R. D. Norton. 1986. "Mathematical Programming for Economic Analysis in Agriculture.” New York: Macmillan.

Houssou1, Nazaire, Michael Johnson, Shashidhara Kolavalli, and Collins AsanteAddo. 2017. "Changes in Ghanaian Farming Systems: Stagnation or a Quiet Transformation?" Agriculture and Human Values 35(1): 41-66.

Johnson, M., W. A. Masters, and P. V. Preckel. 2006. "Diffusion and Spillover of New Technology: A Heterogeneous-agent Model for Cassava in West Africa." Agricultural Economics 35(2): 119-129.

Ragasa, C., A. Dankyi, P. Acheampong et al. 2013. "Patterns of Adoption of Improved Maize Technologies in Ghana.” GSSP Working Paper No. 35. Washington, DC: International Food Policy Research Institute. 


\title{
7 \\ Public Expenditure on Agriculture and its Impact
}

\author{
Samuel Benin
}

\subsection{Introduction}

Along with the creation of enabling policies, public investment in agriculture plays a crucial role in promoting agricultural growth and conditioning its distributional outcomes. These linkages are well established in the literature (Aschauer 1989; Barro 1990; Thirtle et al. 2003; Fan 2008), but their realization requires sufficient levels of public spending, the right types of spending (e.g., amongst agricultural research, extension, irrigation, input subsides, roads, education, and health), an appropriate distribution of spending across geographic areas to improve the distributional outcomes and impacts, and striking an appropriate balance between capital investment for long-term growth and recurrent costs incurred in providing public services.

This chapter examines past patterns of public spending on agriculture in Ghana, and asks whether Ghana has invested enough resources in agriculture and how the patterns of investment in the sector have impacted agricultural productivity growth.

The scope and rigor of the analysis is constrained by the available data, and only partial insights are possible drawing on a variety of data sources and studies. The chapter is structured as follows. The next section examines trends in public agriculture spending over the period 1961-2012, and disaggregates that spending into the cocoa and noncocoa sectors. The noncocoa subsector is managed by the general government sector within the national budget and procurement systems, whereas the cocoa subsector is managed exclusively by a public corporation or state-owned enterprise-Ghana Cocoa Board (Cocobod)-directly from the proceeds of the export of cocoa beans purchased from the farmers. Relative to the subsector's value-added, the amount spent by the Cocobod on the cocoa subsector far outweighs the amount spent by the government on the noncocoa subsector, which includes 
all the country's food staples. To obtain more detailed insights about the types of spending within the agricultural sector, we draw on a study by Benin et al. (2012) who provide some insights into the types of government spending and their regional allocation for the period 2000-7. The subsequent section then reports on two econometric analyses that estimate the impact of public spending on agricultural productivity growth, and provide some useful insights into the marginal returns to public investments in the cocoa and noncocoa subsectors, and by type of public investment. This is followed by a discussion of the government's recent attempts to promote noncocoa agricultural growth through several new subsidy programs, and this leads to our concluding section.

\subsection{Trends in Public Agriculture Spending, 1961-2012}

\subsubsection{Data Sources}

Data on public agriculture expenditure in Ghana were compiled from various national and international sources from 1961 to 2012 for the agriculture sector as a whole, and separately for the cocoa and noncocoa subsectors (Table 7.1). The noncocoa subsector includes noncocoa crops (including food staples), livestock, forestry, and fishery. Agricultural production data were compiled from FAOStat, and disaggregated for the cocoa and noncocoa subsectors.

Table 7.1. Data sources for public spending and agricultural output, 1961-2012

\begin{tabular}{|c|c|c|}
\hline Variable & Description/Disaggregation & Data sources \\
\hline $\begin{array}{l}\text { Total } \\
\text { expenditure } \\
(T E)\end{array}$ & $\begin{array}{l}\text { Total government expenditure in } \\
\text { constant } 2006 \text { GHS, million }\end{array}$ & \multirow{2}{*}{$\begin{array}{l}\text { Stryker (1990), IMF }(1998,2000 \text {, } \\
\text { 2005), Kolavalli et al. (2012), } \\
\text { MoFA (2013), GCB (2013), CAGD } \\
\text { (2011, 2013, 2014), IFPRI (2015), } \\
\text { World Bank (2015) }\end{array}$} \\
\hline $\begin{array}{l}\text { Agricultural } \\
\text { public } \\
\text { expenditure } \\
(\text { agEXP) }\end{array}$ & $\begin{array}{l}\text { Government expenditure on } \\
\text { agriculture in constant } 2006 \text { GHS, } \\
\text { million, disaggregated into: } \\
\text { - Cocoa subsector } \\
\text { - Noncocoa subsector (noncocoa } \\
\text { crops, livestock, forestry, fishery) }\end{array}$ & \\
\hline $\begin{array}{l}\text { Agricultural } \\
\text { output }(Y)\end{array}$ & $\begin{array}{l}\text { Gross output in constant 2004-6 } \\
\text { GHS, million, divided by } \\
\text { agricultural area (including arable } \\
\text { land, permanent crops, permanent } \\
\text { meadows and pastures, forest area, } \\
\text { and inland water), disaggregated into: } \\
\text { - Cocoa subsector } \\
\text { - Noncocoa subsector }\end{array}$ & FAO (2016) \\
\hline
\end{tabular}


Appendix Table 7A shows details of how the annual expenditure data were compiled, including the sources for each data point.

\subsubsection{Trends in Public Agriculture Expenditure and Output per Hectare}

Trends in agricultural public expenditure and gross agricultural output per hectare of agricultural land are shown in Figures 7.1 and 7.2, respectively, and Table 7.2. The ratio of expenditure to output is shown in Figure 7.3 There have been considerable fluctuations in public spending over the years, driven by changing governments and their policy agendas, but very little upward trend until the 1990s after the economic reforms. Spending by the Cocobod on the

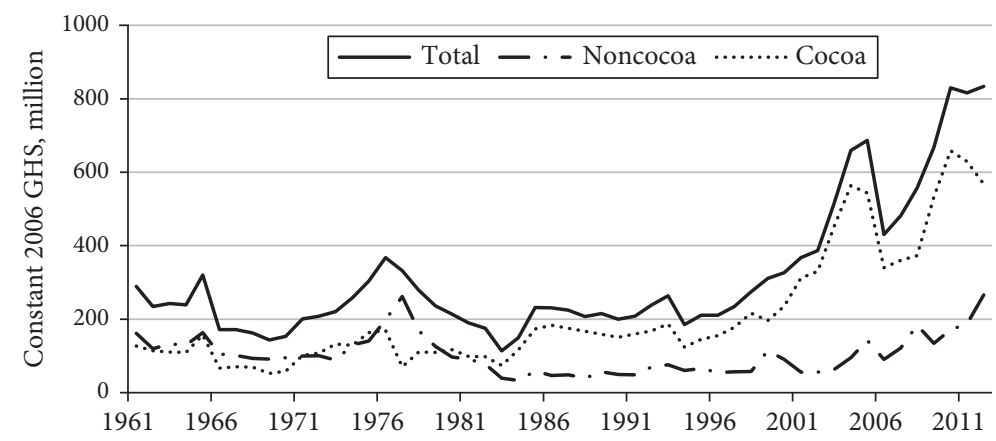

Figure 7.1. Agricultural public expenditure in Ghana by subsector, 1961-2012 Note: GHS = Ghanaian cedi. Expenditure on the noncocoa subsector is by the government and that on the cocoa subsector is by the Cocobod. Total is from adding the two.

Source: Author's illustration based on compiled data (see Tables 7.1 and 7A).

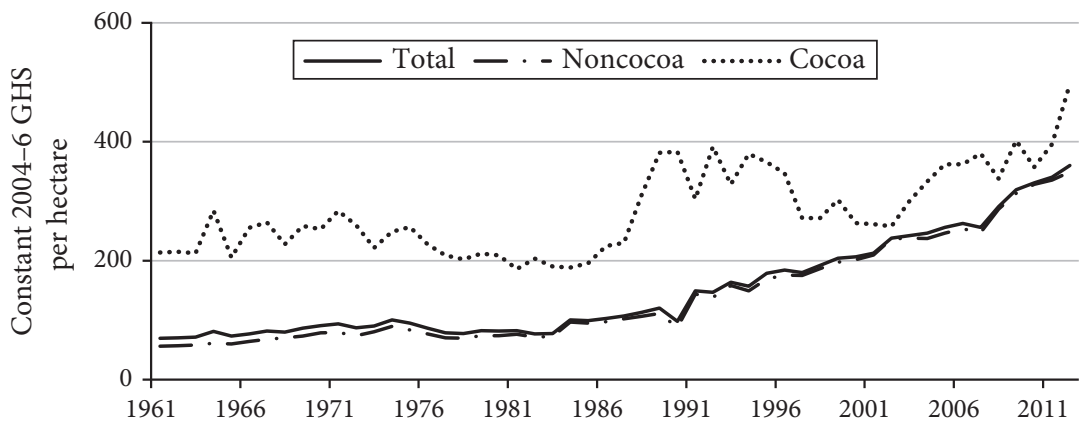

Figure 7.2. Agricultural output per hectare by subsector in Ghana, 1961-2012 Note: GHS = Ghanaian cedi.

Source: Author's illustration based on FAO (2016). 


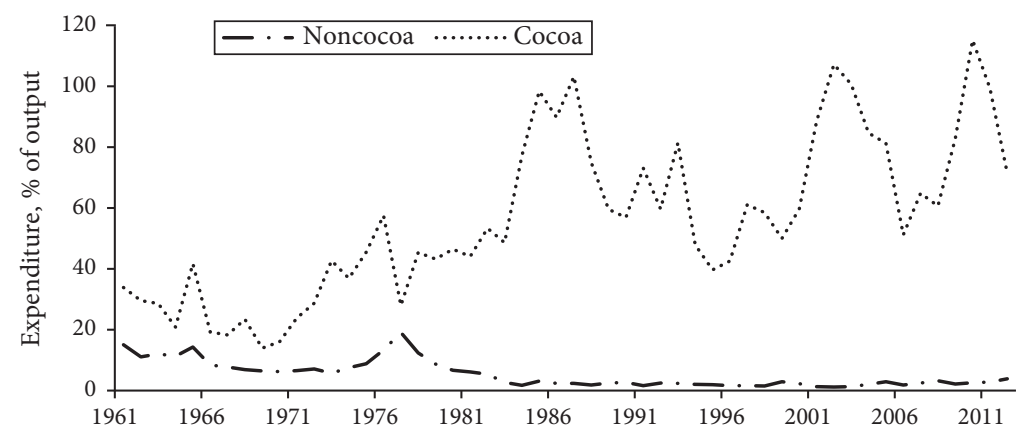

Figure 7.3. Ratio of agricultural public expenditure to output by subsector in Ghana, 1961-2012

Note: Expenditure on the noncocoa subsector is by the government and that on the cocoa subsector is by the Cocobod.

Source: Author's illustration based on compiled data (see Tables 7.1 and 7A).

Table 7.2. Agricultural expenditure and output per hectare by subsector in Ghana, 1961-2012

Indicator $\quad 1961-5 \quad 1966-71 \quad 1972-9 \quad 1980-1 \quad 1982-92 \quad 1993-2000 \quad 2001-8 \quad 2009-12$

Agriculture expenditure, growth rate (\%)

$\begin{array}{lrrrrrrrr}\text { Total } & 2.3 & 1.0 & 3.6 & -11.3 & 4.2 & 6.1 & 4.3 & 6.7 \\ \text { Cocoa } & 3.8 & 3.9 & -3.0 & -15.6 & 5.9 & 6.4 & 1.0 & 1.5 \\ \text { Noncocoa } & 1.0 & -1.4 & 9.0 & -6.1 & 1.1 & 4.9 & 17.8 & 23.7\end{array}$

Agriculture expenditure (\% of output)

Total $\quad 17.4 \quad 9.5 \quad 15.3$

$\begin{array}{llll}\text { Cocoa } & 30.1 & 19.1 & 40.7\end{array}$

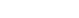

Noncocoa

12.7

$7.0 \quad 10.1$

6.4

2.5

2.0

$76.5 \quad 90.3$

Agriculture output per hectare, growth rate (\%)

\begin{tabular}{lrrrrrrrr} 
Total & 2.4 & 4.2 & -2.4 & 0.8 & 5.9 & 3.8 & 3.5 & 3.9 \\
Cocoa & 3.1 & 3.4 & -6.0 & -11.1 & 5.8 & 6.9 & 10.0 & 7.7 \\
Noncocoa & 2.1 & 4.5 & -1.8 & 2.8 & 5.8 & 4.1 & 3.2 & 3.6 \\
\hline
\end{tabular}

Note: Expenditure on the noncocoa subsector is by the government and that on the cocoa subsector is by the Cocobod. Total is from adding the two.

Source: Author's calculation based on compiled data (see Tables 7.1 and 7A).

cocoa subsector has far exceeded government spending on the noncocoa subsector, both in terms of the absolute amount spent and as a share of the value of output. This gap widened in the 1990s and has only recently begun to close with an acceleration in the growth rate of government spending on the noncocoa subsector. Average land productivity has grown slowly but steadily over the years, but despite the spending bias towards the cocoa subsector, the long-term trend has been for land productivity to grow at similar rates in the two subsectors. 
To better understand these trends and fluctuations in public expenditure, it is useful to relate them to the underlying agricultural policies of successive governments. Major influential factors include the following:

- Until 1990, there was direct agricultural production by the government through state farms and cooperatives.

- Subsidization of farm production stopped in 1990 and returned in 2007.

- Implementation of policies and strategies was mostly through projects until the 1990s and then through programs and sector-wide approaches afterward.

- Government and public spending was decentralized, including the enactment of the Local Government Law in 1988, establishment of the District Assembly Common Fund in 1993, and implementation of direct district budgeting and execution starting in 2012.

- Agricultural public expenditure reviews were conducted in 1977, 1998, 2006, and 2012.

- The country signed the CAADP compact in 2009.

- Specific to the cocoa subsector, Cocobod is constitutionalized in 1984, licensed buying companies are introduced in 1993, the Produce Buying Company is privatized in 1999 , and a hi-tech program is initiated in 2004.

Table 7.2 summarizes the trends in public expenditure and land productivity by sub-periods that correspond to successive governments, beginning in 1961. A short summary of the agricultural policies of each period follows.

\subsubsection{1958 to 1966}

The post-Independence policies of the Convention People's Party government led by Dr. Kwame Nkrumah extended until 1966, and were dictated by the overall economic development agenda of rapid industrialization, which was primarily financed by taxing agriculture. An Agricultural Development Corporation (ADC) was established to promote the production of export crops (mainly cocoa) for foreign exchange earnings and production of industrial crops (mainly rubber, sugar cane, oil palm, and cotton) to feed the ambitious local factories that were being set up. As such, the bulk of agriculture expenditure was allocated to ADC and spent on input subsidies (imports of fertilizers, other chemicals, tractors, and implements) and on distribution and marketing of produce associated with the state farms. Following the ADC's forced closure 
in 1962, due to its accumulated large debts and unsuccessful large-scale production and marketing activities, state farms and cooperatives were established to take over ADC's projects and the ministry's stations. Price controls, input and credit subsidies, and obligatory credit allocations continued to be used to support the heavy state involvement in agricultural production, distribution, and marketing (Stryker 1990; Dappah 1995). At the time of Nkrumah government's overthrow in 1966, there were 105 state farms (42 of them were inherited from ADC) cultivating about 22,396 hectares, with 62 percent under permanent crops (mainly rubber, oil palm, sugar cane, cotton, coconut, banana, and kola nut) and the remaining 38 percent under food crops (mainly maize and rice) (Austin and Luckham 1975). As Table 7.2 shows, agriculture expenditure in 1961-5 grew at an annual average rate of 2.3 percent, with expenditures on cocoa growing faster (3.8 percent) than combined expenditures on the noncocoa subsector (1.0 percent). The amount spent as a share of the respective subsector's agricultural output was much higher for cocoa (30.1 percent) than for noncocoa (12.7 percent). Growth in the land productivity for the agricultural sector as a whole averaged 2.4 percent year, with growth in the noncocoa subsector ( 2.1 percent) being lower compared with the growth in the cocoa subsector (3.1 percent).

\subsubsection{1966 to 1971}

This era was governed by the National Liberation Council military government under Lieutenant General Joseph Arthur Ankrah and Lieutenant General Akwasi Afrifa (1966-9), followed by the second republic under Doctor Kofi Busia and the Progress Party (1969-72). The main strategy of the National Liberation Council government that had significant bearing on the level of agriculture expenditure and how it was allocated was in trying to ward off the domestic crisis (mainly, high food prices and low producer prices) and to pay off the large debts amassed by the previous government (Austin and Luckham 1975). Doing so involved stimulating more agricultural primary exports (cocoa and timber) and cutting back on direct state involvement in agricultural production. For example, between the 1966 coup d'état and May 1968, the producer price of cocoa was doubled, no new state farms were established, and some state farms and factories were closed or sold off. This trend continued into the Busia-led government. Although there was marked structural change in the rest of the economy (especially nationalism and promotion or takeover of businesses by Ghanaians), agricultural policy and finance mostly continued as before-that is, promoting production of cocoa for export, promoting industrial crops to feed factories, importing and 
subsidizing fertilizer and capital for production of these crops, and importing food to feed the urban consumers.

The biased support to state farms and individual large-scale farms or farmers is reflected in the lending practices to the sector by banks that were obligated to provide agricultural loans. The banks typically gave loans to those farms operating 20-1,000 acres of farmland and producing industrial crops or engaged in agro-industry (Austin and Luckham 1975). As Table 7.2 shows, agriculture expenditure during this era grew at an average rate of 1.0 percent per year, with expenditures on cocoa growing much faster (3.9 percent) than combined expenditures on the noncocoa subsector ( -1.4 percent). Here too, the amount spent as a share of the respective subsector's agricultural output was more than twice as high for cocoa (19.1 percent) as it was for noncocoa (7.0 percent). Growth in land productivity for the agricultural sector as a whole averaged 4.2 percent per year, which was dominated by growth in the noncocoa subsector (4.5 percent), as compared with growth in the cocoa subsector (3.4 percent).

\subsubsection{1972 to 1979}

Promotion of private large-scale agricultural production was enhanced following the second coup d'état and rule of the country by the National Redemption Council military government under General Ignatius Acheampong (1972-5) and the Supreme Military Council government under Lieutenant General Frederick Akuffo (1975-9). It was during this era that the first agricultural-specific initiatives were launched-Operation Feed Yourself, which aimed to help reduce food imports, and Operation Feed Your Industries, which aimed to continue providing raw materials to feed local factories. During these years, fertilizer subsidies were substantial, and bank loans to large-scale operators increased rapidly (Quartey-Papafio 1977). Although small-scale farmers were not directly supported under these policies and interventions, they seem to have had easy access to fertilizer and seed, which contributed favorably to their well-being (Wiemers 2015). In general, the economic development agenda of rapid import-substitution industrialization continued.

As Table 7.2 shows, agriculture expenditure in $1972-9$ grew at an average rate of 3.6 percent year, with expenditures on cocoa experiencing a declining growth rate ( -3.0 percent) and combined expenditures on the noncocoa subsector rising rapidly ( 9.0 percent). Still, the amount spent as a share of the respective subsector's agricultural output was much higher for cocoa (40.7 percent) than for noncocoa (10.1 percent). There was a declining trend 
in land productivity for the entire agricultural sector, which averaged -2.4 percent per year, with the decline in the noncocoa subsector ( -1.8 percent) being lower than in the cocoa subsector (-6.0 percent).

\subsubsection{1979 to 1981}

Following another coup d'état in June 1979 came the brief military government of the Armed Forces Revolutionary Council, led by Flight Lieutenant Jerry John Rawlings from June to September 1979, and then the third republic, led by the government of the People's National Party under Doctor Hilla Limann from September 1979 to December 1981. Dr. Limann's government launched a two-year program, Action Programme for Agricultural Production, 1980-1 (Andah 1980). As Table 7.2 shows, there was negative growth in most indicators during this relatively short period, likely reflecting the widely acclaimed economic mismanagement of the government prior to the coup d'état. The amount spent as a share of the respective subsector's agricultural output continued to be much higher for cocoa ( 45.3 percent) than for noncocoa (6.4 percent).

\subsubsection{1982 to 2000}

Jerry Rawlings came back to power, first through another coup d'état under the government of the Provisional National Defence Council from the eve of 1982 until 1993, and then through the ballot box, ushering in the fourth republic under the National Democratic Congress government until January 2001. This roughly twenty-year period is known for the Structural Adjustment Program, which is locally called the Economic Recovery Program. In addition, numerous agricultural sector-specific plans, strategies, projects, or programs were launched. As expected with the structural adjustment, there was a substantial cutback in government spending in general, and agricultural input subsidies were stopped in 1990. Overall agriculture expenditure grew at an average rate of 4.2 percent in 1982-92 and 6.1 percent in 1993-2000, with expenditures on the cocoa subsector growing faster than combined expenditures on the noncocoa subsector. As Table 7.2 shows, the amount spent as the share of the respective subsector's agricultural output continued to be much higher for the cocoa subsector than for the noncocoa subsector.

With the launch of the Local Government Law, the decentralization policy, and institution of the District Assembly Common Fund, direct spending and accounting of expenditures at lower levels increased, likely increasing the targeting of expenditures for agricultural and rural development (Mogues and Benin 2012). Comparative growth in land productivity was mixed, 
however; whereas it was equal (5.8 percent per year) in the cocoa and noncocoa subsectors in 1982-92, it was higher for the cocoa subsector (6.9 percent per year) than for the noncocoa subsector (4.1 percent percent) in 1993-2000.

\subsubsection{2001 to 2008}

With the National Patriotic Party, led by John Agyekum Kufuor, coming into power in January 2001, there was a shift from project-based agricultural development to program-based and sector-wide approaches. Some of the most influential approaches on the sector were the Presidential Special Initiatives, the Agricultural Services Subsector Investment Program, and the Food and Agricultural Sector Development Policy, among others. It was during this era that CAADP, the Africa-wide, agriculture-led development initiative, was launched in the continent, though Ghana did not officially complete and sign its national compact until 2009. The CAADP raised the profile of agricultural expenditures and influenced the definition and accounting of agriculture expenditure (the debate of which continues today).

In 2007, the government announced that it would reintroduce agricultural input subsidies (fertilizer, block farms, mechanization, and buffer stock) and then went on to spend an average of GHS 7.9 million each year in 2007 and 2008 to implement it (Benin et al. 2013). Direct spending at subnational levels continued. As Table 7.2 shows, at the national level, agriculture expenditure during this era grew at an average rate of 4.3 percent per year, with growth in expenditure on the cocoa subsector being almost stagnant (1.0 percent) compared with growth in expenditure on the noncocoa subsector (17.8 percent). The amount spent as a share of the respective subsector's agricultural output continued to be much higher for cocoa than for noncocoa. For example, the share of expenditure on cocoa as a share of the subsector's agricultural output was 76.5 percent, compared with only 2.1 percent for the noncocoa subsector. Growth in land productivity for the entire agricultural sector averaged 3.5 percent per year, with the average growth being lower in the noncocoa subsector (3.2 percent), compared with growth in the cocoa subsector (10.0 percent).

\subsubsection{2009 to 2012}

From January 2009 until 2016, the National Democratic Congress has been the ruling government in Ghana-first under Professor John Evans Atta Mills (2009-12) and then John Dramani Mahama (2012-16). Some of the key policies, programs, and projects undertaken during this era include the Ghana Commercial Agriculture Project and the Soil, Land, and Water 
Management Project. Direct spending at subnational levels continued. In 2012, the composite budgeting system was introduced for all metropolitan, municipal, and district assemblies ${ }^{1}$ to effect fiscal decentralization of the 1988 Local Government Law, in which all decentralized functions of government are directly managed by the assemblies at the respective levels of government.

Agricultural input subsidies also remained strong. The overall trends in agriculture expenditure at the national level are similar to trends seen in the preceding periods analyzed. For example, agriculture expenditure during 2009-12 grew at an average rate of 6.7 percent per year, with expenditure on cocoa barely growing (1.5 percent), as compared with combined expenditure on the noncocoa subsector (23.7 percent). The share of expenditure on cocoa as a share of the subsector's agricultural output was 90.3 percent per year, compared with only 2.9 percent per year for the noncocoa subsector. Growth in land productivity for the entire agricultural sector was 3.9 percent, with growth in the cocoa subsector (7.7 percent) outperforming growth in the noncocoa subsector (3.6 percent).

\subsubsection{Overall trends from 1961 to 2012}

To summarize, overall agricultural policy and expenditure have favored the cocoa subsector. Between 1961 and 2012, the periods over which the data used here are available, agricultural expenditure on the cocoa subsector grew at an average rate of 3.7 percent per year, compared with -0.3 percent for the noncocoa subsector. The share of expenditures on the cocoa subsector as a share of the subsector's agricultural output was 57.6 percent per year, compared to only 3.7 percent per year for the noncocoa subsector. The annual average growth rate in land productivity for the entire agricultural sector averaged 3.3 percent per year, driven by growth in the noncocoa subsector (3.7 percent), as compared with growth in the cocoa subsector (1.0 percent).

In terms of fulfilling its Maputo Declaration target of allocating at least 10 percent of total government spending to agriculture, Ghana has failed to meet this requirement, amidst several reports that show otherwise following confusion on differentiating mostly expenditures of the government sector and those of public corporations such as the Ghana Cocoa Board (Benin 2014). Considering only expenditures of the general government sector (i.e., expenditures on the noncocoa subsector as shown in Table 7.2), the

\footnotetext{
${ }^{1}$ These include six metropolitan assemblies, forty-nine municipal assemblies, and 161 district assemblies.
} 
share of government expenditure on agriculture as a share of total government expenditure amounts to only 2.1 percent during 2001-8 and 2.8 percent during 2009-12. This is low even by African standards (Benin and Yu 2013), especially as it includes all the country's food staples. When expenditures of the Ghana Cocoa Board are included as part of public expenditures on agriculture, and expenditures of other public corporations are included as part of total public expenditure, Benin (2014) estimates the share to be about 3.8-5.3 percent, which still falls short of the 10 percent Maputo Declaration target.

\subsubsection{Composition of Public Spending on Agriculture, 2000-7}

Benin et al. (2012) provide more detailed insights into the composition of public spending in rural areas for 2000-7. Their analysis includes levels and trends for public spending differentiated by type of spending and by regional priorities. Government spending on agriculture is channeled through a number of ministries and institutions ${ }^{2}$ and Benin et al. (2012) report these by major channel in Table 7.3. The government's resource allocation to the agricultural sector increased by nearly four times between 2000 and $2007^{3}$. Interestingly, MoFA, the conventional ministry responsible for the agricultural sector, accounted for only 25 percent of total public spending on the sector, down from about one half of the total expenditures in the sector in the mid-1990s (MoFA 1999). The share for CSIR average 14.2 percent, increasing from 12.5 percent in 2000 to 27.2 percent in 2007. This shows that agencies other

${ }^{2}$ Public spending on the agricultural sector takes place not only through conventional allocation by the Ministry of Agriculture, but also through various other government ministries, departments, and agencies, in addition to public corporations or state-owned enterprises. In Ghana for example, fishery and forestry each fall under their own separate ministry, both distinct from the Ministry of Food and Agriculture (MoFA), which is responsible for crops, other than cocoa, and livestock. Cocoa is managed by the Ghana Cocoa Board (Cocobod), which in turn is under the Ministry of Finance and Economic Planning. Agricultural R\&D is managed by the Council for Scientific and Industrial Research (CSIR), which reports to the Ministry of Education, Sports, and Science. Other expenditures related to agriculture in Ghana are undertaken by the Ministry of Trade and Industry (such as spending relating to food imports and agricultural marketing and trade), the Ministry of Roads and Transport (such as feeder roads development), the Ministry of Local Government and Rural Development, Ministry of Women and Children's Affairs, Ministry of Manpower Development and Employment (all three allocate resources to agricultural community-based development projects), and the Presidential Special Initiatives on agriculture. Thus, even with a clearly defined agricultural sector, it is usually difficult to obtain expenditure data on the sector when the audited public accounts do not have clearly defined line items for each of the above, and as the ministries and institutions evolve.

${ }^{3}$ Unless otherwise stated, all monetary values are in 2000 constant prices. 
Table 7.3. Government expenditures on agriculture and rural development (2000 GHS, millions)

\begin{tabular}{lcccccc}
\hline Year & MoFA and MoF $^{\mathrm{a}}$ & DoF $^{\mathrm{b}}$ & CSIR $^{\mathrm{c}}$ & Cocobod $^{\mathrm{d}}$ & PSI $^{\mathrm{e}}$ & Total \\
\hline 2000 & 5.16 & 0.94 & 3.80 & 20.51 & 0.00 & 30.41 \\
2001 & 4.74 & 0.73 & 3.63 & 22.71 & 0.00 & 31.81 \\
2002 & 5.30 & 0.68 & 4.50 & 18.06 & 0.00 & 28.54 \\
2003 & 11.13 & 0.72 & 3.88 & 25.10 & 1.48 & 42.31 \\
2004 & 19.96 & 3.93 & 6.36 & 36.84 & 2.92 & 70.01 \\
2005 & 14.56 & 2.08 & 5.08 & 36.43 & 5.47 & 63.62 \\
2006 & 28.47 & 5.57 & 24.17 & 53.49 & 5.65 & 117.35 \\
2007 & 27.60 & 8.65 & 31.44 & 37.69 & 10.30 & 115.68 \\
\hline
\end{tabular}

Notes: Government expenditures are financed from internally generated funds and from overseas developmental assistance in the form of loans and grants. GHS = Ghanaian cedi. In 2000, US\$ $1 \approx$ GHS0.55.

${ }^{\text {a }}$ Until 2005, MoF (Ministry of Fisheries) was part of MoFA (Ministry of Food and Agriculture).

${ }^{b}$ DoF is the Department of Forestry under the Ministry of Lands and Forestry.

${ }^{c}$ CSIR is the Council for Scientific and Industrial Research.

${ }^{d}$ Cocobod is the Ghana Cocoa Board.

e PSI is presidential special initiatives.

Source: Benin et al. (2012).

than the core ministry have gained over time in their relative importance for developing the sector.

\subsubsection{Spending issues}

Benin et al. (2012) identify some important issues about public spending. First, most of the government's expenditure on the sector is allocated to recurrent activities, particularly salaries (Figure 7.4), while donors are picking up most of the capital investments through various multilateral and bilateral grants and loans. This level of dependence on donor funding for development activities is also underestimated, because the data shown here do not include funds that some donors, including USAID, channel directly to partners in the private and NGO sectors. This high dependence on donor funding for capital investment in the sector raises questions about the government's capacity to sustain such crucial investments should donor priorities change.

Another issue identified by Benin et al. (2012) is that the lion's share of regional agricultural spending in the noncocoa subsector is allocated to the central and southern parts of the country, while the northern areas receive the least expenditure. In particular, the Volta region attracted the largest share of MoFA spending, followed by the Eastern, Ashanti, and BrongAhafo regions, while the Upper-West and Upper-East regions attracted the least. The amount spent per person is higher in the northern than the 


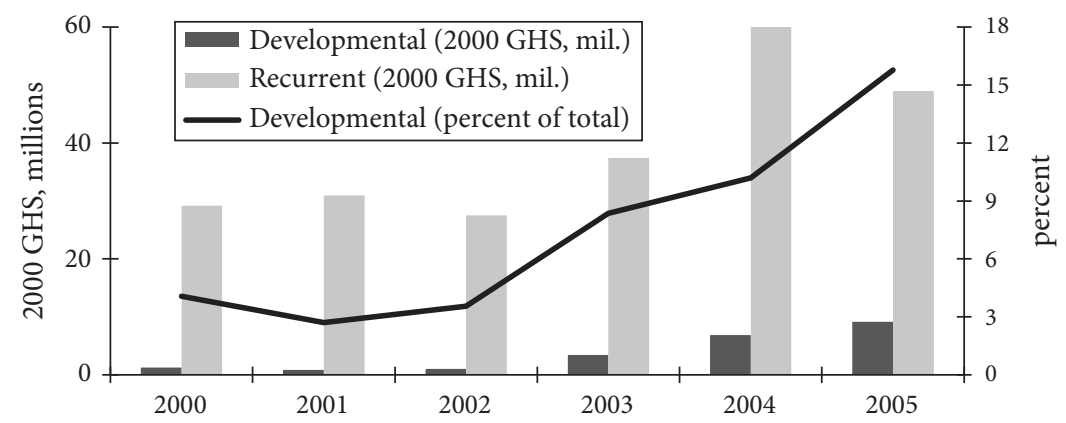

Figure 7.4. Government recurrent and developmental expenditures in agriculture (2000 GHS, millions)

Notes: GHS $=$ Ghanaian cedi.

Source: Benin et al.

Table 7.4. Government expenditures, by sector

\begin{tabular}{lcccccccr}
\hline & $\mathbf{2 0 0 0}$ & $\mathbf{2 0 0 1}$ & $\mathbf{2 0 0 2}$ & $\mathbf{2 0 0 3}$ & $\mathbf{2 0 0 4}$ & $\mathbf{2 0 0 5}$ & $\mathbf{2 0 0 6}$ & $\mathbf{2 0 0 7}$ \\
\hline Total (2006 GHS, billion) & 3.81 & 4.51 & 3.91 & 4.47 & 5.41 & 5.55 & 4.06 & 4.87 \\
Sector shares (\% of total expenditures) & & & & & & & \\
Agriculture & 2.4 & 1.2 & 1.4 & 1.4 & 1.8 & 2.6 & 2.2 & 2.5 \\
Education & 14.8 & 14.2 & 18.1 & 16.2 & 15.2 & 17.1 & 17.7 & 17.0 \\
Health & 3.0 & 3.8 & 5.2 & 5.1 & 4.6 & 5.7 & 6.7 & 6.8 \\
Transport \& communication & 2.3 & 1.3 & 0.7 & 1.1 & 1.1 & 1.3 & 1.3 & 1.4 \\
Defense & 2.2 & 2.4 & 2.3 & 2.5 & 1.9 & 2.3 & 2.3 & 2.1 \\
Other & 75.4 & 77.1 & 72.2 & 73.7 & 75.3 & 71.0 & 69.8 & 70.1 \\
\hline
\end{tabular}

Notes: GHS = Ghanaian cedi.

Source: Authors' calculation based on IFPRI (2015) and World Bank (2015).

southern areas, but the amount spent per hectare of land area is smaller in the north.

A final issue concerns the allocation of public expenditure across different types of spending. Access to other public goods and services such as education, health, roads, and other infrastructure can be as important as agricultural investment for promoting long-term agricultural productivity growth (Fan 2008). As shown in Table 7.4, the government has not neglected such nonagricultural spending, and total spending increased at an average rate of 2.5 percent per year between 2000 and 2007 in constant prices. However, the lion's share of the increase went to spending on education and health, while the spending shares for agriculture and transport (including all types of roads, ports, harbors and railways, etc.) and communication remained 
flat. This pattern of spending has been broadly consistent since the $1980 \mathrm{~s}$ (see Chapter 3). A relevant question is whether these were the best spending priorities for supporting agricultural productivity growth.

\subsection{Growth Effects of Public Spending on Agriculture}

Three key questions arise from our analysis of past patterns of public spending on agriculture. First, though a relatively small share of total government spending has been allocated to agriculture since 1961 (between 1 and 3 percent on average per year), has this been money well spent? Second, given the relatively high expenditure-to-output ratio in the cocoa subsector compared to the noncocoa subsector, has the noncocoa sector been unduly neglected? Third, we would like to know how effective the government's spending allocation across different types of investments and regions has been for agricultural growth. Our analysis draws on two recent studies. One study is by Benin (2016) who uses national-level data to estimate the marginal return to total public spending in agriculture over 1970-2012, and also the marginal returns for spending within the cocoa and noncocoa subsectors. We update this study using a revised model and data over 1961-2012. The other study by Benin et al. (2012) uses GLSS household survey data from 2005/6 and districtand region-disaggregated expenditure data over 2001-6 to estimate the productivity impacts of different types of public spending.

\subsubsection{Conceptual Framework}

The analysis in this chapter is based on a conceptual framework that sees public spending as contributing to a stock of public capital in rural areas, and this stock contributes to agricultural growth. This growth linkage can arise through various channels:

- Technology-advancing productivity effects, which typically derive from the yield-enhancing technologies of public expenditure in agricultural $\mathrm{R} \& \mathrm{D}$

- Human-capital-enhancing productivity effects, which typically derive from public expenditure in agricultural education, extension, and information, which all help raise the knowledge and skills of farmers and those engaged in agricultural production (Schultz 1982) 
- Transaction cost-reducing productivity effects, which derive from public expenditure on infrastructure (such as storage facilities, market information, and feeder roads) in the agricultural sector, which in turn contributes to improved access to input and output markets and thus reduces the cost of agricultural inputs and technologies (Sadoulet and de Janvry 1995)

- Crowding-in productivity effects, which is a second-order effect in which the increase in public capital induces an increase in private investment in agricultural production and along agricultural value chains.

In addition to the various channels through which productivity effects of public agriculture expenditure may materialize, the literature also shows that the effects are not the same for all types of expenditure. Also, the effects often materialize with a lag rather than contemporaneously. See Benin (2016) for further discussion.

These various effects can be captured in a model in which agricultural output is specified as a function of the stocks of both public and private capital in agriculture, as well as the use of resources like land, labor, and modern inputs, and other exogenous factors like rainfall. The stocks of public and private capital depend, respectively, on accumulated public and private spending over time, with relevant time-lag structures and depreciation rates. The stocks of public capital can also be disaggregated by type of spending. A second set of equations specifies that the stock of private capital and the use of other resources (land, labor, and modern inputs) is a function of the stock of public capital, along with other variables such as prices, policies, terms of trade, infrastructure, access to financial and technical services, access to input and output markets, land pressure, etc.

The literature on public investment analysis shows that the public spending decision, too, may be endogenous, since the amount spent or invested on a sector or activity may depend on the performance of the sector or returns to investment in the activity. So is the notion that growth in public capital is an endogenous process, that is, an outcome of growth in income rather than only a cause of it. As such, it is good practice to add a third equation to explain the level of public spending each year, typically using variables on political processes and institutional arrangements. When estimating the model, allowance must also be made for other variables that could be endogenous to the model or which are serially correlated over time. This modeling approach is well established in the literature (e.g.,, Aschauer 1989; Barro 1990, Thirtle et al. 2003, Fan 2008). 


\subsubsection{Disaggregated Impact of Public Spending in the Cocoa and Noncocoa Subsectors}

\subsubsection{The model}

Using national data for the period 1961-2012, we estimate a variant of Benin's (2016) model for Ghana's agricultural sector as a whole, and then separately for the cocoa and noncocoa subsectors. The model is a semi-reduced-form, single equation that is specified as follows:

$$
Y_{s t}=f\left(a g E X P_{s t}, a g S T K_{s t}, Z 1_{s t}, Z 2_{t}, t\right),
$$

where $Y$ is the value of gross agricultural output; agEXP is public agriculture expenditure; agSTK is public agriculture capital stock; $t$ is a time trend; and $Z 1$ and $Z 2$ are vectors of exogenous factors affecting agricultural output and use of inputs such as public nonagriculture expenditure, policies, institutions, infrastructure, prices, differentiating those that are subsector specific $(Z 1$, as related to some policies and institutions for example) and those that are not ( $Z 2$, such as land pressure, climate and agroecology).

Public agriculture expenditure equation is specified as follows:

$$
\operatorname{agEXP} P_{s t}=h\left(\operatorname{agSTK} K_{s t}, Z 3_{s t}, Z 4_{t}, t\right),
$$

where $\mathrm{Z} 3$ and $Z 4$ represents the variables that affect agEXP, some of which may also affect $Y$ and inputs and, therefore, are common to $Z 1$ and $Z 2$. Here too, differentiating those that are subsector specific $(Z 3)$ and those that are not $(Z 4)$. All the variables used in the estimation are observed with the exception of the public agriculture capital stock, agSTK, which was constructed using the following capital formation approach:

$$
\begin{gathered}
a g S T K_{s t}=I_{s t}+(1-\delta) a g S T K_{s t-1}, \\
a g S T K_{s, 1961}=\frac{I_{s, 1961}}{(\delta+r)}
\end{gathered}
$$

Where $I$ is the gross capital formation, $\delta$ is the depreciation rate, $r$ is the real interest rate, and the initial capital stock, agSTK ${ }_{1961}$, is estimated using the procedure of Kohli (1982). The annual values of $I$ are based on the share of capital expenditure in total expenditure for the entire economy (compiled from the same sources of expenditure listed in Table 7.1), $\delta$ is compiled from (Knoema 2016), and $r$ from the World Bank (2016). 
From the estimation, the elasticity of agricultural output with respect to public agriculture expenditure $\left(\vartheta_{s}\right)$ can be obtained as:

$$
\vartheta_{s}=\frac{\partial Y_{s}}{\partial a g E X P_{s}}+\frac{\partial Y_{s}}{\partial a g S T K_{s}}
$$

where $\partial$ refers to the partial derivative. The elasticity is interpreted as the percentage change in agricultural output $(Y)$ due to a 1 percent change in public agriculture expenditure (agEXP).

\subsubsection{Empirical model}

The empirical model estimated comprises two sets of a system of equations that can be written as:

$$
\begin{gathered}
a g E X P_{s t}=a+\gamma_{s} a g S T K_{s t}+Z 3_{s t}^{\prime} \tau_{s}+Z 4_{t}^{\prime} \pi+t+e_{t} \\
Y_{t}=a+\sum_{s} \beta_{s} a g E X P_{s t}+\sum_{s} \gamma_{s} a g S T K_{s t}+Z 1_{s t}^{\prime} \tau_{s}+Z 2_{t}^{\prime} \pi+t+e_{t}
\end{gathered}
$$

and

$$
\begin{gathered}
a g E X P_{s t}=a+\gamma_{s} a g S T K_{s t}+Z 3_{s t}^{\prime} \tau_{s}+Z 4_{t}^{\prime} \pi+t+e_{t} \\
Y_{s t}=a_{s}+\beta_{s} a g E X P_{s t}+\gamma_{s} a g S T K_{s t}+Z 1_{s t}^{\prime} \tau_{s}+Z 2_{t}^{\prime} \pi_{s}+t+e_{s t} .
\end{gathered}
$$

where (5a) and (5b) are for estimating the effect of subsector-disaggregated expenditures on total agricultural output, and (6a) and (6b) are separate equations for estimating the effect of subsector-disaggregated expenditures on subsector-disaggregated output.

Table 7.5 presents descriptive statistics of the specific variables used in the econometric analysis from 1961 to 2012. Most variables are self-explanatory but a few explanations are in order. For variables captured by $Z 3$ and $Z 4$, that is, factors affecting expenditures, we follow the literature closely and use, for example, GDP per capita (GDPCAP) to test Wagner's law that public expenditure rises constantly as income growth expands (Wagner 1883); and different shocks such as change in government and political party systems (GOVTYP), change in the minister of finance (MINFIN), change in the minister of agriculture (MINAG), change in the chief executive officer of the Cocobod (CEOCOB), policy reforms in the agriculture sector (AGPOL) and cocoa subsector (COPOL), and monetary policy (MONPOL) to test the displacement hypothesis (Peacock and Wiseman 1961). Another noncocoa-specific 
Table 7.5. Description and summary statistics of variables, 1961-2012 annual average

\begin{tabular}{|c|c|c|c|}
\hline Variable & $\begin{array}{l}\text { Name in } \\
\text { model }\end{array}$ & Mean & $\begin{array}{l}\text { Standard } \\
\text { error }\end{array}$ \\
\hline Agricultural GDP, million 2004-6 GHS & $\mathrm{Y}$ & & \\
\hline Total agriculture & $\mathrm{Y}_{\text {tot }}$ & $4,145.59$ & 172.03 \\
\hline Noncocoa subsector & $Y_{\text {non }}$ & $3,584.98$ & 170.64 \\
\hline Cocoa subsector & $Y_{\text {coc }}$ & 560.62 & 26.07 \\
\hline Agricultural expenditure, million 2006 GHS & agEXP & & \\
\hline Noncocoa subsector & $\operatorname{agEXP}_{\text {non }}$ & 103.98 & 7.43 \\
\hline Cocoa subsector & $\operatorname{agEXP} P_{\text {coc }}$ & 211.02 & 22.25 \\
\hline Agricultural capital stock, million 2006 GHS & agSTK & & \\
\hline Noncocoa subsector & agSTK non $_{\text {non }}$ & $2,276.08$ & 46.40 \\
\hline Cocoa subsector & agSTK $_{\mathrm{coc}}$ & $2,729.56$ & 212.88 \\
\hline \multicolumn{4}{|l|}{ Variables in expenditure equations only } \\
\hline GDP per capita, 2006 GHS & GDPPCAP & 739.15 & 17.84 \\
\hline Real foreign exchange, GHS/US $\$ 1$ & FOREX & 1.84 & 0.15 \\
\hline Official development assistance, share of GDP & ODAGDP & 6.17 & 0.57 \\
\hline Type of government: 1966, 1972, 1979, 1982 & GOVTYP & 0.08 & \\
\hline $\begin{array}{l}\text { Minister of finance: } 1966,1969,1972,1978, \\
1979,1980,1982,1995,2001,2005,2007,2009\end{array}$ & MINFIN & 0.23 & \\
\hline $\begin{array}{l}\text { Minister of agriculture: } 1962,1963,1966,1967 \text {, } \\
\text { 1968, 1969, 1971, 1972, 1973, 1977, 1979, 1980, } \\
\text { 1981, 1982, 1984, 1985, 1986, 1992, 1996, 1997, } \\
1998,2001,2005,2009\end{array}$ & MINAG & 0.46 & \\
\hline $\begin{array}{l}\text { Chief executive officer of Cocobod: 1973, 1976, } \\
\text { 1978,1980,1984,1992, 1994, 1997, 2001, 2002, } \\
\text { 2006, 2009 }\end{array}$ & CEOCOB & 0.23 & \\
\hline $\begin{array}{l}\text { Agricultural sector policy: 1972, 1983, 1988, } \\
\text { 1991, 1994, 1997, } 2007\end{array}$ & AGPOL & 0.13 & \\
\hline $\begin{array}{l}\text { Cocoa subsector policy: 1966, 1977, 1984, 1993, } \\
1996,1999,2004\end{array}$ & COPOL & 0.13 & \\
\hline $\begin{array}{l}\text { Agriculture expenditure review: 1977, } \\
\text { 1997, } 2006\end{array}$ & AGPER & 0.06 & 0.05 \\
\hline \multicolumn{4}{|l|}{$\begin{array}{l}\text { Variables in both expenditure and output } \\
\text { equations }\end{array}$} \\
\hline Government total expenditure, share of GDP & TOTEXP & 22.49 & 1.02 \\
\hline Share of cocoa price (f.o.b.) received by farmers & SHCOCPR & 53.22 & 5.16 \\
\hline $\begin{array}{l}\text { Openness of economy, ratio of value of imports } \\
\text { to exports }\end{array}$ & OPENECON & 1.31 & 0.03 \\
\hline Population growth, \% & POPGROW & 2.59 & 0.06 \\
\hline $\begin{array}{l}\text { Monetary policy: } 1967,1971,1975,1977,1980 \text {, } \\
1982,1983,1993,2006,2007\end{array}$ & MONPOL & 0.19 & \\
\hline Rainfall, mm & RAINTOT & $1,177.36$ & 20.13 \\
\hline Rainfall, monthly coefficient of variation & RAINCOV & 70.05 & 0.92 \\
\hline $\begin{array}{l}\text { Variables in output equations only } \\
\text { Ratio of cocoa price index to fertilizer price } \\
\text { index }\end{array}$ & COCFERT & 1.51 & 0.11 \\
\hline $\begin{array}{l}\text { Ratio of agriculture price index to fertilizer } \\
\text { price index }\end{array}$ & AGRFERT & 1.58 & 0.07 \\
\hline
\end{tabular}


Table 7.5. Continued

\begin{tabular}{|c|c|c|c|}
\hline Variable & $\begin{array}{l}\text { Name in } \\
\text { model }\end{array}$ & Mean & $\begin{array}{l}\text { Standard } \\
\text { error }\end{array}$ \\
\hline Ratio of gold price index to cocoa price index & GOLDCOC & 0.53 & 0.05 \\
\hline $\begin{array}{l}\text { Ratio of gold price index to agriculture price } \\
\text { index }\end{array}$ & GOLDAGR & 0.45 & 0.04 \\
\hline $\begin{array}{l}\text { Ratio of area under cocoa to area under } \\
\text { noncocoa }\end{array}$ & SHCOAREA & 0.07 & 0.00 \\
\hline
\end{tabular}

Note: For the exogenous or predetermined variables, the lagged values are used (this includes the lagged values of the endogenous variables). The exogenous categorical variables take on the value of 1 in 1961 and subsequent years until a change in regime or an incident takes place and then the value goes up to 2 , then 3 , 4, etc., for the respective years indicated. For these, the mean values represent the frequency of change in the fifty-two years of the data. All continuous variables are transformed by natural logarithm, excluding those measured as indexes or as percentages or shares. Then the first differences of all transformed or nontransformed variables are used in the estimation.

Source: Author's calculation based on various data sources (see Table 7A.2 for details).

variable is measured by the dummy variable for the three years following the year $(1977,1997,2006$, and 2012) in which an agriculture public expenditure review was undertaken (agPER). For these shock variables, they take on the value of 1 in 1961 and subsequent years until a change in regime or an incident takes place and then the value goes up to 2 , then 3 , 4 , etc., for the respective years indicated in Table 7.5. Taking the variable AGPOL as an example, which is used for the general evolution of policies, institutions, infrastructure etc., it represents change occurring at successive time periods: 1961-1971 $=1$ (as the baseline following Independence), 1972-1982 = 2 (period after the first agriculture-sector-specific strategy embodied in the operation Feed Yourself), $1983-1990=3$ (start of the Economic Recovery Program), 1988-1990 = 4 (start of decentralization), 1991-9 = 5 (for complete pullout of the direct government involvement in production, stoppage of subsidies, etc.), 1994-5 = 6 (establishment of the District Assembly Common Fund), 1997-2006 = 7 (incorporation of the district agricultural development units into the District Assembly), and 2007-12 = 8 (for PRSP, CAADP, reintroduction of subsidies, etc.). For the MONPOL, we combine major incidents in currency change (1967, 1982, 2007), GDP rebasing (1993 and 2008), and drought (1971, 1977,1980 , and 1983). A measure of the openness of the economy (OPENECON) is used to test the efficiency or compensatory theory of the effects of globalization (Rodrik 1998; Garrett 2001). Other variables include total government expenditure (TOTEXP, which is used to capture overall budget constraint), foreign exchange rate (FOREX), official development assistance 
(ODAGDP), share of cocoa prices received by farmers (SHCOCPR), and population growth (POPGROW). Rainfall, measured as total annual amount (RAINTOT) and monthly coefficient of variation (RAINCOV), obtained from HarvestChoice (2015) are used to capture the effect of weather shocks.

For variables captured by $Z 1$ and $Z 2$, that is, factors affecting inputs and output, they include several of those described above such as OPENECON, TOTEXP, MONPOL, SHCOCPR, POPGROW, RAINTOT, and RAINCOV. In addition, we include four variables on relative price indexes (cocoa/fertilizer, agriculture/fertilizer, gold/cocoa, and gold/agriculture) and ratio of cocoa area to noncocoa area.

The two sets of equations, $5 \mathrm{a}$ and $5 \mathrm{~b}$ and then $6 \mathrm{a}$ and $6 \mathrm{~b}$, were estimated using simultaneous equations modeling (SEM) methods. A number of estimation issues had to be addressed and these are discussed in Appendix 7B. The model results and statistical tests are also presented and discussed in Appendix 7B, along with tables showing the regression results. A brief discussion of the general results is provided there.

\subsubsection{Estimated elasticities or growth effects of public agricultural spending}

Whereas, the estimated elasticities of government spending on output in the noncocoa subsector are mostly positive and statistically significant, those with respect to Cocobod spending on output in the cocoa subsector are mostly insignificant with a mix of positive and negative effects. Considering the effect of the disaggregated spending on total agricultural output, for example, both expenditure and capital stock in the noncocoa subsector have direct positive and statistically significant effects, with elasticities in the range of $0.10-0.13$ for expenditures and 0.9-1.21 for stocks. However, the total effect after accounting for an indirect effect arising from an increase in the stock of capital reducing the government's spending leads to a smaller elasticity estimates (0.34-0.48) that are not statistically significant. On the other hand, the direct or total effect of expenditures and stocks in the cocoa subsector on total output is not statistically significant. A similar pattern is observed for the estimated elasticities of subsector-disaggregated expenditures and stocks on subsectordisaggregated output, with some mixed results. For the noncocoa subsector, the direct effect of expenditures is not statistically significant, but the direct effect of stocks is statistically significant $(0.7-1.1)$, and so is the total effect (0.7-1.0). For the cocoa subsector, the direct effect of expenditures is significant (0.5-0.7), but the direct effect of stocks is not statistically significant, and the total effect too, which is negative, is not statistically significant. Because of 
the larger expenditure-to-output ratios in the cocoa subsector compared to the noncocoa subsector (which is about twenty times larger on average in 1961-2012 and more in recent years-see Table 7.2), these estimated elasticities translate into higher marginal effects or returns to spending in the noncocoa subsector than in the cocoa subsector.

Because the financial management and expenditure determination processes are different for the two subsectors, there is no direct way of reallocating expenditures on the cocoa subsector to the noncocoa subsector as the results may imply. Expenditures on the noncocoa subsector by the government derive from the national budget that is approved by parliament, whereas the expenditures on cocoa by the Cocobod are directly financed from the proceeds of cocoa exports. But the two are linked since the government revenue and spending depends on the tax on cocoa exports and profits, both of which in turn depend on the share of cocoa f.o.b. prices that is given to farmers (SHCOCPR in the model). As expected, SHCOCPR has a negative effect on expenditures in both the noncocoa and cocoa subsectors. But SHCOCPR has a relatively larger positive effect on output. Therefore, increasing the share of cocoa f.o.b. prices that is given to farmers may be an indirect way of reallocating expenditures to boost output and raise the returns to spending in especially the cocoa subsector.

One reason government spending has had a weaker long-term impact on noncocoa output is because the government tended to reduce its spending over time as the capital stock increased, leading to a negative feedback effect in the model. If the government were to change this behavior in the future and focus more on building up the capital stock in the noncocoa sector, then the returns to its investment would be enhanced.

Results of the aggregate analysis also mask differences between the two subsectors in terms of the importance of other variables. Detailed results are again discussed in Appendix 7B, but of particular interest are the following. With respect to total agricultural output, for example, the main statistically significant variables are OPENECON (-), SHCOCPR (+), and MONPOL (-). These suggest that globalization (importing more relative to exports) has had a dampening effect on agricultural growth. The same with MONPOL, which is associated with incidents of currency change, GDP rebasing, and drought. Giving a higher share of the cocoa f.o.b. price to farmers (SHCOCPR) has a boosting effect, perhaps by increasing farmers' investment in the agricultural sector. The results by subsector suggest that whereas the negative effect of MONPOL derives from both subsectors, the negative effect of OPENECON derives mostly from the noncocoa subsector and the positive effect of SHCOCPR derives mostly from the cocoa subsector. 
In general, there is a low number of variables that have a statistically significant effect on expenditures in the cocoa subsector (see Table 7B.2a and Table 7B.3a), which suggest that the expenditure determination process in the cocoa subsector as modeled here may not have been realistic. With a likely omitted variables problem, any resulting bias in the cocoa subsector expenditure equation may have been transmitted to the other equations. Further research is needed on this. Also, there are other objectives such as food security and foreign exchange earnings beyond production that will be useful to include in the model. Thus, further disaggregation and analysis of expenditures in the noncocoa subsector into, for example, export and food subgroups is needed, in addition to disaggregated data on foreign exchange earnings and food imports.

\subsubsection{Relative Returns to Public Expenditure by Type of Spending, 2000-6}

Beyond differentiating between spending on the cocoa and noncocoa subsectors, the previous analysis sheds little light on which types of public spending are the most productive, and hence which types of spending should be prioritized for agricultural growth. The available data for Ghana limit the level of analysis that can be undertaken, but Benin et al. (2012) have estimated the marginal returns to public spending on agriculture verses other sectors, including education, health, and rural roads. Their analysis follows the same basic conceptual framework as described earlier, but with a different empirical approach. Unlike the reduced-form, single-equation approach used in the preceding analysis, Benin et al. (2012) estimate a system of equations consisting of a household agricultural production function and separate equations to explain the levels of farm investment and public agriculture expenditure. The production function and farm investment are estimated using household level data from the 2005/6 GLSS household survey, and the agricultural public expenditures and capital stocks are calculated using district- and regiondisaggregated public expenditure data from 2000 to 2006. The effect of public spending on the other sectors of rural roads, education, and health were modeled via the impact of rural road density, literacy rate, and access to a health facility, respectively, on farm investments and agricultural production.

Their results show that an increase in public spending on the agricultural sector by 1 percent is associated with a $0.22-0.35$ percent increase in households' agricultural productivity (i.e., value of household total agricultural 
production per capita). This translates into very high economic returns. For the marginal Ghana cedi (GHS) spent, GHS3.51-4.15 is returned in terms of increase in agricultural GDP.

Regarding spending on other sectors, greater rural road density-the indicator used for public capital in the sector-is significantly associated with greater household agricultural productivity, with an estimated productivity effect of $0.19-0.26$ percent for a 1 percent increase in the rural road density. ${ }^{4}$

Literacy rate, or the proportion of the population that is literate-the indicator used for public capital in the education sector-has no statistically significant effect. This may seem surprising given the large share of and increment in spending on the education sector (Table 7.4). However, while both net enrollment and adult literacy improved over time at the national level, they declined in rural areas, suggesting that the increase in total public spending on the sector has not benefited the agricultural sector.

The effect of the public capital variables in the health sector is mixed, and is also somewhat surprising. The public capital stock is measured by the proportion of the population living within $1 \mathrm{~km}$ and between $1-5 \mathrm{~km}$ of a health facility, against the comparative base of the population living more than $5 \mathrm{~km}$ away from a health facility. While the association between agricultural productivity and the indicator for those living within $1 \mathrm{~km}$ of a health facility is positive, the level of statistical significance is weak.

As captured in this analysis, it would seem that government spending on agriculture and rural roads have been the best investments for increasing agricultural productivity growth, whilst government spending on education and health does not seem to have translated into measurable agricultural productivity effects. This is concerning given that government spending on health and education has grown rapidly in recent years and (together) accounts for about a quarter percent of the total expenditures (Table 7.4), while spending on agriculture and rural roads has remained flat and accounts for less than 5 percent of the total expenditures. The analysis has not attempted to capture the impacts of public spending on the different sectors in the nonagricultural sector or the entire economy, so it is hard to draw strong conclusions on their relative importance for raising overall growth or in reducing overall poverty. Also missing is any disaggregated analysis of the impacts of different kinds of agricultural spending. For example, is it better to

\footnotetext{
4 Estimating the marginal returns to public spending on the nonagricultural sectors was not done as the author did not have data on the relevant expenditures to estimate the relationship between the expenditures and the public capital stocks, as was done for the agricultural sector.
} 
spend more on $\mathrm{R} \& \mathrm{D}$ or irrigation versus other kinds of agricultural spending such as market infrastructure or subsidies? All we know at this point is that spending on the noncocoa subsector gives higher returns than spending on the cocoa subsector. There is a need for more research on this topic.

\subsection{New Directions in Government Spending on Agriculture}

With the reintroduction of fertilizer subsidies in 2007, the government seems to have started paying more attention to the noncocoa subsector, with the introduction of four major subsidy and credit programs being implemented by MoFA. These involve:

- Subsidization of agricultural mechanization services via support to the establishment and operation of Agricultural Mechanization Service Centers (AMSEC)

- Subsidization of fertilizers via the National Fertilizer Subsidy Program

- Establishment and management of block farms that benefit from subsidized mechanization services and inputs (fertilizers, improved seed, and pesticides) and extension services, and

- Stabilization of output prices via the establishment and operation of the National Food Buffer Stock Company (NAFCO).

Food crops are the target, with the major ones including maize grain and seed, rice grain and seed, soybean, sorghum, tomato, and onions. The government spent about GHS 7.9 million each year in 2007 and 2008 on these programs, but the costs have since escalated. Benin et al. (2013) estimated that the combined cost of the fertilizer subsidy, block farming, and AMSEC programs was 25 percent of MoFA's budget in 2010, with the fertilizer subsidy accounting for the bulk. Because of the escalation in the cost, the government was not able to implement the fertilizer program in 2014, though it resumed it in 2015.

Early evidence suggested that the fertilizer subsidy did increase fertilizer use, and farmers who applied fertilizer on their farms obtained higher yields and net income than those who did not use any (Benin et al. 2013). On the basis of that evidence, Benin et al. (2013) projected that the overall future economic return of the program would be positive, with an estimated benefit-cost ratio of 1.7. The same study also found initial benefits from the AMSEC and block 
farming programs, and strong synergies between the benefits of the fertilizer subsidy, AMSEC and block farming programs and the price support program implemented by NAFCO. Benin (2015) found that the AMSEC program has had mixed impact on different outcome indicators-whereas the program has contributed to improving availability of mechanization services, reducing drudgery, and raising yield, it has had no impact on the change in the prices paid by farmers for the services used and the change in the amount of area plowed. The initial gains from these programs is reflected in the positive growth rate (3.6 percent per annum) over 2009-12 in agriculture output per hectare for the noncocoa subsector (Table 7.2). The relative contribution of the four programs to this overall productivity performance is unknown, however. Given the weak relationship between fertilizer use and yields found in other chapters of this book, the rationale for spending the bulk of the funds on the fertilizer subsidy program is questioned. The evidence in the other chapters shows that fertilizer use is related more to maintaining soil fertility as fallow periods are shortened rather than to intensify land productivity. Similarly, the analysis of AMSEC in Chapter 9 also raises questions as to whether the reliance on heavy-duty tractors and equipment is a sound intervention for promoting agricultural mechanization in Ghana. While this chapter has demonstrated the need to rebalance public spending towards the noncocoa subsector, and the government's ongoing attempt to do that must be welcomed, serious concerns remain about whether the current approach is likely to be successful or cost effective.

\subsection{Conclusions}

The government's public spending on agriculture has fallen short of 10 percent of its total expenditure in most years since 1961. In recent times, the share was only 2.1 percent during 2001-8 and 2.8 percent during 2009-12. This is low even by African standards, especially as it includes food staples, and in terms of fulfilling the Maputo Declaration target of 10 percent. This excludes the cocoa subsector, which is managed by the Cocobod (a state-owned enterprise). Relative to the respective output of the subsector, the amount spent by the Cocobod on the cocoa subsector far outweighs the amount spent by the government on the noncocoa subsector. One reason for the low share of government spending on the noncocoa subsector is that the tax on cocoa exports sustains a lot of the spending in the cocoa subsector. This is consistent with the finding of a negative effect of the share of cocoa prices received by farmers on expenditure in the noncocoa subsector. 
Overall, public spending on agriculture has given favorable returns in Ghana, and better than some other public investments in rural areas. One study, for example, found that on the margin, each Ghanaian cedi (GHS) spent on agriculture during 2000-6 returned GHS3.51-4.15 in terms of increases in agricultural GDP, and that government spending on agriculture and rural roads had bigger marginal impacts on agricultural productivity than government spending on education and health (Benin et al. 2012). The detailed analysis reported in this chapter for 1961-2000 also found significant and positive direct impacts from public spending in agriculture, but with more powerful and statistically significant impacts in the noncocoa than the cocoa subsector. It was also found that government spending in the noncocoa subsector was negatively related to the size of the capital stock, and this had a negative and indirect impact on the returns. If in the future the government were to change its behavior and attach more importance to building up the capital stock, this would enhance the long-run returns on its investments.

Although the expenditure-to-GDP ratio is much higher in the cocoa than in the noncocoa subsector, there is no direct way of reallocating expenditures from the cocoa to the noncocoa subsector as the expenditures on cocoa are directly financed by the proceeds of cocoa exports. The government simply needs to boost its spending on the noncocoa subsector. In 2007 the government launched several subsidy programs to help grow the noncocoa subsector. These include the fertilizer subsidy program, and the AMSEC and block farming programs, as well as a price support program implemented by NAFCO. The cost of these programs was initially modest at GHS7.5 million per year in 2007 and 2008, but had escalated to 25 percent of MoFA's budget in 2010, and seems likely to increase to about half MoFA's budget by 2020. Unfortunately, the available evidence does not show these programs to be generating the full benefits that were expected, and there is need to reevaluate them to ascertain whether this is the best way to spend available public resources to promote agricultural growth.

In terms of its total budget, the government spends far more on health and education than on agriculture and rural roads. Analysis shows that government spending on agriculture and rural roads has been the best investment for increasing agricultural productivity growth, whilst government spending on education and health does not seem to have translated into measurable agricultural productivity effects. The analysis has not attempted to capture the impacts of this public spending on overall growth or poverty reduction, so it is hard to draw strong conclusions. Also missing is any disaggregated analysis of the impacts of different kinds of agricultural spending, for example $\mathrm{R} \& \mathrm{D}$ or irrigation versus other kinds of agricultural spending. There is a need for more research on this topic. 


\section{APPENDIX}

7A: Data Sources on Public Expenditures in Ghana, 1961-2012

Table 7A.1. Data and sources on public expenditures in Ghana, 1961-2012

\begin{tabular}{|c|c|c|c|c|c|c|}
\hline \multirow[t]{2}{*}{ Year } & \multicolumn{2}{|c|}{ Total government expenditure } & \multicolumn{2}{|c|}{ Agriculture expenditure (million GHS) } & \multirow{2}{*}{$\frac{\text { Deflator }^{\mathrm{d}}}{2006=100}$} & \multirow{2}{*}{$\begin{array}{l}\text { Agriculture expenditure data sources } \\
(\mathrm{N}=\text { noncocoa, } \mathrm{C}=\text { cocoa })\end{array}$} \\
\hline & Million GHS ${ }^{\mathrm{a}}$ & Capital $(\%)^{\mathbf{b}}$ & Noncocoa subsector & Cocoa subsector $^{c}$ & & \\
\hline 1961 & 0.023 & 39.1 & 0.0028 & 0.0022 & 0.0017 & Stryker (1990) \\
\hline 1962 & 0.025 & 40.7 & 0.0021 & 0.0020 & 0.0017 & Stryker (1990) \\
\hline 1963 & 0.027 & 39.3 & 0.0025 & 0.0021 & 0.0019 & Stryker (1990) \\
\hline 1964 & 0.033 & 38.8 & 0.0027 & 0.0022 & 0.0020 & Stryker (1990) \\
\hline 1965 & 0.036 & 39.2 & 0.0039 & 0.0038 & 0.0024 & Stryker (1990) \\
\hline 1966 & 0.027 & 24.2 & 0.0027 & 0.0017 & 0.0026 & Stryker (1990) \\
\hline 1967 & 0.031 & 22.0 & 0.0025 & 0.0018 & 0.0025 & Stryker (1990) \\
\hline 1968 & 0.037 & 18.3 & 0.0026 & 0.0020 & 0.0028 & Stryker (1990) \\
\hline 1969 & 0.044 & 19.0 & 0.0029 & 0.0016 & 0.0031 & Stryker (1990) \\
\hline 1970 & 0.047 & 23.0 & 0.0030 & 0.0019 & 0.0032 & Stryker (1990) \\
\hline 1971 & 0.050 & 20.6 & 0.0034 & 0.0034 & 0.0034 & Stryker (1990) \\
\hline 1972 & 0.054 & 17.9 & 0.0039 & 0.0042 & 0.0039 & Stryker (1990) \\
\hline 1973 & 0.077 & 22.1 & 0.0042 & 0.0062 & 0.0047 & Stryker (1990) \\
\hline 1974 & 0.114 & 25.2 & 0.0076 & 0.0075 & 0.0059 & Stryker (1990) \\
\hline 1975 & 0.150 & 29.5 & 0.0107 & 0.0124 & 0.0076 & Stryker (1990) \\
\hline 1976 & 0.200 & 31.9 & 0.0192 & 0.0165 & 0.0097 & Stryker (1990) \\
\hline 1977 & 0.306 & 22.7 & 0.0426 & 0.0114 & 0.0163 & Stryker (1990) \\
\hline 1978 & 0.374 & 20.3 & 0.0476 & 0.0311 & 0.0282 & Stryker (1990) \\
\hline 1979 & 0.409 & 16.9 & 0.0490 & 0.0427 & 0.0389 & Stryker (1990) \\
\hline 1980 & 0.467 & 10.5 & 0.0570 & 0.0685 & 0.0588 & N=IFPRI (2015), C=Stryker (1990) \\
\hline 1981 & 0.772 & 14.8 & 0.0940 & 0.1015 & 0.1032 & $\mathrm{~N}=$ IFPRI (2015), C=Stryker (1990) \\
\hline 1982 & 0.953 & 8.7 & 0.1020 & 0.1290 & 0.1320 & N=IFPRI (2015), C=Stryker (1990) \\
\hline 1983 & 1.476 & 8.1 & 0.1171 & 0.2178 & 0.2944 & N=IFPRI (2015), C=Stryker (1990) \\
\hline
\end{tabular}




\begin{tabular}{|c|c|c|c|c|c|c|}
\hline 1984 & 2.669 & 12.6 & 0.1320 & 0.4641 & 0.3984 & N=IFPRI (2015), C=Stryker (1990) \\
\hline 1985 & 4.576 & 13.1 & 0.2830 & 0.8321 & 0.4807 & N=IFPRI (2015), C=Stryker (1990) \\
\hline 1986 & 7.066 & 11.9 & 0.3200 & 1.2524 & 0.6811 & N=IFPRI (2015), C=Stryker (1990) \\
\hline 1987 & 10.213 & 19.7 & 0.4630 & 1.6651 & 0.9481 & $\mathrm{~N}=$ IFPRI (2015), C=linear interpolation \\
\hline 1988 & 14.390 & 19.4 & 0.5000 & 2.1168 & 1.2648 & $\mathrm{~N}=\mathrm{IFPRI}$ (2015), C=linear interpolation \\
\hline 1989 & 19.647 & 21.9 & 0.9140 & 2.5817 & 1.6227 & $\mathrm{~N}=$ IFPRI (2015), C=linear interpolation \\
\hline 1990 & 25.447 & 20.9 & 1.0438 & 3.2105 & 2.1284 & $\mathrm{~N}=\mathrm{IFPRI}(2015), \mathrm{C}=\mathrm{IMF}(1998)$ \\
\hline 1991 & 34.026 & 20.8 & 1.2378 & 4.0886 & 2.5550 & $\mathrm{~N}=\mathrm{IFPRI}(2015), \mathrm{C}=\mathrm{IMF}(1998)$ \\
\hline 1992 & 49.881 & 24.1 & 1.9815 & 4.7814 & 2.8399 & $\mathrm{~N}=\mathrm{IFPRI}(2015), \mathrm{C}=\mathrm{IMF}(2000)$ \\
\hline 1993 & 81.353 & 19.1 & 2.8449 & 7.0119 & 3.7418 & $\mathrm{~N}=\mathrm{IFPRI}(2015), \mathrm{C}=\mathrm{IMF}(2000)$ \\
\hline 1994 & 177.231 & 25.8 & 2.9427 & 6.0667 & 4.8691 & $\mathrm{~N}=\mathrm{CAGD}$ (2011), C=IMF (2000) \\
\hline 1997 & 464.865 & 18.2 & 6.5785 & 20.7430 & 11.6350 & $\mathrm{~N}=\mathrm{CAGD}(2011), \mathrm{C}=\mathrm{IMF}(2000)$ \\
\hline 1998 & 560.744 & 18.6 & 7.8291 & 29.5062 & 13.6186 & $\mathrm{~N}=\mathrm{CAGD}(2011), \mathrm{C}=\mathrm{IMF}(2000)$ \\
\hline 1999 & 656.622 & 27.9 & 17.7458 & 30.4868 & 15.5213 & $\mathrm{~N}=\mathrm{CAGD}(2011), \mathrm{C}=\mathrm{IMF}(2000)$ \\
\hline 2000 & 752.500 & 36.9 & 17.9186 & 46.5510 & 19.7477 & $\mathrm{~N}=\mathrm{CAGD}$ (2011), C=IMF (2005) \\
\hline 2001 & $1,199.760$ & 51.6 & 14.7664 & 83.0808 & 26.6235 & $\mathrm{~N}=$ MoFA (2013), C=Kolavalli et al. (2012) \\
\hline 2002 & $1,277.780$ & 43.4 & 18.3890 & 107.9965 & 32.6985 & N=MoFA (2013), C=Kolavalli et al. (2012) \\
\hline 2003 & $1,880.200$ & 48.4 & 26.3825 & 190.3620 & 42.0845 & $\mathrm{~N}=$ MoFA (2013), C=Kolavalli et al. (2012) \\
\hline 2004 & $2,603.466$ & 53.5 & 45.7670 & 271.3823 & 48.1237 & $\mathrm{~N}=$ MoFA (2013), C=Kolavalli et al. (2012) \\
\hline 2005 & $3,070.353$ & 48.9 & 78.9841 & 300.8731 & 55.3247 & $\mathrm{~N}=$ MoFA (2013), C=Kolavalli et al. (2012) \\
\hline 2006 & $4,056.891$ & 31.5 & 90.6267 & 340.0949 & 100.0000 & N=MoFA (2013), C=Kolavalli et al. (2012) \\
\hline 2007 & $5,661.918$ & 41.3 & 141.4683 & 418.8755 & 116.2760 & $\mathrm{~N}=$ MoFA (2013), C=Kolavalli et al. (2012) \\
\hline 2008 & $7,407.220$ & 43.4 & 256.6725 & 521.9458 & 139.7663 & $\mathrm{~N}=$ MoFA (2013), C=Kolavalli et al. (2012) \\
\hline 2009 & $8,869.230$ & 53.9 & 220.6086 & 872.2741 & 163.8475 & $\mathrm{~N}=$ MoFA (2013), C=Kolavalli et al. (2012) \\
\hline 2010 & $12,173.835$ & 44.1 & 327.9592 & $1,257.9316$ & 191.0390 & $\mathrm{~N}=$ MoFA (2013), C=Kolavalli et al. (2012) \\
\hline 2011 & $13,829.000$ & 38.2 & 406.5289 & $1,368.8934$ & 217.6239 & $\mathrm{~N}=\mathrm{MoFA}(2013), \mathrm{C}=\mathrm{GCB}$ (2013) \\
\hline 2012 & $22,675.000$ & 15.8 & 667.0152 & $1,423.1870$ & 250.7148 & $\mathrm{~N}=\mathrm{CAGD}(2013), \mathrm{C}=\mathrm{GCB}(2013)$ \\
\hline
\end{tabular}

Notes: Expenditure data prior to 2007 were mostly in the old currency units (GHC), which were divided by 10,000 to obtain the new currency equivalent (GHS).

${ }^{a}$ Data series on total government expenditure were compiled from three sources: 1961-1979 from Stryker (1990), 1980-2010 from IFPRI (2015), and 2011-2012 from CAGD (2014). These total expenditures do not include expenditures on cocoa that were incurred by the Ghana Cocoa Board, which is an autonomous public corporation. In the analysis therefore, we add the expenditures on cocoa to total government expenditure to obtain total public expenditure.

b Data series on total capital expenditures were compiled from two sources: 1961-1979 from Stryker (1990) and 1980-2012 from various issues of government finance statistics issued by the Controller of Accountant General's Department (CAGD).

${ }^{c}$ Expenditures on the cocoa were reported for financial years from October to September. We use the last year in the financial year as the calendar year to compile the data (e.g., 1978 for 1977/1978).

${ }^{d}$ Data series on the deflator is calculated by dividing GDP in current GHS by GDP in constant 2006 GHS, which were obtained from the World Bank (2015). 
Table 7A.2. Sources of data for the variables used in the regression analysis, 1961-2012

\begin{tabular}{|c|c|}
\hline Variable & Source of data \\
\hline $\begin{array}{l}\text { Agricultural GDP, million } 2006 \text { GHS }(Y) \\
\text { Total agriculture }\left(\mathrm{Y}_{\text {tot }}\right) \\
\text { Noncoca subsector }\left(\mathrm{Y}_{\text {non }}\right) \\
\text { Cocoa subsector }\left(\mathrm{Y}_{\mathrm{coc}}\right)\end{array}$ & GSS (2016), FAO (2016) \\
\hline $\begin{array}{l}\text { Agricultural expenditure, million } 2006 \text { GHS (agEXP) } \\
\text { Noncoca subsector }\left(\mathrm{agEXP}_{\text {non }}\right) \\
\text { Cocoa subsector }\left(\mathrm{agEXP}_{\mathrm{coc}}\right) \\
\text { Agricultural capital stock, million } 2006 \text { GHS (agSTK) } \\
\text { Noncoca subsector }\left(\mathrm{agSTK}_{\text {non }}\right) \\
\text { Cocoa subsector }\left(\mathrm{agSTK}_{\mathrm{coc}}\right)\end{array}$ & $\begin{array}{l}\text { Stryker (1990), IMF (1998, } \\
\text { 2000, 2005), Kolavalli et al. } \\
\text { (2012), MoFA (2013), GCB } \\
\text { (2013), CAGD (2011, 2013, } \\
\text { 2014), IFPRI (2015), World } \\
\text { Bank (2015) }\end{array}$ \\
\hline $\begin{array}{l}\text { Variables in expenditure equations only } \\
\text { GDP per capita, } 2006 \text { GHS (GDPPCAP) } \\
\text { Real foreign exchange, GHS/US\$1 (FOREX) } \\
\text { Official development assistance, share of GDP } \\
\text { (ODAGDP) }\end{array}$ & $\begin{array}{l}\text { GSS (2016), FAO (2016) } \\
\text { World Bank (2016a) } \\
\text { World Bank (2016a) }\end{array}$ \\
\hline $\begin{array}{l}\text { Type of government (GOVTYP): } \\
\text { Minister of finance (MINFIN): } \\
\text { Minister of agriculture (MINAG): } \\
\text { Chief executive officer of Cocobob (CEOCOB): } \\
\text { Agricultural sector policy (AGPOL): } \\
\text { Cocoa subsector policy (COPOL): } \\
\text { Agriculture expenditure review (AGPER): 1977, } \\
\text { 1997, } 2006\end{array}$ & $\begin{array}{l}\text { Authors, based on historical } \\
\text { accounts from various sources }\end{array}$ \\
\hline $\begin{array}{l}\text { Variables in both expenditure and output equations } \\
\text { Government total expenditure, share of GDP (TOTEXP) } \\
\text { Share of cocoa price (f.o.b.) received by farmers } \\
\text { (SHCOCPR) }\end{array}$ & $\begin{array}{l}\text { See sources on expenditure } \\
\text { above }\end{array}$ \\
\hline $\begin{array}{l}\text { Openness of economy, ratio of value of imports to } \\
\text { exports (OPENECON) }\end{array}$ & World Bank (2016a) \\
\hline $\begin{array}{l}\text { Population growth, \% (POPGROW) } \\
\text { Monetary policy (MONPOL): } \\
\text { Rainfall, mm (RAINTOT) } \\
\text { Rainfall, monthly coefficient of variation (RAINCOV) }\end{array}$ & $\begin{array}{l}\text { World Bank }(2016 \mathrm{a}) \\
\text { See sources on policies } \\
\text { HarvestChoice }(2015)\end{array}$ \\
\hline $\begin{array}{l}\text { Variables in output equations only } \\
\text { Ratio of cocoa price index to fertilizer price index } \\
\text { (COCFERT) } \\
\text { Ratio of agriculture price index to fertilizer price index } \\
\text { (AGRFERT) } \\
\text { Ratio of gold price index to cocoa price index } \\
\text { (GOLDCOC) } \\
\text { Ratio of gold price index to agriculture price index } \\
\text { (GOLDAGR) }\end{array}$ & World Bank (2016b) \\
\hline $\begin{array}{l}\text { Ratio of area under cocoa to area under noncocoa } \\
\text { (SHCOAREA) }\end{array}$ & FAO (2016) \\
\hline
\end{tabular}

Source: Author's compilation based on cited sources. 


\title{
7B: Regression Results on Impact of Agricultural Public Expenditure on Agricultural Output, 1961-2012
}

\author{
Brief Discussion of Estimation and Results
}

The model presented in the main text (equations $5 \mathrm{a}, 5 \mathrm{~b}, 6 \mathrm{a}$ and $6 \mathrm{~b}$ ) was estimated for the agricultural sector as a whole and then separately for the cocoa and noncocoa subsectors, using simultaneous equations modeling (SEM) estimation techniques. Table 7.5 in the main text presented the specific variables used and their descriptive statistics. The same set of variables were used in the aggregate and disaggregated analysis, with the exception of a few variables that were included or excluded as they were hypothesized to be subsector specific or affecting expenditures or output only.

Two major estimation issues were addressed. First, in applying SEM methods, the error terms $e_{s t}$ are assumed to have a mean of zero and constant variance, and be uncorrelated with the explanatory variables and uncorrelated across equations or over time (Zellner and Theil 1962; Greene 1993). For the latter, autocorrelation, we test the null hypothesis of no autocorrelation using the Harvey Lagrange multiplier (LM) test (Harvey 1990; Judge et al. 1985), separately for each equation and then for the overall system. The second issue is identification of the system, which we use exclusion restrictions to accomplish. The rule of thumb for using exclusion restrictions is that the number of exogenous variables excluded from equation q must be at least as large as the number of endogenous variables included in equation q. In addition to the explanatory factors discussed earlier, we use the lagged value of $Y$ as its instrument in some model specification to assess the strength of identification.

As we are using time-series data, another issue to deal with is stationarity of especially the dependent variables, which we find to be nonstationary in their levels but stationary in their first differences. Therefore, we estimate the first-difference equations. This means that the initial constant term $a$ drops out and is replaced by a new one since $t-(t-1)=1$. In general, first differencing helps address expenditure endogeneity due to omitted timeinvariant factors such as agroclimatic conditions that are fixed over time (Fan, Hazell, and Thorat 2000). Also, differencing can address expenditure endogeneity due to simultaneity if expenditure decisions are driven by levels, but not changes in the hypothesized outcome, or agricultural output in this case. The drawback of differencing, however, is that it could remove the long-term effect of expenditures whose benefits typically materialize with a lag rather than contemporaneously (Hsiao 1986). All continuous variables are transformed by natural logarithm so that their estimated coefficients are interpreted directly as elasticities. Then, the elasticity of agricultural output with respect to public agriculture expenditure is obtained as:

$$
\vartheta_{s}=\hat{\beta}_{s}+\hat{\gamma}_{s} .
$$

The stationarity test results are presented in Table 7B.1. The results for the agricultural sector as a whole are presented in Tables 7B.2a for subsector expenditure equations and $7 \mathrm{~B} .2 \mathrm{~b}$ for the aggregate output equations. This is followed by the estimation for the separate subsectors in Table 7B.3a for the subsector expenditure equations and 7B.3b for the subsector output equations. In each set of estimation, we use different model specifications in terms of allowing the $a g S T K_{t}$ in one subsector to be a determinant of $a g E X P_{t}$ or $Y_{t}$ in the other subsector.

Stationarity test results for the dependent variables: Details of the stationarity test results for the dependent variables shown in Table 7B.1 suggest that unit root is a problem with the 
Table 7B.1. Stationarity test results for level and first difference of dependent variables, 1961-2012

\begin{tabular}{|c|c|c|c|c|c|}
\hline \multirow[t]{2}{*}{ Variable } & \multirow[t]{2}{*}{ Unit root test } & \multicolumn{2}{|c|}{ Level } & \multicolumn{2}{|c|}{ First difference } \\
\hline & & Test statistic & $p$-value & Test statistic & $p$-value \\
\hline \multirow[t]{2}{*}{$a g E X P_{\text {non }}$} & $\mathrm{ADF}$ & -1.51 & 0.827 & $-7.78^{\star * \star}$ & 0.000 \\
\hline & $\mathrm{PP}$ & -1.35 & 0.873 & $-7.89^{* * *}$ & 0.000 \\
\hline \multirow[t]{2}{*}{$a g E X P_{c o c}$} & $\mathrm{ADF}$ & -3.06 & 0.115 & $-8.28^{\star * *}$ & 0.000 \\
\hline & $\mathrm{PP}$ & $-3.15^{\star}$ & 0.095 & $-8.44^{\star * *}$ & 0.000 \\
\hline \multirow[t]{2}{*}{$Y_{\text {tot }}$} & $\mathrm{ADF}$ & -2.74 & 0.219 & $-7.26^{* * *}$ & 0.000 \\
\hline & $\mathrm{PP}$ & -2.66 & 0.253 & $-7.45^{\star * *}$ & 0.000 \\
\hline \multirow{2}{*}{$Y_{\text {non }}$} & $\mathrm{ADF}$ & -2.65 & 0.259 & $-7.08^{\star * *}$ & 0.000 \\
\hline & $\mathrm{PP}$ & -2.57 & 0.292 & $-7.14^{\star \star *}$ & 0.000 \\
\hline \multirow[t]{2}{*}{$Y_{c o c}$} & $\mathrm{ADF}$ & $-3.14^{\star}$ & 0.097 & $-7.25^{\star * *}$ & 0.000 \\
\hline & PP & $-3.32^{\star}$ & 0.064 & $-7.28^{\star \star *}$ & 0.000 \\
\hline
\end{tabular}

Note: See Table 7A.2 for detailed descriptions of variables. ADF $=$ augmented Dickey-Fuller (Dickey and Fuller 1979). PP = Phillips-Perron (Phillips and Perron 1988). ${ }^{*},{ }^{* *}$, and ${ }^{* * *}$ mean the test is statistically significant at the 10,5 , and 1 percent level, respectively.

Source: Authors' model results.

level measures but not the first differences. The exceptions are in the cocoa subsector where the levels of expenditure and output are weakly stationary. Therefore, the first-difference measures of the variables were used in the estimation to avoid spurious regressions, which are possible when using the level measures of the variables.

Overall model results: The overall model results are strong. The F-statistics for the individual equations and the system are statistically significant at the 1 percent level. Also, the R-squared for the individual equations is within the range of 0.4 and 0.7 , with those for the systems being generally greater, considering the two different measures of the $\mathrm{R}$-squared that is used. Also, the test for the presence of autocorrelation is rejected for the individual equations as well as for the systems. With respect to efficiency in the use of the system of equations, the results are mixed. In the estimation with respect to total agricultural output, efficiency is gained from allowing cross-over effect of agSTK, that is, by allowing the agSTK in one subsector to affect agEXP in the other subsector. This is indicated by rejection of the Breusch-Pagan LM diagonal covariance matrix test, which the null hypothesis is that there is no contemporaneous correlation across the equations (Judge et al. 1985). In the estimation with respect to subsector-disaggregated agricultural output however, there is no efficiency gain when from allowing cross-over effect of agSTK.

Determinants of subsector expenditures: The statistical significant factors and their signs are the same whether estimated jointly with total agricultural output (Table 7B.2a) or with subsector-disaggregated output (Table 7B.3a). Subsector agricultural capital stock, agSTK , has a negative effect on its respective subsector agricultural expenditure, agEXP ${ }_{s}$. The crossover effect is positive, but only statistically significant for agSTK $\mathrm{goc}_{\mathrm{cos}}$ on $\mathrm{gXX}_{\text {non. }}$ With respect to the other variables, most of their effects are consistent with the literature, although many of them have a statistical significant effect $\operatorname{agEXP}_{\text {non }}$ only. Those with a positive effect are GDPPCAP, TOTEXP, ODAGDP, and MONPOL; whereas FOREX, OPENECON, MINFIN, and RAINCOV have a negative effect. The share of cocoa price received by farmers (SHCOCPR) has a negative effect on both subsector expenditures, which is intuitive, by reducing the amount available to Cocobod to spend and reducing the 
taxes or revenue to the government. Total rainfall (RAINTOT) has a negative effect on agEXP $\mathrm{Coc}_{\mathrm{c}}$ only. The low number of variables having a statistical significant effect on agEXP $_{\text {coc }}$ seems surprising, although it may indicate a different expenditure determination process in the cocoa subsector. More on this later.

Agricultural growth effects of agricultural public expenditure: With respect to total agricultural output (Table 7B.2b), both agEXP ${ }_{\text {non }}$ and $\operatorname{agSTK}_{\text {non }}$ have direct positive and statistical significant effect. This is without the $\operatorname{agSTK}_{\mathrm{s}}-\mathrm{agEXP}_{\mathrm{s}}$ crossover (about 0.1 elasticity for agEXP $\mathrm{Enn}_{\text {non }}$ and 0.9 for agSTK $\mathrm{non}_{\text {n }}$ ) and with the crossover (0.11-0.13 for $\operatorname{agEXP}_{\text {non }}$ and 1.01-1.21 for agSTK non $)$. However, the total elasticity, that is, accounting for the negative indirect effect via agSTK $\mathrm{non}_{\text {on }}$ agEXP $\mathrm{En}_{\text {non }}$ (Table 7B.2a) is not statistically significant (see bottom rows of Table 7B.2b). The effect of agricultural expenditures and stocks in the cocoa subsector on total output is not statistically significant, considering the direct or total effect. With respect to the effect of subsector-disaggregated expenditures and stocks on subsector-disaggregated output, the results shown in Table 7B.3b are mixed: agSTK $_{\text {non }}$ has direct statistical significant effect on $\mathrm{Y}_{\text {non }}(0.7-1.1)$ and agEXP ${ }_{\text {coc }}$ has direct statistical significant effect on $Y_{c o c}(0.5-0.7)$; the crossover effects are not statistically significant; the total effect in the noncocoa subsector is statistically significant (0.7-1.0); but the total effect in the cocoa subsector is not statistically significant.

Might the low number of variables having a statistical significant effect on agEXP $\mathrm{Poc}_{\text {coe }}$ (see Table 7B.2a and Table 7B.3a) have something to do with these results? In the agSTK $\operatorname{agEXP}_{s}$ crossover specification models, we see that agSTK $\mathrm{coc}_{\text {has }}$ a strong positive effect on $\operatorname{agEXP}_{\text {non }}$, but the opposite is not observed-i.e., effect of agSTK $\mathrm{non}_{\text {on }}$ agEXP $\mathrm{Poc}_{\text {co }}$ is not significant. Also, the negative effect of agSTK $\mathrm{non}_{\text {on }} \operatorname{agEXP}_{\text {non }}$ increases with the crossover. Together, these suggest that the expenditure determination process in the cocoa subsector as modeled here may not be realistic, likely suffering from omitted variables bias that has been transmitted to the other equations. ${ }^{5}$ Further research is needed on this.

Influence of other factors on agricultural growth: With respect to total agricultural output (Table 7B.2b), all the variables that have a statistical significant effect are consistent under the different model specifications-excluding or including $\operatorname{agSTK}_{\mathrm{s}}-\mathrm{agEXP}_{\mathrm{s}}$ crossover and excluding or including lagged value of output. The main statistical significant variables are OPENECON (-), SHCOCPR (+), and MONPOL (-). These suggest that globalization (importing more relative to exports) has had dampening effect on agricultural growth. The same with MONPOL, which is associated with incidents of currency change, GDP rebasing, and drought. Giving a higher share of the cocoa f.o.b. price to farmers (SHCOCPR) has a boosting effect, perhaps by increasing farmers' investment in the agricultural sector. With respect to subsector-disaggregated output (7B.3b), those discussed above are also important in addition to several others, some differentiation by subsector. Those that have a common effect on both subsectors are MONPOL (-) and SHCOCAREA ( - for $Y_{c o c}$ and + for $Y_{\text {non }}$ ). Those that have a statistical significant effect on $Y_{\text {non }}$ only are OPENECON (-) and AGRFERT (+), whereas those that have a statistically significant effect on $Y_{c o c}$ only are SHCOCPR $(+)$, COCFERT $(+)$, and RAINCOV (-). Together with the above, these suggest the negative effect of MONPOL derives from both subsectors, whereas the negative effect of OPENECON derives mostly from the noncocoa subsector and the positive effect of SHCOCPR derives mostly from the cocoa subsector.

\footnotetext{
${ }^{5}$ Related to this, the subsector-disaggregated equations were estimated separately-i.e., the expenditure and output equations were jointly estimated for the noncocoa subsector, and then the expenditure and output equations were jointly estimated for the cocoa subsector. The results, which are not reported here, are consistent with those reported in this chapter.
} 
Table 7B.2a. Determinants of agricultural expenditure on cocoa and noncocoa subsectors in Ghana (with total agricultural output), 1961-2012

\begin{tabular}{|c|c|c|c|c|c|c|c|c|c|c|c|c|c|c|c|c|}
\hline & \multicolumn{8}{|c|}{ Allowing agSTK in one subsector to affect agEXP in own subsector only } & \multicolumn{8}{|c|}{ Allowing agSTK in one subsector to affect agEXP in the other subsector } \\
\hline & \multicolumn{4}{|c|}{ Without lag of output } & \multicolumn{4}{|c|}{ With lag of output } & \multicolumn{4}{|c|}{ Without lag of output } & \multicolumn{4}{|c|}{ With lag of output } \\
\hline & \multicolumn{2}{|c|}{ Noncocoa } & \multicolumn{2}{|c|}{ Cocoa } & \multicolumn{2}{|c|}{ Noncocoa } & \multicolumn{2}{|c|}{ Cocoa } & \multicolumn{2}{|c|}{ Noncocoa } & \multicolumn{2}{|c|}{ Cocoa } & \multicolumn{2}{|c|}{ Noncocoa } & \multicolumn{2}{|c|}{ Cocoa } \\
\hline & coeff & sig & coeff & sig & coeff & sig & coeff & sig & coeff & sig & coeff & sig & coeff & sig & coeff & sig \\
\hline agSTKnon & -4.972 & $* * *$ & & & -4.972 & $* * *$ & & & -7.668 & $* * *$ & 0.943 & & -7.615 & $* * *$ & 1.821 & \\
\hline agSTKcoc & & & -3.614 & $* *$ & & & -3.643 & $* *$ & 5.201 & $* * *$ & -3.639 & $* *$ & 5.260 & $* * *$ & -4.489 & $* * *$ \\
\hline GDPCAP & 1.029 & & -0.731 & & 1.046 & & -0.730 & & 1.686 & $* * *$ & -0.790 & & 1.613 & $* *$ & -1.192 & \\
\hline FOREX & -0.610 & $* * *$ & 0.065 & & -0.610 & $* * *$ & 0.064 & & -0.589 & $* * *$ & 0.102 & & -0.562 & $* * *$ & 0.066 & \\
\hline SHCOCPR & -0.004 & $* * *$ & -0.002 & $* *$ & -0.004 & $* * *$ & -0.002 & $* *$ & -0.005 & $* * *$ & -0.002 & $* *$ & -0.005 & $* * *$ & -0.001 & \\
\hline TOTEXP & 0.017 & $\star$ & -0.003 & & 0.017 & * & -0.003 & & 0.022 & $* *$ & -0.002 & & 0.022 & $* *$ & -0.007 & \\
\hline OPENECON & -0.429 & $* *$ & -0.124 & & -0.428 & $* *$ & -0.122 & & -0.603 & $* * *$ & -0.121 & & -0.598 & $* * *$ & -0.077 & \\
\hline ODAGDP & 0.039 & $* *$ & 0.011 & & 0.040 & $* *$ & 0.011 & & 0.033 & $* *$ & 0.010 & & 0.032 & $* *$ & 0.007 & \\
\hline GOVTYP & -0.091 & & -0.086 & & -0.093 & & -0.088 & & 0.009 & & -0.086 & & 0.013 & & -0.097 & \\
\hline MINFIN & -0.171 & $* *$ & -0.124 & & -0.170 & $* *$ & -0.124 & & -0.121 & * & -0.131 & & -0.116 & & -0.175 & $* *$ \\
\hline MINAG & 0.027 & & & & 0.028 & & & & -0.001 & & & & -0.012 & & & \\
\hline CEOCOB & & & -0.020 & & & & -0.020 & & & & -0.009 & & & & 0.047 & \\
\hline AGPOL & 0.088 & & & & 0.089 & & & & 0.065 & & & & 0.052 & & & \\
\hline COPOL & & & 0.032 & & & & 0.033 & & & & 0.022 & & & & 0.096 & \\
\hline AGPER & 0.013 & & 0.071 & & 0.011 & & 0.067 & & 0.204 & $* *$ & 0.073 & & 0.215 & $* *$ & 0.029 & \\
\hline POPGROW & -0.175 & & 0.287 & & -0.177 & & 0.285 & & -0.026 & & 0.326 & * & -0.017 & & 0.387 & * \\
\hline MONPOL & 0.159 & * & -0.068 & & 0.160 & * & -0.068 & & 0.193 & $* *$ & -0.074 & & 0.189 & $* *$ & -0.047 & \\
\hline RAINTOT & 0.101 & & -0.343 & * & 0.101 & & -0.340 & * & -0.059 & & -0.354 & * & -0.097 & & -0.274 & \\
\hline RAINCOV & -0.699 & $* * *$ & -0.051 & & -0.696 & $* * *$ & -0.053 & & -0.605 & $* * *$ & -0.053 & & -0.592 & $* * *$ & -0.283 & \\
\hline Intercept & 0.069 & & 0.267 & $* *$ & 0.069 & & 0.270 & $* *$ & -0.204 & $* *$ & 0.260 & $\star *$ & -0.203 & $* *$ & 0.280 & $* *$ \\
\hline F-statistic & 3.610 & $* * *$ & 2.590 & $* * *$ & 3.610 & $* * *$ & 2.590 & $* * *$ & 4.870 & $* * *$ & 2.380 & $* * *$ & 4.480 & $* * *$ & 2.350 & $* * *$ \\
\hline R-squared & 0.539 & & 0.441 & & 0.540 & & 0.441 & & 0.621 & & 0.445 & & 0.616 & & 0.446 & \\
\hline Rho & 0.000 & $(0.90)$ & 0.001 & $(0.86)$ & 0.000 & $(0.89)$ & 0.001 & $(0.86)$ & 0.000 & $(0.87)$ & 0.000 & $(0.93)$ & 0.000 & $(0.88)$ & 0.000 & $(0.93)$ \\
\hline System results & Rho $=0$ & $19(0.98$ & $\mathrm{BP}=3.4$ & $(0.32)$ & Rho $=0$ & $11(0.99$ & $3 \mathrm{P}=3.2$ & $(0.36)$ & Rho $=0$. & $15(0.98)$ & $\mathrm{BP}=8.07$ & $(0.04)^{\star *}$ & Rho $=0$. & $07(0.9$ & $\mathrm{BP}=7.6 \mathrm{~S}$ & $(0.05)^{\star *}$ \\
\hline
\end{tabular}

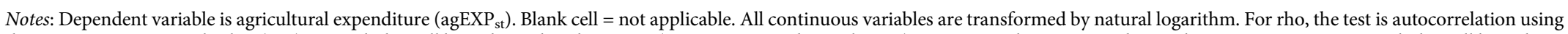

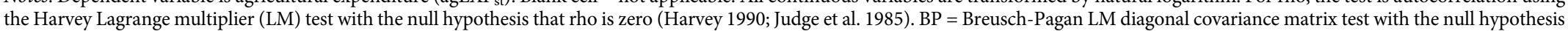

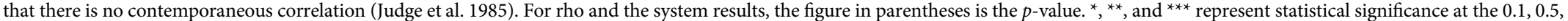
and 0.01 probability level, respectively.

Source: Author's representation based on model results. See Table 7B.1 for detail description of variables. 
Table 7B.2b. Effect of agricultural expenditure on total agricultural output in Ghana, 1961-2012

\begin{tabular}{|c|c|c|c|c|c|c|c|c|}
\hline & \multicolumn{4}{|c|}{$\begin{array}{l}\text { Allowing agSTK in one } \\
\text { subsector to affect agEXP } \\
\text { in own subsector only }\end{array}$} & \multicolumn{4}{|c|}{$\begin{array}{l}\text { Allowing agSTK in one } \\
\text { subsector to affect agEXP } \\
\text { in the other subsector }\end{array}$} \\
\hline & \multicolumn{2}{|c|}{$\begin{array}{l}\text { Without lag of } \\
\text { output }\end{array}$} & \multicolumn{2}{|c|}{$\begin{array}{l}\text { With lag of } \\
\text { output }\end{array}$} & \multicolumn{2}{|c|}{$\begin{array}{l}\text { Without lag of } \\
\text { output }\end{array}$} & \multicolumn{2}{|c|}{$\begin{array}{l}\text { With lag of } \\
\text { output }\end{array}$} \\
\hline & coeff & sig & coeff & sig & coeff & sig & coeff & sig \\
\hline $\operatorname{agEXP}_{\text {non }}$ & 0.103 & $* *$ & 0.101 & $* *$ & 0.112 & $* * *$ & 0.130 & $* * *$ \\
\hline $\operatorname{agSTK}_{\text {non }}$ & 0.860 & * & 0.882 & * & 1.011 & $* *$ & 1.214 & $* *$ \\
\hline $\operatorname{agEXP}_{c o c}$ & 0.058 & & 0.054 & & 0.076 & & 0.002 & \\
\hline $\operatorname{agSTK}_{\mathrm{coc}}$ & -0.182 & & -0.195 & & -0.363 & & -0.729 & \\
\hline TOTEXP & 0.000 & & 0.000 & & 0.001 & & 0.001 & \\
\hline OPENECON & -0.085 & * & -0.083 & * & -0.081 & * & -0.091 & * \\
\hline SHCOCPR & 0.001 & $* *$ & 0.001 & $* *$ & 0.001 & $* *$ & 0.001 & * \\
\hline COCFERT & 0.032 & & 0.032 & & 0.025 & & 0.018 & \\
\hline AGRFERT & 0.035 & & 0.034 & & 0.050 & & 0.073 & * \\
\hline GOLDCOC & -0.057 & & -0.060 & & -0.046 & & -0.026 & \\
\hline GOLDAGR & -0.087 & & -0.084 & & -0.094 & & -0.089 & \\
\hline SHCOCAREA & 0.748 & & 0.825 & & 0.402 & & 0.746 & \\
\hline POPGROW & -0.010 & & -0.010 & & -0.019 & & 0.002 & \\
\hline MONPOL & -0.088 & $* * *$ & -0.090 & $* * *$ & -0.092 & $* * *$ & -0.100 & $* * *$ \\
\hline RAINTOT & -0.061 & & -0.059 & & -0.078 & & -0.079 & \\
\hline RAINCOV & 0.020 & & 0.020 & & 0.011 & & 0.001 & \\
\hline $\begin{array}{l}\text { Lag of output } \\
\left(\mathrm{Y}_{\mathrm{t}-1}\right)\end{array}$ & & & -0.035 & & & & -0.037 & \\
\hline Intercept & 0.038 & * & 0.040 & * & 0.044 & * & 0.062 & $* * *$ \\
\hline F-statistic & 4.360 & $* * *$ & 4.140 & $* * *$ & 4.530 & $* * *$ & 4.600 & $* * *$ \\
\hline R-squared & 0.571 & & 0.574 & & 0.555 & & 0.494 & \\
\hline $\begin{array}{l}\text { Total effect } \\
\left(\text { agEXP }_{\text {non }}+\right. \\
\left.\text { agSTK }_{\text {non }}\right)\end{array}$ & 0.452 & & 0.479 & & 0.336 & & 0.356 & \\
\hline $\begin{array}{l}\text { Total effect } \\
\left(\text { agEXP }_{\text {coc }}+\right. \\
\left.\text { agSTK }_{\text {coc }}\right)\end{array}$ & -0.334 & & -0.337 & & 0.018 & & -0.051 & \\
\hline Rho & 0.003 & $(0.70)$ & 0.001 & $(0.80)$ & 0.002 & $(0.73)$ & 0.001 & $(0.84)$ \\
\hline System results & \multicolumn{2}{|c|}{$\begin{array}{l}\text { Rho }=0.19 \\
(0.98) ; \mathrm{BP}= \\
3.47(0.32)\end{array}$} & \multicolumn{2}{|c|}{$\begin{array}{l}\text { Rho }=0.11 \\
(0.99) ; \mathrm{BP}= \\
3.21(0.36)\end{array}$} & \multicolumn{2}{|c|}{$\begin{array}{l}\text { Rho }=0.15 \\
(0.98) ; \mathrm{BP}= \\
8.07(0.04)^{\star *}\end{array}$} & \multicolumn{2}{|c|}{$\begin{array}{l}\text { Rho }=0.07 \\
(0.99) ; \mathrm{BP}= \\
7.69(0.05)^{\star *}\end{array}$} \\
\hline
\end{tabular}

Notes: Dependent variable is agricultural output $\left(\mathrm{Y}_{\mathrm{t}}\right)$. Blank cell $=$ not applicable. All continuous variables are transformed by natural logarithm. Total effect is obtained by summing elasticities with respect to agEXP st $_{\text {and agSTK }}$. and agSTK st $_{\text {indirectly via agEXP }}$ st. For rho, the test is autocorrelation using the Harvey Lagrange multiplier (LM) test with the null hypothesis that rho is zero (Harvey 1990; Judge et al. 1985). BP = Breusch-Pagan LM diagonal covariance matrix test with the null hypothesis that there is no contemporaneous correlation (Judge et al. 1985). For rho and the system results, the figure in parentheses is the $p$-value. ${ }^{*}, * *$, and ${ }^{* *}$ represent statistical significance at the $0.1,0.5$, and 0.01 probability level, respectively.

Source: Author's representation based on model results. See Table 7B.1 for detail description of variables. 
Table 7B.3a. Determinants of agricultural expenditure on cocoa and noncocoa subsectors in Ghana (with subsector agricultural output), 1961-2012

\begin{tabular}{|c|c|c|c|c|c|c|c|c|c|c|c|c|c|c|c|c|}
\hline & \multicolumn{8}{|c|}{ Allowing agSTK in one subsector to affect agEXP in own subsector only } & \multicolumn{8}{|c|}{ Allowing agSTK in one subsector to affect agEXP in the other subsector } \\
\hline & \multicolumn{4}{|c|}{ Without lag of output } & \multicolumn{4}{|c|}{ With lag of output } & \multicolumn{4}{|c|}{ Without lag of output } & \multicolumn{4}{|c|}{ With lag of output } \\
\hline & \multicolumn{2}{|c|}{ Noncocoa } & \multicolumn{2}{|c|}{ Cocoa } & \multicolumn{2}{|c|}{ Noncocoa } & \multicolumn{2}{|c|}{ Cocoa } & \multicolumn{2}{|c|}{ Noncocoa } & \multicolumn{2}{|c|}{ Cocoa } & \multicolumn{2}{|c|}{ Noncocoa } & \multicolumn{2}{|c|}{ Cocoa } \\
\hline & coeff & sig & coeff & sig & coeff & sig & coeff & sig & coeff & sig & coeff & sig & coeff & sig & coeff & sig \\
\hline $\operatorname{agSTK}_{\text {non }}$ & -4.782 & $* * *$ & & & -4.842 & $* * *$ & & & -7.022 & $* * *$ & 1.282 & & -7.201 & $* * *$ & 1.295 & \\
\hline agSTK $_{\mathrm{coc}}$ & & & -3.641 & $* *$ & & & -3.454 & ** & 4.419 & $* * *$ & -4.052 & $* *$ & 4.601 & $* * *$ & -3.879 & ** \\
\hline GDPCAP & 1.125 & * & -0.753 & & 1.165 & * & -0.557 & & 1.739 & $* * *$ & -0.873 & & 1.765 & $* * *$ & -0.703 & \\
\hline FOREX & -0.582 & $* * *$ & 0.077 & & -0.606 & $* * *$ & 0.135 & & -0.580 & $* * *$ & 0.104 & & -0.591 & $* * *$ & 0.138 & \\
\hline SHCOCPR & -0.004 & $* * *$ & -0.003 & $* *$ & -0.004 & $* * *$ & -0.002 & $* *$ & -0.005 & $* * *$ & -0.003 & $* *$ & -0.005 & $* * *$ & -0.002 & $* *$ \\
\hline TOTEXP & 0.011 & & -0.004 & & 0.012 & & -0.004 & & 0.016 & $*$ & -0.003 & & 0.017 & $* *$ & -0.003 & \\
\hline OPENECON & -0.359 & $* *$ & -0.110 & & -0.374 & ** & -0.137 & & -0.528 & $* * *$ & -0.097 & & -0.546 & $* * *$ & -0.118 & \\
\hline ODAGDP & 0.048 & $* * *$ & 0.012 & & 0.048 & $* * *$ & 0.012 & & 0.042 & $* * *$ & 0.012 & & 0.041 & $* *$ & 0.012 & \\
\hline GOVTYP & -0.154 & $* *$ & -0.098 & & -0.147 & $* *$ & -0.098 & & -0.063 & & -0.110 & & -0.050 & & -0.106 & \\
\hline MINFIN & -0.168 & $* *$ & -0.110 & & -0.172 & $* *$ & -0.120 & & -0.133 & * & -0.121 & & -0.133 & * & -0.125 & \\
\hline MINAG & 0.095 & & & & 0.085 & & & & 0.056 & & & & 0.045 & & & \\
\hline CEOCOB & & & -0.017 & & & & -0.009 & & & & -0.002 & & & & 0.000 & \\
\hline AGPOL & 0.167 & * & & & 0.159 & & & & 0.145 & & & & 0.133 & & & \\
\hline COPOL & & & 0.044 & & & & 0.059 & & & & 0.034 & & & & 0.042 & \\
\hline AGPER & -0.081 & & 0.037 & & -0.066 & & 0.046 & & 0.106 & & 0.021 & & 0.130 & & 0.036 & \\
\hline POPGROW & -0.252 & & 0.277 & & -0.240 & & 0.292 & & -0.105 & & 0.312 & & -0.091 & & 0.327 & * \\
\hline MONPOL & 0.198 & $* *$ & -0.061 & & 0.194 & $* *$ & -0.050 & & 0.225 & $* * *$ & -0.068 & & 0.220 & $* * *$ & -0.061 & \\
\hline RAINTOT & 0.187 & & -0.320 & * & 0.173 & & -0.293 & & 0.048 & & -0.318 & * & 0.031 & & -0.306 & \\
\hline RAINCOV & -0.767 & $* * *$ & -0.061 & & -0.763 & $* * *$ & -0.066 & & -0.691 & $* * *$ & -0.078 & & 0.678 & $* * *$ & -0.075 & \\
\hline Intercept & 0.060 & & 0.273 & $* * *$ & 0.061 & & 0.261 & $* *$ & -0.171 & $*$ & 0.287 & $* *$ & -0.179 & $* *$ & 0.274 & $* *$ \\
\hline F-statistic & 3.920 & $* * *$ & 2.620 & $* * *$ & 3.910 & $* * *$ & 2.590 & $* * *$ & 4.990 & $* * *$ & 2.450 & $* * *$ & 5.020 & $* * *$ & 2.420 & $* * *$ \\
\hline R-squared & 0.530 & & 0.438 & & 0.536 & & 0.433 & & 0.625 & & 0.443 & & 0.628 & & 0.442 & \\
\hline Rho & 0.002 & $(0.75)$ & 0.000 & $(0.94)$ & 0.001 & $(0.79)$ & 0.000 & $(0.97)$ & 0.000 & $(1.00)$ & 0.000 & $(0.92)$ & 0.000 & $(1.00)$ & 0.000 & $(0.94)$ \\
\hline System results & Rho $=1$ & $2(0.89)$ & $=13.8 \mathrm{C}$ & $(0.03)^{* *}$ & Rho $=0$. & $19(0.99)$ & $=12.5$ & $(0.05)^{* *}$ & Rho $=1$ & $10(0.89$ & $\mathrm{P}=10.3$ & $7(0.11)$ & Rho $=0$ & $21(0.5$ & $3 \mathrm{P}=8.6$ & $9(0.19)$ \\
\hline
\end{tabular}

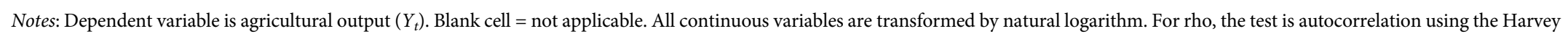

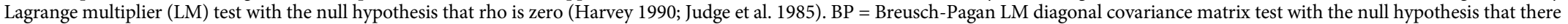

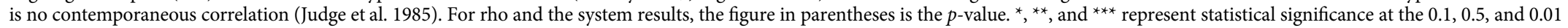
probability level, respectively.

Source: Author's representation based on model results. See Table 5B.1 for detail description of variables. 
Table 7B.3b. Effect of subsector agricultural expenditure on subsector agricultural output in Ghana, 1961-2012

\begin{tabular}{|c|c|c|c|c|c|c|c|c|c|c|c|c|c|c|c|c|}
\hline & \multicolumn{8}{|c|}{ Allowing agSTK and agEXP own subsector output only } & \multicolumn{8}{|c|}{ Allowing agSTK in one subsector to affect output in the other subsector } \\
\hline & \multicolumn{4}{|c|}{ Without lag of output } & \multicolumn{4}{|c|}{ With lag of output } & \multicolumn{4}{|c|}{ Without lag of output } & \multicolumn{4}{|c|}{ With lag of output } \\
\hline & \multicolumn{2}{|c|}{ Noncocoa } & \multicolumn{2}{|c|}{ Cocoa } & \multicolumn{2}{|c|}{ Noncocoa } & \multicolumn{2}{|c|}{ Cocoa } & \multicolumn{2}{|c|}{ Noncocoa } & \multicolumn{2}{|c|}{ Cocoa } & \multicolumn{2}{|c|}{ Noncocoa } & \multicolumn{2}{|c|}{ Cocoa } \\
\hline & coeff & sig & coeff & sig & coeff & sig & coeff & sig & coeff & sig & coeff & sig & coeff & sig & coeff & sig \\
\hline $\operatorname{agEXP}_{\text {non }}$ & -0.010 & & & & 0.016 & & & & 0.013 & & & & 0.038 & & & \\
\hline agSTK $_{\text {non }}$ & 0.748 & * & & & 0.781 & * & & & 1.086 & $* *$ & -2.712 & & 1.103 & $* *$ & -2.597 & \\
\hline $\operatorname{agEXP}_{\mathrm{coc}}$ & & & 0.487 & & & & 0.697 & $* *$ & & & 0.498 & * & & & 0.631 & $* *$ \\
\hline $\operatorname{agSTK}_{\mathrm{coc}}$ & & & -0.837 & & & & -0.211 & & -0.058 & & 0.272 & & -0.149 & & 0.639 & \\
\hline TOTEXP & 0.001 & & 0.014 & & 0.001 & & 0.012 & & 0.001 & & 0.011 & & 0.001 & & 0.009 & \\
\hline OPENECON & -0.182 & $* * *$ & 0.212 & & -0.185 & $* * *$ & 0.287 & & -0.177 & $* * *$ & 0.225 & & -0.181 & $* * *$ & 0.276 & \\
\hline SHCOCPR & & & 0.002 & * & & & 0.003 & $* *$ & & & 0.002 & * & & & 0.003 & ** \\
\hline COCFERT & & & 0.156 & * & & & 0.153 & * & & & 0.183 & $* *$ & & & 0.178 & * \\
\hline AGRFERT & 0.081 & $* * *$ & & & 0.083 & $* * *$ & & & 0.081 & $* * *$ & & & 0.084 & $* * *$ & & \\
\hline GOLDCOC & & & 0.107 & & & & 0.044 & & & & 0.181 & & & & 0.138 & \\
\hline GOLDAGR & -0.193 & & & & -0.189 & & & & -0.175 & & & & -0.168 & & & \\
\hline SHCOCAREA & 2.684 & $* *$ & -10.525 & $* *$ & 2.577 & $* *$ & -12.528 & $* *$ & 2.646 & $* *$ & -11.121 & $* *$ & 2.505 & $* *$ & -12.543 & $* *$ \\
\hline POPGROW & -0.004 & & -0.300 & & 0.005 & & -0.342 & & 0.013 & & -0.369 & & 0.019 & & -0.390 & \\
\hline MONPOL & -0.066 & $* * *$ & -0.250 & $* *$ & -0.062 & $* *$ & -0.229 & $* *$ & -0.067 & $* * *$ & -0.228 & $* *$ & -0.064 & $* *$ & -0.213 & * \\
\hline RAINTOT & -0.088 & & 0.084 & & -0.086 & & 0.042 & & -0.080 & & 0.065 & & -0.083 & & 0.036 & \\
\hline RAINCOV & -0.055 & & 1.056 & $* * *$ & -0.063 & & 1.117 & $* * *$ & -0.053 & & 1.030 & $* * *$ & -0.064 & & 1.085 & $* * *$ \\
\hline Lag of output $\left(\mathrm{Y}_{\text {non }}\right)$ & & & & & 0.072 & & & & & & & & 0.082 & & & \\
\hline Lag of output $\left(\mathrm{Y}_{\mathrm{coc}}\right)$ & & & & & & & 0.134 & & & & & & & & 0.107 & \\
\hline Intercept & 0.036 & $* * *$ & 0.070 & & 0.033 & $* * *$ & 0.032 & & 0.034 & * & 0.047 & & 0.035 & * & 0.022 & \\
\hline F-statistic & 4.460 & $* * *$ & 3.130 & $* * *$ & 4.250 & $* * *$ & 3.130 & $* * *$ & 4.190 & $* * *$ & 3.020 & $* * *$ & 4.050 & $* * *$ & 2.950 & $* * *$ \\
\hline R-squared & 0.476 & & 0.440 & & 0.499 & & 0.441 & & 0.493 & & 0.456 & & 0.506 & & 0.465 & \\
\hline Total effect $\left(\operatorname{agEXP}_{\text {non }}+\operatorname{agSTK}_{\text {non }}\right)$ & 0.787 & * & & & 0.718 & & & & 1.007 & $* *$ & -2.074 & & 0.865 & * & -1.781 & \\
\hline 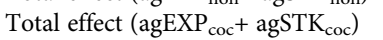 & & & -2.123 & & & & -1.922 & & -1.248 & & -0.001 & & -1.177 & & 0.028 & \\
\hline Rho & 0.010 & $(0.48)$ & 0.010 & $(0.47)$ & 0.002 & $(0.77)$ & 0.001 & $(0.87)$ & 0.008 & $(0.52)$ & 0.014 & $(0.41)$ & 0.006 & $(0.86)$ & 0.003 & $(0.68)$ \\
\hline System results & Rho $=1$ & $12(0.89)$ & $3 P=13.86$ & $(0.03)^{\star *}$ & Rho $=0$. & $9(0.99)$ & $3 \mathrm{P}=12.57$ & $(0.05)^{* *}$ & Rho $=1$. & $(0.89)$ & $=10.37($ & 11) & Rho $=$ & $1(0.99)$ & $=8.69(0$. & \\
\hline
\end{tabular}

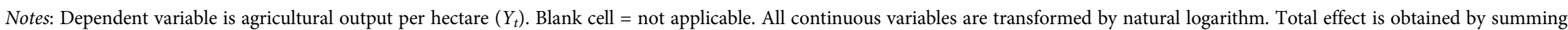

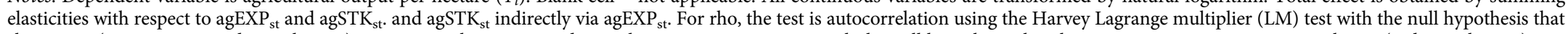

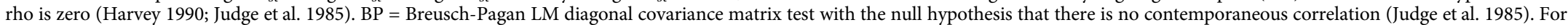
rho and the system results, the figure in parentheses is the $p$-value. ${ }^{*},{ }^{* *}$, and ${ }^{* * *}$ represent statistical significance at the $0.1,0.5$, and 0.01 probability level, respectively.

Source: Author's representation based on model results. See Table 5B.1 for detailed description of variables. 


\section{References}

Andah, E. K. 1980. “Action Programme for Agricultural production, 1980-81.” Accra: Ministry of Food and Agriculture.

Aschauer, D. A. 1989. “Is Public Expenditure Productive?” Journal of Monetary Economics 23: 177-200.

Austin, D., and R. Luckham. 1975. Politicians and Soldiers in Ghana 1966-1972. London: Cass University Paperbacks.

Barro, R. 1990. "Government Spending in a Simple Model of Endogenous Growth.” Journal of Political Economy 98(5): 103-25.

Benin, Samuel. 2014. "Identifying Agricultural Expenditures within the Public Financial Accounts and Coding System in Ghana: Is the 10 Percent Government Agriculture Expenditure Overestimated?” IFPRI Discussion Paper No. 1365. Washington, DC: International Food Policy Research Institute.

Benin, Samuel. 2015. “Impact of Ghana’s Agricultural Mechanization Services Center Program.” Agricultural Economics 46(1): 103-17.

Benin, Samuel. 2016. "Returns to Agricultural Public Spending in Ghana: Cocoa versus Noncocoa Subsector.” IFPRI Discussion Paper No. 01503. Washington DC: International Food Policy Research Institute.

Benin, S., M. Johnson, E. Abokyi et al. 2013. "Revisiting Agricultural Input and Farm Support Subsidies in Africa: The Case of Ghana's Mechanization, Fertilizer, Block Farms, and Marketing Programs.” IFPRI Discussion Paper No. 1300. Washington, DC: International Food Policy Research Institute.

Benin, S., T. Mogues, G. Cudjoe, and J. Randriamamonjy. 2012. "Public Expenditures and Agricultural Productivity Growth in Ghana," in T. Mogues and S. Benin (eds), Public Expenditures for Agricultural and Rural Development in Africa. London: Routledge; New York: Taylor and Francis Group.

Benin, S., and B. Yu. 2013. "Complying with the Maputo Declaration Target: Trends in Public Agricultural Expenditures and Implications for Pursuit of Optimal Allocation of Public Agricultural Spending. ReSAKSS Annual Trends and Outlook Report 2012." Washington, DC: International Food Policy Research Institute.

Breusch, T. S., and A. R. Pagan. 1980. "The Lagrange Multiplier Test and its Applications to Model Specification in Econometrics." Review of Economic Studies 47: 239-53.

CAGD (Controller and Accountant General's Department). 2011. "Report of the Auditor General on the Public Accounts of the Government of Ghana for the Year Ended 31 December 2010." Accra, Ghana.

CAGD (Controller and Accountant General's Department). 2013. "Report of the Auditor General on the Public Accounts of the Government of Ghana for the Year Ended 31 December 2012." Accra, Ghana. 
CAGD (Controller and Accountant General's Department). 2014. "Report of the Auditor General on the Public Accounts of the Government of Ghana for the Year Ended 31 December 2013.” Accra, Ghana.

Dappah, S. K. 1995. "Empirical Analysis of the Likely Future Evolution of Agriculture in Ghana and How It Will Affect the Prospects for Longer-term Growth of Agriculture, the Food System and the Broader Economy." Paper presented at the workshop on Agricultural Transformation in Africa, Abidjan, Cote d'Ivoire, September 26-29.

Dickey, D. A., and W. A. Fuller. 1979. "Distribution of the Estimators for Autoregressive Time Series with a Unit Root." Journal of the American Statistical Association 74: 427-31.

Fan, S. (ed.). 2008. Public Expenditures, Growth, and Poverty: Lessons from Developing Countries. Baltimore, MD: Johns Hopkins University Press.

Fan, Shenggen, Peter Hazell, and Sukhadeo Thorat. 2000. "Government Spending, Growth and Poverty in India." American Journal of Agricultural Economics 82(4): 1038-51.

FAO (Food and Agriculture Organization of the United Nations). 2016. "FAOSTAT: Commodities by Country.” Available at: http://faostat.fao.org/site/339/ default.aspx.

Garrett, G. 2001. "Globalization and Government Spending around the World." Studies in Comparative International Development 35(4): 3-29.

GCB (The Ghana Cocoa Board). 2013. “44th Annual Report \& Financial Statements for the Year Ended 30th September, 2013.” Accra: Ghana Cocoa Board.

Greene, W. H. 1993. Econometric Analysis. New York: Macmillan.

HarvestChoice. 2015. "Long-Term Climate Trends for Sub-Saharan Africa." Database. Available at: http://harvestchoice.org/tools/long-term-climate-trendsand-variations-sub-saharan-africa.

Harvey, A. C. 1990. The Econometric Analysis of Time Series, 2nd ed. Cambridge, MA: MIT Press.

Hsiao, C. 1986. Analysis of Panel Data. Cambridge: Cambridge University Press.

IFPRI (International Food Policy Research Institute). 2015. "Public Expenditure Database: Statistics on Public Expenditure for Economic Development (SPEED)." Available at: http://www.ifpri.org/book-39/ourwork/programs/priorities-publicinvestment/speed-database.

IMF. 1998. Ghana: Statistical Annex. IMF Country Report No. 98/2. Washington, DC: IMF.

IMF. 2000. Ghana: Statistical Annex. IMF Staff Country Report No. 1. Washington, DC: IMF.

IMF. 2005. Ghana: Statistical Appendix. IMF Country Report No. 05/286. Washington, DC: IMF. 
Judge, G., W. E. Griffiths, R. C. Hill et al. 1985. The Theory and Practice of Econometrics, 2nd ed. New York: John Wiley \& Sons.

Kohli, U. 1982. "A Gross National Function Product and the Derived Demand for Imports and Supply of Exports." Canadian Journal of Economics 18: 369-86.

Kolavalli, S., M. Vigneri, H. Maamah, and J. Poku. 2012. “The Partially Liberalized Cocoa Sector in Ghana: Producer Price Determination, Quality Control, and Service Provision.” IFPRI Discussion Paper No. 1213. Washington, DC: International Food Policy Research Institute.

Knoema. 2016. “Average Depreciation Rate of the Capital Stock.” Available at: https://knoema.com/PWT2015/penn-world-table-9-0?tsId=1015390.

MoFA. 1999. Agricultural Sector Expenditure Review, 1995-1997. Accra: Ministry of Food and Agriculture.

MoFA. 2013. “Basic Agricultural Public Expenditure Diagnostic Review.” Report under Strengthening National Comprehensive Agricultural Public Expenditure in Sub-Saharan Africa. Washington, DC: World Bank.

Mogues, T., and S. Benin. 2012. "Do External Grants to District Governments Leverage Own-revenue Generation? A Look at Local Public Finance Dynamics in Ghana." World Development 40(5): 1054-67.

Peacock, A. T., and J. Wiseman. 1961. "The Growth of Public Expenditure in the United Kingdom.” NBER General Series 72. Princeton, NJ: Princeton University Press.

Phillips, P. C. B., and P. Perron. 1988. “Testing for a Unit Root in Time Series Regression.” Biometrika 75: 335-46.

Quartey-Papafio, H. K. 1977. "Report of the Operation Feed Yourself and Operation Feed Your Industries Review Committee.” Accra: Council for Scientific and Industrial Research.

Rodrik, D. 1998. "Why Do More Open Economies Have Bigger Governments?" Journal of Political Economy 106(5): 997-1032.

Sadoulet, E., and A. de Janvry. 1995. Quantitative Development Policy Analysis. Baltimore, MD: Johns Hopkins University Press.

Schultz, T. W. 1982. Investing in People: The Economics of Population Quality. Berkeley, CA: University of California Press.

Stryker, J. D. 1990. Trade, Exchange Rate, and Agricultural Pricing Policies in Ghana. World Bank Comparative Studies 8399. Washington, DC: World Bank.

Thirtle, C., J. Piesse, and L. Lin. 2003. “The Impact of Research-Led Agricultural Productivity Growth on Poverty Reduction in Africa, Asia and Latin America.” World Development 31(12): 1959-75.

Wagner, A. 1883. Finanzwissenschaft, 3rd ed. Leipzig: C. F. Winter. Partially reprinted in R. A. Musgrave and A. T. Peacock (eds), Classics in the Theory of Public Finance. London: Macmillan. 
Wiemers, A. 2015. “'Time of Agric': Rethinking the 'Failure' of Agricultural Programs in 1970s Ghana.” World Development 66: 104-17.

World Bank. 2015. World Development Indicators. Washington, DC.

World Bank. 2016a. World Development Indicators. Washington, DC.

World Bank. 2016b. “Commodity Markets: Annual Prices.” Available at: http:// www.worldbank.org/en/research/commodity-markets.

Zellner, A., and H. Theil. 1962. "Three Stage Least Squares: Simultaneous Estimate of Simultaneous Equations.” Econometrica 29: 54-78. 


\title{
8 \\ Developing Agricultural Value Chains
}

\author{
Shashidhara Kolavalli
}

\subsection{Introduction}

Although Ghana's agricultural sector output grew at an impressive 4.5 percent per annum between 1994 and 2013, most of this growth was from cocoa and roots and tubers, which together account for nearly 75 percent of the total value of agricultural output (see Chapter 4). As a result, while the country remains largely self sufficient in basic staples, and continues to expand its traditional export crop, cocoa, the composition of agricultural output has not changed adequately to match the growth in the domestic demand for higherincome elastic foods like rice and tomatoes, nor has agro-processing expanded to meet a growing urban demand for processed and pre-cooked foods. One consequence has been rapid growth in the importation of rice, poultry meat, and processed tomato paste, while nontraditional agricultural exports like pineapples have languished. This begs the question: Is it sufficient for government policy to focus largely on fundamentals, such as creating an enabling, but commodity neutral, policy environment, and relying on the private sector to take it from there (see Chapters 3 and 4)? This approach seems to have worked reasonably well for many traditional food commodities produced for the domestic market (e.g., many local food staples and vegetables), but has been much less successful in developing value chains for commodities that compete internationally, either as exports or import substitutes, in raw or processed form.

In many developing countries, governments have played leading roles in developing value chains for priority commodities, particularly nontraditional commodities (Chandra 2006). This can be a very successful approach, as illustrated by the development of coffee exports from Vietnam, and tropical fruit juices from Thailand (Thoburn 2009). It was also a very successful strategy during Asia's green revolution, where most states assumed many of the functions along value chains for wheat and rice. Ghana's own 
experience with cocoa is another example of where the state has actively intervened along an entire value chain, from direct support of technology, farm inputs, and pest management to control of marketing and exports, and this has been very successful since the policy reforms of the 1980s. When successful, these value chain interventions have served as important growth motors helping to drive broader patterns of agricultural development and structural transformation.

However, the approach has not always worked, especially in Africa, including some of Ghana's earlier attempts with state agro-industries in the immediate post-Independence period, and its "Operation Feed Yourself" (OFY) and "Operation Feed Your Factories" programs of the 1970s (Rothchild 2015). ${ }^{1}$ As discussed in Chapter 3 , part of the problem has been a weak public sector capacity for developing and implementing effective value chain interventions, a weakness that has been amplified by the government's often antagonistic and weak relationships with the private sector. However, this may be changing, and the government has recently committed to the policy framework of the "New Alliance for Food Security and Nutrition", an initiative of the G7 and African Union. In return for committing to policies that would enable the private sector to participate more fully in input markets, reduce transactions costs, and engage in a more transparent development of evidence-based policies that would encourage private investments, nearly fifteen domestic and global companies have signed letters of intent to invest in the agricultural sector.

The question now is whether the Ghanaian government should again try to promote the development of value chains for specific commodities, and if so in what ways? Possible interventions might range from state interventions which complement the private sector by fixing specific weak points along value chains, to more comprehensive interventions where the state either assumes many of the functions along the value chain, or seeks coordinated solutions in partnership with the private sector.

This chapter examines and compares four important but different types of value chains in Ghana: two export crops-cocoa and pineapples, and two import-substitution crops-rice and tomatoes. Apart from cocoa, these crops have under-exploited opportunities, and we examine the opportunities and constraints along their value chains, and the roles that the public sector has or

\footnotetext{
${ }^{1}$ Weimers (2015) has argued that some of the earlier commodity and subsidy programs were helpful for small farmers, but there is little evidence to show they had sufficient impacts on national supplies of targeted crops or the agricultural growth rate to justify their high costs.
} 
might need to play. This leads to some more general conclusions about the best ways to develop these and related agricultural value chains in Ghana.

\subsection{The Selected Value Chains}

The selected value chains demonstrate mixed experiences in developing domestic and export value chains for commodities exposed to international competition. Cocoa is a notable success, the production and export of which has increased dramatically since the early 2000s, and Ghana had regained its status as a major global producer by 2010 . On the other hand, after making some inroads into expanding nontraditional exports in the late 1990s, the export of pineapples, the principal nontraditional export crop, has nearly halved. Nor have domestic value chains developed adequately to take advantage of import-substitution opportunities. Concerned about growing food imports, the president noted in 2014 that Ghana was spending nearly a billion dollars annually to import food that it could produce. The big items on the list were rice, poultry meat, and tomato products. Rice consumption has raced ahead of domestic production, necessitating imports of nearly half a million tons of rice annually, equivalent to about half of domestic rice consumption. Processing of tomato, which has been an ambition since Independence, has yet to turn into reality; Ghana is now one of the largest importers of processed tomato products in West Africa. Ghana does not even produce enough fresh tomatoes to meet its domestic demand. Further details about each of the four value chains are considered below.

Cocoa, rice, and tomatoes are all labor-intensive crops that are hard to mechanize and hence are grown predominantly by smallholders, who, with their more abundant family labor per hectare, have a competitive edge over larger holdings. Smallholders also tend to obtain higher yields. With cocoa, for example, smallholders use higher levels of fertilizers and obtain yields that are nearly double those obtained on larger holdings. Smallholders also dominate the production of pineapples for the local market, but play a smaller role in producing for the export market. This is because they are less able to adopt the more capital- and knowledge-intensive technologies that are needed to produce the varieties required as export materials, or to meet the high quality standards for fresh fruits. The few smallholders who do participate in the export market either belong to a cooperative or are vertically integrated with pineapple exporters, such as through "core-satellite" systems (Suzuki, Jarvis, and Sexton 2011). 


\subsubsection{Cocoa}

Cocoa was developed by indigenous capitalist farmers who were already producing export crops like oil palm and saw an opportunity to sell cocoa to European trading houses (Hill 1963). By the time Ghana became independent, it was the largest cocoa producer in the world, with an established marketing board that had built up huge financial reserves. These reserves, plus revenues from a continuing cocoa tax, became available to the first administration to launch an ambitious but unsuccessful industrialization strategy. During the economic crisis leading up to the policy reforms of the 1980s, the government had become highly dependent on cocoa taxes for most of its revenue, and producers were so squeezed by a high cocoa tax, an over-valued currency, and rapid inflation, that cocoa production for many farmers was barely profitable. By the early 1980s, production had fallen below 200,000 tons, less than one half of the peak production of 565,000 tons achieved in the 1960s.

The policy reforms of the 1980s, together with an upward trend in world cocoa prices beginning in the early 2000s, revived the fortunes of the cocoa sector (Kolavalli and Vigneri 2011). Production soared to a million tons in 2010 , though it has since stabilized at around 850,000 tons. At the heart of the policy reform was the commitment by the government to increase the producers' share of export prices. Unlike some neighboring countries, the government decided not to fully liberalize the cocoa value chain, and instead reorganized the marketing board to limit the scope of its activities and reduce its staff strength drastically. It also established the Producer Price Review Committee comprising of stakeholder representatives to recommend producer prices and prices for various services in the sector. It also gradually reduced export taxes from nearly a third of export prices to less than 3 percent by 2010 . The marketing board continued to control the quality of cocoa exports, a practice that was discontinued in the liberalized sectors of some neighboring countries, and this has enabled Ghana to maintain its reputation for cocoa of high quality, which earns a price premium of around 5 percent in the world market (Kolavalli et al. 2012).

\subsubsection{Marketing}

Since colonial times, all trade in cocoa for both the domestic and export markets has been controlled by a marketing board, originally the Cocoa Marketing Board (CMB) but later named the Cocobod. Cocobod pays producers a guaranteed pan-seasonal, pan-national price that is announced at the 
beginning of each season. Growers sell to private buying companies, who are selected and licensed by Cocobod. The trading companies receive a margin that is determined by a stakeholder committee, which also recommends the producer price to be paid by Cocobod.

Cocobod is able to offer a guaranteed price to growers at the beginning of each season by selling three-quarters of its crop in advance of the season in international markets. Its ability to advance sell comes from its established international reputation for reliable supplies of large quantities of beans of superior and uniform quality. It also helps that there are international futures markets in which importers can hedge their price risks. While it stabilizes prices within a season, Cocobod is not able to do this across years. It tried this to some extent in 2012 when it used some $\$ 100$ million of reserves to offer higher-than-world prices to growers, but this is not a sustainable strategy when world cocoa prices are trending down.

Building a national reputation for quality cocoa has paid off well for Ghana. This has been achieved because of Cocobod's monopoly over exports and its ability to deliver large quantities of uniform quality beans. Quality Control Company (QCC), a subsidiary of Cocobod, which is primarily responsible for maintaining export quality, enforces stringent regulations that maintain the quality of cocoa delivered to Cocobod by its licensed buyers. The cost of maintaining quality averages less than 2 percent of the value of the cocoa, which is worthwhile given the price premium for quality is about 5 percent.

\subsubsection{Production}

Cocoa is cultivated and processed using the same labor-intensive methods and tools that have been used for decades. Labor is the main input, and labor use per hectare has increased over the years with greater use of complementary inputs and the need to harvest and process the additional production. However, because of improved trees and plant protection practices, yields have increased faster than labor use, and labor per unit of cocoa about halved between 2002 and 2010 (Vigneri and Kolavalli 2016).

There has been a major effort to replace traditional cocoa trees with hybrids, but so far only about half the cocoa area has been replanted with hybrids. One reason for the slow progress is that there are problems with the supply of seeds, which is controlled by Cocobod. Another reason is that farmers tend to wait until older trees become unproductive before replanting with hybrids. Yet another reason is that hybrids do not give higher yields for all growers; performance is moderated by the age of the trees, level of shade, fertilizer application, and other cultivation practices. 
Yield response to fertilizer is generally modest, but its use is maintained with the aid of a fertilizer subsidy. The subsidy reached nearly 100 percent in 2015 when fertilizers were supplied free to well-maintained farms. Pesticides are also subsidized for cocoa, and public sprays to control some contagious pests and diseases are undertaken by Cocobod, paid for using cocoa export revenue held back from growers.

\subsubsection{Competitiveness}

Ghanaian cocoa is internationally competitive because its high-quality beans ensure that the beans are sought after and sell at a premium. Major competitors of other countries in the world market have achieved higher yields with lower costs of production, but because their product quality is lower, their returns are no higher. For example, under comparable levels of technology, the gross margins earned per hectare in Ghana are similar to those obtained in Cote d'Ivoire (LMC 2014).

Despite producing high-quality beans, Ghana has not been able to develop any agro-processing activities like manufacturing chocolate. This is primarily because cocoa beans make up less than 20 percent of the cost of raw material going into production of chocolates (Gilbert 2008), and for the other materials used in chocolate production, including dairy products, Ghana simply cannot compete with Western Europe on a cost basis.

\subsubsection{Pineapples}

Indigenous farmers also initiated the production of pineapples in Ghana. The Aburi botanical gardens, established by German missionaries in the late nineteenth century, introduced the smooth Cayenne variety into Ghana and peasant farmers near Accra started growing it. The first serious attempt to export pineapples was made during the mid-1960s, when a processing plant and a state-owned plantation were established as part of the country's post-Independence strategy for industrialization and import substitution (Whitfield 2010). However, production stalled when the public processing plants that were established in the early 1960s failed because of weak raw material supply, in addition to the usual management problems that beset most parastatals.

Pineapple exports were revived in the 1990s by private importers who saw an opportunity to compete in the European markets when airfreight costs to Europe became favorable as a result of the economic reforms (Danielou and 
Ravry 2005). Airfreight from Ghana actually became cheaper than sea freight from neighboring Cote d'Ivoire, the major exporter from West Africa. Ghana dramatically increased its exports of fresh pineapples to Europe between 1994 and 2004, reaching annual exports of 71,000 MT, and increasing its market share in Europe to 10 percent in 2004 (Gatune et al. 2013). This expansion was temporarily checked when airfreight was liberalized in Cote d'Ivoire, but with a public effort that involved organizing producers into a cooperativeSea-Freight Pineapple Exporters Ghana (SPEG) - to bulk up their exports to attract ships to Ghanaian ports to pick up the produce, producers were able to switch back to sea freight and exports continued. However, the quality of exports declined with the longer delays incurred with sea freight.

Exports crashed in 2005 when a new variety of pineapple, MD2, went into production in Costa Rica and was introduced into the European markets. MD2 was developed by the Hawaii Pineapple Research Institute and further modified by Del Monte, and is sweeter, smaller in size, yellowish (golden) in appearance and more consistent in flavor than the traditional Smooth Cayenne exported by Ghana. Retailers also considered it to be superior because of its longer shelf life and easier storability (Fold and Gough 2008). Even though planting material for MD2 became available in Ghana, most growers were not able to acquire the necessary knowledge to grow it in the absence of any forward-looking national investments in research and development to support local production (Whitfield 2010). Some large-scale growers hired consultants from Costa Rica to guide them in their production practices, but these practices do not seem to have been suitable for Ghanaian conditions (Moss et al. 2014).

Ghana's exports fell from 71,000 MT in 2004 to 35,000 MT in 2008, and the export of Smooth Cayenne by sea ceased in 2006 (Gatune et al. 2013). Several fruit-processing firms that had sprung up to take advantage of pineapples rejected for export closed down as they were no longer able to procure sufficient fruits from growers (Gatune, etal. 2013). Processing Smooth Cayenne and Sugar Loaf varieties, which are produced for the local market, has evolved as a strategy to replace some exports (Kleemann, Abdulai, and Buss 2014).

\subsubsection{Marketing}

There are two markets for pineapples: export of fresh pineapples, and a domestic market for fresh and processed pineapples. Most of the production for the domestic market is produced by small-scale growers and sold to itinerant traders who supply fresh fruits to consumer markets throughout 
the country, and to fruit-processing companies. All pineapple exports are undertaken by private companies, many of which also have their own pineapple farms. There were about sixty exporters prior to 2004, but Suzuki (2014) found only fourteen a decade later. Relatively few smallholders produce pineapples for the export market, and those who do are vertically linked to pineapple exporters, such as in "core-satellite" systems (Suzuki, Jarvis, and Sexton 2011). Contract farmers may receive inputs and services from the exporter, but there is no commitment to buy specific quantities from them at the time of planting. Under this system, the smallholders bear most of the marketing risk (Suzuki et al. 2011). This is because exporters have first call on the growers' harvest, but they only purchase the amount of pineapples they can export, and this amount is often not known until the last moment. Smallholders have to sell any surplus production in the domestic market.

\subsubsection{Competitiveness}

Ghana struggles to remain competitive as a pineapple exporter. Its last export surge depended on sea freight, and that depended on producers and exporters producing fruits of good quality with an adequate shelf life, and delivered to the port in good condition and kept under cool conditions. This has always been a challenge in Ghana. Growers do not follow standardized practices capable of producing homogenous, good quality fruits, and there is significant loss and deterioration of quality at the post-harvest stage because of insufficient investments in handling, cooling, and transporting facilities (Whitfield 2010). In addition, facilities at the main seaport are not organized for perishable exports as there are no packing sheds and cold stores.

Ghanaian exporters have never been able to achieve the volumes of exports and standards of management needed to gain leverage in the European market and increase their profit margins. Ghana's pineapple exports were estimated to earn 20 percent gross margin on turnover compared to 49 percent by Costa Rican exporters; Costa Rican producers also have six times more revenue per hectare than Ghana in the conventional market (Gatune et al. 2013). Competitiveness took another shock in 2005 with the introduction of MD2 into the European market, and the failure of most Ghanaian producers to adopt it.

\subsubsection{Rice}

Rice is one of the main staples in Ghana, and because demand is income elastic, the growth in per capita incomes has helped increase per capita 
consumption of rice by about 20 percent since the 1980s (MoFA 2010). Production grew by 7.6 percent per year over 1980-94, and 5.4 percent per year over 1995-2012, and total production grew from about 80,000 MT of paddy rice per year in the late 1980s, to nearly half a million MT in 2010 (see Chapter 4). However, national demand grew faster and rice imports (in milled rice equivalents) increased from 16,358 tons in 1980 , to 166,828 tons in 2000 , to 320,143 tons in 2010 (FAOSTAT). Most of the imported rice is of the long grain, aromatic varieties that consumers generally prefer, and which originate principally from Vietnam and Thailand (Amanor-Boadu 2012; Modzakeh and Angelucci 2016). Locally produced rice is perceived to be of lower quality because of the type of varieties grown and the way it is milled. Rice is typically processed through parboiling techniques, which makes the rice harder, glassier, and firmer when cooked, and this does not appeal to the many urban consumers who now dominate the domestic rice market (Kranjac-Berisavljevic et al. 2003).

\subsubsection{Marketing}

Rice production and trading is fully in the hands of the private sector. There are essentially two markets, one for imported rice and the other for locally produced rice. Smallholder rice producers usually sell their produce to market women who then sell to retailers and consumers. Just a few producers are able to sell their produce directly to final consumers (Amanor-Boadu 2012). The market women, who constitute the majority of wholesalers and retailers, travel to rice-producing areas to assemble production from numerous smallholder producers. These itinerant traders operate an oligopolistic system with strong influences on both consumer and producer prices (Kranjac-Berisavljevic et al. 2003; Amanor-Boadu 2012).

Imported rice is sold to wholesalers and retailers at the local ports in Tema and Takoradi. Although middlemen are often used to link wholesalers to retailers and consumers, consumers are also able to directly purchase from importers (Amanor-Boadu 2012). Various brands of imported rice are marketed through television and other media (Kranjac-Berisavljevic et al. 2003).

Imported rice is priced higher than local rice, by about $15-40$ percent on average, and is mainly associated with better-quality, long-grain perfumed rice of good taste and appearance (Ragasa et al. 2013). Grade 1 rice accounts for about 6 percent of total imports, while grade 2 accounts for 51 percent. Grade 1 rice is not produced in Ghana, and grade 2 rice represents only 4 percent of total production. Most of the domestic production (83 percent) is of grade 5 (USAID 2009). 


\subsubsection{Production}

The bulk of the rice is produced in northern Ghana under lowland or irrigated conditions. While non-irrigated yields are generally 2 tons per ha, yields averaging 5.5 tons per hectare have been achieved in the Kpong Irrigation Project (KIP), where producers benefit from good irrigation, grow consumerpreferred fragrant rice varieties, use certified seeds, and adopt a well-developed set of agronomic practices that are communicated through an effective extension system (Takeshima et al. 2013).

Tractors are used to prepare land for rice cultivation, and machines are also used for harvesting and threshing. Mechanization costs are high compared to competing countries like Thailand (Byerlee et al. 2013). The adoption and replacement of modern varieties in rice production is about average for a West African country; the average age of rice varieties is fifteen years (Ragasa et al. 2013). Although nearly twenty rice varieties have been officially released in Ghana since the 1970s, significant quantities of certified seeds are only produced for three varieties. Use of fertilizer is generally not profitable except under irrigated conditions (Ragasa et al. 2013).

\subsubsection{Competitiveness}

With few exceptions, domestically grown rice cannot compete with imported long grain, aromatic rice, and is protected by levies and taxes that add nearly 40 percent to the price of imports. One exception is the Kpong Irrigation Project which can compete, but this required substantial public investment in irrigation infrastructure. On average, domestic rice sells at prices that are 10-30 percent less than those of imported rice (Ragasa et al. 2013). The costs of producing and marketing rice in Ghana are considerably higher than in Thailand or Senegal (Byerlee et al. 2013). There are opportunities for improving competitiveness by growing more of the types of rice that consumers want, by growing more rice under irrigated conditions, and by improving rice milling and processing to improve conversion rates and quality (Winter-Nelson and Aggrey-Fynn 2008).

\subsubsection{Tomatoes}

Tomatoes and processed products such as tomato paste are an integral part of the Ghanaian diet, and a significant share of household expenditures on vegetables is for tomatoes and tomato products. National consumption has 
grown steadily, while domestic production has stagnated. Beginning at about 100,000 tons in the 1970s, production peaked at about 200,000 tons per year in the late 1990s, but has since gradually declined. Yields were about 13 tons per hectare in the 1990s (Wolff 1999), but averaged only about 7.5 tons/ha in the early 2000s, and 6.7 tons/ha by the end of the decade (Asuming-Brempong and Asuming Boakye 2008). Ghana is now a major importer of tomato paste and anywhere from a third to one half of the fresh tomatoes consumed in the country are imported from Burkina Faso.

Government invested in the processing of tomatoes as part of the postIndependence industrialization strategy, but the industry failed. Apart from public sector inefficiencies, a key reason for failure was an inability to source tomatoes of acceptable quality at remunerative prices from Ghanaian farmers (Robinson and Kolavalli 2010a). Recent surveys suggest that nearly threequarters of producers have production costs that are higher than the prices that processors can viably afford to pay given the price of available imports (Robinson and Kolavalli 2010a). Privatization of some of the state-owned factories also failed, basically because the processors were also unable to source adequate raw material through out-grower arrangements.

\subsubsection{Marketing}

Producers sell their tomatoes to itinerant traders. The movement of tomatoes to major markets is controlled by an association of traders, which acts as a cartel controlling the total volume that enters a market. The cartel effectively widens the price wedge between farmers and consumers in major urban markets, but the prices producers receive are still higher than what they would get selling in local markets (Robinson and Ngleza 2011). Paste and other processed tomato products are imported into the country by private traders; one company imports paste in bulk to repackage for the local market.

\subsubsection{Production}

Most tomatoes are grown seasonally under rain-fed conditions, though some growers irrigate manually by lifting water from shallow wells. Improved varieties are important for achieving higher yields. Two varieties, Power Rano, grown widely in Brong Ahafo under rain-fed conditions, and Pectomech, a variety suitable for processing that is grown widely in the Upper East, outperform other varieties under most conditions. However, farmers in Ghana have historically appeared reluctant to purchase seeds (Orchard and Suglo 1999). Recent surveys suggest that less than one half of the producers purchase all their seeds, and nearly a third use seeds extracted from unsold tomatoes 
(Monney et al. 2009). In the northeastern part of the country, where tomato is cultivated intensively with appropriate varieties and adequate levels of fertilizers, yields are declining because of a "the tomato disease complex", which involves the excessive buildup of soil nematodes and uncontrollable proliferation of fungal, bacterial, viral, and other diseases (Baba et al. 2013).

\subsubsection{Competitiveness}

The tomato sector struggles to compete with imports. Imported fresh tomatoes are typically of higher quality than local products, and they are not as seasonal in their supply, making them more attractive to urban retailers and supermarkets. Traders claim that locally produced tomatoes are watery, too seedy, and have shorter lifespans than imported varieties. Local tomatoes are also too expensive for processing given the low price of imported products. A major reason for this is low yields, which range from 10 to 20 tons/ha, depending on whether production is rain-fed or irrigated, compared to 60 to 80 tons/ha obtained in major processing countries. More than half of producers incur production costs that are higher than $\mathrm{GH} \$ 100$ per ton, which is the price that processors can afford to pay growers and still compete with imported products (Robinson and Kolavalli 2010a).

\subsection{Policies to Support Value Chains}

We turn now to an examination of the kinds of public interventions that might help strengthen the four value chains described above. A value chain comprises a series of value-adding activities that extend from various stages in farm production, through post-harvest handling, processing, and marketing until the product reaches its final destination. Most activities along value chains are best undertaken by the private sector, and the need for public interventions arises when the private sector is unable to adequately perform its roles. There may be many reasons for private sector failings, including market failure problems (e.g., lack of complementary inputs, or first mover problems), discriminatory government policies (e.g., taxes and tariffs, preferential treatment of state-owned enterprises), and insufficient provision of public goods and services (e.g., rural roads, agricultural R\&D, seed regulations, and cold storage facilities). Public interventions to resolve value chain problems range from ones designed to fix specific weaknesses along the value chain for an individual commodity, through public-private partnerships to coordinate activities along the value chain, to the public sector taking control of 
large parts of the value chain (as with cocoa). We consider recent examples of government interventions in Ghana, and identify some important gaps and failures that remain for our selected value chain case studies.

\subsubsection{Targeted Interventions along Value Chains}

We consider interventions along value chains, beginning with inputs needed for farm production and working up the chain to processing and marketing. Some value chain interventions are specific to a commodity, but many are cross cutting and impact on several value chains at a time.

\subsubsection{Seeds}

Apart from cocoa, where Cocobod has proactively supported the development and dissemination of improved cocoa trees, Ghanaian farmers have limited access to improved crop varieties, either because they have not been developed and adapted to local conditions, or because the seeds are unattainable. A recent IFPRI study (Tripp and Ragasa 2015) identified several weaknesses along the seed supply chain and made recommendations for improving the situation. These included: a) additional government support of public research institutions to implement long-term strategies to supply farmers with superior seed varieties, and to maintain pure lines that are accessible to private breeders; b) strengthening the functioning of critical institutions in the seed sector, such as the National Seed Council; c) providing more effective coordination and regulation; d) guaranteeing the availability of foundation seeds; and e) ensuring the integrity and pureness of seeds sold to farmers. It was also noted that access to seeds could be improved immediately by implementing the existing ECOWAS harmonization policy on seeds to benefit from a larger market for seeds and to encourage private investments.

\subsubsection{Chemical Inputs}

Chemical inputs of fertilizers and pesticides are mainly supplied by the private sector in Ghana. However, use levels are still low, and this reflects demand as well as supply-side issues. One reason demand is low is because for many farmers, the returns to fertilizer use are low and risky, especially when crops are grown without irrigation. Higher returns depend on complementary actions like the use of improved seeds, better management of soil fertility, better agronomic practices, and additional irrigation. In the case of cocoa, Cocobod provides extension services for cocoa growers to help establish the 
complementary requirements for achieving higher yields, but there is little systematic support for other commodities. The private sector plays a small role in providing information to farmers growing other crops, such as export firms that enter into contract-farming arrangements (e.g., pineapples), or input suppliers who have incentive to help farmers increase their crop yield responses, and hence their demand for chemicals. However, there is clearly an important knowledge gap that is not currently being met by the public extension system (Moore, Ferguson, and Lolig 2015). There is also need for more widespread soil testing and mapping so that fertilizer dealers and farmers can better match fertilizer blends with regional soil nutrient deficiencies. Other public responsibilities include regulating and guiding proper use of fertilizers and chemicals.

Cocobod has been subsidizing fertilizer use on cocoa since 2003 as part of its $\mathrm{Hi}-\mathrm{Tech}$ Program, but in order to encourage greater use on other crops the government introduced a subsidy in 2007 as part of a broader package of interventions to support agricultural growth (see Chapter 7). The subsidy covered about half the fertilizer price in 2008, but had fallen to 26 percent in 2016. Partly as a result of the subsidy, fertilizer use in Ghana was six to ten times higher in 2010 than it was in the early 2000s. Although the subsidy has encouraged greater fertilizer use, the evidence provided in other chapters of this book suggests that this has contributed little to crop yield growth, but by helping to maintain soil fertility, has enabled farmers to reduce the length of their fallow periods and expand their cropped areas. As discussed in Chapter 7, the fertilizer subsidy has become an important financial burden of the state that may not be sustainable, and there is a need to explore smarter and less costly ways of supporting the uptake of fertilizer use. Ghana does a poor job of targeting fertilizer subsidies compared to some other African countries, and the financial cost could be reduced with little impact on fertilizer use by targeting subsidies to smallholders for the production of food grains who would not otherwise buy fertilizers (Houssou et al. 2018). Moreover, investments in seed supplies, irrigation, and soil mapping and testing, as well as the development of more effective fertilizer products, could help improve crop-yield response to fertilizer, making it more profitable for farmers to use even in the absence of a subsidy (Jayne et al. 2015).

\subsubsection{Mechanization}

Farming systems in Ghana have evolved to the extent that mechanization of some operations has become necessary. Currently, the main demand for mechanization is for land preparation, which is important for regularly 
planted crops like rice, pineapples, and tomatoes. Most land preparation is undertaken using four-wheel tractors, and since few farmers can afford to own these, they are available for hire through parallel supply systems (see Chapter 9 for more details). One is a network of Agricultural Mechanization Services Centers (AMSECs) established by the government beginning in 2007 through the supply of subsidized machinery and credit to selected private sector contractors. The other is a well-developed private sector supply chain of importers, machinery service contractors (mostly farmers), and repair and maintenance shops. The private system has developed without government support, and its lynchpin is a cadre of medium- and large-scale farmers who own used tractors and hire out tractor services to smaller-scale farmers when they are not required for use on the home farm. These contractor farmers interface with private firms who import secondhand tractors, and machinery repair and maintenance shops, which also stock spare parts. This system is working well and has created a competitive market for hiring-in services. On the other hand, the AMSEC model recently promoted by the government seems not to be viable in its present form (see Chapter 9). Many of the AMSECs have unprofitable business models and struggle to pay their debts to the government. One reason is a lack of development of spare parts and maintenance services for the machines imported by the government, which prevents them from making effective use of the machines.

As argued in Chapters 7 and 9, continuation of the AMSEC program in its present form will only add to the financial burden on the government. It would be better if the government were to phase out its AMSEC program, or suitably modify it to make machines available to commercial growers, and focus its efforts on supporting the private sector by funding appropriate mechanization research, technical training of young mechanics, and ensuring that financial institutions can provide the longer-term lending needed by private agents and farmers in the mechanization supply chain (see Chapter 9).

\subsubsection{Credit}

High-value crops like pineapples and tomatoes also have high input costs, and seasonal cash flow can be a problem for many smallholders. At present, the formal financial sector provides little credit to smallholders other than for cocoa, and smallholders borrow mainly from relatives and traders. Banks are reluctant to lend for agricultural activities, which are perceived to be risky, especially at a time when the return on T-bills exceeds 20 percent. When commercial bank loans are available, loan rates range from 30-35 percent in addition to a hefty administrative fee. Finding effective ways of facilitating 
greater farmer access to credit would seem to be one area where additional research is needed.

\subsubsection{Organizing farmers into groups}

All four of our selected value chains are predominantly supplied by smallholders, and this poses challenges in maintaining competitiveness in world markets, either for export or import substitution. To keep costs down and quality up, it helps to organize smallholders into groups for marketing purposes, and for supplying them with modern inputs, extension, credit, and the like. In the case of cocoa, Cocobod serves this role, acting rather like a national cooperative. But farmers are much more fragmented for other commodities.

There have been many project interventions in Ghana to organize smallholders into Farmer Based Organizations (FBOs), but overall the experience has not been encouraging. For example, there was a World Bank attempt in 1999 to set up a pineapple exporting cooperative for smallholders (Farmapine Ghana Ltd) that initially had 178 smallholder members. The cooperative offered technical advice to its members and bulked up their output for marketing (Takane 2004). At its peak in 2000 the cooperative became the second-largest exporter of pineapples from Ghana. However, because of high operating costs, the prices it offered to its members were less than the prices offered by commercial exporters and the company went bankrupt in 2003-4, just as the global market for Smooth Cayenne pineapples collapsed (Halbach 2011).

A recent review of one project in which FBOs were organized found no evidence of the groups obtaining higher prices by acting collectively (IFAD 2015). One survey of FBOs found that a significant share was organized largely for receiving grants and services from projects, rather than filling any marketing or input supply need (Salifu et al. 2012).

Many private companies also try to work with groups of farmers rather than individuals. One input supply company organizes cocoa producers into small groups so as to provide them with inputs on credit, and train them in best practices (Opoko et al. 2009). Masara N'zarki is a program in which maize growers are organized into groups to receive inputs on credit, in some cases with an arrangement to buy the grains from them (Guyver and MacCarthy 2011). While on average participants in these programs become more productive, it is disappointing that a surprisingly large share of them undermine the programs by side-selling produce to avoid debt repayment. Moreover, proliferation of programs that offer inputs for free or on a subsidized basis also discourage participation in commercial contracts (Lambrecht and 
Asare 2016). One donor teamed up with a private processing company, a marketing company, and the Ministry of Agriculture to support farmers in producing tomatoes for the processor on contract. For various reasons, including the inability to supply inputs on time to farmers and delayed rainfall, producers were not able to increase productivity as expected and many of them side-sold to itinerant traders (Robinson and Kolavalli 2010b).

The need to organize smallholders seems less compelling for rice than pineapples or tomatoes, since rice is a nonperishable commodity and there are competitive marketing arrangements with many traders and many different sized mills.

\subsubsection{Agro-processing}

The private sector plays the primary role in agro-processing in Ghana today; past attempts with state-owned processing plants for a range of commodities all failed. However, there are a number of constraints that hold back private investment in agro-processing. One is comparative advantage. In the case of cocoa, Ghana has no comparative advantage in exporting processed chocolate products, but it has developed private processing capacity for the domestic market. Unfortunately, less than 50 percent of the local capacity to grind cocoa beans (nearly half a million tons) is utilized. In the case of tomatoes, yields are too low and per unit growing costs too high to enable processors to compete with imported tomato paste. This has led to many failed and under-utilized tomato processing plants.

Another constraint is the challenge of obtaining adequate supplies of raw materials of the right qualities and on a sustained basis. Small-scale rice mill owners in the Kpong area attempt to obtain adequate paddy supplies to keep their mills running by extending credit to smallholders. In the case of pineapples and tomatoes, growers look to processors primarily to absorb surpluses they cannot sell for export or in the fresh market. Viable processing, however, cannot be built on seasonal gluts, as they may not be suitable for processing (e.g., tomatoes for processing need to have higher level of solids than that contained in tomatoes marketed to consumers), and mills need more sustained supplies over the year to operate their capacity efficiently.

Government policy can have a major impact on the development of agroprocessing. Writing on the globalization of tomato processing, Prichard and Burch (2003) note that in Thailand, the sector emerged because of the congruence of a growing domestic demand for paste, producers who were already used to contract-farming systems, government incentives offered to industries to site themselves in the region, and cheap capital from Taiwan. 
In China, another country in which processing has flourished, financing arrangements with Italian firms enabled them to invest in state-of-the-art equipment by paying for it in processed outputs. The arrangement also gave them access to markets.

The four value chains studied here suggest that private sector investments in processing usually follow the availability of raw materials rather than the other way round, in which case it is better for policymakers to focus on ways of increasing the productivity and quality of crops and to leave processing investments to the private sector. But government does have an important facilitating role to play in supporting private firms, especially during their establishment phase. The experience of some of the agro-processing units in the northern part of Ghana suggests that incentives such as tax breaks do not make much of a difference, whereas a reliable supply of raw material and infrastructure that influence the cost of operations are more important to the viability of operations. ${ }^{2}$ A recent enterprise survey in Ghana found that access to finance was overwhelmingly identified as the main obstacle to growth (World Bank 2014). Land rights are another important constraint, both for obtaining sites for building agro-processing and storage facilities, and for establishing large-scale commercial farms, even when the latter might serve as hubs for smallholder out-grower schemes (Amanor 2013; Throup et al. 2014). For perishable commodities like pineapples and tomatoes, public support for investments in transport systems and cold storage facilities is also important for building up supply chains for agro-processing.

\subsubsection{Quality control}

Quality control is particularly important for exports, with the potential to create a regional/national reputation to either obtain a price premium or serve niche markets. Ghana's experience in exporting high-quality cocoa beans is a good example of the benefits of quality control. The absence of it can be disastrous, as illustrated by a recent EC ban on imports of all fruits and vegetables from Ghana because of contamination with harmful organisms and poor documentation. Investing in improving quality is also worthwhile in the domestic market. Domestically produced rice, for example, has not been able to adequately compete with imported rice because of quality issues, and sells at prices that are 15 percent lower than imported rice, despite an import

\footnotetext{
2 Based on discussions by the author with the heads of Ghana's investment promotion council and the free trade zone authority.
} 
tariff on the latter. Desired attributes of rice quality include fragrance, polish, and freedom from contamination with stones and chaff.

Quality improvement needs to be undertaken at two levels: during on-farm production, and during post-harvest handling, processing, and marketing. Table 8.1 indicates key quality aspects for each of our four commodities, as well as some of the infrastructure requirements needed to achieve them.

Quality improvement on-farm requires the adoption of appropriate production and post-harvest practices by producers. In the case of cocoa, for example, quality depends on plant protection practices, timely harvesting, and proper fermenting and drying of beans. For rice, pineapples, and tomatoes, quality could be significantly improved by growing varieties that better meet consumer and processor requirements. Proper post-harvest handling of perishable crops like tomatoes and pineapples requires farmers have good access to transport and appropriate storage facilities (e.g., cold storage for pineapples) to avoid spoilage. Rice farmers need to thresh and bag their paddy without adding stones and soil. Tomato growers need to adopt watering practices prior to harvesting that lead to acceptable solids content in the fruit, which is important for processing.

Agricultural processors and exporters need access to good transport and storage facilities, which link back to the farm. Some of the needed infrastructure investments will be privately made, but public investments in rural roads, warehouses, cold storage, port facilities, and the like, play crucial complementary roles. Limited access to feeder roads and farm tracks still discourage

Table 8.1. Requirements for improving quality in selected value chains

\begin{tabular}{|c|c|c|c|c|}
\hline & Cocoa & Rice & Tomato & Pineapple \\
\hline $\begin{array}{l}\text { Production } \\
\text { practices }\end{array}$ & $\begin{array}{l}\text { Appropriate } \\
\text { harvesting } \\
\text { practices }\end{array}$ & $\begin{array}{l}\text { Cultivation of a } \\
\text { fragrant variety }\end{array}$ & $\begin{array}{l}\text { Suitable variety } \\
\text { and watering } \\
\text { practices to reduce } \\
\text { water content }\end{array}$ & $\begin{array}{l}\text { Suitable } \\
\text { variety and } \\
\text { production } \\
\text { practices }\end{array}$ \\
\hline $\begin{array}{l}\text { Post-harvest } \\
\text { handling/ } \\
\text { Processing }\end{array}$ & $\begin{array}{l}\text { Proper } \\
\text { fermentation } \\
\text { and drying }\end{array}$ & $\begin{array}{l}\text { Threshing and } \\
\text { bagging without } \\
\text { stones and soil; } \\
\text { proper milling }\end{array}$ & $\begin{array}{l}\text { Sorting and } \\
\text { packing; } \\
\text { appropriate } \\
\text { containers }\end{array}$ & $\begin{array}{l}\text { Sorting and } \\
\text { packing in a } \\
\text { cold chain }\end{array}$ \\
\hline $\begin{array}{l}\text { Infrastructure } \\
\text { required }\end{array}$ & $\begin{array}{l}\text { Minimal: } \\
\text { low-tech } \\
\text { frames for } \\
\text { drying on } \\
\text { farms }\end{array}$ & $\begin{array}{l}\text { Appropriate } \\
\text { milling and } \\
\text { grading facility }\end{array}$ & Transport & $\begin{array}{l}\text { On-farm } \\
\text { cold chain }\end{array}$ \\
\hline
\end{tabular}

Source: Author. 
investment, particularly in the northern part of Ghana. The bulk of the produce has to be carried in head loads from farm to homes and then on to markets. Perishable crops such as tomatoes still suffer serious damage in road transport.

Market incentives are also crucial for maintaining quality. Incentives need to begin with a grading system so that the prices paid by exporters, processors, or retailers reflect the quality of the product delivered to them, and these price signals then need to be transmitted back along the value chain to the grower. This happens in the case of cocoa, but rarely for rice, pineapples, or tomatoes. Growers of these crops do not have their produce graded, and hence have little incentive to produce higher-quality products. Tomato traders, for example, trade tomatoes in crates they take to producers, the size of which has grown so that when full they can no longer be carried by a single person. The tomatoes are simply packed into the crates without sorting, and the crates are stacked and transported over long distances, during which time many tomatoes get crushed. The traders have sufficient market power to prevent retailers from choosing among crates, thus preventing grading even at their destination. Nor do rice traders invest in grading, although the costs of doing so are marginal compared to a 20 percent price premium paid on graded rice. Although an association of pineapple exporters exists, they have not been able to maintain the quality of Ghana's exports. Nor has quality improvement and grading yet emerged in the domestic market.

Ghana's recent effort to offer grading as part of a warehouse receipt system does not appear to have encouraged grading, or the emergence of a quality premium for commodities like maize. There have also been many privatesector-led efforts to produce certified traceable outputs for export markets, but these have not succeeded. Some producers, on the other hand, have responded to market opportunities for quality products. For example, a number of greenhouses have set up to meet the demand for high-quality tomatoes as substitutes for imports from South Africa.

\subsubsection{Other supporting policies}

Government can directly influence value chains for internationally traded goods through imposition of taxes and tariffs. In Ghana, domestic rice production is protected by levies and taxes that add nearly 40 percent to the price of imported rice (Ragasa et al. 2013). Yet this does not seem to have encouraged a shift towards a more competitive domestic rice sector; if anything it may have helped sustain an inefficient system of producing inferior types of rice that are poorly milled and unappealing to many urban consumers. In the 
case of cocoa, production for export is still taxed, though since the economic reforms the rate of taxation has been kept low enough so as not to discourage production. Moreover, a substantial share of the tax is returned to cocoa growers in the form of services provided by Cocobod (Kolavalli, 2017).

\subsubsection{More Comprehensive Institutional Interventions within Value Chains}

Given obvious failures at various points along the value chains for pineapples, rice, and tomatoes, might there be a case for greater public sector coordination, as has been done successfully for cocoa for many decades? We consider first the case of cocoa and identify reasons why the Cocobod model is unlikely to work for other commodities like pineapples, rice, or tomatoes. This leads to consideration of alternative forms of public intervention for these commodities.

\subsubsection{The Cocobod model}

The Cocobod model is one in which the state, through a parastatal, has taken almost full control of the value chain for cocoa. While some functions along the value chain have been privatized, such as the collection of cocoa from farmers, supplying fertilizers, and processing, most of these functions are undertaken by private firms that are vetted and licensed by Cocobod.

There are two compelling reasons that justify Cocobod's continuing and extensive interventions along the value chain for cocoa. One is the need to achieve quality control along the entire value chain to ensure high quality cocoa beans for export that attract a price premium. Quality control is especially challenging given that the crop is grown by a large number of diverse smallholders scattered throughout the forest zone. Second, is the need to have the marketing power to obtain and maintain leverage and branding in the world market, something that no private exporting firm could easily replicate. Cocobod has been able to fulfill these needs because, unlike the cocoa sectors in some neighboring countries, it has retained a monopoly power over cocoa exports. It also helps that Ghana is an established and major player in the world market. Cocobod has also strengthened its competitiveness by using its marketing power to retain some of the cocoa revenues to invest in cocoa research and to supply productivity- and quality-enhancing services to farmers, such as hybrid trees, extension, and public sprays.

The experience with marketing boards in Africa has generally been unfavorable, but Cocobod stands out as an exception. Contrary to what might be 
expected, Cocobod and its associated marketing organizations (Quality Control Company and the Cocoa Marketing Company) seem not to have been corrupted or lured into major inefficiencies as a result of their monopoly power. It is not clear that there are any specific characteristics of cocoa as a commodity that explain the development of a marketing organization as "capable" and accountable as Cocobod, and its success may simply reflect a capacity that originates from its accumulated institutional heritage and marketing experience from prior to Independence, and its initial base in London. It also benefited from cost-cutting and performance-improving measures introduced as part of the economic reforms, and to continuing government oversight. Yet its success with cocoa does not seem to be easily transferable, as demonstrated by Cocobod's recent and less successful foray into developing the value chain for shea nut exports.

Would the Cocobod model work for other export commodities like pineapples? Probably not. Ghana is a relatively small player in the world pineapple market and the successful exporting of fresh pineapples requires finding a niche in a very competitive and dynamic world market, and overcoming quality and transport problems with a perishable commodity. There is need for nimble solutions that only the private sector is likely to find. Rather than a publicly controlled marketing board, perhaps what Ghana needs for its pineapple exports is some large private firms, or an association of private firms, to develop and integrate the value chain themselves, especially firms that have access to export markets and foreign investment capital, and who could set up their own production networks and invest in domestic processing as appropriate. The state could still play a supporting role, such as promoting exports, much as the Chilean government promotes the branding and export of Chilean wine (Benavente 2006).

In the case of tomatoes, the challenge is to be able to match the quality of imported tomatoes and processed products, not to create world market niches for exports. A parastatal marketing board would likely lobby for import tariffs and taxes on competing imports, which would not only discourage development of a more competitive domestic value chain for tomatoes and tomato products, but would also raise the prices of some important and nutritious foods for the poor.

The market for rice is quite different. It is a non-perishable commodity with a highly competitive domestic market with lots of traders and millers of different scales. As with tomatoes, a major challenge is to improve the quality of domestically grown and milled rice to compete with imports, and this calls for a more limited but supportive public sector role. There is already an import 
tariff on imported rice, but it has done little to promote a more competitive domestic value chain, yet has increased the price of an important food for the poor.

\subsubsection{Alternative Models}

Resolving many of the weaknesses along the value chains for pineapples, tomatoes, and rice does call for some more coordinated interventions along their value chains. Quality control, for example, requires an adequate grading system of the final product, and also the ability to transmit the price differentials associated with different qualities back along the value chain to relevant decision-makers, including farmers. This might require some coordination of the supply of desired seed varieties to farmers with appropriate advice on agronomic practices, with improved post-harvest grading and handling by farmers, traders, and transporters, as well as improvements in processing plants. Getting all the relevant decision-makers to agree and work in complementary ways and at the right times is not something that necessarily evolves when left to market forces alone.

As an alternative to the marketing board solution, there have been several recent attempts to find more flexible institutional structures that can facilitate and encourage coordination and the development of non-market relationships among value chain actors, but without undermining a basic laissez-faire approach to the market. Particular attention has been given to the problem of giving smallholders access to inputs and markets (Kolavalli et al. 2015). Some programs in Ghana such as the Northern Rural Growth Project (NRGP) and the Market Oriented Agricultural Project (MoAP), enable various actors in value chains to interact with each other by organizing value chain committees. Whether these efforts are useful to overcome some of the market failures to give smallholders greater access to inputs and output markets remains to be seen.

Crop development strategies too have been developed with the participation of private value chain actors. Maize and yam development strategies were developed in Ghana with substantial participation of value chain actors in the belief that when they come together problems can be better diagnosed and resolved (Kolavalli et al 2015). The strategies that emerge from such approaches, however, lack focus and often neglect the role of technologies. For example, value-chain-based studies attribute low productivity and production of rice in Ghana to a whole range of factors: low profitability and trader oligopoly, low processing premiums, insufficient knowledge of packaging, insufficient availability of inputs including certified seeds, insufficient mechanization 
and private-sector development for machine parts or appropriate milling machines, high labor costs, poor performance of public irrigation projects, weak extension services with poor knowledge of production practices for lowland/irrigated rice production, lack of credit and high interest rates, inadequate drying space, warehousing and storage, weak land tenure that discourages investment in irrigation and land improvements (KranjacBerisavljevic et al. 2003; USAID 2009; CARD 2010; IFDC 2008; Somado et al. 2008). Without some prioritization of these problems it is not clear how any committee would be able to begin to resolve them.

As discussed in Chapter 3, the development of more cohesive strategies for value chain development such as practiced in some East Asian countries has been constrained by a weak public sector capacity and the government's often antagonistic and weak relationships with the private sector.

\subsection{Conclusions}

This chapter has examined the value chains four important agricultural commodities, each of which has to compete internationally, either as an export commodity (cocoa and pineapples) or as a substitute for imports (tomatoes and rice).

The cocoa value chain is controlled by a parastatal, Cocobod, and works reasonably well. Ghana is able to maintain a high-quality product that is recognized in the world market and receives a price premium. Quality control is effectively managed all the way down from the export market to the smallholder. Growers have access to hybrids and needed inputs, and Cocobod even does some of the spraying. While there have been government aspirations to develop more value addition from cocoa, it seems clear that apart from the domestic market, Ghana has no competitive advantage in developing an industry for producing chocolate products for export. The puzzle with cocoa is why Cocobod has been so successful given the generally poor experience with marketing boards and parastatals in Ghana and elsewhere in Africa. Its success may lie with a unique institutional capacity that is the outcome of its long history and accumulated marketing experience, together with effective government oversight.

Pineapples provide an example of failed coordination along a value chain. The problems faced by the Ghanaian pineapple industry is not so much access to world markets, but rather challenges with production, quality control, responding to market shifts, and transitioning to new game-changing varieties like MD2. It is not clear that the government has the capacity to establish a 
marketing board that would do for pineapples what Cocobod has done for cocoa. A better option is to provide public sector support to large private firms, or an association of private firms, in developing and integrating the value chain themselves for pineapple exports; firms that have access to export markets and foreign investment capital, and who can set up their own production and quality control systems, and invest in domestic processing as appropriate. Such models already exist in Ghana, and the public sector could help scale up such ventures and link in more smallholders by investing in agricultural extension and infrastructure development, such as rural roads and cold storage facilities at airport or docks; also by supporting pineapple grading systems, making land accessible for hub-and-spoke estates, providing tax incentives, and promoting Ghana's pineapple exports and branding in overseas markets. Many of these investments might be financed by introducing a levy on exports, much as is done with cocoa. The lack of such government support in the past helps explain why private firms have not been more successful (Whitfield 2012).

Tomato is another value chain that is best left to private sector initiative. However, in this case there is scope for parallel supply systems: one that is more highly organized for quality control to meet the requirements of processing plants and high-end retailers and supermarkets, and another lessorganized chain to produce fresh fruits for the domestic market. Again, the private sector should be encouraged to invest in developing the value chain for quality controlled fruits and to set up its own supply, quality control, and processing systems. But again this requires a more supportive environment than the government has been willing to provide so far, especially in helping small farmers improve their yields and the quality of their produce.

The value chain for rice is quite different. It is a non-perishable commodity with a highly competitive domestic market with lots of traders and millers of different scales. A major challenge is to improve the quality of domestically grown and milled rice to compete with imports. Rice does not easily lend itself to contract farming or out-grower schemes, so it is difficult for the milling sector to improve the quality of the paddy it receives from farmers for milling. Rice growers need more public sector support to increase the productivity and quality of their product, and among other things this requires greater investment in irrigation, agricultural research, and rural infrastructure. So far the main policy intervention has been the introduction of an import tariff on imported rice, but it has done little to promote a more competitive domestic value chain, yet has increased the price of an important food for the poor.

The findings for pineapples, tomatoes, and rice are illustrative of the problems facing most other agricultural value chains in Ghana, and which arise 
from inadequate levels of state support for farmers and private sector players along value chains. Part of the problem is weak state capacity to intervene more effectively along value chains (Cocobod being an exception), but more fundamentally it reflects low levels of public investment in the noncocoa subsector (Chapter 7), and a constraining business environment. Important failures have been: the poor performance of the public R\&D system in developing more appropriate crop varieties to meet market needs; breakdowns in the supply chain for providing farmers with improved seeds; and inadequate agricultural extension, all of which are needed to further the development and uptake of better technologies that could help make Ghanaian farmers more competitive. Another failure has been insufficient provision of finance to agribusiness. Land rights are another important issue, both for obtaining sites for building agro-processing and storage facilities, but also for establishing large-scale commercial farms, even when the latter might serve as hubs for smallholder out-grower schemes (Amanor 2013; Throup et al. 2014). Greater investment in these fundamentals would go a long way towards helping Ghana's small farmers become more competitive in their domestic as well as export markets.

Beyond these fundamentals, there is need for government to be more proactive in working with private sector players, both large and small, in developing grading systems and coordinating value chains through various forms of marketing associations, or multi-stakeholder platforms (Devaux et al. 2016). However, as discussed in Chapter 3 , for government to play more proactive roles along value chains requires overcoming inherently weak public sector capacities, and a greater willingness to engage with the private sector. As the Government is again turning towards a more proactive approach to the noncocoa subsector, it remains to be seen whether its recent commitment to the policy framework of the "New Alliance for Food Security and Nutrition" will lead to more effective partnerships with the private sector.

\section{References}

Amanor, Kojo Sebastian. 2013. "Expanding Agri-business: China and Brazil in Ghanaian Agriculture." IDS Bulletin 44(4): 80-90.

Amanor Boadu, V. 2012. "Rice Price Trends in Ghana (2006-2011)." Ghana Research and Issue Paper Series No. 02-2012. Accra: Monitoring, Evaluation and Technical Support Services (METSS), United States Agency for International Development (USAID). 
Asuming-Brempong S., and A. Asuming Boakye. 2008. "Socio-economic Analysis of Tomato Production in Ghana." Technical report prepared for the Ghana trade and livelihood coalition. University of Ghana Affiliates: Accra. (Mimeo.)

Baba, I. Y., J. Yirzagla, and M. Mawunya. 2013. “The Tomato Industry in GhanaFundamental Challenges, Surmounting Strategies, and Perspectives: A Review.” International Journal of Current Research 5(12): 4102-7.

Banful, A. B. 2009. “Operational Details of the 2008 Fertilizer Subsidy in Ghana: Preliminary Report.” GSSP Background Paper 18. Washington, DC: International Food Policy Research Institute.

Benavente, J. M. 2006. "Wine Production in Chile," in V. Chandra (ed.), Technology Adaptation and Exports. Washington, DC: World Bank.

Benin, S., M. Johnson, E. Abokyi et al. 2013. "Revisiting Agricultural Input and Farm Support Subsidies in Africa: The Case of Ghana's Mechanization, Fertilizer, Block Farms, and Marketing Programs.” IFPRI Discussion Paper No. 1300. Washington, DC: International Food Policy Research Institute.

Byerlee, Derek, Andres F. Garcia, Asa Giertz et al. 2013. Growing Africa: Unlocking the Potential of Agribusiness: Main Report. Washington, DC: World Bank.

CARD (Coalition for African Rice Development). 2010. “Mapping of Poverty Reduction Strategy Papers (PRSPs), Sector Strategies and Policies Related to Rice Development in Ghana." Nairobi: CARD-Alliance for a Green Revolution in Africa (AGRA).

Chandra, Vandana (ed). 2006. “Technology, Adaptation, and Exports: How Some Developing Countries Got It Right.” Washington DC: World Bank.

Danielou, M., and C. Ravry. 2005. “The Rise of Ghana’s Pineapple Industry: From Successful Takeoff to Sustainable Expansion.” Africa region working paper series. Washington, DC: World Bank.

Devaux, A., M. Torero, J. Donovan, and D. Horton. 2016. "Innovation for Inclusive Value-chain Development." Washington, DC: International Food Policy Research Institute.

Fold, N., and Gough, K. V. 2008. "From Smallholders to Transnationals: The Impact of Changing Consumer Preferences in the EU on Ghana's Pineapple Sector." Geoforum 39:1687-97.

Gatune, J., M. Chapman-Kodam, K. Korboe et al. 2013. “Analysis of Trade Impacts on the Fresh Pineapple Sector in Ghana.” Research Working Paper No. 41. Rome: Food and Agriculture Organization of the United Nations.

Gilbert, C. L. 2008. "Value Chain Analysis and Market Power in Commodity Processing with Application to the Cocoa and Coffee Sector." Discussion Paper No. 5. Trento: Universita degli Studi de Trento.

Halbach, M. 2011. "Facilitating Collective Action for Common Marketing." Masters thesis, University of Utrecht. 
Hill, P. 1963. Migrant Cocoa Farmers of Southern Ghana. Cambridge: Cambridge University Press.

Houssou, Nazaire, Collins Asante-Addo, Kwaw S. Andam, and Catherine Ragasa. 2018. "How Can African Governments Reach Poor Farmers with Fertiliser Subsidies? Exploring a Targeting Approach in Ghana," The Journal of Development Studies. Article in press. https://doi.org/10.1080/00220388.2018.1528353.

IFAD. 2015. "Roots and Tuber Improvement and Marketing Programme: Project Completion Report.” Rome: International Fund for Agriculture.

IFDC (International Fertilizer Development Center). 2008. "Study of the Domestic Rice Value Chains in the Niger Basin of Mali, Niger, and Nigeria, West Africa." Lomé: IFDC North and West Africa Division.

Jayne et al. 2015. “Towards a Sustainable Soil Fertility Strategy in Ghana.” Report submitted to the Ministry of Food and Agriculture, Government of Ghana.

Kleemann, L., A. Abdulai, and M. Buss. 2014. "Certification and Access to Export Markets: Adoption and Return on Investment of Organic-Certified Pineapple Farming in Ghana." World Development 64: 79-92.

Kolavalli, S. and M. Vigneri. 2011. "Cocoa in Ghana: Shaping the Success of an Economy," in P. Chuhan-Pole and M. Angwafo (eds), Yes Africa Can: Success Stories from a Dynamic Continent. Washington, DC: World Bank.

Kolavalli, S., M. Vigneri, H. Maamah, and J. Poku. 2012. “The Partially Liberalized Cocoa Sector in Ghana: Producer Price Determination, Quality Control, and Service Provision.” IFPRI Discussion Paper No. 01213. Washington, DC: Development Strategy and Governance Division, IFPRI.

Kolavalli, Shashidhara, Akwesi Mensah-Bonsu, and Saima Zaman. 2015. “Agricultural Value Chain Development in Practice: Private Sector-led Smallholder Development.” IFPRI Discussion Paper No. 1460. Washington, DC: International Food Policy Research Institute.

Kranjac-Berisavljevic, G., R. M. Blench, and R. Chapman. 2003. "Multi-agency Partnerships (MAPS) for Technical Change in West African Agriculture: Rice Production and Livelihoods in Ghana." London: Overseas Development Institute.

Kwakye, J. K. 2010. “High Interest Rates in Ghana: A Critical Analysis.” Accra: The Institute of Economic Affairs.

Lambrecht, I., and C. Ragasa. 2016. "Do Development Projects Crowd out Private Sector Activities? A Survival Analysis of Contract Farming Participation in Northern Ghana.” IFPRI Discussion Paper No. 01575. Washington, DC: International Food Policy Research Institute.

LMC International. 2014. "Cocoa Comparative Household Economy Study: West Africa Smallholder Cocoa Farmers.” Washington, DC: World Cocoa Foundation. 
Modzakah, David, and Federica Angelucci. 2016. “Analysis of Price Incentives for Rice in Ghana 2005-2013.” Technical Notes Series. Rome: FAO.

Monney, E., V. Edusei Poku, and E. Armah. 2009. "Baseline Survey of Tomato Production in Ghana: A Study of Twelve Production Districts in Four Regions." Ghana: The Horticulture Development Unit, Directorate of Crop Services and Post-Harvest Management Unit, Agriculture Engineering Services Directorate, Ministry of Food and Agriculture.

Moore, Austen, Oliver Ferguson, and Victor Lolig. 2015. "Assessment of Extension and Advisory Services in Ghana's Feed the Future Zone of Influence." MEAS Country Assessment. Available at: https://agrilinks.org/sites/default/ files/resource/files/MEAS\%20Country\%20Report\%20GHANA\%20-\%20August\% 202015.pdf.

Moss, R., Garcia, J., and Osei, P. S. 2014. “An Integrated Approach to Disease Control and Soil Fertility Management for MD2 Pineapple: A Preliminary Trial in Ghana." Pineapple News 21: 39. Available at: http://www.ishs-horticulture. org/workinggroups/pineapple/PineNews21.pdf.

Overseas Development Institute (ODI). 2003. “Multi-agency Partnership for Technical Change in West African Agriculture: Rice Production and Livelihood in Ghana." London: ODI.

Opoko, Emmanuel, Richman Dzene, Stefano Cariaet al. 2009. “Impacts of Groupbased Microfinance in Agriculture: Evidence from Ghana's Cocoa Abrabopa Association." Oxford: Centre for the Study of African Economies Department of Economics, University of Oxford.

Orchard, J. E., and K. J. Suglo. 1999. “Integrated Food Crops Projects: Enhancing Smallholder Livelihoods through Reducing Cost and Adding Value to Agricultural Production." Final Technical Report. Kent: Natural Resource Institute and Ministry of Agriculture Ghana.

Patrick Guyver, and Mavis MacCarthy. 2011. "The Ghana Grains Partnership.” International Journal of Agricultural Sustainability 9(1): 35-41.

Pritchard, B., and D. Burch. 2003. Agro-food Globalisation in Perspective: International Restructuring in the Processing Tomato Industry. Aldershot: Ashgate.

Ragasa, Catherine, Awere Dankyi, Patricia Acheampong et al. 2013. "Patterns of Adoption of Improved Rice Technologies in Ghana." GSSP Working Paper No. 35. Washington, DC: International Food Policy Research Institute.

Robinson, Elizabeth, and Shashi Kolavalli. 2010a. "The Case of Tomato in Ghana: Processing.” GSSP Working Paper No. 21. Accra: GSSP.

Robinson, Elizabeth, and Shashi Kolavalli. 2010b. “The Case of Tomato in Ghana: Instutional Support.” GSSP Working Paper No. 22. Accra: GSSP.

Robinson, Elizabeth, and Guylain Ngleza. 2011. "Cartels and Rent-sharing at the Farmer-trader Interface: An Example from Ghana's Tomato Sector.” IFPRI 
Discussion Paper No. 01065. Washington, DC: International Food Policy Research Institute.

Rothchild, Donald. 1980. "Military Regime Performance: An Appraisal of the Ghana Experience, 1972-78." Comparative Politics 12(4): 459-79.

Salifu, Adam, Rebecca Lee Funk, Meagan Keefe, and Shashidhara Kolavalli. 2012. "Farmer-based Organizations in Ghana." GSSP Working Paper No. 13. Washington, DC: International Food Policy Research Institute.

Somado, E., R. G. Guei, and N. Nguyen. 2008. "Module 1: Overview: Rice in Africa," in E. A. Somado, R. G. Guel, and S. O. Keya (eds), NERICA: The New Rice for Africa-a Compendium. Bouaké: Africa Rice Center (WARDA), 1-9.

Suzuki, Aya. 2014. "Risk on Dynamic Behavior of Farmers in the Export Market: A Case from the Pineapple Industry in Ghana." Selected Paper prepared for presentation at the Agricultural \& Applied Economics Association's 2014 AAEA Annual Meeting, Minneapolis, MN.

Suzuki, A., L. S. Jarvis, and R. J. Sexton. 2011. "Partial Vertical Integration, Risk Shifting, and Product Rejection in the High-Value Export Supply Chain: The Ghana Pineapple Sector.” World Development 39(9): 1611-23.

Takane, T. 2004. "Smallholders and Nontraditional Exports under Economic Liberalization: The Case of Pineapples in Ghana." African Study Monographs 25(1): 29-43.

Takeshima, Hiroyuki, Kipo Jimah, Shashidhara Kolavalli et al. 2013. "Dynamics of Transformation: Insights from an Exploratory Review of Rice Farming in the Kpong Irrigation Project.” IFPRI Discussion Paper No. 1271 Washington, DC: International Food Policy Research Institute.

Thoburn, John. 2009. "Vietnam as a Role Model for Development." Research Paper No. 2009/30. Helsinki: UNU/WIDER.

Throup, David, Chris Jackson, Katherine Bain, and Rachel Ort. 2014. “Developing Commercial Agriculture in Ghana," in Verena Fritz, Brian Levy, and Rachel Ort (eds), Problem-Driven Political Economy Analysis. Washington, DC: World Bank, ch. 6.

Tripp, Robert and Ragasa, Catherine. 2015. "Hybrid Maize Seed Supply in Ghana.” GSSP Working Paper No. 40. Washington, DC: International Food Policy Research Institute.

USAID. 2009. “ Global Food Security Response: West Africa Rice Value Chain Analysis.” Washington, DC: USAID.

Vingeri, Marcella, and Shashi Kolavalli. 2018. "Growth through Pricing Policy: The Case of Cocoa in Ghana." Background paper for UNCTAD-FAO Commodities and Development Report 2017: Commodity Markets, Economic Growth and Development. Rome: FAO. 
Weimer, Alice. 2015. “A 'Time of Agric': Rethinking the 'Failure' of Agricultural Programs in 1970s Ghana.” World Development 66: 104-17.

Whitfield, Lindsay. 2010. "Developing Technological Capabilities in AgroIndustry: Ghana's Experience with Fresh Pineapple Exports in Comparative Perspective.” DIIS Working Paper No. 2010:28. Copenhagen: Danish Institute for International Studies.

Winter-Nelson and Aggrey-Fynn. 2008. "Identifying Opportunities in Ghana's Agriculture: Results from a Policy Analysis Matrix." GSSP Background Paper No. 12. Washington, DC: International Food Policy Research Institute.

Wolf, H. 1999. "Economics of Tomato Production with Special Reference to Aspects of Plant Protection: A Case Study of Two Tomato Production Systems in Brong-Ahafo Region, Ghana. Prepared for Ghanaian-German Project for Integrated Crop Protection.” GTZ: Eschborn.

World Bank. 2014. Ghana: Country Profile 2013. Enterprise Surveys. Washington, DC: World Bank. 


\title{
9
}

\section{Unleashing the Power of Mechanization}

\author{
Xinshen Diao, Frances Cossar, Nazaire Houssou, \\ and Shashidhara Kolavalli
}

\subsection{Introduction}

As in most of Africa, agricultural mechanization in Ghana has been slow to develop, either in the form of animal or tractor power. But this has changed markedly since the early 2000s, and today about one third of all Ghana's farmers report using some form of mechanization, mostly tractors for land preparation, as do over half the farmers with five or more hectares of cropped land. However, policymakers often are skeptical of the role played by the private sector in providing mechanization services and worry that supplyside issues may be constraining its uptake, especially amongst smaller-sized farms. With this in mind, the government recently started to directly engage in the importation and subsidization of tractors, and has established a network of subsidized agricultural mechanization service centers around the country (Diao et al. 2014). The government program operates in direct competition with an already established private sector supply system, and this raises a number of important questions. In particular, is the government program overcoming some inherent market failure problems or is it introducing market distortions in machinery prices, encouraging rent-seeking behavior and possibly crowding out more efficient private suppliers? If the latter, then as suggested in Chapter 6, the program may be an unnecessary and costly addition to the financial burden of the public sector.

To address these issues, we review recent developments in the uptake of agricultural mechanization in Ghana, and of the factors that are driving the growth in farmers' demand. We then discuss possible supply-side constraints, and evaluate the government's recent interventions and their impact on the existing private sector alternative. This leads to our conclusions about appropriate mechanization policies for the future. 


\subsection{Mechanization Trends in Ghana}

Until recently, most cropped land in Ghana was cultivated manually, and use of animals or tractors for plowing was limited, despite early governmentsponsored mechanization programs in the 1960s. The use of animal traction has always been constrained by tsetse fly problems in much of the country, ${ }^{1}$ but recent years have seen rapid growth in demand for tractor plowing.

The agricultural census data are unreliable for showing trends in the ownership of tractors, but Figure 9.1 shows the substantial growth in the import of new and used tractors since 2003. Data on the use of mechanization is also available from the GLSS surveys and a recent Labor Force Survey conducted in 2015/16 (GSS 2016). The share of households incurring expenses for any type of agricultural mechanization (including purchasing or hiring machines and operating, maintenance, and repair costs) increased from virtually zero in 1991/2 to 17.5 percent in 2005/6, and then almost doubled to 32.5 percent in 2012/13. Mechanization is most prevalent in the Upper West and Northern regions and in the Greater Accra region, regions where 75 percent or more of farmers report spending on mechanization. The least mechanized regions are the Central and Ashanti regions, where less than 10 percent of farmers report spending on mechanization. One reason for this regional distribution is that the dominant

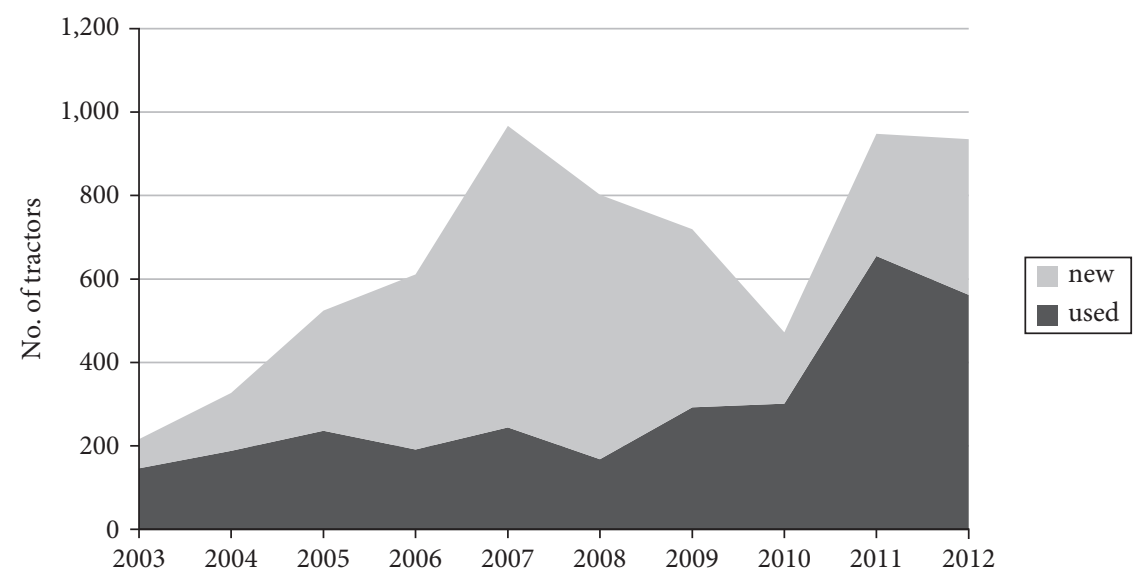

Figure 9.1. Tractor imports, 2003 to 2012

Note: Data for 2012 are to July 2012.

Source: Customs, Excise and Preventive Service, Government of Ghana.

${ }^{1}$ Draft animals are used more widely in the very north of the country where they are complementary with tractors (Houssou et al. 2013a). 
Table 9.1. Share of rural households using mechanization (percent)

\begin{tabular}{|c|c|c|c|c|c|}
\hline & \multicolumn{4}{|c|}{ Farm size } & \multirow[t]{2}{*}{ Total } \\
\hline & $<2$ ha & $2-5$ ha & $5-20$ ha & $>20$ ha & \\
\hline $\begin{array}{l}\text { National: } \\
1991 / 2\end{array}$ & & & & & 1.0 \\
\hline $2005 / 6$ & 12.9 & 20.3 & 27.0 & 34.4 & 17.5 \\
\hline $2012 / 13$ & 22.0 & 37.8 & 53.6 & 72.8 & 32.5 \\
\hline $\begin{array}{l}\text { North: } \\
2005 / 6 \\
2012 / 13\end{array}$ & $\begin{array}{l}10.2 \\
22.2\end{array}$ & $\begin{array}{l}13.4 \\
37.9\end{array}$ & $\begin{array}{l}17.6 \\
56.3\end{array}$ & $\begin{array}{l}22.8 \\
76.4\end{array}$ & $\begin{array}{l}12.8 \\
35.9\end{array}$ \\
\hline $\begin{array}{l}\text { South: } \\
2005 / 6 \\
2012 / 13\end{array}$ & $\begin{array}{l}14.0 \\
21.9\end{array}$ & $\begin{array}{l}24.7 \\
37.7\end{array}$ & $\begin{array}{l}32.1 \\
51.3\end{array}$ & $\begin{array}{l}47.4 \\
67.2\end{array}$ & $\begin{array}{l}19.8 \\
30.8\end{array}$ \\
\hline
\end{tabular}

Note South $=$ Coastal + Forest zones; North $=$ Savannah + Transition zone . Source: Authors' calculations using GLSS3, GLSS5, and GLSS6.

form of mechanization is tractor plowing, and this is more relevant in regions that grow field crops than in the forest and cocoa growing areas.

Larger farms with more than five hectares are much more mechanized than smaller farms in both the North and the South (Table 9.1). While the largest farms often own their own tractors, most other farms are too small to justify such a lumpy investment and must hire in tractor services. Some medium-sized farms are able to justify purchasing a tractor by hiring out tractor services once they have met their own mechanization needs. A 2013 survey jointly conducted by IFPRI and the Savannah Agricultural Research Institute (SARI) in eight districts in the Northern and Central regions of Ghana found that more than 60 percent of the surveyed farmers used tractors for plowing, and that two thirds of them (who were all medium- and small- scale farmers) did not own a tractor but hired tractor services in (Diao et al. 2014). Of the medium- and large-scale farmers who owned tractors, 78 percent reported hiring out plowing services to other farmers during the survey year. Since the average farm size is larger in the Northern region and large farms are more likely to mechanize, then it can also be inferred that the share of the cropped area that is mechanized has also increased.

\subsection{The Emerging Demand for Agricultural Mechanization in Ghana}

Why has mechanization finally taken off in Ghana since the early 2000s? What has driven demand and to what extent has the supply of mechanization 
services kept up with potential demand? We explore the determinants of demand in this section, and then consider supply-side issues in Section 9.4.

A large literature exists that aims to explain the slow evolution of agricultural mechanization in Africa. One theory, developed by Hans Ruthenburg (1980) and based on his historical analysis of the evolution of tropical farming systems, predicts that farming communities will only adopt draft animals or tractors for land preparation once their land-use intensity reaches a critical threshold. Ruthenburg measured land-use intensity as the ratio of the harvested area to the total agricultural area (cropland plus fallow land) - which he called the $\mathrm{R}$ ratio, and concluded that this ratio needed to exceed 33 percent before mechanization of land preparation would take hold. This is equivalent to when the average fallow period has been shortened to less than two years for each year of cultivation. One reason for the switch in technology is that as fallows get shorter, grassy weeds and hardened soils become more serious problems and they are hard to overcome with hand hoeing, making animal or tractor plowing more attractive.

Diao et al. (2014) have calculated annual R-values for Ghana over the period 1961 to 2011 (Figure 9.2). Ghana was a relatively land-abundant country with low R-values until the late 1990s, during which time there was little evidence of rising demand for tractor mechanization. From the late 1990s onwards, however, the R-values have permanently risen above the threshold of 33, reaching 40 to 43 in the late 2000s. While this highly aggregated data fails to capture important regional variations, it does suggest that farming systems and land-use intensity have changed significantly in Ghana since the late 1990s, and which is consistent with the recent growth in demand for tractor plowing.

Ruthenburg's $\mathrm{R}$ ratio does not consider other economic factors that might affect mechanization besides land-use intensity, and these need to be taken

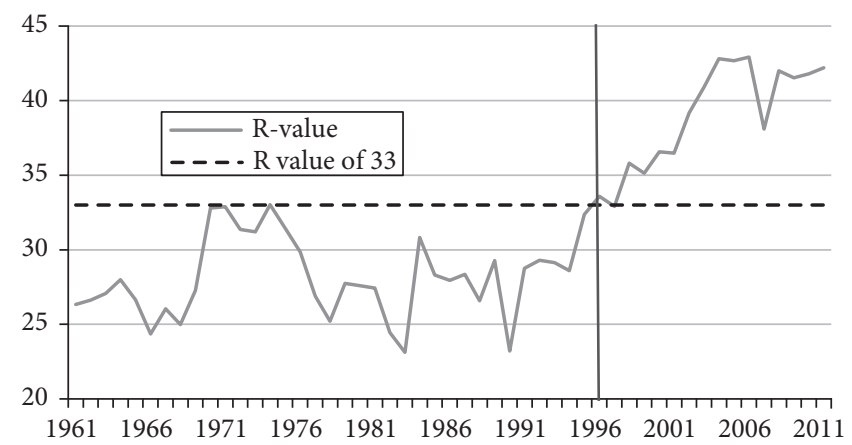

Figure 9.2. R-value measure of farming system evolution in Ghana, 1961-2011 Source: Compiled from FAO data. 
into account in explaining the recent growth of agricultural mechanization in Ghana. Another relevant theory from the literature is the induced innovation theory, which essentially predicts that since mechanization is a labor-saving technology, demand will develop once labor becomes sufficiently costly relative to capital and other purchased inputs (Hayami and Ruttan 1970, 1985; Binswanger and Ruttan 1978; Pingali et al. 1987). This typically happens after a country has reached a point in its economic transformation where the absolute number of workers remaining in agriculture begins to decline, and the land/labor ratio increases. For field crops, this usually leads to farms getting bigger, and with greater scarcity of labor relative to land, farmers have incentive to adopt labor-saving technologies like mechanization. However, as Chapter 5 shows, this change can be accelerated by rapid urbanization, which in addition to pulling workers out of agriculture, leads to more diversified rural livelihoods amongst remaining farm households, and hence to greater wage competition between agriculture and the nonagricultural sectors. Changes in urban diets may also lead to expansion of more labor-intensive crops, adding to the competition for labor.

We look at the evidence on three key drivers that may have led to induced innovation: changes in the land/labor ratio, changes in farm size, and changes in urbanization.

\subsubsection{Land/Labor Ratio}

Unlike many African countries, Ghana is still a relatively land-abundant country, and as shown in Table 9.2, the average cropped area per rural person actually increased by 11.8 percent between 2000 and 2010. This happened despite continued population growth because the rapid urbanization of the country has pulled many workers out of agriculture on a full- or part-time basis, while at the same time changing market opportunities have led farmers to increase their cultivated areas (see Chapters 4 and 6). However, there are important regional differences in these changes as shown in Table 9.2. Looking across regions, there is an inverse relationship between increases in the cropped area per rural person over 2000 to 2010 and population density. For example, the Brong Ahafo region experienced the largest percentage increase in its cropped area per rural person (52.5 percent) and it was also the region with the lowest population density in 2010. At the other extreme, the Greater Accra region experienced a 38.8 percent decline in its cropped area per rural worker, and had the highest population density in 2010. 
Table 9.2. Crop area per rural person, by region, 2000 and 2010

\begin{tabular}{|c|c|c|c|c|c|}
\hline \multirow[t]{2}{*}{ Region } & \multirow{2}{*}{$\begin{array}{l}2010 \text { Rural } \\
\text { population density } \\
\left(\text { persons } / \mathrm{km}^{2}\right)\end{array}$} & \multirow{2}{*}{$\begin{array}{l}2010 \text { share in national } \\
\text { food crop area } \\
\text { (percent) }\end{array}$} & \multicolumn{3}{|c|}{$\begin{array}{l}\text { Crop area per rural } \\
\text { person (ha) }\end{array}$} \\
\hline & & & 2000 & 2010 & $\begin{array}{l}\text { Percent } \\
\text { change }\end{array}$ \\
\hline Western & 57 & 6.7 & 0.20 & 0.18 & -6.7 \\
\hline Central & 118 & 7.0 & 0.20 & 0.23 & 12.3 \\
\hline Greater Accra & 117 & 0.3 & 0.06 & 0.03 & -38.8 \\
\hline Eastern & 77 & 14.1 & 0.34 & 0.35 & 4.0 \\
\hline Volta & 68 & 5.9 & 0.14 & 0.16 & 16.2 \\
\hline Ashanti & 77 & 12.8 & 0.24 & 0.26 & 7.7 \\
\hline Brong Ahafo & 32 & 18.5 & 0.35 & 0.54 & 52.5 \\
\hline Northern & 25 & 16.1 & 0.33 & 0.35 & 7.0 \\
\hline Upper West & 32 & 10.6 & 0.58 & 0.68 & 16.8 \\
\hline Upper East & 94 & 8.0 & 0.41 & 0.36 & -12.6 \\
\hline National & 51 & 100.0 & 0.28 & 0.31 & 11.8 \\
\hline
\end{tabular}

Source: Diao et al (2014).

The regions that experienced the largest increases in their land/labor ratios are also the most important regions in terms of national food-crop production (Table 9.2). Labor also became more expensive as real wage rates were pulled up by competition from rural nonfarm jobs, growing by nearly 7 percent per year on average over 1991 to 2012 at both national and regional levels (Chapter 4, Tables 4.9 and 4.10). As revealed in the village studies, these increases have been an important driver of changes in farming practices, including mechanization, in the agriculturally important savannah and transition zones (Chapter 6).

\subsubsection{Farm Size}

One consequence of an increasing land/labor ratio has been that farms have grown larger in size. Nationally, there has been an increase in the share of middle-sized (2-20 ha) farms at the expense of small ( $<2 \mathrm{ha}$ ) and large ( $>20 \mathrm{ha}$ ) farms, and medium-sized farms now account for half of all farms (Table 9.3). This change masks important differences at regional levels. In the Northern region (comprising the savannah and transition zones), medium-sized farms have forged ahead and now account for 60 percent of all farms, and this has been at the expense of small and large farms. However, there has been a reverse trend in the south (comprising the forest and coastal zones), where the share of medium-sized farms has actually declined (from 44.7 to 41.1 percent) and the 
Table 9.3. Changes in the farm size distribution, 2005/6 and 2012/13

\begin{tabular}{lccc}
\hline & Small $(<2$ ha $)$ & Medium $(\mathbf{2}-20$ ha $)$ & Large $(>20$ ha $)$ \\
\hline National: & & & \\
$2005 / 06$ & 53.3 & 44.7 & 1.9 \\
$2012 / 13$ & 49.3 & 49.8 & 0.9 \\
North: & & & \\
$2005 / 06$ & 44.3 & 52.5 & 3.2 \\
$2012 / 13$ & 38.6 & 60.0 & 1.4 \\
South: & & & \\
$2005 / 06$ & 53.3 & 44.7 & 1.9 \\
$2012 / 13$ & 58.4 & 41.1 & 0.5 \\
\hline
\end{tabular}

Note: South $=$ Coastal + Forest zones; North $=$ Savannah + Transition zone.

Source: Authors' calculations using GLSS5 and GLSS6.

share of small farms has increased. Since medium- and large-sized farms are the most likely to mechanize, then these trends suggest that mechanization is likely to have grown faster in the north than in the south of the country.

\subsubsection{Urbanization}

The impact of urbanization on mechanization is explored in detail in Chapter 5. A key finding is that while there is no consistent pattern of mechanization across levels of urbanization in the south, in the north the level of mechanization is significantly higher in the districts with larger cities than other districts, particularly among smallholders with less than two hectares.

Given the above patterns of change in land/labor ratios, farm size, and urbanization, the induced innovation theory leads us to infer that mechanization should: a) be more likely in northern Ghana where the land/labor ratio is highest and the share of small sized farms is lowest, b) increase with farm size, and c) increase with urbanization. These expectations are consistent with the actual patterns of adoption reported in Table 9.1, confirming that mechanization in Ghana is demand led and a response to evolving economic incentives. This conclusion is consistent with findings in Chapter 6 which show that farmers in the savannah and transition zones are increasing their cropped areas and adapting their farming practices, including mechanization, in response to higher local wages and better market opportunities.

Although mechanization has been demand led, there is still the question of whether the supply of mechanization services has kept pace with potential 
demand. Hard evidence on possible market failures is hard to come by, but as found in the farm modeling work in Chapter 6, the optimal share of the cropped area that should have been mechanized in 2010 is much higher than the actual that year. This suggests that supply is constraining the adoption of mechanization, although there could of course be other reasons why farmers are not optimizing in the way the model predicts. We end this section with some of our own observations from multiple field visits in Ghana during 2012-18 when we interviewed many different types of farmers, including tractor owners and renters, specialized tractor contractors, and smallholders. We heard many complaints from smallholder farmers who hire in about the difficulties of obtaining adequate tractor services for plowing and at the right times, and how they often had to approach several tractor owners before securing the plowing services they needed. However, we did not hear a single complaint from a tractor owner about there being insufficient demand for his/her services; in fact, most said they were inundated with more requests than they could handle during the plowing season.

\subsection{The Supply of Mechanization Services in Ghana}

Demand for mechanization need not always lead to an adequate supply response, particularly when such demand comes from many small- and medium-scale farmers and the industry is at an early stage of development. While many farmers might be willing to pay market prices for hired services, few have a sufficiently large farm to justify owning a tractor given the sizeable lump-sum cost involved. Governments in Africa, including Ghana, often use this as an argument to justify a subsidized mechanization program. However, while this might improve access for smaller farms, there is a risk that subsidized programs can distort market prices for agricultural machinery and discourage private investment, leading to market inefficiencies and long-term costs to the government, and impede the longer-term development of a vibrant private sector supply chain.

In Ghana, there are currently two parallel supply channels for agricultural mechanization services for farmers; a government-sponsored Agricultural Mechanization Services Center (AMSEC) program; and a private sector system of importers, machinery service providers (many of which are medium-scale farmers), and repair and maintenance shops. We consider each in Sections 9.4.1 and 9.4.2 that follow. 


\subsubsection{Ghana's Agricultural Mechanization Services Center (AMSEC) Program}

The government's current involvement in mechanization services through its AMSEC program is not a new phenomenon in Ghana. In the 1960s, the Ministry of Agriculture owned and operated an estimated 1,500 tractors in its thirty-two district mechanization stations in the savannah zone (Seager and Fieldson 1984). This program failed partly because of weak farmer demand for mechanization, but also because service charges for the provision of plowing services were set too low (about 50 percent of their real costs) making the program financially unsustainable for the government. From then until the early 2000s, the supply of mechanization was left largely to the private sector. However, since 2003 the Government started again to intervene in the market with its AMSEC program, on the grounds that small-scale farmers were not receiving adequate tractor services. The program operates with the government importing tractors and providing them on a subsidized basis to its machinery service centers.

\subsubsection{State-led tractor imports}

The main source of funding for AMSEC is through concessional loans received by the government from various emerging economies such as Brazil, China, and India. Such concessional loan agreements require that Ghana import tractors from the lender country. Therefore, different loan agreements have brought in different brands of tractors from different countries. In theory, the government does not directly handle the importation of any tractors, but uses private agents to act on its behalf. However, the government selects the private agents and they have no say over the type of machinery to be imported or to negotiate prices; these are determined as part of the loan agreements between the government and the donor countries. The import of Farmtrac tractors is a good example of the process and its problems. After receiving a concessional loan for tractor imports in 2007 and 2008 from the Export-Import Bank of India, the government selected a local company as its import agent. The company imported 500 Farmtrac tractors from India during 2007 and 2008, but had no say in the selection of the Farmtrac brand, the tractor models chosen, or the import prices. Expecting their business to continue with the government, the company constructed a large warehouse and built up stocks of spare parts with its own money. However, in 2009 the government entered into a new concessional loan arrangement with 
the Indian government for importing John Deere machinery manufactured in India, and a new local company was selected as the government's importing agent. This undercut the company importing Farmtrac tractors; not only could they no longer import subsidized tractors from India, but their own investment in building up a stock of spare parts was devalued. Similar onetime arrangements have been made recently for importing Mahindra tractors from India and other brands from China, Brazil, and other countries.

\subsubsection{Government-selected "private" entities as amsecs}

In order to avoid direct government management of mechanization services, private agents are selected by the government to own and operate the machinery services centers. The first group of seventeen AMSECs was established in 2007/8, a second group of fifty-two was established in 2009, and another twenty were established in 2010/11 (Diao et al. 2018). For the sixty-nine AMSECs established in 2007/9, each was given a package of five to seven tractors, with plows, harrows, and trailers, by the government. The cost of the tractors to the centers was subsidized by 30 percent, and the centers only had to pay 10-20 percent of the subsidized price as a down payment for a five-year interest-free loan. Given that the subsidized tractor prices are well below market prices to begin with, the generous financial arrangements seemingly make AMSECs a lucrative and attractive business, and the government has not had any difficulties in attracting applicants. In fact, there have been sufficient applicants and the government has had to turn many down, yet the criteria for selection is not known. This raises concerns about possible rent-seeking behavior.

\subsubsection{Difficulties with the amsecs program}

The AMSECs were designed to provide specialized tractor services to the local market without adequate consideration of whether this is profitable. Unfortunately, it turned out that many AMSECs were not profitable and have defaulted on their debt repayments, leaving the government responsible for the repayment of concessional loans. ${ }^{2}$

Houssou et al. (2013b) have demonstrated why tractor hiring alone is not profitable for many AMSECs. Based on subsidized tractor prices, actual operational costs in Ghana, and an assumed 10 percent capital depreciation

\footnotetext{
${ }^{2}$ According to a report published by Japan International Cooperation Agency (JICA) in 2015, the loan repayment rate for AMSECs established in 2007/8 was only 17.2 percent and 44.9 percent for those established in 2009. Almost one third of AMSECs have not made any repayment at all after the down payment (JICA 2015).
} 
rate, they calculate that a minimum of 287 hectares must be plowed per tractor each season in order for the net profit from plowing services to be comparable to the interest earnings from a similar-sized savings deposit in a bank account-a necessary condition for tractor renting to break even. Using survey data, Houssou et al. (2013b) also show that few AMSECs plow sufficient acreages to be profitable. An important reason is that the plowing season is too short to enable tractors to plow larger acreages within the localities that each AMSEC serves.

One way to increase the utilization of tractors is through seasonal migration to different regions with complementary plowing seasons. South Ghana, for example, has two cropping seasons while the North has one, and this difference could in theory be exploited by mobile tractor service providers to increase the number of operational days per tractor (Houssou et al. 2013b). In practice, there is little evidence of any of the AMSECs attempting to be regionally mobile, although there is evidence that some private tractor owners are doing so.

Another possible way to make AMSECs more profitable would be for them to diversify beyond plowing and offer a wider range of mechanization services. A survey by Benin et al. (2012) showed that in 2010, only thirty-eight machinery services firms among 136 surveyed provided services other than plowing, and even for such firms 80-90 percent of their revenue came from plowing. However, so far there has not been much demand for additional services in Ghana, and as experience in some other countries has shown, demand typically develops in parallel with innovation in the design and adaptation of other kinds of tractor implements and machines tailored to the niche needs of specific groups of farmers or localities (Diao et al. 2014). This kind of innovation is much more likely to arise in the private sector than with the government sponsored AMSECs.

\subsubsection{The Private Sector Alternative}

In addition to the heavily subsidized and state interventionist AMSEC program, there is a well-developed private sector supply chain of importers, machinery service contractors (mostly farmers), and repair and maintenance shops. Other than benefiting from an import tariff exemption that applies to all agricultural machinery imports, the private sector receives no other support from the government. The scale of the private sector alternative is significant; while the government imported about 3,000 new tractors and 300 power tillers 
over ten years, a similar, or even larger number of used tractors were imported by private importers in the same period (Ghana, CEPS 2012). The share of used tractors in total imports has increased substantially since 2010, and it is estimated that more than 10,000 tractors are currently operating in Ghana (Diao et al. 2018), suggesting considerable and growing demand for affordable tractors by the private sector.

Private importers are predominantly small-scale businessmen who have well-developed import channels, and tractors are typically only part of their business. This diversification enables then to spread their risks, and to smooth out the seasonal nature of the demand for tractors. Their clients are mostly medium- and larger-scale farmers, who find imported secondhand tractors much more affordable than new ones (USAID/ACDI-VOCA 2013).

Secondhand tractors are attractive to farmers not only because they are more affordable, but because they can obtain tractor brands of their own choice. Moreover, since the private sector has operated in the tractor import business for many years, the spare parts for the brands they import are available in most locations at reasonable prices. By contrast, the brands of new tractors imported by the government keep changing, and spare parts for them are harder to obtain.

Medium- and large-scale farmers are the main buyers of secondhand tractors from private importers, and they are also the main providers of mechanized services to other farmers. For most of them, hiring out tractor services after they have plowed their own land is an important way to justify the substantial lump-sum investment cost involved. On the other hand, as farmers they are not as dependent as the AMSECs on hiring out services for their income.

The 2013 IFPRI/SARI survey found that almost half of the small-scale farmers surveyed hired in tractor services for plowing, and these services were nearly all sourced locally, and mostly from other farmers (Benin et al. 2012). On average, tractor-owning farmers who hire out have 100-120 farmer clients, of which 45-51 are small-scale farmers with land less than two hectares. Because of the dominant role of medium- and large-scale farmers in providing tractor services, the market for land-preparation services is competitive. One outcome is that farmers in different locations are paying similar prices for plowing services, regardless of whether they hire in from private or AMSEC sources (Benin et al. 2012). 


\subsection{Conclusions}

Ghana's farming systems have undergone significant changes in the last thirty years and this has led to a growing demand for mechanization. So far, the demand has been primarily for tractor plowing, and this need is being met by parallel supply systems; the heavily subsidized and state interventionist AMSEC program, and a well-developed private sector supply chain of importers, machinery service contractors (mostly farmers), and repair and maintenance shops. Table 9.4 provides a summary of the key characteristics of the two supply systems.

The private system has developed without government support, and its lynchpin is a cadre of medium- and large-scale farmers who own used tractors and hire out tractor services to smaller-scale farmers when they are not

Table 9.4. Summary of Ghana's current supply models for agricultural mechanization

\begin{tabular}{|c|c|c|c|}
\hline & & AMSECs & The private sector \\
\hline \multirow[t]{4}{*}{$\begin{array}{l}\text { Service } \\
\text { provision }\end{array}$} & $\begin{array}{l}\text { Who owns } \\
\text { machinery }\end{array}$ & Nonfarm private enterprises & Medium and larger farmers \\
\hline & $\begin{array}{l}\text { Type of } \\
\text { machinery }\end{array}$ & New tractors $(50-80 \mathrm{hp})$ & $\begin{array}{l}\text { Used tractors and some } \\
\text { subsidized new tractors }\end{array}$ \\
\hline & $\begin{array}{l}\text { Type of } \\
\text { main } \\
\text { operation }\end{array}$ & $\begin{array}{l}\text { Hiring services: mainly } \\
\text { plowing }\end{array}$ & $\begin{array}{l}\text { Self-service and hiring } \\
\text { services: plowing, carting, } \\
\text { and maize shelling }\end{array}$ \\
\hline & $\begin{array}{l}\text { Scale of } \\
\text { operation }\end{array}$ & $5-7$ tractors & $1-2$ tractors \\
\hline $\begin{array}{l}\text { Machinery } \\
\text { supply }\end{array}$ & $\begin{array}{l}\text { Key } \\
\text { supplier }\end{array}$ & Government & $\begin{array}{l}\text { Private importers for used } \\
\text { machinery, and government } \\
\text { for new tractors }\end{array}$ \\
\hline $\begin{array}{l}\text { Supply of } \\
\text { attachments }\end{array}$ & $\begin{array}{l}\text { Market } \\
\text { players }\end{array}$ & $\begin{array}{l}\text { Government for imported } \\
\text { attachments and private } \\
\text { sector for imported spare } \\
\text { parts }\end{array}$ & $\begin{array}{l}\text { Private sector; some basic } \\
\text { implements manufactured } \\
\text { domestically }\end{array}$ \\
\hline $\begin{array}{l}\text { The key role } \\
\text { of the } \\
\text { government }\end{array}$ & $\begin{array}{l}\text { Policy } \\
\text { instruments }\end{array}$ & $\begin{array}{l}\text { Direct importation and } \\
\text { distribution of new } \\
\text { machinery; heavy price } \\
\text { subsidy and no interest } \\
\text { charge on outstanding } \\
\text { payment }\end{array}$ & $\begin{array}{l}\text { Duty-free imports of new } \\
\text { and used machinery; some } \\
\text { new tractors received from } \\
\text { MoFA at the subsidized } \\
\text { price }\end{array}$ \\
\hline $\begin{array}{l}\text { Source of } \\
\text { financing }\end{array}$ & & $\begin{array}{l}\text { Concessional loans from } \\
\text { foreign countries' } \\
\text { governments }\end{array}$ & $\begin{array}{l}\text { Cash transaction in used } \\
\text { machinery and no financial } \\
\text { support to the private } \\
\text { importers }\end{array}$ \\
\hline
\end{tabular}

Source: Authors' creation based on fieldwork interviews and review of policy documents. 
required for use on the home farm. These contractor farmers interface with private firms who import the tractors, and own machinery repair and maintenance shops, which also stock spare parts. This system is working well and has created a competitive market for hiring-in services. On the other hand, the AMSEC model recently promoted by the government seems not to be viable in its present form. Many of the AMSECs have unprofitable business models and struggle to pay their debts to the government, while the constant changing of imported tractor models and a lack of spare parts undermines the demand for the subsidized tractors that the government procures through its agents.

Continuation of the AMSEC program in its present form will only add to the financial burden on the government, diminish the role of the private sector in further developing the mechanization supply chain, and lead to rentseeking behavior amongst government selected agents who import tractors or run the AMSECs.

So far, the demand for mechanization in Ghana has not evolved much beyond tractors for land preparation and for shelling maize after harvesting. As wages continue to rise and farms get larger, additional demands for mechanizing other aspects of crop production, harvesting, transportation, water pumping, post-harvest processing and the like, will inevitable grow. Meeting this demand will require a flexible supply chain, one which can develop and/or adapt a variety of machinery types and services to meet a diverse set of farmer needs that will vary by type of farm and locality. Experience in several Asian countries, where farm mechanization for small-scale farms is much more advanced than in Ghana, shows that only the private sector has the capability to develop these kinds of flexible supply chains, and that heavy-handed government interventions can be counterproductive (Diao et al. 2014).

That said, there are things the government can do to support these developments. For example, the government could do more through field demonstration and perhaps some directed credit subsidies to promote the value of yieldenhancing mechanization practices like second-plowing and harrowing, and the adaptation and uptake of smaller tractors. The government might also usefully support appropriate mechanization research and technical training of young mechanics (Diao et al. 2018). However, a key question is whether the government will be willing to recognize the dominant role played by the private sector, and especially the renting-out services provided by medium- and largescale farmers, and rethink its AMSEC program. An effective mechanization policy should aim to strengthen the entire value chain for mechanization services and not just be limited to targeting specific types of services or providers. 


\section{References}

Benin, S., M. Johnson, K. Jimah, J. Taabazuing, A. Tenga, E. Abokyi, and G. Nasser. 2012. "Evaluation of Four Special Initiatives of the Ministry of Food and Agriculture, Government of Ghana." Draft Report, International Food Policy Research Institute, Washington, DC.

Binswanger, Hans and Vernon Ruttan. 1978. Induced Innovation. Baltimore: The Johns Hopkins University Press.

Boserup, E. 1965. The Conditions of Agricultural Growth: The Economics of Agrarian Change under Population Pressure. London: George Allen and Unwin.

Diao, X., F. Cossar, N. Houssou, and S. Kolavalli. 2014. "Mechanization in Ghana: Emerging Demand, and the Search for Alternative Supply Models." Food Policy 48(2014): 168-81.

Diao, X., J. Agandin, P. Fang, S. E. Justice, D. Kufoalor, and H. Takeshima. 2018. "Agricultural Mechanization in Ghana: Insights from a Recent Field Study." IFPRI Discussion Paper 10729, International Food Policy Research Institute, Washington DC.

Ghana, CEPS (Customs, Excise and Preventive Services). 2012. Import Data.

GSS (Ghana Statistical Service). 2016. 2015. “Labor Force Survey Report.” December 2016.

Hayami, Y., and V. W. Ruttan. 1985. Agricultural Development: An International Perspective. Baltimore: Johns Hopkins University Press.

Hayami, Y., and V. W. Ruttan. 1970. "Factor Prices and Technical Change in Agricultural Development: The United States and Japan, 1880-1960.” Journal of Political Economy 78(5): 1115-41.

Houssou, N, S. Kolavalli, E. Bobobee, and V. Owusu. 2013a. “Animal Traction in Ghana." Ghana Strategy Support Program Working Paper No. 34. Washington, DC: International Food Policy Research Institute.

Houssou, N., X. Diao, F. Cossar, S. Kolavalli, K. Jimah, and P. Aboagye. 2013b. "Agricultural Mechanization in Ghana: Is Specialization in Agricultural Mechanization a Viable Business Model?" American Journal of Agricultural Economics 95(5): 1237-44; doi: 10.1093/ajae/aat026.

JICA (Japan International Cooperation Agency). 2015. “Expert on Smallholder Farmers' Access to Agriculture Mechanization in Ghana-Project Completion Report." Tokyo.

Pingali, P., Y. Bigot, and H. Binswanger. 1987. Agricultural Mechanization and the Evolution of Farming Systems in Sub-Saharan Africa. Washington, DC: World Bank.

Ruthenburg, H. 1980. Farming Systems in the Tropics. Oxford: Oxford University Press. 
Seager, P. J., and R. S. Fieldson. 1984. "Public Sector: Tractor Hire and Equipment Hire Schemes in Developing Countries." Paper Prepared by the Overseas Division of NIAE.

USAID/ACDI-VOCA. 2013. "ADVANCE Tractor Census of Northern Ghana." Washington, DC. 


\title{
10
}

\section{Future Prospects}

\author{
Xinshen Diao, Peter Hazell, Shashidhara Kolavalli, \\ and Danielle Resnick
}

\subsection{Introduction}

This final chapter pulls together the main findings of the book, highlights future challenges and opportunities for Ghana, and provides some guidance on the kinds of strategic changes that might help the country's efforts towards more sustained structural change. It also concludes with some reflections on what the Ghanaian experience suggests for the rest of Africa.

\subsection{Economic Prospects and Options}

\subsubsection{The National Economy}

As reviewed in Chapter 2, Ghana has followed a slow but steady growth transformation since its Structural Adjustment Program (SAP) of the 1980s, and national income has grown by 5.4 percent per annum on average (or 2.8 percent per capita) for over thirty years. This growth has been driven mainly by growth in labor productivity within sectors rather than the transfer of workers from low-productivity sectors like traditional agriculture to highproductivity sectors like modern manufacturing. In Rodrik's (2014) terminology, Ghana has benefited more from improvements in its fundamentals than from structural change. This is the result of a policy regime since the SAP focused on creating the enabling conditions for private-sector-led growth rather than many proactive state interventions in production. Although many workers have left agriculture, they have mostly moved into lowproductivity jobs in the service sector, and this has added little to average labor productivity. Contrary to the Asian pattern of transformation, Ghana's industrial sector has stagnated rather than grown, and failed to create the highproductivity, less-skilled jobs in manufacturing that helped transform Asian living standards. 
The agricultural sector has also performed reasonably well since the SAP, and grew by 4.5 percent per annum over 1994-2013. The cocoa sector grew by 5.6 percent per annum over this period, and remains a major source of foreign exchange. It also continues to produce high-quality beans that attract a price premium in the world market. The noncocoa subsector has also grown successfully, particularly roots and tubers and other agriculture (4.9 percent and 5.6 percent per annum, respectively). However, agricultural growth has been driven more by land expansion than agricultural intensification. Although labor productivity has increased through use of mechanization and other labor-saving technologies, Ghana has yet to widely adopt gamechanging technologies that can significantly increase yields and land productivity, or to invest adequately in post-harvest handling and quality control. As a result, much of the noncocoa subsector is not internationally competitive, and struggles to compete with many imported foods or to expand into the export of commodities other than cocoa.

This pattern of "transformation without industrialization" has important implications for future growth opportunities. While the economy will continue to benefit from growth in within-sector productivities, these are likely to remain modest without significant new investments and technologies. In the case of agriculture, even past rates of productivity growth will become unsustainable without a major shift to land-intensification technologies as the land frontier is exhausted. Just to maintain, let alone accelerate, past levels of economic growth, Ghana will need to tap into new sources of productivity growth as well move more workers from low- to higher-productivity sectors. This means growing high-productivity sectors like manufacturing, modern agriculture, and formal services. However, this strategy faces demand as well as supply-side challenges.

On the demand side, high-productivity sectors can only expand if there is an adequate market. The best markets are export markets because demand is then highly elastic. One option is for Ghana to expand its traditional exports of cocoa, gold, and oil. Another is to develop new exports, such as manufactured goods and nontraditional agricultural exports. There is also scope to produce manufactured and agricultural goods that can substitute for imports, at least until those substitution opportunities have been exhausted. Growth in most other sectors will be constrained by growth in domestic demand, and relying heavily on these would effectively mean a "balanced growth" strategy for Ghana in which sectors that produce predominantly nontradables could only grow in proportion to growth in their domestic demand. For agriculture, which apart from cocoa faces an inelastic aggregate demand, this may mean that growth of the noncocoa subsector would hit a ceiling at around 6 percent 
per annum (Breisinger et al. 2012), beyond which the domestic terms of trade would turn against agriculture and act as a break on further growth. It will also be hard for the national economy to grow much faster than its past average without a significant increase in exports.

On the supply side, it seems likely that as a result of recent discoveries and investments in oil, oil exports will expand and provide an important, if volatile, source of government revenue. But its contribution to national per capita GDP is likely to remain small, and the sector is not likely to create much additional employment. Much the same is true for gold and other mineral exports. While these opportunities should of course be seized, the better opportunities for achieving structural change with growth in productive employment appear to lie with manufacturing and agriculture, both for export and import substitution.

However, manufacturing has shrunk in Ghana since the SAP, while the industrial sector at large has stagnated. Major constraints include the business environment, high transport costs, inadequate and costly port facilities, unreliable power supplies, inadequate access to finance, difficulties in obtaining land rights, high labor costs, and weak or ineffective industrial policies and state-business relationships. These constraints make it difficult for Ghanaian manufacturing firms to compete with imports, let alone expand into export markets. There is some recent indication of foreign investments in the assembly of bulky products such as tractors and cars imported into Ghana, and an Indian tractor company has opened a small unit. But, whether all of this will turn into significant assembly in the country remains to be seen.

Agro-processing, which is a major component of the manufacturing sector, offers brighter prospects because of its potential to substitute for imports in meeting a rapidly growing domestic demand for processed and pre-cooked foods. A fairly high share of processed foods on Ghanaian shelves are imports, even in smaller towns away from the ports (Andam et al. 2018). Ghanaian firms are producing niche products such as fufu flour and banana chips. They might also be able to export into the regional West African market. But the local processing sector, which is predominantly engaged in primary processing such as drying and milling, is not doing well. Employment in the sector shrank between 2014 and 2017 from an average of thirty workers to twenty-one workers per firm (Andam and Asante 2018). The sector is held back by many of the same constraints as manufacturing in general, as well as challenges in obtaining reliable supplies of raw materials of the right qualities from farmers. Its growth potential is therefore closely linked to a successful agricultural transformation that can produce raw materials of the right quality and at competitive prices. 


\subsubsection{Agriculture}

The agricultural sector is still a major employer in Ghana, and while its labor productivity has about doubled since 1991 since the SAP, it is still lower than all other sectors except trade and personal services. However, it has good growth potential, both by expanding into growing markets and also by transitioning from traditional to improved technologies that could enhance its productivity and competitiveness.

Some of the best growth opportunities from the demand side are as follows:

- Further growth in cocoa exports. However, expansion of the cocoa area is reaching its limit and further growth has mainly to come from replacement of older trees with high-quality cocoa trees that can give higher yields while sustaining, perhaps improving the country's reputation for high-quality cocoa beans. This will require carefully rebalancing the use of cocoa revenues to more effectively supply critical inputs, including superior performing cocoa trees, while also maintaining adequate aftertax price incentives for growers (Kolavalli and Vigneri 2017). While productivity increases are needed, major producing countries such as Ghana and Côte d'Ivoire are becoming aware of the risks of cocoa supplies outpacing international demand, putting downward pressure on prices, as happened in 2016. Along with efforts to increase productivity, farmers need to be assisted to diversify so that they can better weather price volatility.

- Expansion of nontraditional exports like pineapples, mangoes, and vegetables. The biggest challenges here are producing high-quality produce at competitive prices, and delivering them to international markets in the same condition.

- Import-substitution opportunities exist for a wide range of commodities, particularly rice, yellow maize, poultry, vegetables, fish, and livestock, but they need to become more competitive in cost and quality. For example, vegetable yields in Ghana are significantly lower than in neighboring countries, all of whom participate in a regional market that is well integrated (van Asselt et al. 2018a). This in turn requires increased productivity to reduce production costs, improved quality to match those of imports, and improved marketing and distribution channels.

- Growing domestic demand for more nutritious and often perishable foods like fruits, vegetables, and livestock products, many of which are 
ideal for smallholders to grow because they give high returns per hectare of land. For example, gross margins for tomatoes, onions, carrots, and scotch bonnet peppers are considerably greater than those of rice and maize (van Asselt et al. 2018a).

- Leveraging growth in Ghana's broader agri-food system. With rapid urbanization and changing diets, including consumption of more processed and precooked foods, and eating out, there is opportunity for agribusiness to add considerable post-farm-gate value to the foods consumed by urban people. The "quiet revolution" observed in the food systems of some East African and Southern African countries whereby small- and medium-sized enterprises (SMEs) are rapidly populating value chains is surely indicative of the changes Ghana can expect (Reardon 2015; Reardon et al. 2014). Agro-processing should be a major beneficiary of this food system transformation as long as it can develop in ways to compete with processed food imports.

Complementing all these demand-side opportunities is a considerable supply-side opportunity to raise agricultural productivity and increase competitiveness by shifting to improved technologies and farming practices. Yields and land productivity are still low in Ghana, and have increased only modestly since 1991. Many available technology and irrigation potentials for improving productivity have barely been tapped. For example, yield gaps between demonstrated potentials and realized averages are around 40 percent for cereals and 20 percent for legume crops (Breisinger et al. 2012). Some imported maize hybrids yield as much as 5 tons per ha, yet the average maize yield remains below 2 tons per ha (van Asselt et al. 2018b). An important reason is that less than 5 percent of the maize area is planted with improved varieties including hybrids, and the average age of the varieties grown is more than twenty years (Ragasa et al. 2013). Although farmers have replaced nearly all of the traditional varieties of most crops, they are not replacing them fast enough with better varieties.

However, these new opportunities also come with at least three key challenges that need to be confronted. First, the land frontier is tightening. Therefore, continued agricultural growth will become unsustainable without a significant technological transition to the kinds of intensification technologies and farming practices that lead to growth in land as well as labor productivity. Second, labor costs in agriculture are being pulled up by urbanization and competition from the rural nonfarm economy. The available workers are also getting younger and better educated, and less interested in 
traditional farming. This means that labor-intensive technologies, while still used by smallholders growing cocoa and other higher-value crops, are becoming less relevant for low-value crops like cereals and root crops and more so for most medium- and large-sized farms.

Third, the private sector is now in the driving seat along most agricultural value chains, and the public sector must learn to work more effectively with it. Except for the cocoa sector, many Ghanaian farmers have shifted away from weakened public systems to private sector enterprises for accessing their modern inputs, finance, and urban markets. This shift has also been embodied within many recent agricultural development projects promoted both by donors and the government that seek to leverage key private actors in value chains to provide better services to smallholders. However, apart from a relatively small share of farms that are embedded in contract-farming arrangements with large agribusinesses, most small farms depend on SMEs and noncontractual arrangements for linking to markets in value chains. Strengthening these linkages through policy reforms and public support rather than undercutting them provides an opportunity not only to increase efficiency and competitiveness along value chains, but also to generate a more inclusive and employment-intensive transformation within the agri-food system (AGRA 2017).

Relatedly, there is also new interest from large international and regional agribusinesses in Africa's food chains, as exemplified by the commitments made under the New Alliance for Food Security and Nutrition and the efforts of the Grow Africa Investment Forum. Ghana has joined both initiatives, and is actively encouraging such foreign investment. Large agribusinesses can play important roles in developing internationally competitive value chains because of their greater access to new technologies from outside the country (like hybrid seeds), and their scale and market power to develop and enforce quality standards along value chains, or to penetrate into export markets. Despite the promise, Ghana has yet to take any significant advantage of such foreign investments.

What would it take for Ghana to seize the available and growing opportunities within agriculture and the broader agri-food system? Many of the desired changes have been identified and discussed in previous chapters, and here we simply highlight some of the key roles for the public sector:

- Providing enabling policies. Ghana has done reasonably well since the 1980s in maintaining favorable price and trade policies for agriculture. Though the government still leans towards keeping the provision of some 
key services for farmers within the public sector, SMEs now play much bigger roles along value chains, particularly in downstream agribusiness. The government should encourage this trend, and allow private enterprises to take on more of these roles. This will require improvements in the enabling environment for both small and large businesses, and the development of more effective state-business relationships, including with SMEs and small traders.

- Rural infrastructure. Past public investments in rural infrastructure have given good returns, and the government has invested heavily in road and other infrastructure in the recent years. However, additional spending is needed on rural roads, farm tracks connecting farms to communities, electrification and energy, cold storage, urban marketplaces, and port facilities. The benefits from improved road connections are illustrated by the spontaneous development of motorized tricycle services, which have now become widely available in the north for transporting crops from fields to homestead and for bringing people to urban centers and market towns. Better marketing links have also helped households diversify away from staple crops, increase the area they cultivate, and produce and sell more home-processed foods (Mueller, Masias, and Vallury 2018).

- Land policy reforms are needed to ensure farmers have secure access to land, reduce land disputes, facilitate land transfers in both rural and urban areas, and enable agribusinesses to obtain land for commercial development. While long-term formal land-leasing arrangements have become increasingly popular, and institutions such as land banks that could reduce transaction costs for buyers and give landowners fair returns have been talked about and developed to various degrees, these efforts need to be sustained by more transparent land governance and policies. $^{1}$

- Better regulation of modern farm inputs like seeds, herbicides, and fertilizers for quality and safety. Farmers need to be protected from dangerous chemicals, and assured that the inputs they buy are genuine and of acceptable quality (e.g., seeds need to be of the promised variety, disease free, and have acceptable germination rates).

- Investing more in agricultural R\&D. Apart from cocoa, Ghana has seriously underinvested in its agricultural $R \& D$ system and urgently needs to increase its spending and strengthen the capabilities of the national

\footnotetext{
${ }^{1}$ https://ghanaguardian.com/sada-lures-investors-land-bank.
} 
research institutions. Some of the maize varieties released in recent years, for example, do not perform any better than older maize varieties (van Asselt et al. 2018b). The research system needs financially sustainable strategies for developing, testing, and disseminating superior seed varieties, for responding to climate change, and to expand the scope of its work to support farmer diversification into higher value products for the domestic and nontraditional export markets. Research practices also need to be improved to provide better channels of communication between farmers and researchers about research needs and the effectiveness of newly developed research products like seed varieties.

- Improve agricultural extension. The government has hired more extension agents in recent years but extension is only as effective as the technologies available to agents to extend. Preliminary results from an experiment in northern regions of Ghana, for example, suggest that the use of effective extension methods to disseminate best practices for growing maize with existing varieties did not result in increased yields or profits, although farmer knowledge and practices were improved (Udry 2018). ${ }^{2}$ Moreover, despite the devolution of agricultural extension to the local government level in recent years, there is still an urban bias in the distribution of extension agents across the country (Resnick 2018).

- Seed systems. In addition to strengthening the public R\&D system, a recent IFPRI study has shown a need to make complementary improvements in the seed delivery system (Tripp and Ragasa 2015). These include: a) maintaining pure lines that are accessible to private breeders; b) strengthening the functioning of critical institutions in the seed sector, such as the National Seed Council; c) providing more effective coordination and regulation; d) guaranteeing the availability of foundation seeds; and e) ensuring the integrity and pureness of seeds sold to farmers. Regulation is still weak: seed certification and getting spurious seeds off the market remain critical. There still is not a viable mechanism for production of foundation seeds beyond the research, which has made the transfer of genetic material from the public to private sectors unreliable. The entry of a large African seed company that wants to serve the region based in Ghana has the potential to overcome some of the problems faced by Ghanaian seed producers. International seed companies have their own varieties and capabilities for testing them for local

\footnotetext{
${ }^{2}$ https://www.atai-research.org/wp-content/uploads/2018/07/Udry-DIRTS-overview.pdf.
} 
suitability, whereas local seed companies must typically depend on the antiquated public sector facilities for testing. The presence of a regional player in the country can also be expected to hasten the approval of regional harmonization policies on seed standards.

- Fertilizer and soil and nutrient management. Fertilizer use in Ghana is still low and is widely used to offset soil fertility losses arising from shortened fallow periods rather than to increase crop yields. Returns to its use could be improved by more widespread soil testing and mapping so that fertilizer dealers and farmers can better match fertilizer blends with regional soil nutrient deficiencies. To sustain soil fertility, its use also needs to be complemented with improved soil and nutrient management practices, including crop rotations and precision farming. Improved soils would also enhance crop yield response to fertilizer. Initial public investments can attract private investments; e.g., creating a demand for soil testing can lead to private labs, fertilizer firms can be required to produce location specific fertilizers. A positive development is that several donorsupported projects and private companies working with local research organizations have developed region- and crop-specific information and identified fertilizer formulations that might be suitable for various regions. Simultaneously, there have been efforts to develop soil fertility mapping including by Optimizing Fertilizer Recommendations in Africa (OFRA) supported by the Alliance for a Green Revolution in Africa (AGRA). ${ }^{3}$ Ghana is also negotiating with a large company to blend formulations in the country and also manufacture fertilizers.

- Mechanization. The demand for mechanization services, especially tractors for plowing, has grown rapidly in recent years and this demand is currently met by parallel public and private systems. As reviewed in Chapter 9, the private system has developed without government support, and is working well and has created a competitive market for hiringin services. On the other hand, the AMSEC model recently promoted by the government seems not to be viable in its present form. It would be better if the government were to phase out the AMSEC program, and focus its efforts on supporting the private sector by funding appropriate mechanization research, technical training of young mechanics, and ensuring that financial institutions can provide the longer-term lending needed by private agents and farmers in the mechanization supply chain.

\footnotetext{
${ }^{3}$ http://africasoilhealth.cabi.org/wpcms/wp-content/uploads/2017/03/OFRA-book-low-res.pdf.
} 
Of particular benefit would be research to support the mechanization of "control" operations such as seeding, fertilizer application, and harvesting, which can be expected to encourage the adoption of improved agricultural practices or intensification while reducing overall labor requirements. Better utilization of tractors for a range of operations would also make provision of tractor services much more remunerative.

- Irrigation has long been ignored in Ghana, and only about 3 percent of the crop area is irrigated, or less than 20 percent of the irrigable potential. Yet irrigation has a key role to play in increasing land productivity, facilitating the adoption of more intensive technologies, and helping to manage increasing weather risks. A lot of public sector money has gone into rehabilitating old, badly designed surface irrigation systems, and better options may lie in promoting small scale irrigation investments in wells, river lifts, and water harvesting at community levels.

- Financial services. At present, the formal financial sector provides little credit to smallholders other than cocoa growers. Banks are reluctant to lend for agricultural activities, which are perceived to be risky, and when commercial bank loans are available, interest rates range from 30-35 percent, in addition to a hefty administrative fee. SMEs in agribusiness also report that access to finance is a major constraint for them. Publicly provided credit guarantees, insurance or co-financing can be helpful for reducing risk along value chains, and making small farms more attractive to agribusinesses (Varangis et al. 2017). The government has launched the Ghana Incentive-Based Risk-Sharing System for Agricultural Lending (GIRSAL) ${ }^{4}$ to underwrite $20-30$ percent of the agriculturally related default risks assumed by lending institutions, and to help them develop more appropriate credit products.

- Coordination along value chains. Apart from cocoa, the value chain for which is successfully controlled by Cocobod, there are serious market failure issues in many other value chains that prevent the development of grading systems, value chain financing, and export marketing channels. This makes it difficult for domestic products to compete internationally in export markets or to displace more imports. As discussed in Chapter 8, in most cases marketing boards do not appear to be a relevant solution, and there have been several recent attempts to find more flexible

\footnotetext{
${ }^{4}$ http://www.ghana.gov.gh/index.php/media-center/news/3165-bank-of-ghana-launches-girsalscheme.
} 
institutional structures that can facilitate and encourage coordination and the development of non-market relationships among value chain actors, but without undermining a basic laissez-faire approach to the market. Some recent projects in Ghana, such as the Northern Rural Growth Project (NRGP) and the Market-Oriented Agricultural Project (MOAP), have enabled various actors in value chains to interact with each other by organizing value chain committees, but how effective they are remains to be seen. Preliminary findings suggest that the mere offer of platforms for exchange does not lead to technical or institutional innovations.

- Linking small farms to value chains. SMEs are the main entry point for most small farmers to obtain modern inputs or to link to urban markets, so policies that assist the growth of SMEs can be an indirect way of helping small farmers. Such interventions might include improving SME access to credit, and providing training in business management skills. Many value chain development projects including the USAID-funded ADVANCE have sought to strengthen the operations of aggregators/ traders, processors, and tractor service providers through training and grants. Larger agribusinesses tend to avoid linking with many small farms because of the higher transaction costs and uncertainties involved compared to working with larger commercial farms. To overcome this impediment, one option is for small farms to be organized into producer organizations that can link with large agribusinesses, and there have been many attempts to do this in Ghana through the formation of Farmer Based Organizations (FBOs). However, the results have not been encouraging. Many agribusinesses have done it to various degrees on their own, but since, as one firm manager commented, it involves building relationships and trust not just writing contracts, it is not clear how public interventions can help scale up such arrangements.

\subsection{Resources, Politics, and Practicalities}

How likely is it that Ghana will or could adopt an agricultural transformation agenda along the lines suggested above? Fundamentally, the government would need to increase its level of investment in agriculture, take a more proactive role in guiding the agricultural transformation and overcoming 
market failures along important value chains, while at the same time supporting and building stronger alliances with the private sector. There are political as well as economic challenges involved.

Currently the government spends $4-5$ percent of its total budget on agriculture, but the lion's share of that goes to the cocoa subsector. Ideally, this share should be increased to meet the CAADP target of 10 percent, but increasing government spending on agriculture or other agriculture-related development activities will be difficult now that the country is facing serious macroeconomic imbalances (World Bank 2017). Investments therefore must be strategic, focused, and more efficient. There is scope to increase the effectiveness of public spending if many of the off-budget projects funded by donors were better coordinated with each other and with the government's own investments. But differences in the development approaches taken by different donors and the government necessarily limit the extent to which they would be willing to align their programs and pool resources.

Another constraint is a weak state capacity for designing and implementing a more proactive and comprehensive development approach. As reviewed in Chapter 3 , this capacity remains weak despite several past efforts to strengthen the civil service. It is also a barrier to the more effective public-private partnerships that are needed for developing value chains and reaching out to more smallholders and SMEs.

Adding to the challenge of the state's capabilities is the recent decision to devolve responsibility for agricultural policy formulation and implementation from the central Ministry of Food and Agriculture to the District Directors of Agriculture (DDAs) who are located in the country's 254 Metropolitan, Municipal, and District Assemblies (MMDAs). This has real implications for how and whether nationally defined objectives for agricultural transformation can be feasibly implemented. On the one hand, devolution promises to improve citizen oversight over policy priorities and enable farmers to have greater input into the agricultural policy process. On the other hand, staff capabilities may be even weaker at these devolved levels; recent research finds that since agriculture functions officially were devolved in 2012, there have been declines in agricultural extension staff and a general reduction in actual expenditures for the agricultural sector in favor of increased expenditures on visible public works projects that appeal to rural voters (Resnick 2018).

What other options are there for a proactive government effort that can cut across ministries and take a more holistic system view of the development challenges? Rather than trying to drive the entire agricultural sector forward at the same time, with all the public sector capabilities and financial resources that requires, there is growing interest today in more focused "first mover" 
strategies. A first mover might be a nontraditional export crop or a priority food staple that must compete with imports, and the idea would be to concentrate resources and effort on selected value chains and drive these hard for growth and employment creation. There can also be a regional dimension to first movers, for example, starting in high potential areas that have the best infrastructure, market access, and agricultural growth potential. Another spatial approach is the development of agro-corridors, agro-clusters, agro-industrial parks, and agro-based special economic zones. These typically use agro-processing as a driving industry, and seek to make links back to smallholders through various forms of out-grower or contract-farming arrangements. A first mover approach can lead to quick wins in terms of income and employment, and their visibility can also be good for developing political momentum and support for agriculture; government ministers and donors love successes. And once the first movers have been successfully launched and rural incomes and employment are rising, then attention can shift to other activities, regions, and goals.

A first mover strategy is not new. It is very similar to the Asian Green Revolution strategy, where an initial thrust on import substitution for wheat and rice grown in the best-irrigated areas led the successful rural transformation that followed (Rosegrant and Hazell 2000). It has also been used in Asia to drive nontraditional export crops (e.g., Vietnam used the approach to develop coffee production, moving from zero production to a major world exporter over little more than a decade). It has also been tried in Africa in the past (e.g., presidential initiatives for specific commodities, and integrated rural development projects) but with mixed success. What makes it a new and promising approach today is that it can build on embedded market liberalization policies and stronger private sector roles. First mover approaches provide platforms that enable relevant public and private sector players to come together to better serve groups of smallholder farms, while enabling public and private investments in infrastructure and supporting services to achieve critical levels. Moreover, because policymaking in Ghana has become more decentralized and communities and local governments have greater say, some regions are more ready for development projects than others.

\subsection{Recent Developments}

In an encouraging recent development, the government has elevated its level of support for agricultural transformation. However, less encouragingly, key 
components of the new strategy do not align well with the agenda outlined in Section 10.3.

Although Ghana participates in the CAADP process and has a country compact and a National Agricultural Investment Strategy (NAIS), these are not well developed and do not seem to guide the government's actual strategy for agriculture. The current administration came to power promising an explicit strategy for the inclusive transformation of small farms with emphasis on the development of agro-processing. It is implementing three centrally driven agriculture- and industry-related programs that are expected to benefit all the districts: planting for food and jobs (PFJ), "one village one dam," and "one district one factory." The political leadership including the minister and the president is fully behind the programs. It is also holding itself politically accountable by tying these programs to the party's manifesto. Apart from the ambitious PFJ, the vice president also announced recently that Ghana is preparing a Marshall plan for agriculture.

The PFJ aims to increase productivity by encouraging the use of improved seeds and fertilizers (MoFA 2017). The program has five pillars-seeds, fertilizers, extension, marketing, and e-agriculture, but at the heart of it is subsidized supply of seeds and fertilizers. In many ways it is a scaled-up version of strategies Ghana has followed in the past, with minor differences. Many of the past strategies, particularly the one implemented immediately after gaining independence and the "Operation Feed Yourself" implemented in the 1970s, focused on mechanization and the development of large-scale private and state farms. PFJ on the other hand, seeks to pass on subsidized inputs to thousands of farmers in every district in the country.

By supporting the production of seven crops and addressing various issues-extension, markets, and production costs-the program lacks focus. It is not designed to overcome market failures in any specific value chains, but merely to reduce costs to boost the use of fertilizers and seeds. It is an improvement over the fertilizer subsidy programs implemented thus far in that it also encourages the use of improved seeds. But it is not targeted, so will subsidize substantial amounts of fertilizer that would be used anyway, and where it does induce additional fertilizer and seed use, it remains unclear as to whether farmers would continue to use those inputs if the subsidies were removed. Otherwise, as in the past it will be a program of "subsidized fundamentals" through which input use may be increased in the short run without overcoming bottlenecks that may exist in these chains. In parallel, donors are supporting commodity-based projects but because of the very nature of projects, they lack the continuity and the flexibility to effectively develop value chains. 
The government's assumption of the supplier of inputs also reverses the trend in which farmers were becoming market oriented and private sector was developing slowly. Farmers will continue to see the state as the supplier of credit and inputs and the buyer of last resort. Although inputs are purchased from private companies, the private sector becomes tethered to the state, grateful for the business opportunities and its existence. Whether the program will serve as a state-led market development for private sector will depend on whether technologies that are pushed through the project can be sustained without subsidies.

The design of the other two programs, the "one village one dam" and the "one district one factory" to appeal to the electorates all over the country compromises their effectiveness. In addition to the difficulties in adequately financing them, spreading investments over a large area is likely to dilute their potential impact and returns. For example, carefully sited larger irrigation systems are likely to be more productive than small dams in each village, unless the objective is to meet domestic water requirements. Similarly, significant support for processing of a few critical agricultural products in priority districts is likely to be more effective than spreading limited resources uniformly across all districts, unless there are significant investment opportunities in every district to choose from. While the programs are politically appealing and address some real concerns, Ghana is missing an opportunity to use its limited resources to more selectively intervene in critical areas to trigger private-sector-led innovations that can sustain an agricultural transformation.

\subsection{Implications for Other African Countries}

Ghana's economic growth story is particularly relevant because there are key parallels with many other countries in Africa. Despite being unusually blessed in its endowment of minerals and natural resources, and having easy access to world shipping lanes, Ghana is experiencing the same pattern of rapid urbanization without industrialization that is ongoing across most of Africa. Moreover, Ghana is typical of other African countries in that it has not experienced a widespread agricultural revolution, even though the sector is still a major employer. While the agriculture sector has grown at a reasonable rate, it continues to be only a major cocoa exporter, and is becoming increasingly dependent on imported foods. Recent agricultural growth has been achieved mainly through land expansion rather than the uptake of higher-yielding technologies. While labor productivity is growing in agriculture, the sector 
still has one of the lowest labor productivities in the economy, which is also true in many other African countries.

Countries, especially smaller ones like Ghana, cannot get rich by producing predominantly nontradable goods and services. Instead, modern agriculture and agri-business, either for export or import substitution, offer opportunities to Africa for future prosperity. However, Ghana's past experience shows the consequences of neglecting agriculture in the post-SAP era. Despite its rich agricultural endowments and potential, Ghana like most Africa countries has not invested sufficiently in such basics for agricultural development as $R \& D$, irrigation, rural roads, transport and storage systems, and rural financial systems, all of which are needed if the private sector is to successfully lead an agricultural transformation.

Nonetheless, Ghana is unusual by African standards in that it has experienced over three decades of stable and democratic government, during which time it has also worked to develop an enabling environment to attract the private sector. If any country can be seen as a test case of the Washington Consensus approach that guided the SAP reforms, then Ghana is it. And the verdict is that while a focus on enabling policies appears necessary for achieving the kinds of rapid economic growth seen in Asia, it is not sufficient. Moreover, today's globalization has challenged many late developers, including African countries, which are facing limited opportunities for export manufacturing; together with import competition at home, industrialization becomes much more difficult in Africa than it was in previous decades in much of Asia.

Encouragingly, African governments are slowly rediscovering the importance of their agricultural sectors and the need to transform them through more productive technologies, and the CAADP process is an encouraging step in bringing some political pressure to that end. Several key donor agencies are also backing agricultural development again after a long respite. A focus on first-mover strategies that lead to quick and visible successes despite weaknesses in public sector capabilities might also help develop greater political momentum in support of agriculture. But perhaps the best hope lies in the fact that the ongoing changes in Africa's food system are creating a wealth of new opportunities not only for farmers, but also for a growing agribusiness sector. Due to rapid urbanization and rising incomes, there has been a shift in patterns of food demand that is driving rapid growth in a swath of agribusinesses that move foods from rural to urban areas, and process and distribute them in ways that is adding considerable value addition beyond the farm gate. The World Bank has estimated that agribusiness in Africa will 
be worth about $\$ 1$ trillion by 2030 (in 2010 prices), or over $\$ 1,000$ per African. That is a huge market opportunity to be seized, and does not include the additional value of agricultural production that will be required to supply the agribusiness sector.

The sheer size of these opportunities also has been recently recognized in two Africa-wide studies (ACET 2017; AGRA 2017), and they may be large enough to spark a new political dynamic built on complementary public and private sector interests, leading to new investments and partnerships and supporting policies. If so, governments in African countries need to play more proactive roles in partnership with the private sector to fix market and institutional failures along important value chains that constrain private sector development and the effectiveness of market solutions. And they need to do all this while prioritizing small farms and SMEs to ensure that the agricultural transformation is inclusive and employment-intensive.

\section{References}

Andam, Kwaw S., David Tschirley, Seth B. Asante et al. 2018. “The Transformation of Urban Food Systems in Ghana: Findings from Inventories of Processed Products.' Outlook on Agriculture (3): 233-43.

Andam, Kwaw S. and Seth B. Asante. 2018. "Firm Employment, Exit, and Growth in the Food-processing Sector: Evidence from Ghana.” IFPRI Discussion Paper No. 1755. Washington, DC: International Food Policy Research Institute.

Alliance for a Green Revolution in Africa (AGRA). 2017. “African Agriculture Status Report 2017: The Business of Smallholder Agriculture in Sub-Saharan Africa." Nairobi: AGRA.

African Center for Economic Transformation (ACET). 2017. “African Transformation Report 2017: Agriculture Powering Africa’s Economic Transformation.” Accra: ACET.

Breisinger, C., X. Diao, J. Thurlow et al. 2012. “Ghana," in X. Diao, J. Thurlow, S. Benin, and S. Fan (eds), Strategies and Priorities for African Agriculture: Economywide Perspectives from Country Studies. Washington, DC: IFPRI, 141-64.

Diao, Xinshen, Margaret McMillan, and Dani Rodrik. 2017. “The Recent Growth Boom in Developing Economies: A Structural Change Perspective." NBER Working Paper No. 23132. Available at: http://www.nber.org/papers/w23132.

Houssou, Nazaire, Collins Asante-Addo, Kwaw S. Andam, and Catherine Ragasa. 2018. "How Can African Governments Reach Poor Farmers with Fertiliser Subsidies? Exploring a Targeting Approach in Ghana." The Journal of 
Development Studies. Article in press. Available at: https://doi.org/10.1080/ 00220388.2018.1528353.

Kolavalli, Shashidhara, and Marcella Vigneri. 2017. "The Cocoa Coast: The Board-managed Cocoa Sector in Ghana." Washington, DC: International Food Policy Research Institute.

Ministry of Food and Agriculture (MoFA). 2017. "Planting for Food and Jobs: Strategic Plan for Implementation (2017-2020).” Accra: Republic of Ghana.

Mueller, V., I. Masias, and S. Vallury. 2018. "Labor-Saving Technologies and Structural Transformation in Northern Ghana." Working Paper. Washington, DC: International Food Policy Research Institute.

Nutsukpo, Delali Kofi, Abdulai Jalloh, Robert Zougmoré et al. 2013. “Ghana,” in: Abdulai Jalloh, Gerald C. Nelson, Timothy S. Thomas et al. (eds), West African Agriculture and Climate Change: A Comprehensive Analysis. Washington DC: International Food Policy Research Institute, 141-72.

Ragasa, Catherine, Awere Dankyi, Patricia Acheampong et al. 2013. "Patterns of Adoption of Improved Maize Technologies in Ghana." GSSP Working Paper No. 36. Washington, DC: International Food Policy Research Institute.

Reardon, T., D. Tschirley, B. Minten et al. 2014. "Transformation of African Agrifood Systems in the New Era of Rapid Urbanization and the Emergence of a Middle Class" in O. Badiane and T. Makombe (eds), Beyond a Middle Income Africa: Transforming African Economies for Sustained Growth with Rising Employment and Incomes. ReSAKSS, Annual Trends and Outlook Report 2014. Washington, DC: IFPRI, 62-74.

Reardon, Tom. 2015. "The Hidden Middle: The Quiet Revolution in the Midstream of Agrifood Value Chains in Developing Countries." Oxford Review of Economic Policy 31(1): 45-63.

Resnick, D. 2018. “The Devolution Revolution: Implications for Agricultural Service Delivery in Ghana.” IFPRI Discussion Paper No. 1714. Washington, DC: International Food Policy Research Institute.

Resnick, D., and N. M. Mason. 2016. "What Drives Input Subsidy Policy Reform: The Case of Zambia, 2002-2016.” IFPRI Discussion Paper No. 01572. Washington, DC: International Food Policy Research Institute.

Rodrik, D. 2014. “The Past, Present, and Future of Economic Growth,” in Franklin Allen et al., Towards a Better Global Economy: Policy Implications for Citizens Worldwide in the 21st Century. Oxford: Oxford University Press, 70-133.

Rodrik, Dani. 2017. "Growth without Industrialization.” Project Syndicate. October 10. Available at: https://www.economics.utoronto.ca/gindart/201710-10\%20-\%20Growth\%20without\%20industrialization.pdf.

Rosegrant, M., and P. Hazell. 2000. Transforming the Rural Asian Economy: The Unfinished Revolution. Oxford: Oxford University Press for the Asian Development Bank. 
Tripp, Robert, and Catherine Ragasa. 2015. "Hybrid Maize Seed Supply in Ghana.” GSSP Working Paper No. 40. Washington, DC: International Food Policy Research Institute.

Varangis, P., R. Chen, and T. Ono. 2017. "Strengthening Financial Systems for Smallholders," in African Agriculture Status Report 2017: The Business of Smallholder Agriculture in Sub-Saharan Africa. Nairobi: AGRA, 65-88.

van Asselt, Joanna, Ian Masias, and Shashi Kolavalli. 2018a. "Competitiveness of the Ghanaian Vegetable Sector: Findings from a Farmer Survey." GSSP Working Paper No. 47. Washington, DC: International Food Policy Research Institute.

van Asselt, Joanna, Federica Di Battista, Shashi Kolavalli, and Christopher Udry. 2018b. "Agronomic Performance of Open Pollinated and Hybrid Maize Varieties: Results from On-farm Trials in Northern Ghana.” GSSP Working Paper No. 44. Washington, DC: International Food Policy Research Institute.

World Bank. 2017. “Ghana Country Report.” Washington DC: World Bank. Available at: http://www.worldbank.org/en/country/ghana/overview. 



\section{Index}

Note: Tables and figures are indicated by an italic $t$ and $f$ following the page number.

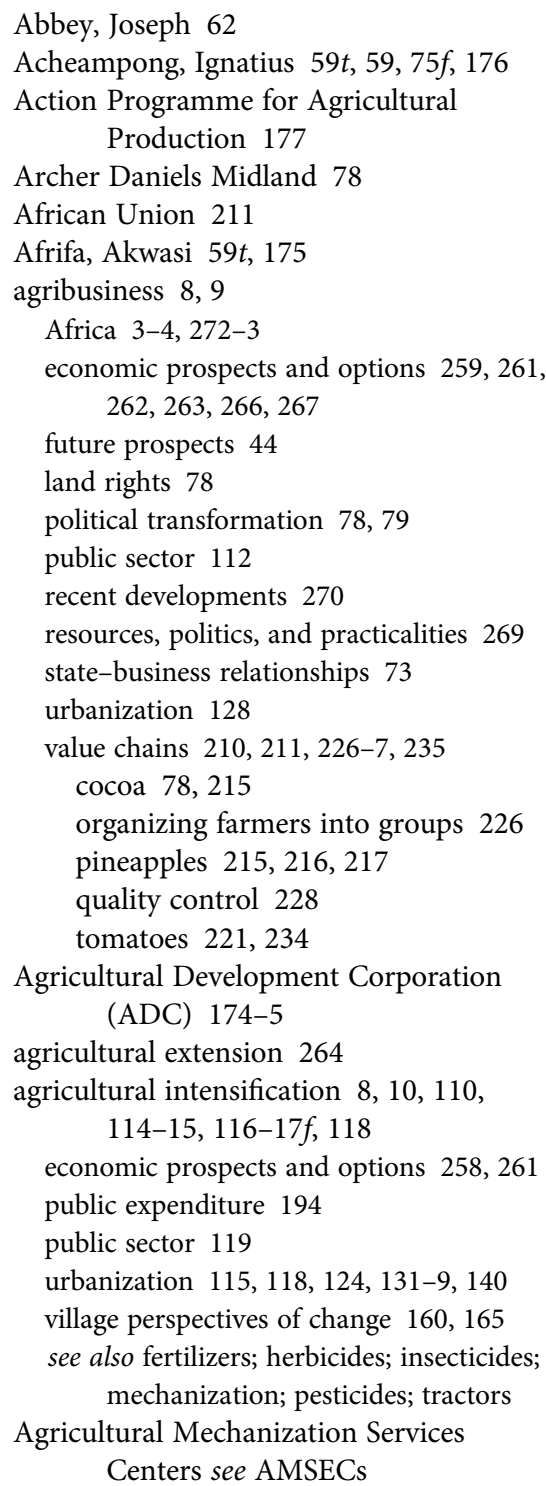

agricultural sector $9-15$

Africa 1, 2, 3-4, 271-2

employment share $2 f$

GDP share $2 f$

assistance, average nominal rates of $63 f$

democracy 53

economic prospects and options $257-67$

economic transformation $6,7-8,39,45$

employment $26,26 t, 27 f, 27$

productivity, sources of growth in 33 , $34,35 t, 36,36 t, 37,38 t$

structural change 22

future prospects $39,40,45$

mechanization see mechanization

political transformation $51,60-1,68$,

76-81, 82

state-business relationships 74,76

public expenditure 12-13, 64, 65f, 111-12, $119,170-205,267,268$

composition $180-3,181 t, 182 f, 182 t$

data sources 171-2, 171t $196-8 \mathrm{t}$

growth effects 183-93, 187-8t

new directions 193-4

recent developments 271

regression results $199-205,200 t$, 202-5t

trends and output per hectare 171-83, $172 f, 173 f, 173 t$

value chains 219,235

recent developments 269-71

resources, politics, and practicalities 267-9

share of total employment $123 f$

transformation 97-120

growth patterns 98-109

land and labor 104-7

policy $110-13$

population pressure on land

base 113-15 
agricultural sector (cont.)

production $98-102,98 t, 99 t, 100 t$, $102 t, 103 f$

rural livelihoods, incomes, and poverty $108-9$

technology see mechanization

urbanization 115-18

urbanization 121-40

farming practices 133-6

farm size distribution 131-3

modern input adoption 136-9

rural employment $124-8$

trends 122-4

welfare outcomes $128-31$

village perspectives of change $142-68$

farm model analysis 152-8, 154t, $156 t, 157 f, 159 t, 161-8,162 t$

narratives $145-52$

selection of villages $143-4,143 t$

Agricultural Services Rehabilitation

Project 60

Agricultural Services Subsector Investment

Program 178

agroecological zones 99-101

food crop distribution $101-2,102 f$

map $101 f$

agro-processing see agribusiness

Akuffo, Frederick 176

Akufo-Addo, Nana 59t, 66, 67-8

Alien Compliance Orders Act 59

Alliance for a Green Revolution in Africa (AGRA) 265

AMSECs (Agricultural Mechanization Services Centers) 14, 112, 248, 249-51, 253-4, 253t, 265

effectiveness 113

public expenditure 193, 194, 195

value chains 224

animal traction 242,244

Ankrah, Joseph Arthur 59t, 175

Armed Forces Revolutionary Council 177

Ashanti Goldfields Company 62

Asian tigers 8

Association of Ghana Industries 73

authoritarianism 61,82

autocracy 82

bananas 98

Banda, Hastings 57
Benin $70,71 t, 75 t$

block farms 112, 193-4, 195

Blue Skies 78

Boahen, Adju 63

Botchwey, Kwesi 62, 67

Botswana

credit $75 t$

developmental state 55,82

economic growth $6,20 t$

public management $70,71 t$

Brazil 50, 75t, 249, 250

Burkina Faso 220

Busia, Kofi 59t, 59, 73n, 75f, 175

business environment see private sector

business services sector

employment $28 t, 29 t, 30 t, 31$

productivity, sources of growth in $35 t$, $36 t, 37,38 t, 38$

CAADP 174, 178, 268, 270, 272

Callebaut 78

Captains of Industry program 74

Cargill 78

cassava $80-1$

productivity $99,101,102$

village perspectives of change 146,154 , $161,163,164,165,167,168 f$

centralized planning 22

Chile 231

China

agro-processing 227

AMSEC program 249, 250

credit $75 t$

growth $20 t, 32$

manufacturing sector 40

civil service $8,61,68-9,71-2,268$

wages 67,69

Civil Service Performance Improvement

Program (CSPIP) 69

Civil Service Reform Program 69

clientelism 53, 57

coastal agroecological zone 106t, 107, 114,124

cocoa

democracy 64

economic prospects and options 258

exports 5, 98, 109, 213, 233, 258, 271 economic prospects and options 260 growth 210 
marketing 230

public expenditure 175, 190, 194, 195

quality control 230

taxation 194, 230

growth 210

mechanization trends 243

political transformation $59,60,61,62,78$

SAP 60,61

state-business relationships $73 \mathrm{n}$

productivity $98,99,102$

public expenditure 12, 13, 111-12, 170, 194, 195, 268

growth effects $183,189-91,193$

trends and output per hectare 172-80, $172 f, 173 f, 173 t$

urbanization 122

value chain $13,211,212,213-15,233$

agro-processing 226

chemical inputs 222-3

Cocobod model 230-2

credit 224

quality control 227, 228, 228t, 229

seeds 222

taxation 230

Cocoa Board see Cocobod

Cocoa Marketing Company 231

Cocobod 110, 180n, 213-14, 215, 233

cocoa processing 78

public expenditure 170, 181t, 194

growth effects 189, 190

trends and output per hectare 172-3, $174,179,180$

tax revenue 230

value chain $230-2$

chemical inputs $222-3$

organizing farmers into groups 225

cocoyams 101, 102

coffee 210

cold storage 263

public sector 112

value chains

agro-processing 227

pineapples 217, 234

quality control 228

collective bargaining 53

communal conflict, sources of $77 t, 77$

communications

public expenditure $64,65 f, 182 t, 182$

village perspectives of change 144 competitiveness 225,226

cocoa 215,230

pineapples 217

rice $219,231,232$

tomatoes 221,231

construction sector

employment $26,26 t, 28 t, 29 t, 30 t, 31$

productivity, sources of growth in $35 t$, $36 t, 38 t, 38$

Convention People's Party 59t, 174

cooperatives 174, 175, 225

Corporate Village Enterprises (COVEs) 79

corporatism 56, 57

corruption 71-2

Costa Rica 80, 216, 217

Côte d'Ivoire

cocoa 215,260

developmental state 58

pineapples $79,80,216$

political instability 50

public management $70,71 t$

cotton 146, 149

Council for Scientific and Industrial

Research (CSIR) 180, 180n, $181 t$

Council of Independent Business

Associations 73

cowpeas

productivity 101,102

village perspectives of change $146,149,160$

farm model analysis 154, 161, 165, $167,168 f$

credit

economic prospects and options 266

interest rates 67

palm oil 79

political transformation $72-3,74-6$, $75 f, 75 t$

public expenditure 175, 176, 193

value chains $224-5$

agro-processing 227

rice 226

village perspectives of change $144,164-5$

crony capitalism 57

crop rotations

economic prospects and options 265

village perspectives of change $149,152,160$

farm model analysis $161,165,165 f$

Crystal Ventures (Rwanda) 58

Customary Land Secretariats 78 
Danquah, J. B. $73 n$

debt forgiveness 67

decentralization $5,174,177,179,268$

defense spending $182 t$

deliberation councils 56

Del Monte 216

democracy $5,8,272$

IIAG 70

policy environment 66

political transformation $50,51,53-4,58$, 63-8

state-business relationships 73

Department for International Development (DfID) 69

Department of Forestry (DoF) $181 t$

developmental states $54-5,82$ neo-patrimonial $57-8$

District Assembly Common Fund 174, 177

District Directors of Agriculture

(DDAs) 268

donors 181, 262, 265, 268, 270, 272

economic prospects and options 257-67

Economic Reform Program (ERP) see Structural Adjustment Program economic transformation 6-9, 19-46, 82,257

employment 26-31

future prospects $39-45$

agriculture 40

manufacturing $40-4$

services $44-5$

investment in fundamentals $58-63$

per capita income $20-1$

productivity

aggregate growth $23-5$

sources of growth 31-9

state-business relationships 73

structural change 21-3

ECOWAS 222

education 68,81

female 65

public expenditure $64,65 f, 65,66,182 t$, 182, 195

growth effects 183, 191, 192

village perspectives of change 144

electricity 144, 263

embedded autonomy 56, 82 employment

Africa $2 f$

agribusiness 259

agricultural sector 260

economic transformation 8 , 26-31

manufacturing sector $41,42,42 t, 44$ productivity, sources of growth in $35 t, 36$

future prospects 40,45

political transformation 82

service sector 6

urbanization 122, 123f, 124-8, 127t, 129t

see also labor

EPRDF 58

Ethiopia 50, 58

ethnic factors 50

Eurobonds 50

Export Development and Investment Fund (EDIF) 74

Export-Import Bank of India 249

exports

Africa 272

cassava 80

cocoa see cocoa: exports

economic prospects and options 258, 259,260

economic transformation 8

future prospects 45

gold 62,259

manufacturing sector 39,41

minerals 5, 259

mining sector 38

pineapples $79-80,112,212,215-17,225$, $229,231,233,234,260$

political transformation 61,74

promotion 112

public expenditure on agriculture 174

shea nuts 231

value chains $210,212,223$

quality control 227, 229

fallow periods 11,104

arable land area 113

economic prospects and options 265

fertilizer use 103

mechanization 244

public expenditure 194

value chains 223 
village perspectives of change $145-6,151$, 153,160

Farmapine Ghana Ltd 225

Farmer Based Organizations (FBOs) 225, 267

farm incomes $151 t, 151,160$

farm model analysis $153,158,159 t$

farm input costs $150,150 t, 158$

farm size $105-7,106 t, 107 t$

crop dynamics 147

fertilizer use 102

labor use 147

mechanization $148 t$

demand 245, 246-7, 254

supply 252

trends $243 t, 243$

rural nonfarm economy $108,108 t$

trends $247 t$

urbanization $115,118,131-3,132 t$, $133 f, 140$

agricultural intensification $134 t$, $134-6,135 t, 137 t, 137-8$

village perspectives of change $145,145 t$, $149,150,150 t, 151,160$

farm model analysis 153, 155-7, 156t, $158,159 t$

Farmtrac 249-50

Federation of Associations of Ghana Exporters 73

Felda 78

female education 65

fertilizers $11,102-3,103 t, 104 t$

economic prospects and options 263, 265

planting for food and jobs program 270

prices 110

public expenditure 176, 193

subsidies 112, 113, 134, 138, 176, 193, 194, 195

cocoa 215,223

SAP 60

value chains 223

urbanization 115-18, 134t, 134, 136-9, $137 t, 138 t, 140$

value chains $222-3$

cocoa $212,215,223,230$

rice 219

tomatoes 221

village perspectives of change 155,156 , $158,159 t, 165,166-7,167 t$ finance sector

employment $26,26 t$

see also credit

firm size

agricultural sector see farm size

manufacturing sector $42-3,42 t$

first mover strategies $268-9,272$

fiscal management 51, 53-4, 67, 81

Food and Agricultural Sector Development Policy (FASDEP II) 78, 178

food crisis (2008) 77

food demand 3,14

food imports 98, 109, 112, 271

economic prospects and options 258, 259

political transformation 59

public expenditure on agriculture 176

value chains 210,212

food security 191

foreign direct investment (FDI) 62, 81

economic prospects and options 259, 262

land rights 77

foreign exchange 60, 191

forest agroecological zone 99, 124

agricultural intensification 114-15, $116 f$

farm size 106t, 107

food crops $101-2,102 t$

map $101 f$

formal sector

employment $27,28 t, 29 t, 30 t, 31$

manufacturing 43

fruit juices 210

fundamentals

agricultural transformation 110

democracy 54

economic prospects and options 257

economic transformation 7,31-2, 33, 39, 45

productivity, sources of growth in 37

future prospects 9

planting for food and jobs program 270

political regime 52

political transformation $49,50,58-63$

value chains 210

G7 211

Germany 50, $75 t$

Ghana Chamber of Mines 73

Ghana Cocoa Board see Cocobod

Ghana Commercial Agricultural

Project 77, 178 
Ghana Free Zones Board (GFZB) 73

Ghana Incentive-Based Risk-Sharing System for Agricultural Lending

(GIRSAL) 266

Ghana Investors Agency Council 74

globalization 190, 226, 272

gold 62, 258, 259

government see public sector

government services sector employment 26, $26 t$

productivity, sources of growth in $35 t, 36$, $36 t, 38 t$

gross domestic product (GDP)

Africa 1, $2 f$

aggregate growth $23-4,24 f, 25 t$

countries with thirty years' uninterrupted growth in $20 t$

economic transformation 20,21-2, 23,39, 45

future prospects 39

per capita 62

sectoral shares $21 f, 22 t$

service sector 6,44

sources of growth $35 t, 36$

groundnuts

productivity 101, 102

village perspectives of change $146,147,160$

farm model analysis 154, 161, 165, $167,168 f$

Grow Africa Investment Forum 262

Growth and Poverty Reduction Strategy (2006-9) 64

Guinness Ghana Breweries Limited 80

Hawaii Pineapple Research Institute 216 health

insurance 81

public expenditure $64,65 f, 65,67,182 t$, 182, 191, 192, 195

Heavily Indebted Poor Countries (HIPC) 64, 66, 67, 74

herbicides 103

economic prospects and options 263

urbanization 115, 134-5, 135t, 137t, 138t, $138-9,140$

village perspectives of change 147,148 , $150,150 t, 152,160$

farm model analysis 158, 165

hired labor see labor

Hong Kong 54
Houphouët-Boigny, Félix 58

human capital 53, 183

human development (IIAG) 70f, 70

human rights (IIAG) $70 f, 70$

Ibrahim Index of African Governance (IIAG) $69-71,70 f, 71 t$

imports

fertilizers 113

food see food imports

rice $98,112,218,219,227-8,234$

tomatoes 112, 220, 221

tractors $241,242,242 f, 249-50,251-2,254$

import substitution $5,14,58$

Africa 272

developmental states 55

economic prospects and options 258, 259, 260

economic transformation 41,45

first mover strategy 269

public expenditure on agriculture 176

value chains $210,212,233$

pineapples 215

tomatoes 229

incomes see per capita incomes

India 20, 20t, 249-50

induced innovation theory $10,114-15,119$

mechanization demand 245, 247

urbanization 124, 133, 140

industrialization 5,6

Africa 3, 271, 272

economic transformation 21,22

pineapple value chain 215

SAP 41

tomato value chain 220

industrial policy $43,45,74,259$

developmental states 54, 55, 56

industrial sector

Africa 1

employment share $2 f$

economic prospects and options 257, 259

economic transformation 6

employment $26 t, 27 f, 27$

structural change 22-3

future prospects 41,45

inflation 62

informal sector

economic transformation 39

employment 27, 28t, 29t, 30t, 31

manufacturing 41, 43-4 
productivity, sources of growth in 33 , $34,38,39$

services 44

urbanization $128,129 t$

infrastructure

economic prospects and options 263

IIAG $70 f, 70$

political transformation 81

public expenditure $64,182,184$

public sector 112,119

value chains

agro-processing 227

pineapples 234

quality control 228

see also roads

innovation see induced innovation theory; research and development

insecticides 103

urbanization $134-5,135 t, 137 t, 138 t, 138-9$

village perspectives of change $150,150 t, 165$

see also pesticides

interest rates 67, 72, 266

International Monetary Fund (IMF) aid disbursements temporarily halted 67 negotiations with Ghana (2014) 69

SAP $6,20,59,60,66$

Investment Code 62

investment environment 8

agricultural sector 9,265

economic fundamentals 58-63

interest rates 67

land rights $77-8$

political transformation $60,74,81$

public expenditure 184

see also foreign direct investment; public expenditure

irrigation 272

economic prospects and options 261, 266

palm oil 79

public expenditure 193, 195

recent developments 271

value chains 222

rice 114,219

tomatoes 220, 221

Italy 227

Japan $54,75 t$

John Deere 250

joint ventures 62
Kagame, Paul 57-8

Kenya $5,71 t, 75 t$

Korea 20, 20t, 50, 54

Kpong Irrigation Project (KIP) 219

Kufuor, John Agyekum 59t

credit $75 f$

palm oil 78

public expenditure on agriculture 178

state-business relationships $72,73-4$

labor $104-7$

cocoa value chain 214

costs see wages

economic prospects and options 261-2

growth $105 t$

mechanization demand 245-6, 246t, 247

productivity see labor productivity

technology 103, 104t

urbanization $137 t, 138 t, 138-9,140$

village perspectives of change 147,150 , $150 t, 152,160$

farm model analysis 155,156 , $158,159 t$

see also employment

labor productivity

Africa 271-2

aggregate growth $23-5,24 f, 25 t$

agricultural transformation $9,10,11$, 12,110

economic prospects and options 257, 258,260

economic transformation $7-8,39,45$

employment 31

manufacturing sector $41,42-3,42 t, 44$

service sector 44

sources of growth $33,34,35 t, 36,36 t$, $37-9,38 t$

future prospects 39,40

public sector 113

trends 104-5, 106f, 118

village perspectives of change $155,156-7$, $157 f, 160$

labor unions 61

land $104-7$

policy 263

population pressure 113-15

productivity see land productivity

rights $76-8,227,235$

scarcity see land scarcity 


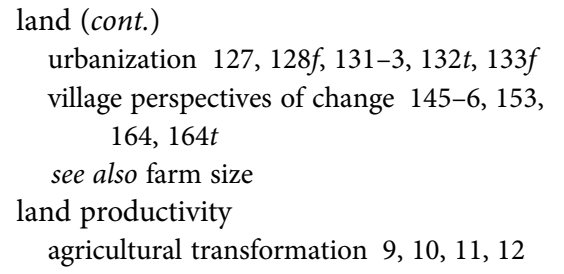

economic prospects and options 258, 261, 266

future prospects 40

public expenditure 173f, 173, 174

new directions 194

trends $175,176,177-8,179$

public sector 113

trends $104-5,106 f, 118$

village perspectives of change 150-1, $150 t, 160$

farm model analysis 155, 156-7, $157 f, 166$

see also agricultural intensification

land rights 76-8, 227, 235

land scarcity $11,12,119$

economic prospects and options 258, 261

labor productivity 39

mechanization demand 245

village perspectives of change $145,151,160$

Limann, Hilla 75f, 177

literacy 65, 129, 191, 192

Livelihood Empowerment Against Poverty Program (LEAP) 65

livestock 98

living standards 25

Local Government Law 174, 177, 179

Mahama, John Dramani 59t, 65, 75f, 178

Mahindra 250

maize

economic prospects and options 260, 261, 264

mechanization 254

productivity $99,101,102$

public expenditure 193

SAP 60

seeds $103,155,156,166-7,167 t$

value chain $225,229,232$

village perspectives of change 146,147 , $148,149,150,160$

farm model analysis $154,155,156$, $161,163,165,165 f, 166-7,168 f$

yields $150,150 t, 166-7,167 t$
Malawi

credit $75 t$

economy 61

neo-patrimonial developmental state 58

political instability 50

public management $70,71 t$

Malaysia 78

mangoes 260

manufacturing sector

Africa 1

GDP share $2 f$

economic prospects and options 257, 258, 259

economic transformation 6,39

employment $26,26 t, 27 f, 27,28 t$, $29 t, 30 t, 31$

productivity, sources of growth in 33 , $34,35 t, 36 t, 37,38 t, 38-9$

structural change 22,23

future prospects $40-4,45$

state-business relationships 73

urbanization $128,129 t$

wages 53

Maputo Declaration 111, 112, 179, 180, 194

market access 139, 232

marketing

economic prospects and options 263

value chains $225,226,235,266$

cocoa 213-14, 230-1, 233

pineapples $216-17,231$

rice 218

tomatoes 220, 231

Market-Oriented Agricultural Project (MOAP) 232, 267

Marshall plan for agriculture 270

Masara N'zarki 225

Mauritius 6, 20t, 55, 57, 82

MDBS 64

mechanization 11-12, 13-14, 104t,

$$
\text { 241-54 }
$$

demand 243-8

economic prospects and options 258, 265-6

public expenditure 193, 194

SAP 60

supply $248-52$

trends $242-3,243 t$

urbanization $115,135 t, 135-6,137 t, 138 t$, $138-9,140$ 
value chains $223-4$

rice 219

village perspectives of change $148,148 t$, $150,150 t, 152$

farm model analysis 158, 165

see also AMSECs; technology; tractors

Mexico $75 t$

Millennium Challenge Corporation 76

Millennium Development Goals

(MDGs) 19, 64-5

millet 101, 146

Mills, John Evans Atta 50, 59t, 65, 75f, 178

mineral exports 5, 259

mining sector

employment $26,26 t, 28 t, 29 t, 30 t, 31$

future prospects $39-40,45$

joint ventures 62

productivity, sources of growth in $35 t, 36 t$, $38 t, 38$

SAP 60

Ministry of Agriculture 60, 180n, 226, 249

Ministry of Education, Sports, and Science $180 \mathrm{n}$

Ministry of Finance and Economic Planning 180n

Ministry of Fisheries (MoF) 180n, $181 t$

Ministry of Food and Agriculture

(MoFA) 180n

budget 113

devolution 268

public expenditure on agriculture 180 , $181 t, 181,193,195$

Ministry of Local Government and Rural Development 180n

Ministry of Manpower Development and Employment 180n

Ministry of Private Sector Development (MPSD) 74

Ministry of Public Sector Reform 69 Ministry of Roads and Transport 180n Ministry of Trade and Industry 76, 180n Ministry of Women and Children's Affairs 180n

mortality rates 129

Mozambique $71 t, 75 t$

Multilateral Debt Relief Initiative 64 multinational corporations 73

Mutharika, Bingu wa 58
National Agricultural Investment Strategy (NAIS) 270

National Democratic Congress (NDC) 50, $59 t, 64,81$

agricultural sector 76

credit $75 f$

elections

199263

201667

fiscal management 67

HIPC 66

political budget cycle 67

public expenditure on agriculture 177,178

social welfare schemes 65

state-business relationships 73, 74

National Fertilizer Subsidy Program 193

National Food Buffer Stock Company (NAFCO) 112, 193, 194, 195

National Health Insurance Scheme 65

National Liberation Council 59t, 175

National Redemption Council 59t, 176

National Seed Council 222, 264

neo-patrimonialism 52, 57-8

New Alliance for Food Security and Nutrition 211, 235, 262

New Patriotic Party (NPP) 50, 59t, 64, 81 agricultural sector $76,78,79$

elections

199263

201667

political budget cycle 67

public expenditure on agriculture 178

social welfare schemes 65

state-business relationships $72,73-4,76$

VAT 66

Nigeria $70,71 t, 75 t$

Nkrumah, Kwame 58, 59t, 75f, 174, 175

Northern Rural Growth Project

(NRGP) 232, 267

Obeng, P. V. 62

oil

aggregate productivity growth 24

future prospects $39-40,44,45,258,259$

productivity, sources of growth in 38

oil palm 78-9, 112

"one district one factory" program 68 , 270,271

“one village one dam” program 270, 271 
onions 193

Operation Feed Your Factories 211

Operation Feed Your Industries 176

Operation Feed Yourself 59, 176, 211, 270

Optimizing Fertilizer Recommendations in Africa (OFRA) 265

palm oil 78-9, 112

patrimonialism 52

People's National Party 177

per capita incomes (PCI) 5, 62

aggregate productivity growth $23-4$, $24 f, 25 t$

agricultural sector 110

economic prospects and options 257

economic transformation $6,7,20-1$, $20 t, 31$

future prospects 39

rice value chain 217

rural 108-9, 109t

sources of growth 31

urbanization 128-9

personal services sector 44

employment $28 t, 29 t, 30 t, 31$

productivity, sources of growth in $35 t, 36$, $36 t, 37,38 t$

pesticides $104 t$

public expenditure 193

value chains 222

cocoa 215

village perspectives of change 165

see also insecticides

pineapples

exports $79-80,112,212,215-17,225,229$, $231,233,234,260$

political transformation 79-80

public sector 112

value chain $13,212,215-17,233-4$

agro-processing 226, 227

chemical inputs 223

credit 224

mechanization 224

organizing farmers into groups 225,226

quality control 228, 228t, 229

support 231, 232

plantains 98, 101, 102

Planting for Food and Jobs (PFJ)

program 68,270 policy environment 8

agricultural transformation 9-10, 110-13

decentralization 269

democracy 66

economic prospects and options $262-3$

economic transformation 45-6, 62

future prospects 39,40

political transformation $49,51,81-2$

value chains $221-33$

political budget cycle $53,66-7$

political instability/stability $50,58-9$, 81,272

political participation (IIAG) 70f, 70

political regimes 52

timeline $59 t$

political stability/instability $50,58-9$, 81,272

political transformation $8-9,49-82$

democracy $53-4,63-8$

developmental states $54-5$

neo-patrimonial $57-8$

economic fundamentals, investment in 58-63

implications for agricultural transformation $76-81$

limitations $68-72$

state-business relationships $55-8,72-6$

population growth 245

port facilities 217, 228, 263

poverty 19

political transformation $64,65,73,74$

rural 109

urbanization 129-31, 130t, 140

Poverty Reduction Strategy (PRS) 64, 74

Presidential Delivery Unit Model 69

President's Special Initiatives (PSIs) 74, 76, 78-9, 80, 81, 178, 180n

public expenditure on agriculture $181 t$

Private Enterprise Foundation (PEF) 73

private sector

Africa 272, 273

business environment (IIAG) 70f, 70

democracy 64

economic prospects and options 262

economic transformation 23,41

first mover strategies 269

mechanization $248,249,250,251-2$, 253-4, 253t

planting for food and jobs program 271 
value chains $211,234-5$

agro-processing 226, 227

chemical inputs 222, 223

cocoa 230

mechanization 224

organizing farmers into groups 225

pineapples 231

policies 221

rice 218

see also public-private partnerships; state-business relationships

privatization 174

cocoa value chain 230

economic transformation 23

political transformation 60,73

SAP 41

tomato factories 220

Produce Buying Company 174

Producer Price Review Committee 213 productivity

aggregate growth $23-5$

see also labor productivity; land productivity; total factor productivity

Progress Party 59t, 175

Provisional National Defense Council (PNDC) 59t, 59, 61-2, 63

credit $75 f$

public expenditure on agriculture 177

repression 66

state-business relationships 72

public expenditure

agricultural sector see agricultural sector: public expenditure

by sector $64,65 f$

Public Financial Management Reform Program (PUF-MARP) 69

public management (IIAG) $70 f$, $70-2,71 t$

public-private partnerships

agricultural transformation 12

future prospects 40

value chains 221

see also state-business relationships

public sector

Africa 272-3

agricultural policy $110-13$

agricultural transformation 9-15

economic prospects and options 262-3, 265-6 economic transformation $6,8,45-6$

manufacturing 41

structural change 22-3

expenditure see public expenditure

first mover strategies 269

mechanization 241, 248-51, 253-4, $253 t$

recent developments 269-71

resources, politics, and practicalities 267-9

value chains $211-12,233-5$

cocoa 213-15

pineapples $215-16$

policies 221-33

tomatoes 220

see also political transformation

Public Sector Reinvention and

Modernization Strategy (PUSER-

MOS) 69

Public Services Commission 69

public transportation 139

quality control

public sector 112

value chains $227-9,232$

cocoa $213,214,230,233$

pineapples 217

rice 218,234

tomatoes 220, 234

Quality Control Company (QCC) 214, 231

rainfall patterns $147,149,152,160$

Rawlings, Jerry John 51, 59t, 59, 61-3

credit $75 f$

economic transformation 6,8

elections

199263

199667

HIPC 66

political transformation 82

public expenditure on agriculture 177

repression 66

state-business relationships 72,73 , 74,76

regional factors

agricultural production $99-102$

agricultural transformation 9

farm size $105-7,106 t$

first mover strategies 269

mechanization 242-3, 245-7, 251

public expenditure on agriculture 181-2 
research and development (R\&D) 272 economic prospects and options 263-4 mechanization 251, 254

public expenditure 183, 193, 195

public sector 112, 119

recent developments 271

value chains 235

rice

pineapples 216

Asia's green revolution 210, 269

economic prospects and options 260

imports 98, 112, 218, 219, 227-8, 234

intensification 114

productivity $99,101-2$

public expenditure 193

SAP 60

value chain $13,212,217-19,233,234$

agro-processing 226

mechanization 224

organizing farmers into groups 226

quality control 227-8, 228t, 229

support 231-3

taxation 229

village perspectives of change $146,147,150$

yields 150

roads 272

democracy 64

economic prospects and options 263

political transformation $64,67,80$

public expenditure 67, 112, 182, 191, 192, 195

value chains $228-9$

pineapples 234

village perspectives of change 144

rural areas

livelihoods, incomes, and poverty $108-9$, $108 t, 109 t$

political transformation 61

population 10, 104, 109, 113-15, 114t, $122 f, 144,144 t$

Rawlings' vote share (1992) 63

spatial typology $122-4$

map $125 f$

population densities $124,126 t$

see also agricultural sector; rural nonfarm economy

rural nonfarm economy $10,108-9,108 t$

economic prospects and options 261

employment 26, 126 mechanization 246

urbanization $115,118,122,133$, $139-40$

employment 126

regional factors 124

welfare outcomes 131

village perspectives of change $151 t, 151$

wages 104

Rwanda 50, 57-8, 70, 71t

Rwandan Patriotic Front (RPF) 57-8

savannah agroecological zone 11, 99

agricultural intensification $115,117 f$

farm size 105, 106t, 107

food crops 101-2, 102t

land base 114

map $101 f$

mechanization 246, 247, 249

technology 103

urbanization 123, 140

village perspectives of change $142-68$

narratives $145-52$

selection of villages $143-4,143 t$

Sea-Freight Pineapple Exporters Ghana (SPEG) 216

seeds 103

economic prospects and options 262, 263, 264-5

planting for food and jobs program 270

public expenditure 176, 193

public sector 112

value chains $222,232,235$

cocoa 214

maize $103,155,156,166-7,167 t$

rice 219

tomatoes $220-1$

village perspectives of change 149,150 , $150 t, 160$

farm model analysis 155,156 , 158,165

Senegal 61, 70, 71t, 75t, 219

service sector 5

Africa 1-3

employment share $2 f$

GDP share $2 f$

democracy 53

economic prospects and options 257, 258

economic transformation 6,7

employment $26,26 t, 27 f, 27$ 
productivity, sources of growth in 33,34

structural change $21,22,23$

future prospects $44-5$

urbanization 121

shea nuts 231

Singapore 20, 20t, 54

social welfare $53,64-5,81$

soil fertility 11

economic prospects and options 265

land rights 77

public expenditure 194

urbanization 140

value chains 223

village perspectives of change 146,147 , $149,151-2,160,166$

see also fertilizers

Soil, Land, and Water Management

Project 179

sorghum 101, 146, 193

South Africa

credit $75 t$

developmental state 55,82

Eurobonds 50

public management $70,71 t$

state-business coalitions 57

South Korea 20, 20t, 50, 54

soybeans 146, 147, 149, 193

standards of living 25

state-business relationships $55-7,72-6,82$

Africa 273

economic prospects and options 263

New Alliance for Feed Security and

Nutrition 235

resources, politics, and practicalities 268

weak $72-6$

see also public-private partnerships

state farms $174,175,176$

state-owned enterprises

agro-processing 226

economic transformation $22-3,41$

political transformation 72

urbanization 122

stock exchange 60

Structural Adjustment Institutional

Support Project (SAIS) 68-9

Structural Adjustment Program (SAP) 3, 6, $19,20,21,22,45,272$

aggregate productivity growth 24 agricultural sector 110

democracy 63

developmental state 8

economic prospects and options 257

employment 26

long-term effects 67

manufacturing sector 41,42

political transformation 51,59-61

productivity, source of growth in 32

public expenditure on agriculture 177

state-business relationships 72

state-owned enterprises 23

technocracy 62

structural change

Africa 3

economic prospects and options 257, 259

economic transformation $7,8,21-3,31-2$, $33,39,45$

productivity, sources of growth in 36 , $36 t, 37$

future prospects 39

political regime 52

political transformation $49-50,51$, 72,81

value chains 211

subsidies 67,112

cocoa value chain 215

fertilizers see fertilizers: subsidies

food production 6

mechanization 241, 248, 249, 254

AMSECs 250

planting for food and jobs program 270

public expenditure on agriculture 174,175 , $177,178,179,193,195$

Supreme Military Council 176

Taiwan 54, 226

Tanzania $62,70,71 t, 75 t$

tariffs

tractors 251

value chains 228,229

rice 232,234

tomatoes 231

taxation 110

political transformation $62,66,71 \mathrm{n}, 74$

value chains $229-30$

agro-processing 227

cassava 80

cocoa 194,213 


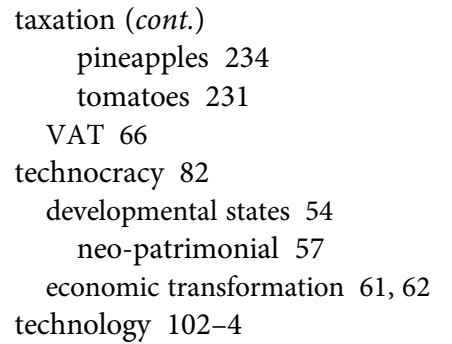

economic prospects and options 260, 261

induced innovation theory 114-15, 119

planting for food and jobs program 271

public expenditure 183

public sector 112

urbanization 115

value chains 235

village perspectives of change 155, 165

see also mechanization

terms of trade 110

Thailand 20t, 210, 218, 219, 226

timber sector $60,73 \mathrm{n}$

tobacco 146

tomatoes

imports 112, 220, 221

public expenditure 193

value chain 13, 212, 219-21, 233, 234

agro-processing 226, 227

credit 224

mechanization 224

organizing farmers into groups 226

quality control 228, 228t, 229

support 231, 232

village perspectives of change 146,167

total factor productivity (TFP) 24-5, 25t, 53

tractors $13-14,103,241,253-4$

demand 244, 247

economic prospects and options 265, 266

imports 241, 242, 242f, 249-50,

$$
\text { 251-2, } 254
$$

public expenditure 194

supply $248,249-51$

trends 242-3

urbanization 135

value chains 224

rice 219

village perspectives of change 146,147 , $148,152,160$

farm model analysis 155, 156, 158, $159 t, 165$ trade policy $3,110,119,262$

trade services sector 39,44

employment $26,26 t, 28 t, 29 t, 30 t, 31$

productivity, sources of growth in $35 t$, $36,36 t, 37,38 t$

Trade Union Congress (TUC) 61

transition agroecological zone 11, 99

farm size $105,106 t$

food crops 101-2, $102 t$

land base 114

map $101 f$

mechanization 246,247

technology 103

urbanization 123,140

village perspectives of change $142-68$

farm model $152-8,154 t, 156 t, 157 f$,

$159 t, 161-8,162 t$

narratives $145-52$

selection of villages $143-4,143 t$

transportation 272

economic prospects and options 263

public 139

public expenditure 64,65f, 182t, 182

public sector 112

road see roads

value chains 227,228

transport services sector

employment $26 t, 28 t, 29 t, 30 t, 31$

productivity, sources of growth in $35 t$, $36 t, 38 t, 38$

Turkey $75 t$

Uganda $70,71 t, 75 t$

unemployment 5

United Kingdom $75 t$

United States 64, 75t

urban areas

political transformation 61

population $122,122 f$

Rawlings' vote share (1992) 63

urbanization 5, 115-18, 121-40

Africa 1, 271, 272

agricultural transformation 10

economic prospects and options 261

economic transformation 6

employment 26

farming practices 133-6

farm size distribution 131-3

mechanization demand 245, 247-8 
modern input adoption 136-9

rural employment $124-8$

service sector 44

trends $122-4$

welfare outcomes $128-31$

Uruguay 55

USAID 181, 267

utilities sector

employment $26,26 t, 28 t, 29 t, 30 t, 31$

productivity, sources of growth in $35 t$, $36,36 t, 38 t, 38$

value-added per worker

aggregate growth $23-4,24 f$

manufacturing sector $42,42 t$

value-added tax (VAT) 66

value chains $8-9,210-35$

Africa 273

agricultural transformation $10,12,13$

cocoa 213-15

economic prospects and options 261, 262, 263, 266-7

pineapples $215-17$

planting for food and jobs program 270

policies 221-33

public sector 111, 112, 119

resources, politics, and practicalities 268, 269

rice $217-19$

tomatoes 219-21

Vietnam 20t, 210, 218, 269

Vision 2020 58, 73, 81

wages

agricultural sector $9,10,105 t, 110$

civil service 67,69

democracy 53

labor productivity 118 manufacturing sector 43

mechanization demand 246, 247, 254

political budget cycle 66,67

rural nonfarm economy 104

urbanization 118

village perspectives of change $158,160,168$

warehouses 228, 229

water 65,144

Weberian bureaucracy 52, 55

welfare outcomes 128-31

wheat 98, 210, 269

World Bank

aid disbursements temporarily halted 67

Economic Management Capacity Building Project 69

Farmapine Ghana Ltd 225

privatization 73

SAP $6,20,60$

Structural Adjustment Institutional Support Project 68-9

yams

productivity 98, 99, 101, 102

value chain 232

village perspectives of change 146, 147, 149

farm model analysis 154, 161, 163, $164,165,167,168 f$

Zambia

credit $75 t$

decentralization 5

economy 61

one-party rule 62

policymaking structure 62

political instability 50

public management $70,71 t$

Zenawi, Meles 58 